\title{
Retinal vascular features as a biomarker for psychiatric disorders
}

Citation for published version (APA):

Appaji, A. M. (2020). Retinal vascular features as a biomarker for psychiatric disorders. [Doctoral Thesis, Maastricht University]. https://doi.org/10.26481/dis.20200130aa

Document status and date:

Published: 01/01/2020

DOI:

10.26481/dis.20200130aa

Document Version:

Publisher's PDF, also known as Version of record

\section{Please check the document version of this publication:}

- A submitted manuscript is the version of the article upon submission and before peer-review. There can be important differences between the submitted version and the official published version of record.

People interested in the research are advised to contact the author for the final version of the publication, or visit the DOI to the publisher's website.

- The final author version and the galley proof are versions of the publication after peer review.

- The final published version features the final layout of the paper including the volume, issue and page numbers.

Link to publication

\footnotetext{
General rights rights.

- You may freely distribute the URL identifying the publication in the public portal. please follow below link for the End User Agreement:

www.umlib.nl/taverne-license

Take down policy

If you believe that this document breaches copyright please contact us at:

repository@maastrichtuniversity.nl

providing details and we will investigate your claim.
}

Copyright and moral rights for the publications made accessible in the public portal are retained by the authors and/or other copyright owners and it is a condition of accessing publications that users recognise and abide by the legal requirements associated with these

- Users may download and print one copy of any publication from the public portal for the purpose of private study or research.

- You may not further distribute the material or use it for any profit-making activity or commercial gain

If the publication is distributed under the terms of Article $25 \mathrm{fa}$ of the Dutch Copyright Act, indicated by the "Taverne" license above, 


\section{RETINAL VASCULAR FEATURES \\ AS A BIOMARKER FOR PSYCHIATRIC DISORDERS}

\section{DISSERTATION}

To obtain the degree of Doctor at Maastricht University, on the authority of the Rector Magnificus

\section{PROF. DR. RIANNE M. LETSCHERT}

in accordance with the decision of the Board of Deans, to be defended in public on

THURSDAY JANUARY $30^{\text {TH }} \mathbf{2 0 2 0}$

at 10:45 hours

by

ABHISHEK MAHESH APPAJI

Born April 23'd 1989

in Hyderabad, India 


\section{SUPERVISOR}

Prof. Dr. C.A.B. Webers

\section{CO-SUPERVISORS}

Dr. T.T.J.M. Berendschot

Dr. Naren P. Rao, Bengaluru, India

\section{ASSESSMENT COMMITTEE}

Prof. Dr. D.E.J. Linden (Chairman)

Prof. Dr. B.F.P. Rutten

Prof. Dr. T.A.M.J. van Amelsvoort

Prof. Dr. F. Verbraak (Amsterdam UMC)

Prof. Dr. B. Van Ginneken (Radboud University Medical Centre, Nijmegen) 
The important thing is to never stop questioning. Curiosity has its own reason for existence.

- ALBERT EINSTEIN 



\section{TABLE OF CONTENTS}

1. GENERAL INTRODUCTION 01 Aims and Outline of Thesis

2. RETINAL VASCULAR ABNORMALITIES 29 IN SCHIZOPHRENIA AND BIPOLAR DISORDER:

A WINDOW TO THE BRAIN

Bipolar Disord. 2019; 21(7): 634-641.

3. RETINAL VASCULAR TORTUOSITY IN SCHIZOPHRENIA AND BIPOLAR DISORDER

Schizophr. Res. 2019; 212: 26-32

4. RETINAL FRACTAL DIMENSIONS IN BIPOLAR

DISORDER AND SCHIZOPHRENIA

J. Affect. Disord. 2019; 259: 98-103.

5. EXAMINATION OF RETINAL VASCULAR

TRAJECTORY IN SCHIZOPHRENIA AND BIPOLAR DISORDER

Psychiatry Clin. Neurosci. 2019; 73(12): 738-744

6. RETINAL VASCULAR ABNORMALITIES AND COGNITIVE IMPAIRMENT IN PATIENTS WITH SCHIZOPHRENIA AND BIPOLAR DISORDER Under review

7. GENERAL DISCUSSION

8. SUMMARY

9. VALORISATION

10. ACKNOWLEDGEMENTS

11. CURRICULUM VITAE AND PUBLICATIONS 

CHAPTER 1

\section{GENERAL INTRODUCTION}

AIMS AND OUTLINE OF THE THESIS 



\section{General Introduction}

\subsection{The Retina: A Window to the Brain}

The retina is an important sensory organ which is easily accessible for examination through imaging techniques. It is considered an extension of the central nervous system (CNS) owing to their common embryological origin, neuronal organization, and metabolic substrates. The retina also exhibits similarities to the brain in terms of development, functionality, and immunology.

The retina is structured across three main levels. The first level decomposes the output of the photoreceptors into informational streams. The second connects these streams to specific types of retinal ganglion cells. The third combines bipolar and amacrine cell activity to create the encoding which is transmitted to the brain through the optic tract.

The retina being an extension of the diencephalon, shares a similar vascularization pattern too ${ }^{1-4}$. Nutrition to the outer retina (photoreceptors) is passively supplied by the choroidal vasculature. However, the retinal vasculature that supplies the inner retina is comparable to the CNS vasculature, and employs a tightly regulated cellular barrier ${ }^{5}$. The microvascular and macrovascular blood supply to the brain and retina have similarities in structure and regulatory process of the vascular system. There is also a close correlation between the anatomy of the vascular system and metabolic needs of the tissue in both the brain and the retina ${ }^{1,6-8}$.

Both the retina and the brain constitute metabolically highly active tissues that exert exceptional demands on metabolic substrates via vascular networks. Unlike tissues of other organs, the brain and retina are exclusively restricted to glucose as a substrate for their energy metabolism?.

The difficulty in accessing the brain poses a major challenge in examining it. Several imaging techniques such as transcranial Doppler ultrasound, positron emission tomography (PET), single photon emission computed tomography (SPECT) and magnetic resonance imaging (MRI) are available for examining brain pathophysiology. However, their use is restricted as these are expensive, rarely accessible, and available only in specialised centres. These are therefore not suitable options for widespread screening of patients at risk of cerebrovascular disease. Hence, we need simpler, more accessible, and less expensive techniques. 
Fundoscopic imaging of the retina is a non-invasive and completely safe method of obtaining images of the posterior chamber of the eye. Light from a low-power camera flash enters the eye through the pupil, is reflected back from the retina along the same path, and collected by the machine. This creates an image of the retina that can be stored in the computer (Figure 1).

Figure 1.

Acquisition of retinal fundus images using a non-mydriatic fundus camera.

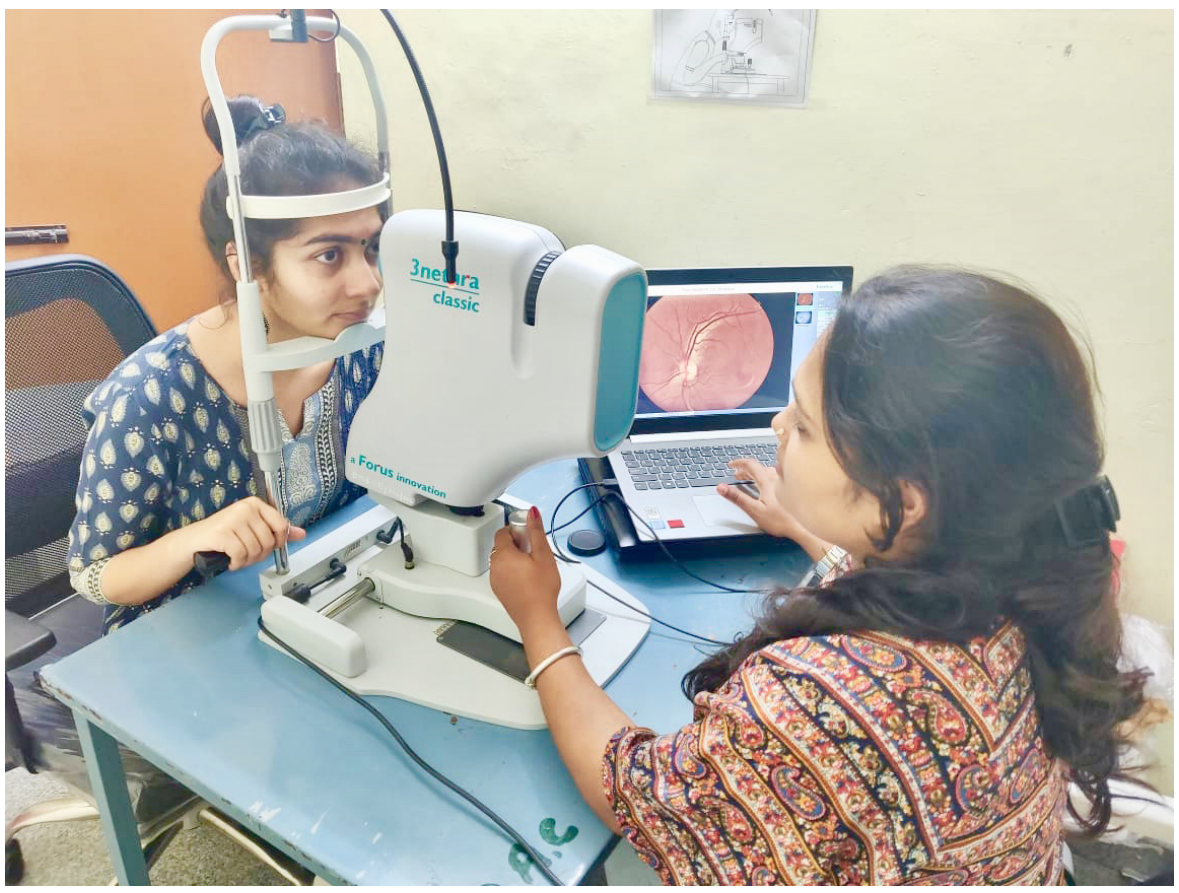

Another widely used tool to assess the retina is Optical Coherence Tomography (OCT). This primarily measures, the retinal nerve fibre layer thickness (RNFL) along with other parameters. OCT generates cross sectional images by analysing the time delay and magnitude change of low coherence light when it is backscattered by ocular tissues. An infrared scanning beam is split into a sample arm (directed toward the subject) and a reference arm (directed toward a mirror). The sample beam that returns to the instrument is compared with the reference arm in order to determine distance and signal change via photodetector measurement. The resultant change in signal amplitude allows for tissue differentiation through analysis of the variations in reflective properties, which are matched to a false colour scale. As the scanning beam moves across tissues, the sequential longitudinal signals, or A-scans, are reassembled into a transverse scan yielding cross-sectional images, or B-scans, of the patient (Figure 2). 
Figure 2.

A typical RNFL OCT image

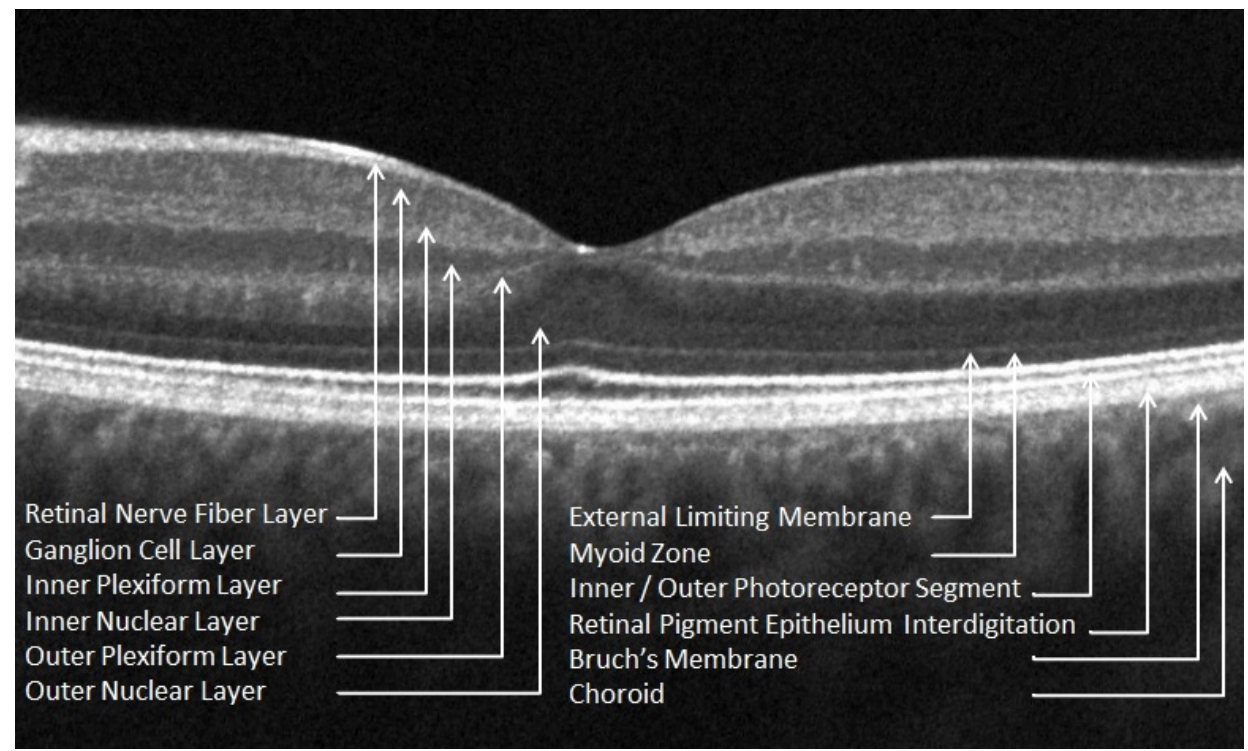

Studies using OCT have shown that RNFL thinning is associated with alterations in the microstructure and volume of the brain ${ }^{10}$. The RNFL thickness correlated with age and axial length of the eye ${ }^{11}$. The RNFL was thickest in the inferior quadrant, followed by the superior, nasal, and temporal quadrants of the retina respectively. It has also been found that the RNFL thickness reduces with increase in age ${ }^{11}$, but does not vary across gender ${ }^{12-14}$. Changes in RNFL thickness have also been demonstrated to be associated with changes in brain structure in pathological conditions. A thin RNFL was found to be related to brain atrophy in multiple sclerosis ${ }^{15}$ and degeneration of the brain in Alzheimer's disease ${ }^{16,17}$. The RNFL thickness has been shown to differ across dementia, mild cognitive impairment, and healthy controls ${ }^{18}$. Retinal haemorrhages have also been found to be associated with brain haemorrhages in children dying of malaria19,20.

Microvascular abnormalities in the retina are defined as the presence of haemorrhages, cotton wool spots, aneurysms, exudates, macular oedema, arteriolar narrowing, or venular widening (Figure 3). The blood vessels in the retina and the brain share many similarities in anatomy and physiology; abnormalities of these blood vessels may occur concomitantly in the retina and the brain. Easy access to the cerebral vasculature continues to pose challenges; the small vessels in the brain are not easily visualized. The retinal vasculature has hence often been used as a non-invasive in vivo surrogate marker to study vascular brain diseases. Although advances in neuroimaging have 
improved our understanding of the role of cerebral vasculature in brain physiology and pathology $y^{21}$, these sophisticated imaging modalities are expensive and timeconsuming. Retinal fundus photography, being a non-invasive and non-expensive technique, is ideal for directly visualizing the retinal microvasculature ${ }^{1,22,23}$. Since the retinal microvasculature shares commonalities with cerebral microvasculature, it could serve as an ideal surrogate platform.

Figure 3.

Retinal vascular abnormalities in relation to brain structure and cerebrovascular abnormalities ${ }^{24}$

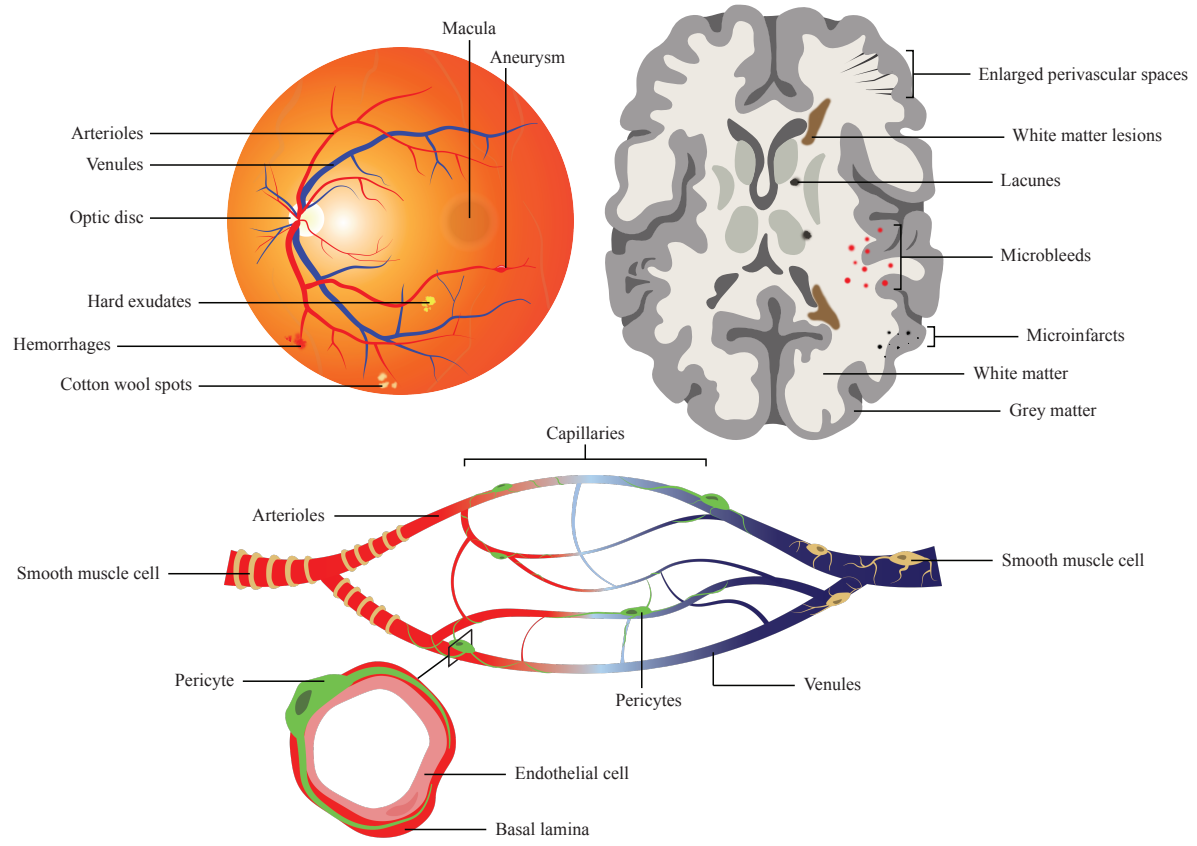

\subsection{Utility of Retinal Vasculature in studying Systemic, Vascular, and Neurodegenerative diseases}

Retinal vasculature has been studied in several cardiovascular and neurodegenerative disorders including hypertension, diabetic retinopathy, stroke, cognitive impairment, Alzheimer's disease, Parkinson's disease, and multiple sclerosis. 


\subsubsection{Retinal Vasculature in Diabetes and Hypertension}

The Atherosclerosis Risk In Communities study (ARIC) is a large population-based study that explored the relation between microvascular abnormalities and cognitive impairment. They reported that retinopathy, microaneurysms, and exudates are independently associated with a decrease in cognitive function ${ }^{25}$. In addition, narrowing of retinal arterioles and the presence of retinal exudates correlated with cerebral white-matter lesions on $\mathrm{MRL}^{26}$. Literature also indicates that there are abnormalities in retinal vascular calibre in cardiovascular diseases. Narrower central retinal arteriolar equivalents (CRAE) and wider central retinal venular equivalents (CRVE) were associated with various systemic diseases like diabetes, obesity, hypertension, and depression (Figure 4). The cardiovascular contributions of these disorders are believed to predict mortality ${ }^{27-29}$.

\section{Figure4.}

Narrow retinal arterioles (solid arrow) and wider retinal venules (dashed arrow) are indicators of various systemic diseases like hypertension and diabetes

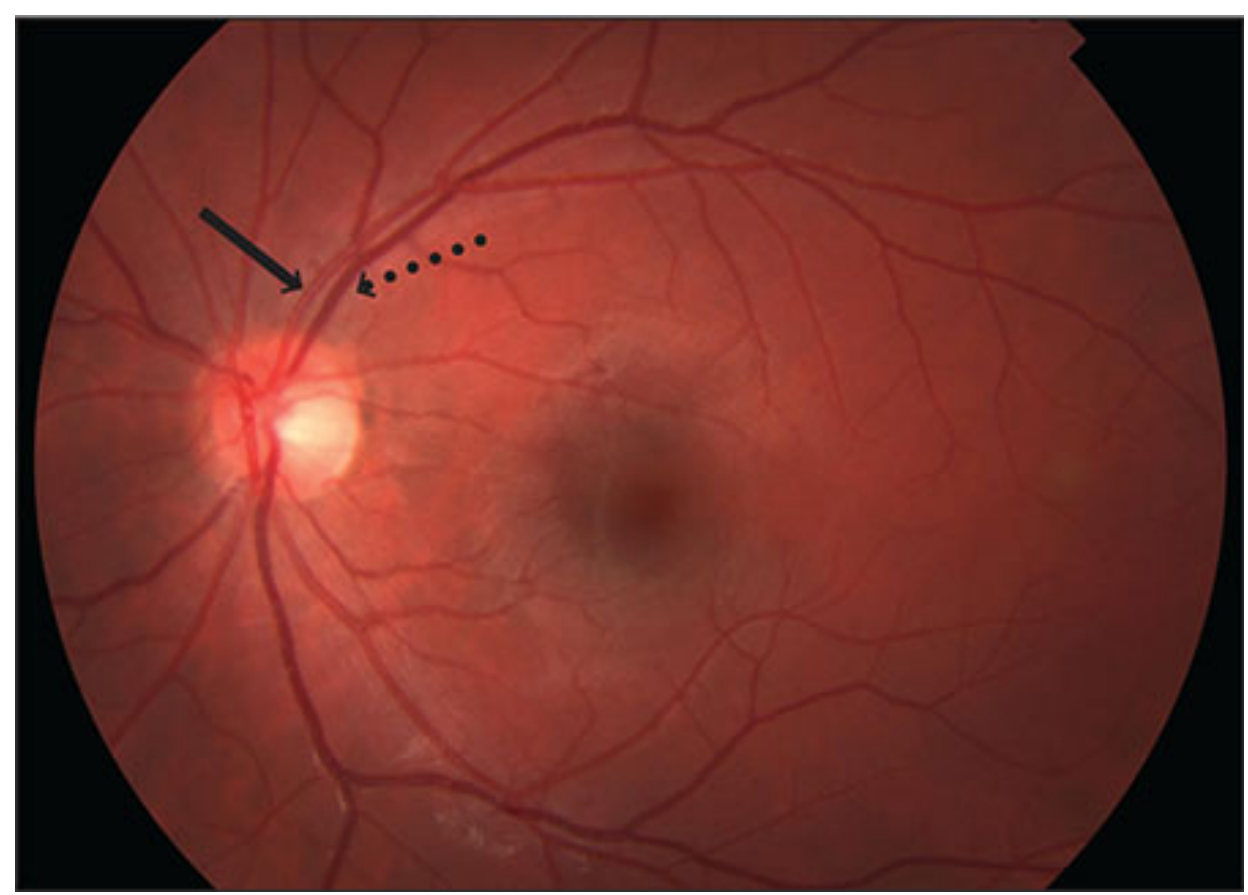




\subsubsection{Retinal Vasculature in Stroke}

Stroke is a major neurological illness in which the retinal microvasculature has been extensively examined. Several studies suggest that retinal microvascular anomalies reflect cerebrovascular changes related to stroke ${ }^{30-35}$. Even after adjusting for other risk factors (age, sex, race, blood pressure, diabetes), the ARIC study found retinal microvascular anomalies to be predictive of incident stroke as well as MRI-detected subclinical stroke ${ }^{36}$. The strongest relationship was demonstrated by microaneurysms and soft exudates. Another population study, the Cardiovascular Health Study found a similar relationship between retinal microvascular changes and stroke, after controlling for blood pressure and other risk factors ${ }^{37}$. Likewise, the Beaver Dam Eye Study also found the presence of retinal microaneurysms, haemorrhages, and retinal arteriolar narrowing to be associated with 10-year risk of stroke and coronary heart disease mortality ${ }^{38}$. The Blue Mountains Study which was prospective found an increased relative risk of stroke for all forms of retinopathy ${ }^{39}$, and unlike previous studies, the association with generalized arteriolar narrowing was as strong as the association with focal microaneurysms and haemorrhages. End diastolic and mean velocities on Central Retinal Artery doppler have also been found to be related to severity of cerebral small vessel disease, independent of ageing ${ }^{40}$. Post mortem studies in patients who had died of stroke have shown correlations between changes in retinal and cerebral vasculature $^{41}$. Other investigators have found relationships between lacunar infarcts and retinal microvascular abnormalities ${ }^{42,43}$. In addition, a prospective study has suggested that $78 \%$ of patients with lacunar stroke had retinal microvascular abnormalities ${ }^{44}$. Interestingly, another study did not find any difference in the prevalence of retinal lesions across patients with lacunar infarcts and cortical strokes ${ }^{45}$.

\subsubsection{Retinal Vasculature in Neurodegenerative disorders}

A few studies have explored the relation between retinal microvascular changes and cognitive impairment ${ }^{25,46,47}$. They support the use of retinal vascular imaging for the screening of cerebral small vessel disease as a potential surrogate marker for patients at risk of cognitive impairments. Studies in Alzheimer's disease have shown characteristic cerebral arteriolar changes including attenuation, increased tortuosity, and increased capillary microaneurysms $\mathrm{s}^{48-52}$. Retinal morphological abnormalities in 
Alzheimer's disease include depletion of optic nerve ganglion cells, loss of retinal nerve fibre layer, and abnormal patterns of ElectroRetinoGram (ERG) responses (reduced implicit time and amplitude ${ }^{53-58}$. Beta-amyloid and amyloid-associated proteins related to the pathogenesis of Alzheimer's disease have also been isolated in retinal ganglion cells and nerve fibers ${ }^{59}$. This indicates a possible common vascular pathway in the neurodegenerative process of Alzheimer's disease and the resultant neuronal loss both at the cerebral and the retinal levels ${ }^{16,60}$. Reduced retinal microvascular density has been demonstrated in Parkinson's disease patients. These retinal microvascular abnormalities are postulated to be contributary to the neurodegeneration in these patients ${ }^{61}$. In addition to neurodegenerative diseases, the association between the retinal vascular abnormality and cognitive dysfunction has also been observed in diabetic retinopathy. Diabetic retinopathy has also been found to be associated with small focal white-matter hyperintensities in the basal ganglia ${ }^{62}$. However, it is important to note that some of these findings are confounded by the presence of comorbid hypertension ${ }^{63-65}$.

Retinal imaging can also assess the amount of brain damage in patients with multiple sclerosis $(\mathrm{MS})^{66}$; the degree of inflammation and swelling in the retinae reflected the severity of inflammation in the brain MRIs. This correlation affirms the value of retinal scans as a stand-alone surrogate for brain damage ${ }^{67}$.

\subsection{Retinal Vascular abnormalities in Psychoses}

Retinal vascular abnormalities in cardiovascular, neurological, and metabolic diseases have been well researched; however, their association with psychiatric disorders remains under-examined. Schizophrenia (SCZ) and Bipolar Disorder (BD) have high global prevalence and morbidity ${ }^{68}$.

SCZ is a severe mental disorder characterized by positive symptoms such as hallucinations and delusions, negative symptoms such as amotivation and anhedonia, and cognitive deficits. Estimates of the international prevalence of schizophrenia among non-institutionalized persons ranges from $0.33 \%$ to $0.75 \% .69,70$. SCZ is usually classified as Type I and Type I| based on predominance of positive symptoms (hallucinations, delusions, paranoid thoughts) or negative symptoms (decreased social affiliation, lack of motivation or initiative, diminished speech, decreased emotions) respectively ${ }^{71-73}$. Symptoms usually begin during late adolescence and early adulthood. 
The developmental progression of the disorder indicates that early symptoms could be cognitive impairment with unusual behaviours, while later stages would be characterized by multiple such symptoms. This possibly reflects the disruptions in brain development and the contributory influences of environmental factors. Cognitive deficits are a core feature of SCZ; this includes impairments in attention, working memory, verbal learning, processing speed, visual learning, problem-solving, and social cognition ${ }^{74}$. Several studies have suggested that cognitive deficits are important determinants of functional outcomes in $\mathrm{SCZ}^{74,75}$. As is the case with most disorders, early detection and timely interventions help to improve life while severe disability results if the disease is left untreated. Treatment for SCZ is often lifelong and has to be continued even after symptoms have subsided.

Another important psychosis, BD, also has a high prevalence of around $1 \%$ in the general population ${ }^{76}$. It is characterized by drastic changes in the mood, energy, and activity levels of the person. These shifts in mood and energy levels are severe and affect daily activities ${ }^{77,78}$. For this reason, it is also referred to as manic-depressive disorder. Manic episodes are characterized by elated mood, irritability, increased energy and activity levels, and reduced need for sleep. During depressive episodes the person is sad, has low energy and motivation, and loss of interest in day to day activities along with impairment in socio-occupational functions. Patients may also have suicidal ideas during the episodes. Each episode can last from weeks to months ${ }^{79}$. More severe episodes, symptoms, comorbidities, and functional impairments accompany the adolescent-onset form of BD than the adult-onset form ${ }^{80}$. Studies also have suggested that cognitive deficits adversely affect functional outcomes in bipolar disorder ${ }^{74}$. Treatment of BD involves medications to both control symptoms during the episode and prevent the occurrence of further episodes while the patient is asymptomatic.

As shown in Figure 5, the retina has its embryonic origins from neural tissue and is connected to the brain through the optic nerve. The optic nerve consists of axons that transmit visual signals to the lateral geniculate nucleus, a thalamic relay centre for the visual pathway. From there, signals are transmitted to the visual cortex where visual stimuli are processed. As the retina and brain are developmentally and structurally connected, global brain damage may manifest as thinning of the retinal layers ${ }^{24}$. 
Figure 5.

Illustration of the connections of retinal nerve tissue to the brain and its use as biomarker for neurodegenerative brain disorder ${ }^{24}$

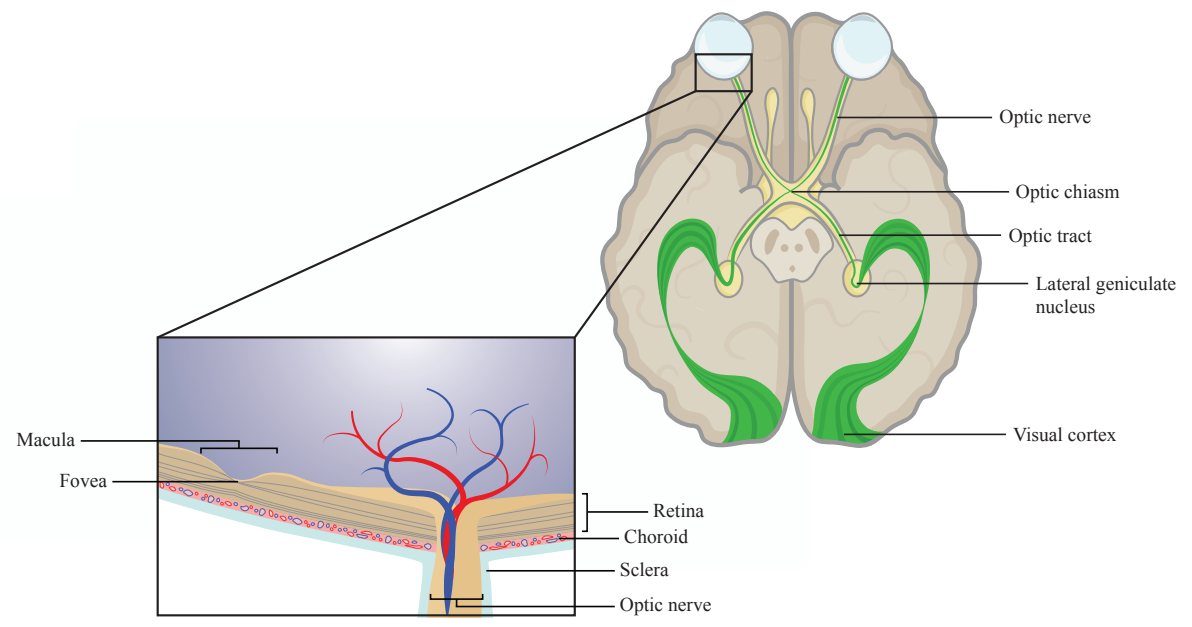

\subsubsection{Retinal Structure abnormalities in SCZ and BD}

Multiple structural and functional disturbances have been observed in the eyes of patients suffering from $S C Z$, including retinal venular widening, retinal nerve fibre layer (RNFL) thinning, abnormal output of retinal cells as measured by ERG, maculopathies, retinopathies, cataracts, poor acuity, and strabismus. Although some of these findings may be due to medications and comorbidities, others could serve as biomarkers for neural pathology and progression of $\mathrm{SCZ}^{81}$. One of the widely published retinal structure abnormalities in psychoses occurs in the RNFL. A typical RNFL OCT image is shown in Figure 2. As the RNFL consists of the axonal origins of the visual pathway and is not myelinated, it provides insight into the pathophysiological processes of diseases that have a neurodegenerative component ${ }^{82}$. Retinal layer abnormalities in SCZ detected using OCT have been found to be correlate with negative symptoms of SCZ in addition to the visual function of the eye ${ }^{83}$. Patients with $\mathrm{BD}$ have significantly quantifiable thinning in the macular RNFL, ganglion cell layers, inner plexiform layers, and inner nuclear layer compared to controls ${ }^{84,85}$. Studies that have examined RNFL thickness in SCZ and BD have derived its relation to brain abnormalities ${ }^{86,87}$. 


\subsubsection{Retinal Vascular abnormalities in SCZ and BD}

Several studies have suggested vascular risk factors and vascular anomalies in these two major psychoses. Abnormal capillary beds in nail folds ${ }^{88}$, abnormal vascular responses to niacin ${ }^{89}$, and abnormalities in the genes regulating cerebral blood flow ${ }^{90}$ have been reported in SCZ. Patients with BD have a higher incidence of vascular disorders and premature mortality; this may include contributions by suicide and other related comordibidities ${ }^{91}$. However, an increased prevalence of deep white matter hyperintensities on magnetic resonance imaging (MRI), indicates cerebral microvascular disease in patients with $\mathrm{BD}^{92}$. Neuroimaging studies have reported reduced cerebral blood flow in the anterior brain regions in both $\mathrm{SCZ}^{93}$ and $\mathrm{BD}^{94}$. Subsequently, the examination of cerebral microvascular abnormalities in SCZ and BD has gained considerable interest. Researchers have explored the retina for potential biomarkers for SCZ and cognitive impairments ${ }^{81}$.

Of these only a few studies have worked on the analysis of retinal images of patients with psychoses. Direct imaging of the retinal microvasculature has been performed only in members of the Dunedin birth cohort at 38 years of age. It was found that patients with SCZ had significantly wider venular calibres when compared to other cohort members. The dilated microvenules could not be explained by measurable confounders of illness, including antipsychotic treatment and other comorbidities found in SCZ such as hypertension, diabetes, and tobacco dependence. This demonstrated that retinal imaging could improve our understanding of the etiopathogenesis of schizophrenia, and that it could be a potential biomarker for $\mathrm{SCZ}^{95}$. Another study by the same group explored whether these retinal microvascular changes reflected familial vulnerability to psychotic symptoms. The retinal venular diameters of those with psychosis and their unaffected twins were analysed along with controls. It was found that the psychotic patients had larger venular diameters compared to controls, while the unaffected twins demonstrated intermediate values after adjusting for confounders like smoking, blood pressure, and body mass index ${ }^{96}$. This suggests that the width of retinal venules may serve as a proxy measure for familial vulnerability to psychotic symptoms.

Another group compared retinal vessels in patients with BD and healthy controls. The retinal vascular abnormalities reflected excessive and premature cardiovascular disease. Retinal vascular calibres are correlated with mood and cognition, vascular risk factors, and endothelial function in adolescent BD. However, there was no significant difference in the retinal vessel calibres between patients with adolescent $\mathrm{BD}$ and healthy controls ${ }^{97}$. 
Apart from the three above-mentioned studies, none have examined retinal vascular abnormalities in SCZ and BD. However, these studies were preliminary and their measurements were restricted to vessel calibre. They have not examined other vascular parameters such as tortuosity, fractal dimension $\left(D_{f}\right)$, or trajectory.

Tortuosity refers to the geometric pattern of the retinal vasculature layout (Figure 6) and reflects the adequacy of the microcirculation status and level of ocular perfusion ${ }^{98}$. Researchers have opined that retinal vascular tortuosity is a more stable marker than retinal vascular calibre as it is not affected by pulse variations ${ }^{99,100}$ and has high heritability ${ }^{101,102}$. Retinal tortuosity has been studied in various diseases but have not provided consistent findings ${ }^{100}$. Hypertension has been shown to be associated with increased retinal venular tortuosity ${ }^{103}$. However, retinal arteriolar tortuosity in hypertension has shown contradictory findings across studies ${ }^{104,105}$. Studies have demonstrated increased tortuosity of retinal vessels in cerebrovascular diseases like ischemic stroke ${ }^{106}$, cognitive dysfunction, Alzheimer's disease ${ }^{107}$, and metabolic disorders like increased body mass index and diabetes ${ }^{108}$.

\section{Figure6.}

Tortuosity measurement in retinal fundus images ${ }^{109}$

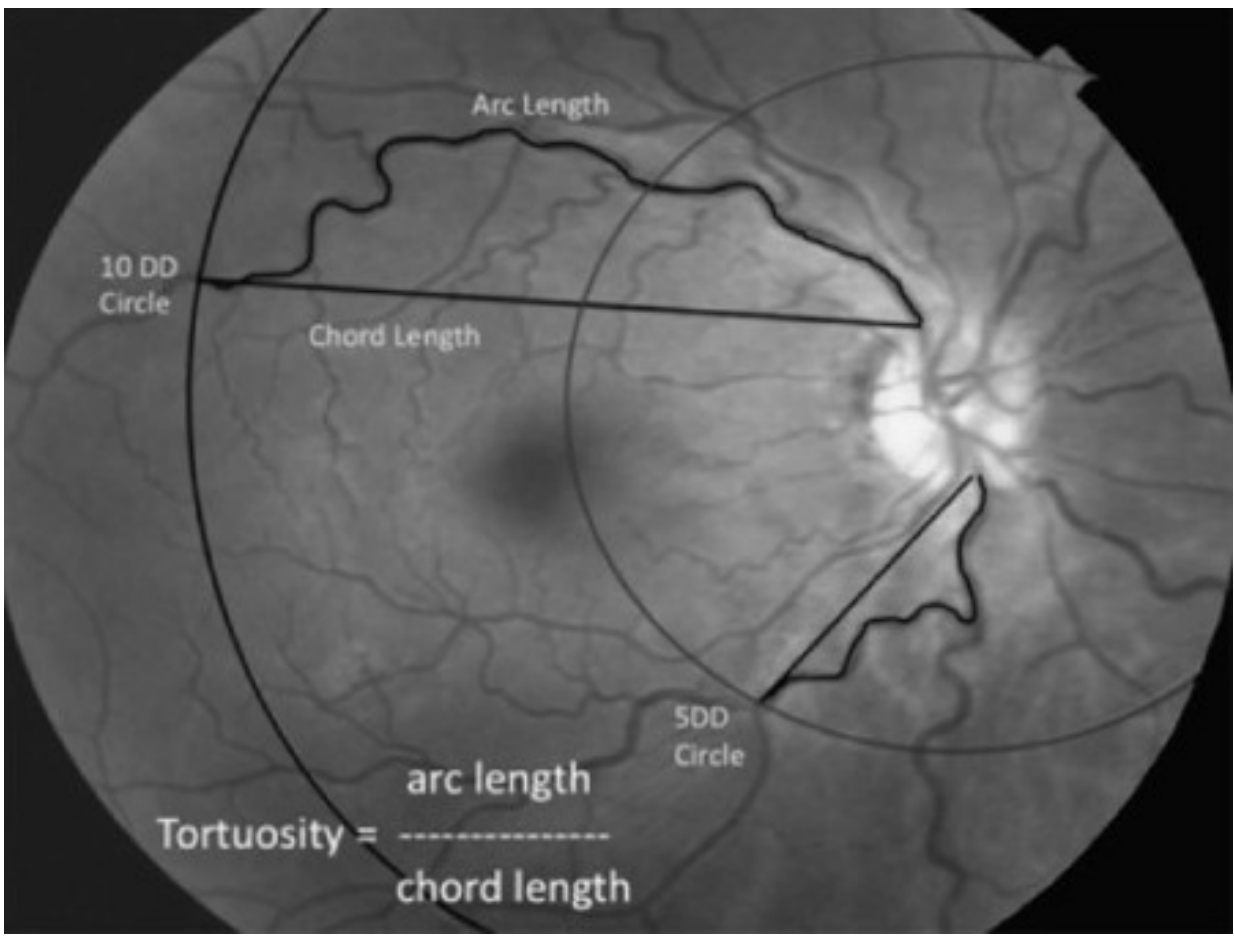


Blood vessels repeatedly subdivide into smaller blood vessels with similar network patterns. This phenomenon can be quantified using fractal dimension $\left(D_{f}\right)$, which expresses the degree of complexity of blood vessel geometry as a single value (Figure 7) ${ }^{10,111}$. Retinal vascular Df depends on the number of bifurcations, angle of bifurcations, and length of vessels between two consecutive bifurcations ${ }^{112}$. It is not affected by factors which may confound the measurement of vascular calibre ${ }^{21}$, such as variations in the pulse cycle or ocular and camera magnification ${ }^{113}$ and is hence more advantageous. Several studies have reported that retinal vascular Df correlates with diabetes and diabetic retinopathy, hypertension, cardiovascular disorder, stroke, and dementia ${ }^{114-127}$; Df has been proposed as a biomarker for these conditions ${ }^{123}$.

\section{Figure7.}

Decreasing fractal dimension values based on complexity of the retinal vasculature ${ }^{128}$

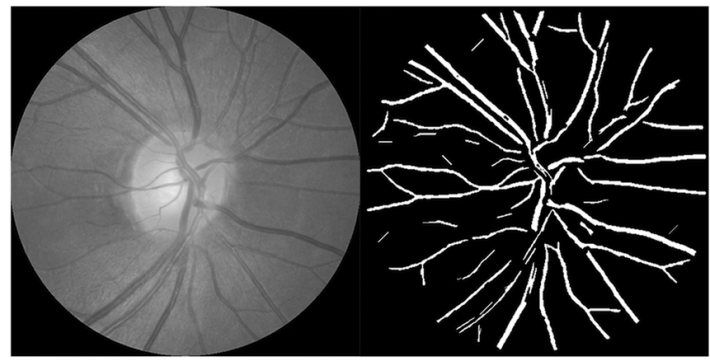

(a) shows a Df of 1.4958

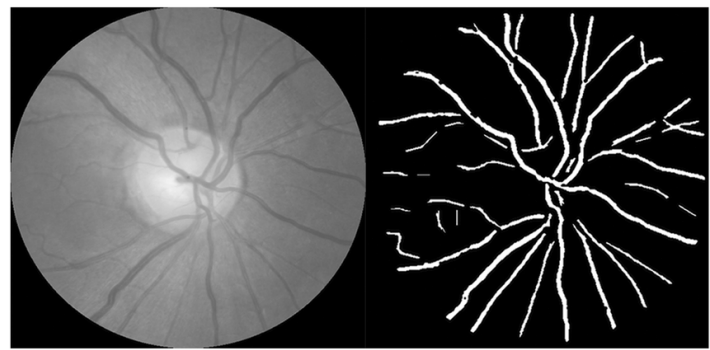

(b) shows a Df of 1.4541

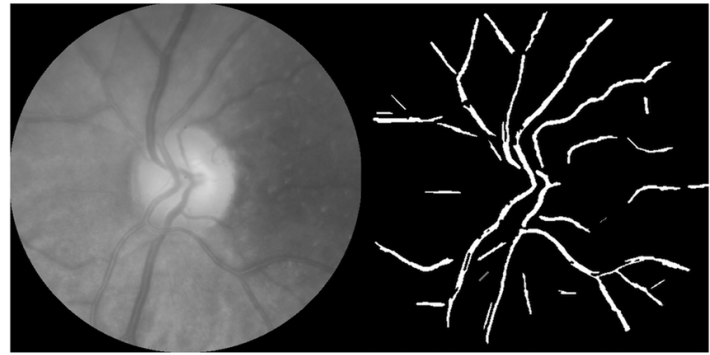

(c) shows a Df of 1.4073 
Figure8.

Retinal vascular trajectory marked in a retinal fundus image

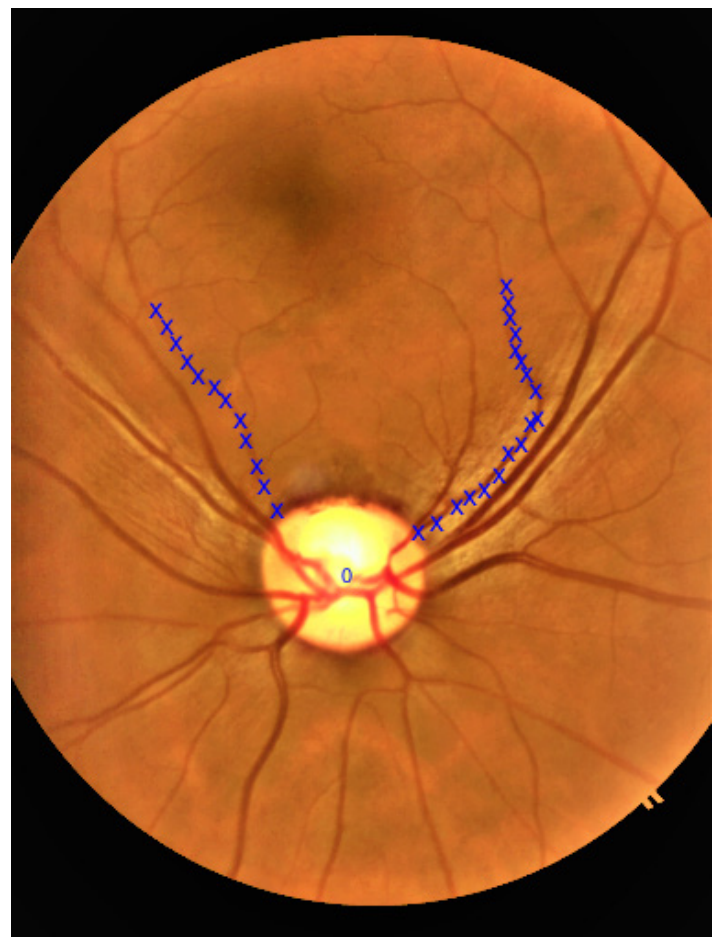

Yet another retinal vascular parameter is the retinal vascular trajectory (Figure 8) measured as retinal artery angle (angle between the supratemporal and infratemporal arteries). A recent study has reported a significant relation of retinal arterial trajectory to RNFL thickness ${ }^{129}$. The retinal arterial trajectory ${ }^{130,131}$, thus provides an opportunity to indirectly examine abnormalities in RNFL thickness. Despite its relationship with RNFL abnormalities, studies are yet to examine the trajectory of retinal vessels in patients with $\mathrm{SCZ}$ and BD.

While these studies have provided the first line of evidence for abnormal retinal vessels in $\mathrm{SCZ}$ and $\mathrm{BD}$, the findings have not been replicated and there have been no comparisons of these parameters across the two major psychoses. In addition, the retinal vascular parameters have also not been examined in relation to cognitive impairment. The employment of machine learning in the assessment of retinal vascular abnormalities as biomarkers in SCZ and BD is also yet to be researched. Retinal vascular changes are potential markers of future cardiovascular morbidity and could help in identifying at-risk individuals at an earlier stage. 


\section{Outline of the Thesis}

This thesis investigates retinal microvasculature abnormalities in two major psychoses, $\mathrm{SCZ}$ and $\mathrm{BD}$, and explores the potential usage of the retina as a surrogate examination platform. Retinal imaging features including retinal vascular calibre, tortuosity, fractal dimension, and trajectory were assessed. In addition, their relation with cognition was also explored.

\section{The outline of this thesis across the upcoming chapters is provided below}

CHAPTER TWO describes the measurement of retinal vascular calibre (retinal vessel thickness) in patients with SCZ and BD, and Healthy Volunteers (HV). It demonstrates that retinal vasculature provides a window to the brain circulation. This study is the first of its kind to compare retinal vascular calibre across two disorders (BD and SCZ).

CHAPTER THREE illustrates the use of retinal tortuosity which is another measurable parameter on the retinal fundus image in SCZ, BD, and HV. Retinal tortuosity is described as the ratio of arc length to chord length in retinal vessels. The variations of retinal arteriolar tortuosity across $\mathrm{SCZ}, \mathrm{BD}$, and $\mathrm{HV}$ are discussed along with its potential as a biomarker for assessing the risk of future adverse vascular events.

CHAPTER FOUR covers the importance of fractal dimension of retinal vasculature in $\mathrm{SCZ}, \mathrm{BD}$, and HV. The retinal vascular fractal dimension represents the complexity of the entire retinal vascular tree, and was measured with the help of an automated algorithm using the box counting method. The potential implications of abnormal $D_{f}$ in psychoses are also discussed.

CHAPTER FIVE demonstrates the measurement of retinal vascular trajectory in SCZ, $\mathrm{BD}$, and HV. The use of machine learning to evaluate retinal vascular trajectory is also described in this chapter, along with the implications of varied findings across patient and control groups.

CHAPTER SIX discusses the correlation between cognitive function as assessed by the one back identification test and retinal vascular calibre in SCZ, BD, and HV. One back test is a standard cognitive test that assesses the working memory of an individual. The chapter also discusses the relation between retinal vascular calibre and memory. 
CHAPTER SEVEN provides an overview of retinal vasculature abnormalities in SCZ and BD patients. It also illustrates the challenges associated with the use of techniques that were employed. In addition to discussing how the thesis has contributed to the existing knowledge base, the chapter also cites recent research advances in this area and directives for future studies.

CHAPTER EIGHT summarizes the thesis. The background of the study, procedures employed, major findings, and their clinical implications are outlined in this chapter. Special emphasis has been given to the utility of the retina as a proxy examination platform and retinal vascular parameters as biomarkers for cerebrovascular disorders. 


\section{References}

1. Patton N, Aslam T, Macgillivray T, Pattie A, Deary IJ, Dhillon B. Retinal vascular image analysis as a potential screening tool for cerebrovascular disease: a rationale based on homology between cerebral and retinal microvasculatures. J Anat. 2005;206(4):319348.

2. Patton N, Pattie A, MacGillivray $T$, et al. The association between retinal vascular network geometry and cognitive ability in an elderly population. Invest Ophthalmol Vis Sci. 2007;48(5):1995-2000.

3. Hughes S, Yang H, Chan-Ling T. Vacsularization of the human fetal retina: roles of vasculogenesis and angiogenesis. Invest Ophthalmol Vis Sci. 2000;41(5):1217-1228.

4. Dorrell MI, Aguilar E, Friedlander M. Retinal vascular development is mediated by endothelial filopodia, a preexisting astrocytic template and specific $R$-cadherin adhesion. Invest Ophthalmol Vis Sci. 2002;43(11):3500-3510.

5. Trost $A$, Lange $S$, Schroedl $F$, et al. Brain and retinal pericytes: origin, function and role. Frontiers in cellular neuroscience. 2016;10:20.

6. Hardy $P$, Varma DR, Chemtoc S. Control of cerebral and ocular blood flow autoregulation in neonates. Pediatric Clinics of North America. 1997;44(1):137-152.

7. Lassen NA. Autoregulation of cerebral blood flow. Circ Res. 1964;14:201-206.

8. Delaey C, Van de Voorde J. Regulatory mechanisms in the retinal and choroidal circulation. Ophthalmic Res. 2000;32:249-256.

9. Clarke D, Sokoloff L. Substrates of cerebral metabolism. Basic Neurochemistry: Molecular, Cellular and Medical Aspects (GJ, S et al, eds) Philadelphia: LippincottRaven. 1999.

10. London A, Benhar I, Schwartz M. The retina as a window to the brain-from eye research to CNS disorders. Nat Rev Neurol. 2013;9(1):44-53.

11. Bendschneider D, Tornow RP, Horn FK, et al. Retinal nerve fiber layer thickness in normals measured by spectral domain OCT. Journal of glaucoma. 2010;19(7):475-482.

12. Alasil $T$, Wang $K$, Keane $P A$, et al. Analysis of normal retinal nerve fiber layer thickness by age, sex, and race using spectral domain optical coherence tomography. Journal of glaucoma. 2013;22(7):532-541. 
13. Pawar $N$, Maheshwari $D$, Ravindran $M$, Ramakrishnan R. Retinal nerve fiber layer thickness in normal Indian pediatric population measured with optical coherence tomography. Indian journal of ophthalmology. 2014;62(4):412.

14. Alasil T, Wang K, Lee H, de Boer JF, Chen TC. Analysis of Normal Retinal Nerve Fiber Layer Thickness by Age, Gender, and Race Using Spectral Domain Optical Coherence Tomography. Investigative Ophthalmology \& Visual Science. 2011;52(14):210-210.

15. Gordon-Lipkin E, Chodkowski B, Reich DS, et al. Retinal nerve fiber layer is associated with brain atrophy in multiple sclerosis. Neurology. 2007;69(16):1603-1609.

16. Sivak JM. The aging eye: common degenerative mechanisms between the Alzheimer's brain and retinal disease. Investigative ophthalmology \& visual science. 2013;54(1):871880 .

17. den Haan J, Verbraak FD, Visser PJ, Bouwman FH. Retinal thickness in Alzheimer's disease: a systematic review and meta-analysis. Alzheimer's \& Dementia: Diagnosis, Assessment \& Disease Monitoring. 2017;6:162-170.

18. Thomson KL, Yeo JM, Waddell B, Cameron JR, Pal S. A systematic review and metaanalysis of retinal nerve fiber layer change in dementia, using optical coherence tomography. Alzheimer's \& Dementia: Diagnosis, Assessment \& Disease Monitoring. 2015;1(2):136-143.

19. White VA, Lewallen S, Beare N, Kayira K, Carr RA, Taylor TE. Correlation of retinal haemorrhages with brain haemorrhages in children dying of cerebral malaria in Malawi. Transactions of the Royal Society of Tropical Medicine and Hygiene. 2001;95(6):618-621.

20. Greiner J, Dorovini-Zis K, Taylor TE, et al. Correlation of hemorrhage, axonal damage, and blood-tissue barrier disruption in brain and retina of Malawian children with fatal cerebral malaria. Frontiers in cellular and infection microbiology. 2015;5:18.

21. Lavina B. Brain Vascular Imaging Techniques. Int J Mol Sci. 2016;18(1).

22. Wong $T Y$, Klein R, Couper DJ, et al. Retinal microvascular abnormalities and incident stroke: the Atherosclerosis Risk in Communities Study. Lancet (London, England). 2001;358(9288):1134-1140.

23. Yatsuya H, Folsom AR, Wong $T Y$, et al. Retinal microvascular abnormalities and risk of lacunar stroke: Atherosclerosis Risk in Communities Study. Stroke. 2010;41(7):13491355. 
24. Mutlu Ü. The Retina as a Biomarker for Vascular and Neurodegenerative Brain Diseases [Ph.D. thesis], Erasmus University Rotterdam; 2018.

25. Wong $T Y$, Klein $R$, Sharrett $A R$, et al. Retinal microvascular abnormalities and cognitive impairment in middle-aged persons: The Atherosclerosis Risk in Communities Study. Stroke. 2002;33:1487-1492.

26. Moss HE. Retinal Vascular Changes are a Marker for Cerebral Vascular Diseases. Curr Neurol Neurosci Rep. 2015;15(7):40.

27. Nguyen TT, Wong TY, Islam FA, et al. Evidence of early retinal microvascular changes in patients with type 2 diabetes and depression. Psychosomatic medicine. 2010;72(6):535538.

28. Gopinath B, Baur LA, Wang J, et al. Blood pressure is associated with retinal vessel signs in preadolescent children. Journal of hypertension. 2010;28(7):1406-1412.

29. Wang JJ, Liew G, Klein R, et al. Retinal vessel diameter and cardiovascular mortality: pooled data analysis from two older populations. European heart journal. 2007;28(16):1984-1992.

30. Aoki N. Epidemiological evaluation of fundoscopic findings in cerebrovascular diseases, II. a multivariate analysis of fundoscopic findings. Jpn Circ J. 1975;39:271-282.

31. Svardsudd K, Wedel H, Aurell E, Tibber G. Hypertensive eye ground changes: prevalence relation to blood pressure and prognostic importance. Acta Med Scand. 1978;204:159167.

32. Okada H, Horibe H, Yoshiyuki O, Hayakawa N, Aoki N. A prospective study of cerebrovascular disease in Japanese rural communities, Akabane and Asahi, part 1: evaluation of risk factors in the occurrence of cerebral hemorrhage and thrombosis. Stroke. 1976;7:599-607.

33. Tanaka H, Hayashi M, Date $C$, et al. Epidemiologic studies of stroke in Shibata, a provincial Japanese city: preliminary report on risk factors for cerebral infarction. Stroke. 1985; 16:773-780.

34. Sano T, Arai H, Ogawa Y. [Relationship of fundus oculi changes to declines in mental and physical health conditions among elderly living in a rural community.]. Nippon Koshu Eisei Zasshi. 1994;41:219-229. 
35. Kobayashi S, Okada K, Koide H, Bokura H, Yamaguchi S. Subcortical silent brain infarction as a risk factor for clinical stroke. Stroke. 1997;28(10):1932-1939.

36. Wong $T Y$, Klein R, Couper DJ, et al. Retinal microvascular abnormalities and incident stroke: the Atherosclerosis Risk in Communities Study. Lancet. 2001;358:1134-1140.

37. Wong $T$, Klein $R$, Sharrett $A$, et al. The prevalence and risk factors of microvascular abnormalities in older people: the Cardiovascular Health Study. Ophthalmology. 2003; 110:658-666.

38. Wong $T$, Klein $R$, Nieto $F$, et al. Retinal microvascular abnormalities and ten-year cardiovascular mortality: a population-based case-control study. Ophthalmology. 2003; 110:933-940.

39. Wong TY. Is retinal photography useful in the measurement of stroke risk? Lancet Neurology. 2004;3:179-183.

40. Hiroki M, Miyashita K, Yoshida H, HiraiS, Fukuyama H. Central retinal artery Dopplerflow parameters reflect the severity of cerebral small-vessel disease. Stroke. 2003;34:e92-e94.

41. Goto I, Kimoto K, Katsuki S, Mimatsu T, Ikui H. Pathological studies on the intracerebral and retinal arteries in cerebrovascular and noncerebrovascular diseases. Stroke. 1975;6:263-269.

42. Schneider R, Rademacher M, Wolf S. Lacunar infarcts and white matter attenuation: ophthalmologic and microcirculatory aspects of the pathophysiology. Stroke. 1993;24:1874-1879.

43. Korber N, Schneider R, Brockmann M. Circulatory parameters of the retina in patients with lacunar stroke. J Neurol. 1986;233:30-33.

44. Kappelle LJ, Koudstaal PJ, van Gijn J, Ramos LM, Keunen JE. Carotid angiography in patients with lacunar infarction. A prospective study. Stroke. 1988;19:1093-1096.

45. Luijckx G-J, Boiten J, van Kroonenburgh M. Systemic small-vessel disease is not exclusively related to lacunar stroke. A pilot study. J Stroke Cerebrovasc Dis. 1998;7:5257.

46. Wong $T Y$, Klein $R$, Nieto FJ, et al. Is early age-related maculopathy related to cognitive function? The atherosclerosis risk in communities study. Am J Ophthalmol. 2002;134(6):828-835. 
47. Kwa V, Van der Sande J, Stam J, Tijmes N, Vrooland J. Retinal arterial changes correlate with cerebral small-vessel disease. Neurology. 2002;59(10):1536-1540.

48. Miyakawa T, Uehara Y, Desaki J, Kimura T, Kuramoto R. Morphological changes of microveseels in the brain with Alzheimer's disease. Jpn J Psychiatry Neurol. 1988;42:819824.

49. Fischer VW, Siddiqi A, Yusufaly Y. Altered angioarchitecture in selected areas of brains with Alzheimer's disease. Acta Neuropathol (Berl). 1990;79:672-679.

50. Kalaria RN. The blood-brain barrier and cerebral microcirculation in Alzheimer disease. Cerebrovasc Brain Metab Rev. 1992;4:226-260.

51. Buee $L, H o f P R$, Bouras $C$, et al. Pathological alterations of the cerebral microvasculature in Alzheimer's disease and related dementing disorders. Acta Neuropathol (Berl). 1994;87:469-480.

52. Moody DM, Brown WR, Challa VR, Ghazi-Birry HS, Reboussin DM. Cerebral microvascular alterations in aging, leukoaraiosis, and Alzheimer's disease. Ann N Y Acad Sci. 1997;826:103-116.

53. Katz B, Rimmer S, Iragui $V$, Katzman R. Abnormal pattern electroretinogram in Alzheimer's disease: evidence for retinal ganglion cell degeneration? Ann Neurol. $1989 ; 26: 221-225$.

54. Trick GL, Barris MC, Bickel-Blut M. Abnormal pattern electroretinogram in patients with senile dementia of the Alzheimer type. Ann Neurol. 1989;26:226-231.

55. Hinton DR, Sadun SA, Blanks IC, Miller CA. Optic-nerve degeneration in Alzheimer's disease. N Engl J Med. 1986;315:485-487.

56. Parisi V, Restuccia R, Fattapposta F, Mina C, Bucci MG, Pierelli F. Morphological and functional retinal impairment in Alzheimer's disease patients. Clinical Neurophysiology. 2001;112:1860-1867.

57. Blanks JC, Torigoe Y, Hinton DR, Blanks RH. Retinal pathology in Alzheimer's disease. I. Ganglion cell loss in foveal/parafoveal retina. Neurobiol Aging. 1996;17:377-384.

58. Blanks JC, Schmidt SY, Torigoe Y, Hinton DR. Retinal pathology in Alzheimer's disease. II. Regional neuron loss and glial changes in GCL. Neurobiol Aging. 1996;1996:385-395. 
59. Loffler KU, Edward DP, Tso MO. Immunoreactivity against tau, amyloid precursor protein, and beta-amyoil in the human retina. Invest Ophthalmol Vis Sci. 1995;36:2431.

60. Ravi Teja KV, Tos Berendschot T, Steinbusch H, Carroll Webers AB, Praveen Murthy $R$, Mathuranath PS. Cerebral and Retinal Neurovascular Changes: A Biomarker for Alzheimer's Disease. J Gerontol Geriatr Res. 2017;6(4).

61. Kwapong WR, Ye H, Peng C, et al. Retinal Microvascular Impairment in the Early Stages of Parkinson's Disease. 2018;59(10):4115-4122.

62. Ferguson SC, Blane A, Perros $P$, et al. Cognitive ability and brain structure in type 1 diabetes. Relation to microangiopathy and preceeding severe hypoglycaemia. Diabetes. 2003;52:149-156.

63. Dejgaard A, Gade A, Larsson H, Balle V, Parving A. Evidence for diabetic encephalopathy. Diabet Med. 1991;8:162-167.

64. Yousen DM, Tasman WS, Grossman RI. Proliferative retinopathy: absence of white matter lesions at MR imaging. Radiology. 1991;179:29-230.

65. Lunetta M, Damanti AR, Fabbri G, Lombardo M, Di Mauro M, Mughini L. Evidence by magnetic resonance imaging of cerebral alterations of atrophy type in young insulindependent diabetic patients. J Endocrinol Invest. 1994;17:241-245.

66. Calabresi PA, Balcer LJ, Frohman EM. Retinal pathology in multiple sclerosis: insight into the mechanisms of neuronal pathology. Brain : a journal of neurology. 2010;133(6):1575-1577.

67. Dörr J, Wernecke KD, Bock M, et al. Association of retinal and macular damage with brain atrophy in multiple sclerosis. PloS one. 2011;6(4):e18132.

68. Perälä J, Suvisaari J, Saarni Sl, et al. Lifetime prevalence of psychotic and bipolar I disorders in a general population. 2007;64(1):19-28.

69. Rössler W, Salize HJ, van Os J, Riecher-Rössler A. Size of burden of schizophrenia and psychotic disorders. European Neuropsychopharmacology. 2005;15(4):399-409.

70. Moreno-Küstner B, Martin C, Pastor L. Prevalence of psychotic disorders and its association with methodological issues. A systematic review and meta-analyses. PloS one. 2018;13(4):e0195687. 
71. Disease GBD, Injuryl, Prevalence C. Global, regional, and national incidence, prevalence, and years lived with disability for 328 diseases and injuries for 195 countries, 19902016: a systematic analysis for the Global Burden of Disease Study 2016. Lancet. 2017;390(10100):1211-1259.

72. Olfson M, Gerhard T, Huang C, Crystal S, Stroup TS. Premature Mortality Among Adults With Schizophrenia in the United States. JAMA Psychiatry. 2015;72(12):1172-1181.

73. Palmer BA, Pankratz VS, Bostwick JM. The lifetime risk of suicide in schizophrenia: $a$ reexamination. Arch Gen Psychiatry. 2005;62(3):247-253.

74. Green MF. Cognitive impairment and functional outcome in schizophrenia and bipolar disorder. J Clin Psychiatry. 2006;67 Suppl 9:3-8; discussion 36-42.

75. Gold JM, Barch DM, Feuerstahler LM, et al. Working Memory Impairment Across Psychotic disorders. Schizophr Bull. 2018.

76. Rowland TA, Marwaha S. Epidemiology and risk factors for bipolar disorder. Therapeutic advances in psychopharmacology. 2018;8(9):251-269.

77. Kessler RC, Chiu WT, Demler O, Merikangas KR, Walters EE. Prevalence, severity, and comorbidity of 12-month DSM-IV disorders in the National Comorbidity Survey Replication. Arch Gen Psychiatry. 2005;62(6):617-627.

78. Merikangas KR, He JP, Burstein M, et al. Lifetime prevalence of mental disorders in U.S. adolescents: results from the National Comorbidity Survey Replication--Adolescent Supplement (NCS-A). J Am Acad Child Adolesc Psychiatry. 2010;49(10):980-989.

79. Swann AC. What is bipolar disorder? Am J Psychiat. 2006;163(2):177-179.

80. Goldstein BI, Levitt AJ. Further evidence for a developmental subtype of bipolar disorder defined by age at onset: Results from the national epidemiologic survey on alcohol and related conditions. American Journal of Psychiatry. 2006;163(9):1633-U1632.

81. Silverstein SM, Rosen R. Schizophrenia and the eye. Schizophrenia Research: Cognition. 2015;2(2):46-55.

82. Schonfeldt-Lecuona C, Kregel T, Schmidt A, et al. From Imaging the Brain to Imaging the Retina: Optical Coherence Tomography (OCT) in Schizophrenia. Schizophr Bull. 2016;42(1):9-14. 
83. Samani NN, Proudlock FA, Siram V, et al. Retinal Layer Abnormalities as Biomarkers of Schizophrenia. Schizophr Bull. 2018;44(4):876-885.

84. Garcia-Martin E, Gavin A, Garcia-Campayo J, et al. VISUAL FUNCTION AND RETINAL CHANGES IN PATIENTS WITH BIPOLAR DISORDER. Retina (Philadelphia, Pa). 2018.

85. Polo V, Satue M, Gavin A, et al. Ability of swept source OCT to detect retinal changes in patients with bipolar disorder. Eye. 2018:1.

86. Pan J, Zhou Y, Xiang Y, Yu J. Retinal nerve fiber layer thickness changes in Schizophrenia: A meta-analysis of case-control studies. Psychiatry research. 2018;270:786-791.

87. Mehraban A, Samimi SM, Entezari M, Seifi MH, Nazari M, Yaseri M. Peripapillary retinal nerve fiber layer thickness in bipolar disorder. Graefes Arch Clin Exp Ophthalmol. 2016;254(2):365-371.

88. Curtis CE, lacono WG, Beiser M. Relationship between nailfold plexus visibility and clinical, neuropsychological, and brain structural measures in schizophrenia. Biological psychiatry. 1999;46(1):102-109.

89. Hudson CJ, Lin A, Cogan S, Cashman F, Warsh JJ. The niacin challenge test: clinical manifestation of altered transmembrane signal transduction in schizophrenia? Biol Psychiatry. 1997;41(5):507-513.

90. Sun C, Wang J, Mackey DA, Wong TY. Retinal vascular caliber: systemic, environmental, and genetic associations. Surv Ophthalmol. 2009;54(1):74-95.

91. Goldstein BI. Bipolar Disorder and the Vascular System: Mechanisms and New Prevention Opportunities. Can J Cardiol. 2017;33(12):1565-1576.

92. Lloyd AJ, Moore PB, Cousins DA, et al. White matter lesions in euthymic patients with bipolar disorder. Acta Psychiatr Scand. 2009;120(6):481-491.

93. Gogtay N. Cortical brain development in schizophrenia: insights from neuroimaging studies in childhood-onset schizophrenia. Schizophr Bull. 2008;34(1):30-36.

94. Kruger S, Alda M, Young LT, Goldapple K, Parikh S, Mayberg HS. Risk and resilience markers in bipolar disorder: brain responses to emotional challenge in bipolar patients and their healthy siblings. Am J Psychiatry. 2006;163(2):257-264.

95. Meier MH, Shalev W, Moffitt TE, et al. Microvascular Abnormality in Schizophrenia as Shown by Retinal Imaging. Am J Psychiat. 2013;170(12):1451-1459. 
96. Meier MH, Gillespie NA, Hansell NK, et al. Retinal microvessels reflect familial vulnerability to psychotic symptoms: A comparison of twins discordant for psychotic symptoms and controls. Schizophrenia research. 2015;164(1-3):47-52.

97. Naiberg MR, Hatch JK, Selkirk B, et al. Retinal photography: A window into the cardiovascular-brain link in adolescent bipolar disorder. J Affect Disord. 2017;218:227237.

98. Patton N, Aslam TM, MacGillivray T, et al. Retinal image analysis: concepts, applications and potential. Prog Retin Eye Res. 2006;25(1):99-127.

99. Hao H, Sasongko MB, Wong TY, et al. Does retinal vascular geometry vary with cardiac cycle? Invest Ophthalmol Vis Sci. 2012;53(9):5799-5805.

100. Kalitzeos AA, Lip GY, Heitmar R. Retinal vessel tortuosity measures and their applications. Exp Eye Res. 2013;106:40-46.

101.Taarnhøj N, Munch I, Sander B, et al. Straight versus tortuous retinal arteries in relation to blood pressure and genetics. British Journal of Ophthalmology. 2008;92(8):10551060.

102. Kirin M, Nagy R, MacGillivray TJ, et al. Determinants of retinal microvascular features and their relationships in two European populations. Journal of hypertension. 2017;35(8):1646.

103.Cheung CY, Tay WT, Mitchell $P$, et al. Quantitative and qualitative retinal microvascular characteristics and blood pressure. Journal of hypertension. 2011;29(7):1380-1391.

104.Owen CG, Rudnicka AR, Nightingale CM, et al. Retinal arteriolar tortuosity and cardiovascular risk factors in a multi-ethnic population study of 10-year-old children; the Child Heart and Health Study in England (CHASE). Arteriosclerosis, thrombosis, and vascular biology. 2011;31(8):1933-1938.

105.Thom S, Stettler C, Stanton A, et al. Differential effects of antihypertensive treatment on the retinal microcirculation: an anglo-scandinavian cardiac outcomes trial substudy. Hypertension. 2009;54(2):405-408.

106.Ong YT, De Silva DA, Cheung CY, et al. Microvascular structure and network in the retina of patients with ischemic stroke. Stroke. 2013;44(8):2121-2127.

107. Cheung CY, Ong YT, Ikram MK, et al. Microvascular network alterations in the retina of patients with Alzheimer's disease. Alzheimers Dement. 2014;10(2):135-142. 
108.Noda K, Nakao S, Zandi S, Sun D, Hayes KC, Hafezi-Moghadam A. Retinopathy in a novel model of metabolic syndrome and type 2 diabetes: new insight on the inflammatory paradigm. FASEB J. 2014;28(5):2038-2046.

109. Mohsenin A, Mohsenin V, Adelman RAJCo. Retinal vascular tortuosity in obstructive sleep apnea. 2013;7:787.

110.Lim SW, Cheung N, Wang JJ, et al. Retinal vascular fractal dimension and risk of early diabetic retinopathy: A prospective study of children and adolescents with type 1 diabetes. Diabetes Care. 2009;32(11):2081-2083.

111. Masters BR. Fractal analysis of the vascular tree in the human retina. Annu Rev Biomed Eng. 2004;6:427-452.

112.Liew G, Wang JJ, Cheung N, et al. The retinal vasculature as a fractal: methodology, reliability, and relationship to blood pressure. Ophthalmology. 2008;115(11):19511956.

113.Cheung N, Tikellis G, Saw SM, et al. Relationship of axial length and retinal vascular caliber in children. American journal of ophthalmology. 2007;144(5):658-662.

114.Ong YT, Hilal S, Cheung CY, et al. Retinal vascular fractals and cognitive impairment. Dement Geriatr Cogn Dis Extra. 2014;4(2):305-313.

115.Cheung N, Liew G, Lindley Rl, et al. Retinal fractals and acute lacunar stroke. Annals of neurology. 2010;68(1):107-111.

116.Doubal FN, MacGillivray TJ, Patton N, Dhillon B, Dennis MS, Wardlaw JM. Fractal analysis of retinal vessels suggests that a distinct vasculopathy causes lacunar stroke. Neurology. 2010;74(14):1102-1107.

117.McGrory S, Cameron JR, Pellegrini E, et al. The application of retinal fundus camera imaging in dementia: A systematic review. Alzheimer's \& dementia (Amsterdam, Netherlands). 2017;6:91-107.

118.Cheung N, Mosley T, Islam A, et al. Retinal microvascular abnormalities and subclinical magnetic resonance imaging brain infarct: A prospective study. Brain : a journal of neurology. 2010;133(7):1987-1993.

119.De Jong F, Schrijvers E, Ikram M, Koudstaal P, De Jong P. Hofman, a; Vingerling, J.; Breteler, M. Retinal vascular caliber and risk of dementia. Neurology. 2011;76:816-821. 
120.Kim DH, Newman AB, Hajjar l, et al. Retinal microvascular signs and functional loss in older persons: The cardiovascular health study. Stroke. 2011;42(6):1589-1595.

121. Lesage SR, Mosley TH, Wong TY, et al. Retinal microvascular abnormalities and cognitive decline: the ARIC 14-year follow-up study. Neurology. 2009;73(11):862-868.

122. Wong $T Y$, Klein $R$, Sharrett AR, et al. Retinal microvascular abnormalities and cognitive impairment in middle-aged persons: the Atherosclerosis Risk in Communities Study. Stroke. 2002;33(6):1487-1492.

123. Huang F, Dashtbozorg B, Zhang J, et al. Reliability of Using Retinal Vascular Fractal Dimension as a Biomarker in the Diabetic Retinopathy Detection. Journal of ophthalmology. 2016;2016:6259047.

124.Talu S, Calugaru DM, Lupascu CA. Characterisation of human non-proliferative diabetic retinopathy using the fractal analysis. Int J Ophthalmol. 2015;8(4):770-776.

125. Popovic N, Radunovic M, Badnjar J, Popovic T. Fractal dimension and lacunarity analysis of retinal microvascular morphology in hypertension and diabetes. Microvascular research. 2018;118:36-43.

126.Zhu P, Huang F, Lin F, et al. The relationship of retinal vessel diameters and fractal dimensions with blood pressure and cardiovascular risk factors. PLoS One. 2014;9(9):e106551.

127. Liew G, Mitchell P, Rochtchina E, et al. Fractal analysis of retinal microvasculature and coronary heart disease mortality. Eur Heart J. 2011;32(4):422-429.

128.Sng CC, Sabanayagam C, Lamoureux EL, et al. Fractal analysis of the retinal vasculature and chronic kidney disease. 2010;25(7):2252-2258.

129. Yamashita T, Asaoka R, Tanaka M, et al. Relationship between position of peak retinal nerve fiber layer thickness and retinal arteries on sectoral retinal nerve fiber layer thickness. Invest Ophthalmol Vis Sci. 2013;54(8):5481-5488.

130.Gupta S, Zivadinov R, Ramanathan M, Weinstock-Guttman B. Optical coherence tomography and neurodegeneration: are eyes the windows to the brain? Expert Rev Neurother. 2016;16(7):765-775.

131.Thomson KL, Yeo JM, Waddell B, Cameron JR, Pal S. A systematic review and metaanalysis of retinal nerve fiber layer change in dementia, using optical coherence tomography. Alzheimer's \& dementia (Amsterdam, Netherlands). 2015;1(2):136-143. 


\section{CHAPTER 2}

\section{RETINAL VASCULAR \\ ABNORMALITIES IN \\ SCHIZOPHRENIA AND BIPOLAR DISORDER: A WINDOW TO THE BRAIN}

Abhishek Appaii, Bhargavi Nagendra, Dona Maria Chako, Ananth Padmanabha, Chaitra V Hiremath, Arpitha Jacob,

Shivarama Varambally, Muralidharan Kesavan, Ganesan Venkatasubramanian, Shyam Vasudeva Rao, Carroll A.B. Webers, Tos T.J.M. Berendschot, Naren P. Rao BIPOLAR DISORDERS 2019: 21 (7); 634-641 



\section{Abstract}

Objectives: The examination of retinal microvascular abnormalities through fundus photography is currently the best available non-invasive technique for assessment of cerebral vascular status. Several studies in the last decade have reported higher incidences of adverse cerebrovascular events in Schizophrenia (SCZ) and bipolar disorder (BD). However, retinal microvasculature abnormalities in SCZ and BD have remained under-explored, and no study has compared this aspect of SCZ and BD till date.

Methods: Retinal Images of $100 \mathrm{SCZ}$ patients, BD patients, and healthy volunteers each were acquired by trained individuals using a non-mydriatic camera with a 40-degree field of view. The retinal images were quantified using a valid semi-automated method. The average of left and right eye diameters of the venules and arterioles passing through the extended zone between 0.5 and 2 disc diameters from the optic disc were calculated.

Results: The groups differed significantly with respect to average diameters of both retinal venules $(p<0.001)$ and retinal arterioles $(p<0.001)$, after controlling for age and sex. Both SCZ and BD patients had significantly narrower arterioles and wider venules compared to HV. There were also significant differences between SCZ and BD patients; patients with $\mathrm{BD}$ had narrower arterioles and wider venules.

Conclusion: Considering the affordability and easy accessibility of the investigative procedure, retinal microvascular examination could serve as a potential screening tool to identify individuals at risk for adverse cerebrovascular events. The findings of the current study also provide a strong rationale for further systematic examination of retinal vascular abnormalities in $\mathrm{SCZ}$ and $\mathrm{BD}$.

Keywords: cerebrovascular event, fundus, neurodevelopment, peripheral marker, psychoses, retinal vessel 


\subsection{INTRODUCTION}

The retina and brain have common developmental origins and share anatomical, physiological, and autoregulational properties ${ }^{1-3}$. Examination of retinal microvascular abnormalities using fundus photography is currently the best available non-invasive technique to assess the status of systemic vascular health; narrower arterioles are associated with hypertension and obesity, while wider venules are linked to diabetes and altered lipid profiles ${ }^{4}$. Several studies in the last decade have reported that retinal vascular abnormalities reflect cerebral vascular abnormalities, with wider venules being predictive of stroke and other cerebrovascular diseases ${ }^{5}$. Narrower arterioles and wider venules have additionally been linked to poorer cognitive function and increased risk of dementia'.

Interestingly, vascular abnormalities have also been implicated in psychiatric disorders. Abnormal capillary bed in nail folds ${ }^{6}$, abnormal vascular response to niacin ${ }^{7}$, and abnormalities in genes regulating cerebral blood flow ${ }^{8}$ have been reported in schizophrenia (SCZ). Patients with bipolar disorder (BD) have a higher incidence of vascular disorders and related premature mortality ${ }^{9}$, and an increased prevalence of deep white matter hyperintensities on magnetic resonance imaging (MRI), indicating cerebral microvascular disease ${ }^{10}$. Neuroimaging studies have reported reduced cerebral blood flow in the anterior brain regions in both $\mathrm{SCZ}^{11}$ and $\mathrm{BD}^{12}$. However, despite the analogies between cerebral and retinal vasculatures, and easy access to the latter, retinal microvascular abnormalities have not been adequately examined in SCZ and BD. A single study that examined retinal vascular abnormalities in participants with SCZ, reported wider retinal venules compared to controls ${ }^{2}$. A related study examined twins discordant for psychotic symptoms with controls, and reported that abnormalities in retinal vessels reflect familial vulnerability to psychotic symptoms ${ }^{13}$. The only study in BD that has examined the retinal microvasculature had adolescent participants, and showed no abnormality ${ }^{14}$. The status of retinal vasculature in adults with BD remains unexplored.

While these studies have provided the first line of evidence for abnormal retinal vessels in $S C Z$ and BD, the findings have not been further replicated. In addition, there have been no comparisons of such abnormalities across these two major psychoses. Considering the shared vascular co-morbidity in SCZ and BD 15,16 it is important to ascertain whether the retinal vascular abnormality is seen in all psychoses or specific to SCZ. The retinal vascular changes if found, are potential markers of future cardiovascular risk and could 
help in identifying at risk individuals. Hence, in the current study, we measured retinal microvascular parameters in patients with SCZ and BD, and healthy volunteers.

While previous studies in schizophrenia have reported wider retinal venules, studies in other neurological disorders have reported narrower retinal arterioles to be linked to stroke, cerebral small vessel disease and dementia ${ }^{1,17}$. Based on these studies we hypothesized that, both SCZ and BD patients would have retinal vascular abnormalities, with wider venules and narrower arterioles, when compared to healthy volunteers; and that there would be no difference between SCZ and BD patients, considering the shared etiopathogenesis and shared vascular comorbidity.

\subsection{METHODOLOGY}

\subsubsection{Subjects}

One hundred patients with SCZ and 100 patients with BD were recruited from the outpatient and inpatient services of the National Institute of Mental Health and Neurosciences, Bangalore, India. Patients were clinically interviewed by a certified psychiatrist, and all patients meeting the diagnostic criteria for SCZ or BD according to the International Classification of Disorders (ICD-10) ${ }^{18}$ were recruited. Patients with a diagnosis of substance use disorder (except nicotine), comorbid psychiatric disorders, medical or neurological illness namely hypertension, diabetes, cerebrovascular accident or history of ocular trauma were excluded. One hundred healthy volunteers (HV) were also recruited from same geographical location via flyers and word of mouth. Relatives of patients were not included as these measures could be endophenotypes. All HV were interviewed by a trained psychiatrist to rule out syndromal axis I psychiatric diagnosis. All HV underwent a clinical evaluation by a trained psychiatrist and were administered self-reported versions of the DSM-5 Cross cutting Symptom measures developed by the DSM-5 Task Force and Work Groups ${ }^{19}$. None of the HV had diagnoses of psychiatric disorder, substance use disorder, diagnosis of hypertension, diabetes, cerebrovascular accident, major neurological illness or history of eye trauma. All participants were between 18 and 50 years of age. The study was approved by the Institute Ethics Committee and all participants were recruited after valid documented informed consent. 


\subsubsection{Assessments}

The severity of clinical symptoms in SCZ was assessed using the Brief Psychiatric Rating Scale (BPRS) ${ }^{20}$, which is designed to measure the severity of positive and negative symptoms, and general psychopathology. Young's Mania Rating Scale (YMRS) ${ }^{21}$, a valid instrument to measure severity of mania, and Hamilton Depression Rating Scale (HDRS) 22, a sensitive tool to measure the severity of depression were used in BD. Functioning was assessed using Global assessment of functioning (GAF) ${ }^{23}$ and Clinical Global Impression (CGI) ${ }^{24}$ in both SCZ and BD.

\subsubsection{Retinal image acquisition}

The process of retinal image acquisition was explained to the participants before the procedure. Images were acquired by trained individuals using a non-mydriatic camera with a 40-degree field of view, the '3nethra classic', which is manufactured by Forus Health Pvt Itd, India. Participants were seated in dark room for 5 minutes before the procedure to facilitate dark adaptation and pupillary dilatation. Optic disc centered posterior retinal images were captured using a valid method described by previous authors $^{25}$. Images were acquired from both the eyes separately and the average of vessel calibers from the right and left eyes was taken as the primary outcome measure as described in a former study².

\subsubsection{Measurement of retinal vasculature}

The retinal images were quantified using the semi-automated software VAMPIRE (Vessel Assessment and Measurement Platform for Images of the REtina) ${ }^{26}$. The images were coded, and the person who performed the grading was blind to the diagnosis. VAMPIRE is a well validated tool for measurement of retinal vasculature and has been used in many studies. The tool provides automatic detection of retinal landmarks (optic disc) and quantifies frequently investigated key parameters such as vessel diameter and vessel branching coefficients. Details of the tool and computation process have been described elsewhere ${ }^{27}$. In brief, we computed the vessel diameter as the crosssectional span of the vessel mask perpendicular to the vessel's estimated axis. Using Guos thinning algorithm, the vessel regions were initially converted to 1-pixel width. The arteriolar and venular diameters passing through the extended zone between 0.5 
and 2 disc diameters from the optic disc were measured (Figure 1); as extended zone ( 0.5 to 2 disc diameters) measurements have been shown to have higher reliability compared to restricted zone (0.5 to 1 -disc diameters) measurements ${ }^{2,28}$.

Based on revised Knudtson-Parr-Hubbard formula, the six largest arterioles and venules present in this extended zone were chosen for calculations ${ }^{29}$, as this has been demonstrated to have better accuracy compared to 3 vessel measurements ${ }^{14}$. The Central Retinal Artery Equivalent (CRAE) for arterioles and Central Retinal Vein Equivalent (CRVE) for venules were calculated using an iterative process, by progressively replacing the largest and smallest vessel diameters at $W_{1}$ and $W_{2}$ in the formula mentioned in the equations (1) and (2) until a single number was reached.

$$
\begin{aligned}
& \text { Arterioles: } \widehat{W}=0.88 * \sqrt{\left(w_{1}^{2}+w_{2}^{2}\right)} \\
& \text { Venules: } \widehat{W}=0.95 * \sqrt{\left(w_{1}^{2}+w_{2}^{2}\right)}
\end{aligned}
$$

Figure 1.

Representative figure showing zone-wise measurement of retinal vascular calibers

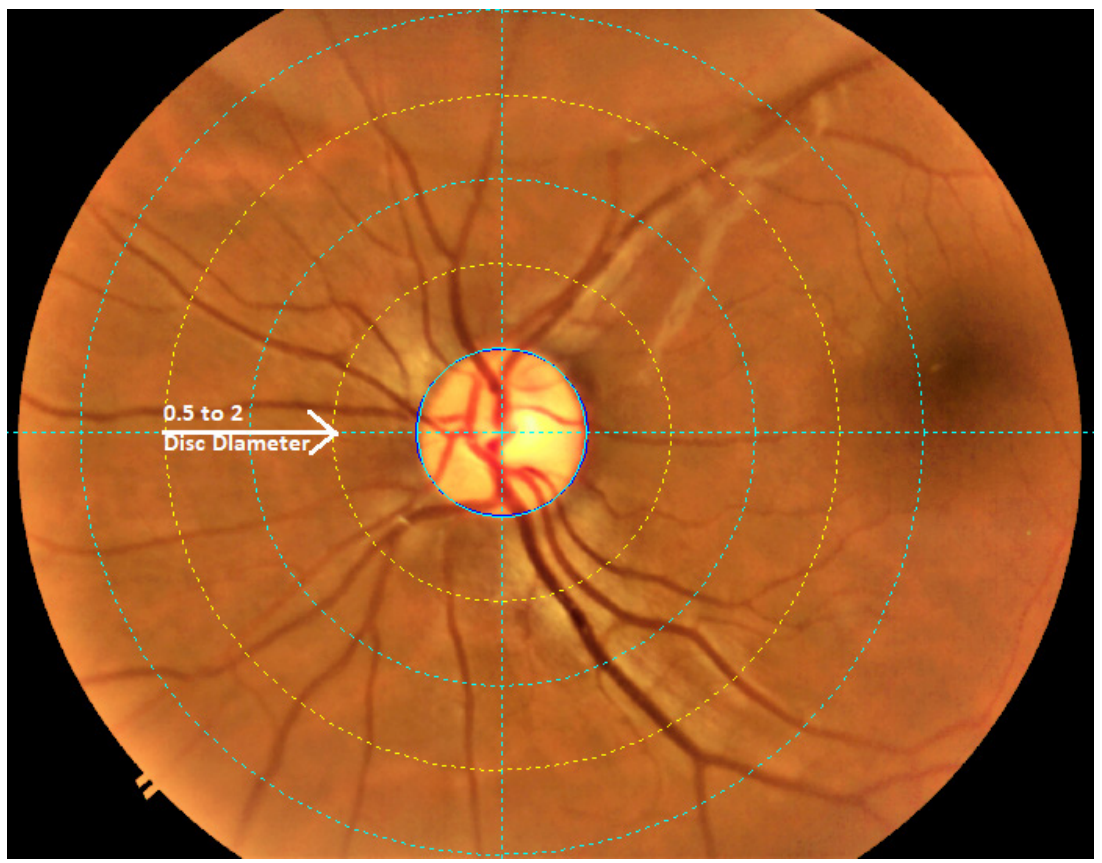


To convert the values obtained in pixels to micrometers $(\mu \mathrm{m})$ we used a calibration factor. This calibration factor adjusted for the magnification differences due to optics of fundus camera, image resolution and refractive errors of the patient as reported by previous study. First, we measured the distance between the centre of the optic disc and centre of the macula for each individual subject's fundus image in pixels. Next, the calibration factor was calculated by using the formula

$$
\text { Calibration factor }=\frac{4500 \mu \mathrm{m}}{\text { Distance between centre of optic disc to centre of macula (in pixels) }}
$$

The value, $4500 \mu \mathrm{m}$ represents the average disc diameter in micron and was calculated based on previous studies; the average disc diameter measured by fundus camera was assumed to be $1800 \mu \mathrm{m}$ and distance from the center of the optic disc to the center of the macula to be two and half times the disc diameter, i.e., $4500 \mu \mathrm{m}^{30}$. Next this calibration factor was multiplied by individual CRAE and CRVE of individual images obtained using equation 1 and 2 to convert the vessel caliber from pixel to $\mu \mathrm{m}$.

CRAE in $\mu \mathrm{m}=$ Calibration factor for individual $\times$ CRAE in pixels $C R V E$ in $\mu \mathrm{m}=$ Calibration factor for individual $\times C R V E$ in pixels

A sub-sample of 30 participants images were graded and analyzed by two persons to check the inter-rater reliability and a good inter-rater reliability of 0.8 was obtained for both CRVE and CRAE (Intra Class Correlation -Average vein - 0.86, Average artery-0.84).

\subsubsection{Statistical Analysis}

All analyses were performed using the Statistical Package for Social Sciences (SPSS) version 25. After establishing normative distribution of data using Shapiro-Wilk test, parametric statistical tests were used. Sex distribution across groups was examined using chi-square test and age difference was analyzed using one-way analysis of variance (ANOVA). As we measured two primary outcome measures, a Bonferroni corrected $a=0.025$ was considered significant. Age and sex-ratio being different across groups, our main outcome measures, i.e., group differences in average CRVE and average CRAE were compared using multiple linear regression after adding age and sex as additional regressors to the model. To examine the relation between retinal vascular measures and clinical-demographic variables, separate stepwise linear regression analyses were 
conducted, with average CRVE and average CRAE as dependent variables, and scores on BPRS, YMRS, HDRS, number of episodes, and duration of illness as predictor variables.

Table 1.

Comparison of demographic and clinical details between the groups

\begin{tabular}{|l|c|c|c|c|c|}
\hline & $\begin{array}{c}\text { HV } \\
(\mathbf{n = 9 2})\end{array}$ & $\begin{array}{c}\text { SCZ } \\
(\mathbf{n = 9 8})\end{array}$ & $\begin{array}{c}\text { BD } \\
(\mathbf{n = 8 7})\end{array}$ & $\mathbf{F / t / \mathbf { 2 }}$ & $\mathbf{P}$ \\
\hline Age & $30.2 \pm 7.8$ & $32.7 \pm 6.0$ & $32.9 \pm 6.0$ & 4.536 & 0.012 \\
\hline Gender ratio (M/F) & $41 / 51$ & $64 / 34$ & $54 / 33$ & 9.479 & 0.009 \\
\hline Age at onset (y) & - & $25.2 \pm 5.3$ & $23.7 \pm 5.9$ & 2.584 & 0.11 \\
\hline $\begin{array}{l}\text { Duration of illness } \\
\text { (y) }\end{array}$ & - & $7.6 \pm 5.1$ & $9.0 \pm 5.6$ & 2.3 & 0.13 \\
\hline BPRS & - & $28.7 \pm 6.9$ & - & - & - \\
\hline HDRS & - & - & $3.9 \pm 5.3$ & - & - \\
\hline YMRS & - & - & $1.9 \pm 3.1$ & - & - \\
\hline
\end{tabular}

Abbreviations: $\chi 2$, Chi square test; $B D$, patients with bipolar disorder; BPRS, Brief Psychiatric rating scale; HDRS, Hamilton depression rating scale; YMRS, Young's mania rating scale; F, Analysis of Variance; HV, healthy volunteer; $\mathrm{SCZ}$, patients with schizophrenia; $t$, Independent t test.

Table 2.

Retinal vascular diameters in the three groups

\begin{tabular}{|l|c|c|c|c|c|}
\hline Parameter & $\begin{array}{c}\text { HV } \\
(\mathbf{n}=\mathbf{9 2})\end{array}$ & $\begin{array}{c}\text { SCZ } \\
(\mathbf{n}=\mathbf{9 8})\end{array}$ & $\begin{array}{c}\text { BD } \\
(\mathbf{n}=\mathbf{9 0})\end{array}$ & $\mathbf{F}$ & P \\
\hline CRVE & $196.5 \pm 21.7$ & $213.4 \pm 27.4$ & $227.6 \pm 26.3$ & 33.8 & $<0.001$ \\
\hline CRAE & $110.7 \pm 21.7$ & $102.5 \pm 15.8$ & $95.8 \pm 16.9$ & 14.9 & $<0.001$ \\
\hline
\end{tabular}

Abbreviations: BD, patients with bipolar disorder; $\mathrm{CRAE}$, Average Central Retinal Artery Equivalent.; CRVE, Average Central Retinal Vein Equivalent; HV, healthy volunteer; SCZ, patients with schizophrenia.

\subsection{RESULTS}

\subsubsection{Comparison of demographic variables}

A total of 300 participants were recruited consisting of 100 healthy controls, 100 patients with SCZ and 100 patients with BD. Twenty-three of them were excluded following quality check of retinal images. The remaining 277 (98 patients with SCZ, 87 
patients with BD and 92 healthy volunteers) were taken up for analyses. Demographic details and clinical variables are given in Table 1. We found significant differences in age and gender distribution across the three groups. Duration of illness and age at onset of illness were not significantly different between patients with SCZ and BD.

\subsubsection{Differences in retinal vascular measures between groups}

There were significant differences across the three groups in both CRVE and CRAE $(p<0.001)$ (Table 2 and Figure 2). Further post-hoc analysis revealed that, both patients with BD $(p<0.001)$, and patients with SCZ $(p<0.001)$ had significantly wider CRVE in comparison to healthy volunteers. In addition, BD patients had significantly wider CRVE than SCZ patients $(p<0.001)$ (Figure 2$)$. The CRAE on the other hand was significantly narrower in both patients with BD $(p<0.001)$ and patients with SCZ $(p=0.002)$ compared to healthy volunteers; and significantly narrower in BD patients compared to SCZ patients $(p=0.014)$ (Figure 2 and supplement Table S1). Since the groups were heterogeneous with respect to age and sex-ratio, we used them as additional regressors to control for possible confounding effects. Table 3 shows the regression analysis results between groups for both CRAE and CRVE, with and without adjustment for age and sex. The regression coefficient was comparable even after controlling for these confounding variables (further details in supplement Table S2). In addition, to rule out the confounding effects of the age and sex, we selected a sub-sample matched on these measures. $66 \mathrm{HV}$ (M:F =32:34; age = 30.6 \pm 5.4 years), $92 \mathrm{SCZ}$ (M:F =60:32 ; age $=32.3 \pm 5.5$ years $)$ and $78 \mathrm{BD}(\mathrm{M}: \mathrm{F}=50: 28$; age $=32.24 \pm 5.0$ years $)$ were selected. These three groups were matched on age $(F=2.33 ; p=0.1)$ and sex ( $x 2=5.24 ; p=0.07)$. On regression analysis, there was still a significant difference between the three groups on CRVE (HV:197.5 $\pm 22.4, S C Z: 212.8 \pm 28.0, B D: 228.8 \pm 26.4 ; F=52.0, \beta=0.4, p<0.001$ ) and CRAE (HV: 106.5 $\pm 21.0 ;$ SCZ: 102.6 $\pm 16.1, B D: 95.2 \pm 17.1 ; F=14.7, \beta=-0.24, p<0.001$ ). Further, the two patient groups were examined using this sub-sample. The two groups were matched on age $(t=0.035 ; p=0.158)$ and $\operatorname{sex}(x 2=0.023 ; p=0.88)$. On regression analysis, these two patient groups had significant difference in CRVE ( $F=14.47 ; \beta=0.3$, $p<0.001)$ and CRAE $(F=8.63 ; \beta=-0.2, p=0.004)$. On stepwise linear regression between average CRAE, CRVE, and clinical variables, none of the clinical variables showed significant contribution to the model suggesting absence of relationship between clinical variables and retinal vascular diameters ( $p>0.05)$. 


\subsection{DISCUSSION}

To the best of our knowledge, this is the first study to have assessed retinal microvasculature abnormalities in both $\mathrm{SCZ}$ and $\mathrm{BD}$ in comparison with healthy individuals. Results from the study show that patients with both SCZ and BD have microvascular abnormalities, i.e., wider venular and narrower arteriolar diameters when compared to healthy volunteers. Interestingly, patients with BD had significantly wider venules and narrower arterioles than patients with SCZ.

Our findings are in accord with, and support the only previous study on SCZ which also reported wider venules and narrower arterioles ${ }^{2}$. However, in contrast to a previous negative study in adolescent $\mathrm{BD}^{14}$, we have found that $\mathrm{BD}$ patients have wider venules and narrower arterioles in the retina. This could be due to a larger sample size $(n=100$ vs. $\mathrm{n}=30$ ) and the inclusion of adult patients in the current study. Our sample also had a higher proportion of patients with type I BD (65/100 vs. 9/30). It is possible that retinal vascular abnormalities in $\mathrm{BD}$ have a progressive nature which could explain the findings in our adult sample with long duration of illness (9.3 \pm 5.6 years) as opposed to adolescents with BD.

The mechanisms underlying retinal venular and arteriolar abnormalities are not completely known. Several theories have been proposed and epidemiological studies have shown that changes in retinal arteriolar and venular diameters are reflective of a wide range of environmental, genetic, and systemic influences ${ }^{31}$ such as aging, inflammation, nitric oxide-dependent endothelial dysfunction, and hypoxia/ischemia. Impaired fasting glucose, diabetes, dyslipidemia, obesity, elevated systemic markers of inflammation, endothelial dysfunction, and cigarette smoking are also associated with narrower arteriolar and wider venular diameters ${ }^{8}$. In the background of these findings, the results of the current study, suggests that patients with $B D$ and $S C Z$ are at a higher risk of cerebrovascular accidents. A significantly increased risk of stroke in patients with $\mathrm{BD}$ and $\mathrm{SCZ}$ has also been reported in previous studies ${ }^{32,33}$. Examination of retinal microvasculature could prove to be an easy and affordable method to identify such patients at risk of adverse vascular events; the reliability of this investigative procedure needs to be explored in future studies. 
Figure 2.

Representative boxplot diagrams showing mean comparison of CRVE and CRAE between groups

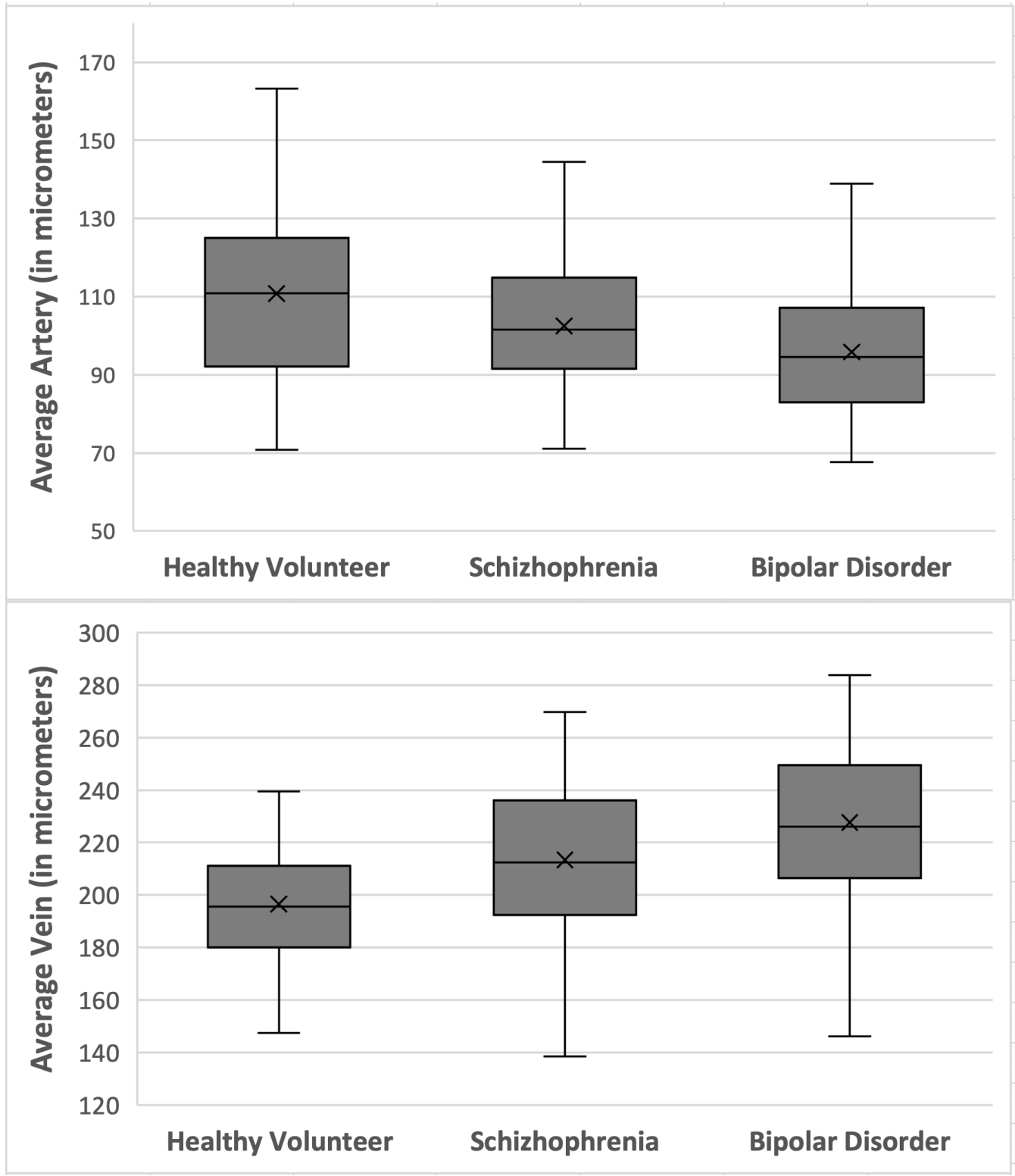


Table 3.

Mean difference of vascular diameter between groups adjusted for age and sex

\begin{tabular}{|c|c|c|c|c|c|c|}
\hline \multirow{2}{*}{} & \multicolumn{2}{|c|}{ Group } & \multicolumn{2}{c|}{ Not adjusted for age and sex } & \multicolumn{2}{c|}{ Adjusted for age and sex } \\
\cline { 3 - 7 } & & $\boldsymbol{\beta}(\mathbf{9 5} \% \mathbf{C I})$ & $\mathbf{P}$ & $\boldsymbol{\beta}(\mathbf{9 5} \% \mathbf{C I})$ & $\mathbf{P}$ \\
\hline \multirow{3}{*}{ CRVE } & HV & SCZ & $0.3(9.7$ to 23.9$)$ & $<0.001$ & $0.3(9.4$ to 24.2$)$ & $<0.001$ \\
\cline { 2 - 7 } & HV & BD & $0.5(23.9$ to 38.2$)$ & $<0.001$ & $0.5(22.8$ to 37.6$)$ & $<0.001$ \\
\cline { 2 - 7 } & SCZ & BD & $0.3(6.4$ to 22.04$))$ & $<0.001$ & $0.3(6.4$ to 22.1$)$ & 0.001 \\
\hline \multirow{4}{*}{ CRAE } & HV & SCZ & $-0.2(-13.6$ to -2.8$)$ & 0.003 & $-0.2(-12.8$ to -1.6$)$ & 0.012 \\
\cline { 2 - 7 } & HV & BD & $-0.4(-20.7$ to -9.1$)$ & $<0.001$ & $-0.3(-19.3$ to -7.5$)$ & $<0.001$ \\
\cline { 2 - 7 } & SCZ & BD & $-0.2(-11.4$ to-1.9) & 0.006 & $-0.2(-11.5$ to -2.1$)$ & 0.004 \\
\hline
\end{tabular}

$\beta$, regression coefficient; $95 \% \mathrm{Cl}, 95 \%$ confidence interval; $\mathrm{BD}$, patients with bipolar disorder; CRAE, Average Central Retinal Artery Equivalent; CRVE, Average Central Retinal Vein Equivalent; HV, healthy volunteer; $\mathrm{SCZ}$, patients with schizophrenia.

The significant difference between SCZ and BD patients with respect to the retinal vessel diameters was an unexpected finding. Several studies in the recent past suggest shared risk factors and considerable overlap in pathophysiological processes between $\mathrm{SCZ}$ and $\mathrm{BD}^{15}$. Considering the common developmental origin between these disorders, we expected similarities, but the study results suggest significant difference between the disorders. The presence of a considerable number of BD-II and non-psychotic BD-I patients in our sample may explain the group differences demonstrated between SCZ and BD; while previous studies have reported considerable overlap between psychotic BD-I and SCZ ${ }^{34}$, it is yet unclear whether similar overlap is present between BD-II/ non-psychotic BD-I and SCZ. It is also important to note that similar cross diagnostic differences between SCZ and BD have been reported by several previous studies that have examined neurocognition ${ }^{35,36}$, functional magnetic resonance imaging (fMRI) ${ }^{37}$ and prevalence of metabolic syndrome ${ }^{38}$. Studies have reported that patients with SCZ have greater impairment in cognitive functions compared to $\mathrm{BD}^{36,39}$. A recent study has reported decreased volume of the CC (corpus callosum) associated with a lower degree of left hemispherical asymmetry for language in BD which was not replicated in SCZ. The authors have suggested that such distinct anomalies in both SCZ and BD may be considered specific biomarkers ${ }^{40}$. Hence, although some susceptibility genes are shared between $\mathrm{SCZ}$ and $\mathrm{BD}$, one cannot rule out the possibility that other genetic and environmental factors may have differential effects ${ }^{41}$. 
Findings of our study could have potential implications. The interesting observation of difference between SCZ and BD needs to be further examined and if replicated, has potential utility as a differential marker. It is important to note that patients who have psychotic symptoms during their first illness episode in BD are commonly misdiagnosed as SCZ or other psychotic disorders ${ }^{42,43}$. This could result in delay in initiation of specific treatment for $\mathrm{BD}$ resulting in more number of hospitalizations and poorer functional outcomes $^{42}$. Hence, a biomarker which can differentiate BD from SCZ could aid early initiation of prompt treatment and better outcomes. A few studies have suggested that brain morphometric measures are potential biomarkers to differentiate BD from HV ${ }^{44}$ and unipolar depression ${ }^{45}$. Further studies are required to ascertain whether retinal imaging measures have similar potential as neuroimaging measures to be used as biomarkers. However, in the background of several confounding factors it is important to note that our findings at this stage need to be considered preliminary and do not definitively suggest that retinal vascular changes are markers for psychosis but markers which may indicate risk for vascular events.

The following limitations of our study need to be considered while interpreting the results. All patients were on treatment with medications and hence the confounding effect of medication on CRVE or CRAE cannot be ruled out. However, there was no correlation between the antipsychotic dose used and retinal vascular measures ( $p>0.05$; details in supplement) suggesting absence of significant confounding effect of medication. Although study subjects were young adults and those subjects with known hypertension or diabetes mellitus were excluded to avoid their confounding effects, blood glucose levels and blood pressure were not documented for all participants on the day of retinal image acquisition. Hence one cannot rule out the possible confounding effect of pre-diabetic or pre-hypertensive status ${ }^{46}$. We excluded the diagnosis of medical disorders based on the history, which may risk the possibility of undiagnosed condition. However, in the sub-group of patients for whom the BMI and systolic blood pressure was available, there was no significant difference between the groups, and the results remained significant even after controlling for these variables (details in supplement). Future studies need to consider measuring the blood pressure, fasting glucose and renal functions using blood tests on the day of examination to control for their confounding effects. We did not collect the information regarding the lifestyle of subjects. As patients might have had sedentary lifestyle compared to HV, this could be a potential confounding factor increasing the risk for vascular events. Future studies need to include assessment of lifestyle factors like diet, exercise etc. As it was 
not the primary aim of the study, we did not have equal representation of BD-I and BD-II patients; this may have affected the results in the BD group as previously discussed. The groups were not age and sex matched. However, even after inclusion of age and sex as covariates the results have remained significant. Also, as seen in Table 3, the regression coefficient was comparable with and without age and sex as additional regressors in the model. Seventeen patients had documented nicotine use which may have affected their retinal vascular measures. However, even after excluding these 17 patients the results remained significant (details in supplement). Finally, while our study suggests abnormalities in retinal vasculature in $\mathrm{BD}$ and $\mathrm{SCZ}$, the study population had varying lengths of illnesses. With the cross-sectional nature of the study design it is not possible to determine whether the retinal micro-vascular changes were static or progressive. In our study, there was no significant relation between retinal vascular diameters and clinical variables including duration of illness, number of episodes, or severity of symptoms. However, a few longitudinal studies have reported changes in brain morphometric measures in individuals with $\mathrm{BD}^{47}$ as well as those with high familial risk for $\mathrm{BD}^{48}$. Similarly, a few studies have also suggested an association between epigenetic factors and specific symptoms in $\mathrm{BD}^{49}$. Considering that the concept of staging in $\mathrm{BD}^{43,50}$ is a relatively recent development, future longitudinal studies need to probe for changes in retinal vascular measures with progression of the illness.

\subsection{Conclusion}

To summarize, our study indicates significant differences in retinal microvascular diameters in patients with SCZ and BD when compared to HV; patients with BD and SCZ have narrower arterioles and wider venules in comparison to HV, and patients with $\mathrm{BD}$ have narrower arterioles and wider venules in comparison to SCZ patients. This line of investigation has important implications as these findings suggest an increased risk of adverse vascular events in patients with SCZ and BD. Considering the affordability and easily accessible nature of the investigative procedure, retinal microvascular examination could serve as a potential screening tool to identify individuals at risk for adverse vascular events. However, with the cross-sectional design of the study we were not be able to determine the threshold value for identifying at risk individuals. Future longitudinal studies will be able to provide the threshold value which may differentiate those at risk of cerebro/cardiovascular risk and the sensitivity, specificity metrics. The findings of current study provide a strong rationale for further systematic examination of retinal vascular abnormalities in patients with $\mathrm{SCZ}$ and $\mathrm{BD}$. 


\section{References}

1. Heringa SM, Bouvy WH, van den Berg E, Moll AC, Kappelle LJ, Biessels GJ. Associations between retinal microvascular changes and dementia, cognitive functioning, and brain imaging abnormalities: a systematic review. Journal of cerebral blood flow and metabolism : official journal of the International Society of Cerebral Blood Flow and Metabolism. 2013;33(7):983-995.

2. Meier MH, Shalev I, Moffitt TE, et al. Microvascular abnormality in schizophrenia as shown by retinal imaging. Am J Psychiatry. 2013;170(12):1451-1459.

3. Patton N, Aslam T, Macgillivray T, Pattie A, Deary IJ, Dhillon B. Retinal vascular image analysis as a potential screening tool for cerebrovascular disease: a rationale based on homology between cerebral and retinal microvasculatures. Journal of anatomy. 2005;206(4):319-348.

4. Ogagarue ER, Lutsey PL, Klein R, Klein BE, Folsom AR. Association of ideal cardiovascular health metrics and retinal microvascular findings: the Atherosclerosis Risk in Communities Study. Journal of the American Heart Association. 2013;2(6):e000430.

5. Ikram MK, de Jong FJ, Bos MJ, et al. Retinal vessel diameters and risk of stroke: the Rotterdam Study. Neurology. 2006;66(9):1339-1343.

6. Curtis CE, lacono WG, Beiser M. Relationship between nailfold plexus visibility and clinical, neuropsychological, and brain structural measures in schizophrenia. Biol Psychiatry. 1999;46(1):102-109.

7. Hudson CJ, Lin A, Cogan S, Cashman F, Warsh JJ. The niacin challenge test: clinical manifestation of altered transmembrane signal transduction in schizophrenia? Biol Psychiatry. 1997;41(5):507-513.

8. Sun C, Wang JJ, Mackey DA, Wong TY. Retinal vascular caliber: systemic, environmental, and genetic associations. Surv Ophthalmol. 2009;54(1):74-95.

9. Goldstein BI. Bipolar Disorder and the Vascular System: Mechanisms and New Prevention Opportunities. Can J Cardiol. 2017;33(12):1565-1576.

10. Lloyd AJ, Moore PB, Cousins DA, et al. White matter lesions in euthymic patients with bipolar disorder. Acta Psychiatr Scand. 2009;120(6):481-491. 
11. Gogtay N. Cortical brain development in schizophrenia: insights from neuroimaging studies in childhood-onset schizophrenia. Schizophr Bull. 2008;34(1):30-36.

12. Kruger S, Alda M, Young LT, Goldapple K, Parikh S, Mayberg HS. Risk and resilience markers in bipolar disorder: brain responses to emotional challenge in bipolar patients and their healthy siblings. Am J Psychiatry. 2006;163(2):257-264.

13. Meier MH, Gillespie NA, Hansell NK, et al. Retinal microvessels reflect familial vulnerability to psychotic symptoms: A comparison of twins discordant for psychotic symptoms and controls. Schizophr Res. 2015;164(1-3):47-52.

14. Naiberg MR, Hatch JK, Selkirk $B$, et al. Retinal photography: $A$ window into the cardiovascular-brain link in adolescent bipolar disorder. J Affect Disord. 2017;218:227237.

15. Craddock N, Owen MJ. The Kraepelinian dichotomy - going, going... but still not gone. Br J Psychiatry. 2010;196(2):92-95.

16. Keshavan MS, Morris DW, Sweeney JA, et al. A dimensional approach to the psychosis spectrum between bipolar disorder and schizophrenia: the Schizo-Bipolar Scale. Schizophr Res. 2011;133(1-3):250-254.

17. Kwa VI, van der Sande JJ, Stam J, Tijmes N, Vrooland JL. Retinal arterial changes correlate with cerebral small-vessel disease. Neurology. 2002;59(10):1536-1540.

18. Sheehan DV, Lecrubier Y, Sheehan KH, et al. The Mini-International Neuropsychiatric Interview (M.I.N.I.): the development and validation of a structured diagnostic psychiatric interview for DSM-IV and ICD-10. J Clin Psychiatry. 1998;59 Suppl 20:2233;quiz 34-57.

19. Narrow WE, Clarke DE, Kuramoto SJ, et al. DSM-5 field trials in the United States and Canada, Part III: development and reliability testing of a cross-cutting symptom assessment for DSM-5. Am J Psychiatry. 2013;170(1):71-82.

20. Overall JE, Gorham DR. The brief psychiatric rating scale. Psychological reports. 1962;10(3):799-812.

21. Young RC, Biggs JT, Ziegler VE, Meyer DA. A rating scale for mania: reliability, validity and sensitivity. Br J Psychiatry. 1978;133:429-435. 
22. Hamilton M. A rating scale for depression. J Neurol Neurosurg Psychiatry. 1960;23:5662.

23. Jones SH, Thornicroft G, Coffey M, Dunn G. A brief mental health outcome scalereliability and validity of the Global Assessment of Functioning (GAF). Br J Psychiatry. 1995;166(5):654-659.

24. Busner J, Targum SD. The clinical global impressions scale: applying a research tool in clinical practice. Psychiatry (Edgmont). 2007;4(7):28-37.

25. Nguyen TT, Islam FM, Farouque HM, et al. Retinal vascular caliber and brachial flowmediated dilation: the Multi-Ethnic Study of Atherosclerosis. Stroke; a journal of cerebral circulation. 2010;41(7):1343-1348.

26. Perez-Rovira A, MacGillivray T, Trucco E, et al. VAMPIRE: Vessel assessment and measurement platform for images of the REtina. Conference proceedings: Annual International Conference of the IEEE Engineering in Medicine and Biology Society IEEE Engineering in Medicine and Biology Society Annual Conference. 2011;2011:33913394.

27. Downie E, Tokarev J, Divani A, Koozekanani DD. Comparison of two free retinal vascular measurement software packages: IVAN and VAMPIRE. Investigative ophthalmology \& visual science. 2015;56(7):3320-3320.

28. Cheung $C Y, H s u W$, Lee $M L$, et al. A new method to measure peripheral retinal vascular caliber over an extended area. Microcirculation. 2010;17(7):495-503.

29. Knudtson MD, Lee KE, Hubbard LD, Wong TY, Klein R, Klein BE. Revised formulas for summarizing retinal vessel diameters. Curr Eye Res. 2003;27(3):143-149.

30. Pakter HM, Fuchs SC, Maestri MK, et al. Computer-assisted methods to evaluate retinal vascular caliber: what are they measuring? Investigative ophthalmology \& visual science. 2011;52(2):810-815.

31. Wong TY, Islam FM, Klein R, et al. Retinal vascular caliber, cardiovascular risk factors, and inflammation: the multi-ethnic study of atherosclerosis (MESA). Investigative ophthalmology \& visual science. 2006;47(6):2341-2350.

32. Prieto ML, Cuellar-Barboza AB, Bobo WV, et al. Risk of myocardial infarction and stroke in bipolar disorder: a systematic review and exploratory meta-analysis. Acta Psychiatr Scand. 2014;130(5):342-353. 
33. Lin HC, Hsiao FH, Pfeiffer S, Hwang YT, Lee HC. An increased risk of stroke among young schizophrenia patients. Schizophr Res. 2008;101(1-3):234-241.

34. Tamminga CA, Ivleva El, Keshavan MS, et al. Clinical phenotypes of psychosis in the Bipolar-Schizophrenia Network on Intermediate Phenotypes (B-SNIP). The American journal of psychiatry. 2013;170(11):1263-1274.

35. Rao NP, Arasappa R, Reddy NN, Venkatasubramanian G, Gangadhar BN. Antithetical asymmetry in schizophrenia and bipolar affective disorder: a line bisection study. Bipolar Disord. 2010;12(3):221-229.

36. Bora E. Differences in cognitive impairment between schizophrenia and bipolar disorder: Considering the role of heterogeneity. Psychiatry and clinical neurosciences. 2016;70(10):424-433.

37. Whalley HC, Papmeyer M, Sprooten E, Lawrie SM, Sussmann JE, Mclntosh AM. Review of functional magnetic resonance imaging studies comparing bipolar disorder and schizophrenia. Bipolar Disord. 2012;14(4):411-431.

38. Grover S, Nebhinani N, Chakrabarti S, et al. Comparative study of prevalence of metabolic syndrome in bipolar disorder and schizophrenia from North India. Nord $J$ Psychiatry. 2014;68(1):72-77.

39. Bowie CR, Best MW, Depp C, et al. Cognitive and functional deficits in bipolar disorder and schizophrenia as a function of the presence and history of psychosis. Bipolar disorders. 2018;20(7):604-613.

40. Tréhout M, Leroux E, Delcroix N, Dollfus S. Relationships between corpus callosum and language lateralization in patients with schizophrenia and bipolar disorders. Bipolar disorders. 2017;19(6):496-504.

41. Walker J, Curtis V, Murray RM. Schizophrenia and bipolar disorder: similarities in pathogenic mechanisms but differences in neurodevelopment. International clinical psychopharmacology. 2002;17 Supp/ 3:S11-19.

42. Altamura AC, Buoli M, Caldiroli A, et al. Misdiagnosis, duration of untreated illness (DUI) and outcome in bipolar patients with psychotic symptoms: a naturalistic study. Journal of Affective Disorders. 2015;182:70-75. 
43. Yatham LN, Kennedy SH, Parikh SV, et al. Canadian Network for Mood and Anxiety Treatments (CANMAT) and International Society for Bipolar Disorders (ISBD) 2018 guidelines for the management of patients with bipolar disorder. Bipolar disorders. 2018;20(2):97-170.

44. Ganzola R, Duchesne S. Voxel囚based morphometry meta冈analysis of gray and white matter finds significant areas of differences in bipolar patients from healthy controls. Bipolar disorders. 2017;19(2):74-83.

45. Repple J, Meinert S, Grotegerd D, et al. A voxe/\based diffusion tensor imaging study in unipolar and bipolar depression. Bipolar disorders. 2017;19(1):23-31.

46. Nguyen TT, Wang JJ, Wong TY. Retinal vascular changes in pre-diabetes and prehypertension: new findings and their research and clinical implications. Diabetes care. 2007;30(10):2708-2715.

47. Passosl, MwangiB, VietaE, BerkM, KapczinskiF.Areas of controversyinneuroprogression in bipolar disorder. Acta Psychiatrica Scandinavica. 2016;134(2):91-103.

48. Ganzola R, Nickson T, Bastin ME, et al. Longitudinal differences in white matter integrity in youth at high familial risk for bipolar disorder. Bipolar disorders. 2017;19(3):158-167.

49. Jeremian $R$, Chen Ya, De Luca $V$, et al. Investigation of correlations between DNA methylation, suicidal behavior and aging. Bipolar disorders. 2017;19(1):32-40.

50. Kapczinski F, Magalhães $P$, BalanzáđMartinez $V$, et al. Staging systems in bipolar disorder: an I nternational S ociety for $B$ ipolar $D$ isorders $T$ ask $F$ orce $R$ eport. Acta psychiatrica scandinavica. 2014;130(5):354-363. 
Supplementary Materials

Table S1.

Mean difference between groups on CRVE and CRAE (Bonferroni post-hoc analysis)

\begin{tabular}{|c|c|c|c|c|c|}
\hline & Group & Group & Mean Difference & Std. Error & Sig. \\
\hline \multirow{6}{*}{ CRVE } & \multirow{2}{*}{$\mathrm{HV}$} & SCZ & $-16.8^{*}$ & 3.7 & $<.001$ \\
\hline & & $\mathrm{BD}$ & $-31.0^{*}$ & 3.8 & $<.001$ \\
\hline & \multirow{2}{*}{ SCZ } & HV & $16.8^{*}$ & 3.7 & $<.001$ \\
\hline & & $\mathrm{BD}$ & $-14.2^{*}$ & 3.7 & .001 \\
\hline & \multirow{2}{*}{$B D$} & $\mathrm{HV}$ & $31.0^{*}$ & 3.8 & $<.001$ \\
\hline & & SCZ & $14.2^{*}$ & 3.7 & .001 \\
\hline \multirow{6}{*}{ CRAE } & \multirow{2}{*}{$\mathrm{HV}$} & SCZ & $8.2^{*}$ & 2.7 & .007 \\
\hline & & $\mathrm{BD}$ & $14.9 *$ & 2.7 & $<.001$ \\
\hline & \multirow{2}{*}{ SCZ } & $\mathrm{HV}$ & $-8.2^{*}$ & 2.7 & .007 \\
\hline & & $\mathrm{BD}$ & $6.7^{*}$ & 2.7 & .042 \\
\hline & \multirow{2}{*}{ BD } & $\mathrm{HV}$ & $-14.9 *$ & 2.7 & .000 \\
\hline & & SCZ & $-6.7^{*}$ & 2.7 & .042 \\
\hline
\end{tabular}

Table S2: Details of regression coefficient between groups with and without age and sex as predictor variables

S2a - Mean difference between HV and SCZ without age and sex as predictors

\begin{tabular}{|c|c|c|c|c|c|}
\hline \multirow[t]{2}{*}{ CRVE } & \multicolumn{2}{|c|}{ Unstandardized Coefficients } & \multirow{2}{*}{$\begin{array}{c}\text { Standardized } \\
\text { Coefficients } \\
\text { Beta }\end{array}$} & \multirow[t]{2}{*}{$\mathbf{t}$} & \multirow{2}{*}{ Sig. } \\
\hline & B & Std. Error & & & \\
\hline (Constant) & 196.5 & 2.6 & & 75.904 & $<.001$ \\
\hline Group & 16.8 & 3.6 & .322 & 4.667 & $<.001$ \\
\hline
\end{tabular}

\begin{tabular}{|l|c|c|c|c|c|}
\hline CRAE & \multicolumn{2}{|c|}{ Unstandardized Coefficients } & $\begin{array}{c}\text { Standardized } \\
\text { Coefficients }\end{array}$ & \multirow{2}{*}{ t } & Sig. \\
\cline { 1 - 4 } & B & Std. Error & Beta & & \\
\hline (Constant) & 110.7 & 2.0 & & 56.114 & $<.001$ \\
\hline Group & -8.2 & 2.7 & -.213 & -2.993 & .003 \\
\hline
\end{tabular}


S2b - Mean difference between HV and SCZ with age and sex as predictors

\begin{tabular}{|l|c|c|c|c|c|}
\hline CRVE & \multicolumn{2}{|c|}{ Unstandardized Coefficients } & $\begin{array}{c}\text { Standardized } \\
\text { Coefficients }\end{array}$ & t & Sig. \\
\hline & B & Std. Error & Beta & & \\
\hline (Constant) & 193.5 & 10.5 & & 18.507 & $<.001$ \\
\hline Group & 16.8 & 3.8 & .321 & 4.472 & $<.001$ \\
\hline Age & .07 & .26 & .018 & .255 & .799 \\
\hline Gender & .6 & 3.7 & .012 & .165 & .869 \\
\hline
\end{tabular}

\begin{tabular}{|l|c|c|c|c|c|}
\hline CRAE & \multicolumn{2}{|c|}{ Unstandardized Coefficients } & $\begin{array}{c}\text { Standardized } \\
\text { Coefficients }\end{array}$ & t & Sig. \\
\cline { 1 - 4 } & B & Std. Error & Beta & & \\
\hline (Constant) & 120.7 & 7.9 & & 15.277 & $<.001$ \\
\hline Group & -7.2 & 2.8 & -.188 & -2.551 & .012 \\
\hline Age & -.4 & .2 & -.129 & -1.789 & .075 \\
\hline Gender & .5 & 2.8 & .013 & .181 & .856 \\
\hline
\end{tabular}

S2c - Mean difference between HV and BD without age and sex as predictors

\begin{tabular}{|l|c|c|c|c|c|}
\hline CRVE & \multicolumn{2}{|c|}{ Unstandardized Coefficients } & $\begin{array}{c}\text { Standardized } \\
\text { Coefficients }\end{array}$ & \multirow{2}{*}{ t } & Sig. \\
\hline & B & Std. Error & Beta & & \\
\hline (Constant) & 196.5 & 2.5 & & 78.316 & $<.001$ \\
\hline Group & 31.0 & 3.6 & .544 & 8.625 & $<.001$ \\
\hline
\end{tabular}

\begin{tabular}{|l|c|c|c|c|c|}
\hline CRAE & \multicolumn{2}{|c|}{ Unstandardized Coefficients } & $\begin{array}{c}\text { Standardized } \\
\text { Coefficients }\end{array}$ & \multirow{2}{*}{ t } & Sig. \\
\cline { 1 - 4 } & B & Std. Error & Beta & & \\
\hline (Constant) & 110.7 & 2.0 & & 54.368 & $<.001$ \\
\hline Group & -14.9 & 2.9 & -.358 & -5.101 & $<.001$ \\
\hline
\end{tabular}


S2d - Mean difference between HV and BD with age and sex as predictors

\begin{tabular}{|c|c|c|c|c|c|}
\hline \multirow[t]{2}{*}{ CRVE } & \multicolumn{2}{|c|}{ Unstandardized Coefficients } & \multirow{2}{*}{$\begin{array}{c}\text { Standardized } \\
\text { Coefficients } \\
\text { Beta }\end{array}$} & \multirow{2}{*}{$\mathbf{t}$} & \multirow{2}{*}{ Sig. } \\
\hline & B & Std. Error & & & \\
\hline (Constant) & 194.5 & 10.1 & & 19.187 & $<.001$ \\
\hline Group & 30.2 & 3.7 & .529 & 8.098 & $<.001$ \\
\hline Age & .17 & .3 & .044 & .685 & .494 \\
\hline Gender & -2.1 & 3.7 & -.038 & -.587 & .558 \\
\hline
\end{tabular}

\begin{tabular}{|l|c|c|c|c|c|}
\hline CRAE & \multicolumn{2}{|c|}{ Unstandardized Coefficients } & $\begin{array}{c}\text { Standardized } \\
\text { Coefficients }\end{array}$ & \multirow{2}{*}{ t } & Sig. \\
\cline { 1 - 4 } & B & Std. Error & Beta & & \\
\hline (Constant) & 118.0 & 8.1 & & 14.502 & $<.001$ \\
\hline Group & -13.4 & 3.0 & -.321 & -4.462 & $<.001$ \\
\hline Gender & 2.9 & 3.0 & .069 & .978 & .329 \\
\hline Age & -.4 & .2 & -.133 & -1.877 & .062 \\
\hline
\end{tabular}

S2e - Mean difference between SCZ and BD without age and sex as predictors

\begin{tabular}{|c|c|c|c|c|c|}
\hline \multirow[t]{2}{*}{ CRVE } & \multicolumn{2}{|c|}{ Unstandardized Coefficients } & \multirow{2}{*}{$\begin{array}{c}\text { Standardized } \\
\text { Coefficients } \\
\text { Beta }\end{array}$} & \multirow{2}{*}{$\mathbf{t}$} & \multirow{2}{*}{ Sig. } \\
\hline & B & Std. Error & & & \\
\hline (Constant) & 213.4 & 2.7 & & 78.505 & $<.001$ \\
\hline Group & 14.2 & 4.0 & .256 & 3.588 & $<.001$ \\
\hline
\end{tabular}

\begin{tabular}{|c|c|c|c|c|c|}
\hline \multirow[t]{2}{*}{ CRAE } & \multicolumn{2}{|c|}{ Unstandardized Coefficients } & \multirow{2}{*}{$\begin{array}{c}\text { Standardized } \\
\text { Coefficients } \\
\text { Beta }\end{array}$} & \multirow{2}{*}{$\mathbf{t}$} & \multirow{2}{*}{ Sig. } \\
\hline & B & Std. Error & & & \\
\hline (Constant) & 102.5 & 1.7 & & 62.080 & $<.001$ \\
\hline Group & -6.7 & 2.4 & -.201 & -2.774 & .006 \\
\hline
\end{tabular}


S2f - Mean difference between SCZ and BD with age and sex as predictors

\begin{tabular}{|l|c|c|c|c|c|}
\hline CRVE & \multicolumn{2}{|c|}{ Unstandardized Coefficients } & $\begin{array}{c}\text { Standardized } \\
\text { Coefficients }\end{array}$ & t & Sig. \\
\cline { 1 - 4 } & B & Std. Error & Beta & & \\
\hline (Constant) & 214.5 & 11.7 & & 18.344 & $<.001$ \\
\hline Group & 14.3 & 4.0 & .257 & 3.583 & $<.001$ \\
\hline Gender & -2.0 & 4.2 & -.035 & -.481 & .631 \\
\hline Age & .04 & .3 & .011 & .143 & .886 \\
\hline
\end{tabular}

\begin{tabular}{|l|c|c|c|c|c|}
\hline CRAE & \multicolumn{2}{|c|}{ Unstandardized Coefficients } & $\begin{array}{c}\text { Standardized } \\
\text { Coefficients }\end{array}$ & t & Sig. \\
\cline { 1 - 4 } & B & Std. Error & Beta & & \\
\hline (Constant) & 103.02 & 7.0 & & 14.798 & $<.001$ \\
\hline Group & -6.8 & 2.3 & -.206 & -2.885 & .004 \\
\hline Age & -.3 & .2 & -.105 & -1.433 & .154 \\
\hline Gender & 6.7 & 2.5 & .194 & 2.653 & .009 \\
\hline
\end{tabular}




\section{Relation between CRVE, CRAE and medications:}

Out of the 185 patients, 128 patients were on treatment with antipsychotics. Dose of individual antipsychotics were noted and chlorpromazine equivalents for these antipsychotics were calculated (Woods SW. Chlorpromazine equivalent doses for the newer atypical antipsychotics. J Clin Psychiatry. 2003 Jun;64(6):663-7). There was no significant relation between the chlorpromazine equivalents of antipsychotics used and average CRVE $(r=-0.08 ; p=0.36)$ or CRAE $(r=0.13 ; p=0.14)$.

\section{Relation between CRVE, CRAE, body mass index and blood pressure:}

For a subgroup of patients height and weight was measured and body mass index (BMI) was calculated on the day of retinal examination. BMI details were available for 48 healthy volunteers, 81 patients with SCZ and 60 patients with BD. Mean BMI for HV was $23.8 \pm 4.2$, for SCZ was $25.2 \pm 4.8$ and for BD was $25.8 \pm 4.4$. On analysis of variance, there was no significant difference between the groups on $B M I(F=2.65, p=0.07)$. As mentioned in the manuscript patients with hypertension were excluded from the study. Among those who participated blood pressure was recorded in 28 patients with SCZ and 57 patients with BD on the day of retinal examination. On independent $t$ test, mean systolic blood pressure between the groups was not significantly different $[S C Z=115.2 \pm 7.5, B D=118.1 \pm 12.1 ; t=1.38, p=0.24]$.

Even after inclusion of the BMI and blood pressure as covariates, the results remained significant. There was significant difference between SCZ and BD on average CRVE $(S C Z=214.1 \pm 31.8 ; B D=230.1 \pm 25.1 ; F=4.68 ; p=0.03)$ and average $C R A E(S C Z=113.4 \pm 15.4$; $B D=94.0 \pm 17.5 ; F=20.23 ; p<0.001)$

\section{Effect of nicotine use on retinal vascular measurements:}

While subjects with nicotine dependence were not included in the study, 13 subjects with SCZ and 4 subjects with BD had nicotine use. Analysis of variance was conducted to examine the differences between groups after exclusion of these subjects to rule out the possible confounding effect of nicotine use. There were significant differences between groups in average CRVE (SCZ=213.3 $\pm 28.2 ; \mathrm{BD}=228.0 \pm 26.3 ; \mathrm{HV}=196.5 \pm 21.7$; $\mathrm{F}=33.48 ; \mathrm{p}<0.001)$ and average $\mathrm{CRAE}(\mathrm{SCZ}=103.1 \pm 15.9 ; \mathrm{BD}=95.9 \pm 17.2 ; \mathrm{HV}=110.7 \pm 21.7$; $F=14.04 ; p<0.001)$. 



\section{CHAPTER 3}

\section{RETINAL VASCULAR TORTUOSITY \\ IN SCHIZOPHRENIA AND BIPOLAR DISORDER}

Abhishek Appaii, Bhargavi Nagendra, Dona Maria Chako, Ananth Padmanabha, Chaitra V Hiremath, Arpitha Jacob, Shivarama Varambally, Muralidharan Kesavan, Ganesan Venkatasubramanian, Shyam Vasudeva Rao, Carroll A.B. Webers, Tos T.J.M. Berendschot, Naren P. Rao 



\section{Abstract}

The micro-vasculature of retina and brain share common morphological, physiological, and pathological properties. Retina being easily accessible, retinal vascular examination provides an indirect assessment of cerebral vasculature. Considering the high prevalence of vascular morbidity in SCZ and BD a few studies have examined retinal vascular caliber and have reported increased retinal venular caliber in schizophrenia (SCZ). Retinal vascular tortuosity could serve as a better structural measure than caliber as it is static and less susceptible to pulse period variations. However, to date, no study has examined retinal vascular tortuosity in SCZ and bipolar disorder (BD). Hence, we examined retinal vascular tortuosity in comparison with healthy volunteers (HV). We included 255 subjects ( $78 \mathrm{HV}, 79 \mathrm{SCZ}$, and $86 \mathrm{BD}$ ) in the age range of 18 to 50 years. Trained personnel acquired images using a non-mydriatic fundus camera. To measure the average retinal arteriolar tortuosity index (RATI) and retinal venular tortuosity index (RVTI), we used a previously validated, semi-automatic algorithm. The results showed significant differences across the three groups in RATI but not in RVTI; both BD and SCZ had significantly increased RATI compared to HV. There was also a significant difference between $\mathrm{SCZ}$ and $\mathrm{BD}$, with $\mathrm{BD}$ having higher RATI. If shown to be of predictive utility in future longitudinal studies, it has the potential to identify patients at risk of development of adverse vascular events. As retinal vascular imaging is non-invasive and inexpensive, it could serve as a proxy marker and window to cerebral vasculature.

\section{Keywords:}

Retinal vascular tortuosity; Fundus; Schizophrenia; Bipolar disorder; Psychoses; Cerebrovascular 


\subsection{INTRODUCTION}

Retinal small vessels share common embryologic origins and have similar anatomical and physiological properties with cerebral small vessels, thus providing a unique "window" to study cerebrovascular disease ${ }^{1,2}$. Several studies have demonstrated a link between presence of retinal microvascular abnormalities and clinical (e.g., stroke, dementia) and subclinical (white matter lesions on magnetic resonance imaging) cerebrovascular disease $^{3-7}$. Considering the increased prevalence of vascular abnormalities and higher incidence of adverse cerebro/cardiovascular events in Schizophrenia (SCZ) and Bipolar disorder $(\mathrm{BD})^{8-13}$, retinal microvasculature has been examined in SCZ and BD. Increased retinal venular caliber has been found in $\mathrm{SCZ}^{14}$ and twins discordant for psychosis symptoms ${ }^{15}$. A significant association has also been reported between retinal vascular caliber, diastolic blood pressure, and endothelial function in adolescents with BD, although no differences in vascular caliber were noted between adolescents with BD and healthy volunteers $(\mathrm{HV})^{16}$. Recently, we examined the retinal vascular caliber in SCZ and BD and reported significantly narrower arterioles and wider venules in SCZ and $\mathrm{BD}$ compared to HV. In addition, there were also significant differences between SCZ and BD patients; patients with BD had narrower arterioles and wider venules ${ }^{17}$. The increased prevalence of comorbid metabolic risk factors is possibly the pathophysiology underlying retinal vascular abnormality. However, the contribution of shared genetic factors cannot be ruled out as wider venules have been observed in discordant twins of patients with psychosis symptoms also suggesting that retinal microvasculature may reflect a familial vulnerability to psychosis symptoms ${ }^{15}$.

Another key parameter measured using fundus imaging is retinal vascular tortuosity or curvature. Tortuosity describes the geometric pattern of the retinal vasculature layout and indicates the adequacy of the state of microcirculation and level of ocular perfusion ${ }^{18}$. A few studies have reported that retinal vascular tortuosity is a more stable marker as it is not affected by pulse variations ${ }^{19,20}$ and has high heritability ${ }^{21,22}$. Alterations in genetic factors, angiogenesis, blood flow, blood pressure and degeneration of vasculature are implicated in the formation of vessel tortuosity. With vascular disease and aging the internal lamina and tunica media of vessel wall degenerate and gets replaced by fibrous tissue. The resulting mechanical instability may give rise to the development of blood vessel tortuosity ${ }^{2,23-25}$. Mutations in genes responsible for formation of basement membrane proteins, namely LAMA1 and COL4A1, are reported to cause retinal vascular tortuosity ${ }^{26,27}$. 
Interestingly, evidence from several lines of research including genetic, neuroimaging and neuropathology suggests a significant role of microvascular anomaly and angiogenesis in the pathogenesis of schizophrenia ${ }^{28}$. It is important to note that a few congenital syndromes with retinal vascular tortuosity have high comorbidity of psychoses, SCZ and BD. Previous studies have reported increased retinal vascular tortuosity in $22 \mathrm{q} 11.2$ microdeletion syndromes ${ }^{29}$. Tortuosity of the retinal vessels, affecting both arterioles and venules, is a common finding and is present in about $30 \%$ of patients with $22 q 11.2$ microdeletion syndrome ${ }^{30}$. It is important to note that 22q11.2 microdeletion syndromes, namely DiGeorge syndrome and Velo-cardio-facial syndrome (VCFS), are associated with an increased risk of $\mathrm{SCZ}^{31}$. Similarly, retinal vascular tortuosity is reported in Moyamoya disease in which psychoses and mood disorders are common neuropsychiatric comorbidities ${ }^{32-34}$. In addition, significant association has been reported between retinal vascular tortuosity and cardiovascular risk factors like carotid intima-medial thickness (CMIT) ${ }^{22}$, metabolic syndrome, and diabetes mellitus ${ }^{35}$. Studies have implicated increased tortuosity of retinal vessels in cerebrovascular diseases like ischemic stroke ${ }^{36}$, cognitive dysfunction, Alzheimer's dementia ${ }^{37}$, and metabolic disorders like high blood pressure, body mass index, and diabetes ${ }^{35}$.

Considering the possible shared genetic vulnerability and the high prevalence of vascular morbidity in $\mathrm{SCZ}$ and $\mathrm{BD}$, we examined retinal vascular tortuosity in $\mathrm{SCZ}$ and $B D$ in this study. It is important to note that no study has examined retinal vascular tortuosity in $\mathrm{SCZ}$ and $\mathrm{BD}$. We hypothesized that both $\mathrm{SCZ}$ and $\mathrm{BD}$ would have increased retinal vascular tortuosity compared to healthy volunteers (HV). As SCZ and BD both have increased vascular morbidity ${ }^{11,38-40}$ and shared pathogenic mechanisms ${ }^{41,42}$ we also hypothesized that there would be no difference in retinal vascular tortuosity between SCZ and BD.

\subsection{METHODOLOGY}

\subsubsection{Sample}

One hundred patients each with SCZ and BD were recruited from the National Institute of Mental Health and Neurosciences (NIMHANS), Bengaluru, India, a tertiary care hospital. We recruited patients between 2015 and 2018. Both inpatients and out-patients 
were recruited. One hundred healthy volunteers (HV) were recruited from the same geographical location through flyers and by word of mouth. All study participants were adults aged between 18 and 50 years. All patients were examined by a board-certified psychiatrist; they met criteria for SCZ or BD as per the International Classification of Disorders 10 (ICD-10). Those patients with concurrent substance abuse or dependence (except nicotine) and comorbid Axis I psychiatric disorders were excluded. All HV were clinically evaluated and administered cross cutting symptom measure checklist by a certified psychiatrist to rule out Axis I psychiatric diagnoses ${ }^{43,44}$. HV were also excluded if they had history of substance use disorder. Participants with serious medical conditions including hypertension, diabetes, stroke, or history of eye trauma and surgery were excluded from the study. The study was approved by the institutional ethics committee and all participants provided written informed consent.

\subsubsection{Assessments}

After recruitment, the SCZ patients were assessed for severity of clinical symptoms using the Brief Psychiatric Rating Scale (BPRS) ${ }^{45}$ to measure the severity of positive and negative symptoms and general psychopathology. Young's Mania Rating Scale (YMRS) ${ }^{46}$, and Hamilton Depression Rating Scale (HDRS) ${ }^{47}$ were used to assess the severity of manic and depressive symptoms respectively in BD. Functioning was assessed using the Global Assessment of Functioning (GAF) ${ }^{48}$ and Clinical Global Impression (CGI) ${ }^{49}$.

\subsubsection{Retinal image acquisition}

After the procedure of retinal image acquisition was explained, the participants were seated in a dark room for 5 min to facilitate auto dilation of the pupil. Images were acquired by a trained individual using a non-mydriatic camera with 40 degrees field of view, 3nethra classic manufactured by Forus Health Pvt Ltd, Bengaluru, India. Optic disc centred retinal images of both the eyes were acquired using a valid method described elsewhere ${ }^{50}$; the colour fundus image was acquired by illumination of light flashes. A representative image of the acquisition of retinal images is given in Supplementary Figure S1.

\subsubsection{Measurement of retinal vasculature}

An initial quality check was conducted to examine the suitability of images for 
measurement of tortuosity. Forty-five out of 300 images were excluded following quality check due to inadequate illumination and the remaining 255 images were considered for analysis. These included $78 \mathrm{HV}, 79 \mathrm{SCZ}$, and 86 BD. We calculated a measure known as Simple Tortuosity (ST) which is defined as the mean ratio of the arc length (actual traced length of the vessel) to the chord length (length of the straight line drawn from the starting to ending point of the vessel) of vessels in the radial zone between 0.5 to 2 disc diameters from the optic disc ${ }^{51,52}$ (Supplementary Figure S2). Arteries and veins were identified and labeled manually. All arteries and veins in the above-said zone were considered for calculation of ST. The arc length and chord length of these vessels were then determined using customized semi-automated software for tortuosity created using MATLAB 2018a (by The MathWorks, Inc., Natick, Massachusetts, United States), similar to other proprietary software ${ }^{20}$. ST was calculated for left and right eyes separately. Finally, the average of the left and right eye tortuosity indices was calculated. Average retinal venular tortuosity index (RVTI) and average retinal arteriolar tortuosity index (RATI) were calculated separately. A sub-sample of 30 participant images were analyzed by two raters to check inter-rater reliability. A good inter-rater reliability was obtained between the graders (Intra Class Correlation for RVTI-0.81 and RATI-0.82).

\subsubsection{Statistical Analysis}

All statistical analyses were performed using the Statistical Package for Social Sciences (SPSS) version 25. The data was initially examined for normative distribution using the Shapiro-Wilk test and parametric tests were applied as the data was normatively distributed. The sex distribution across the three groups was examined using the chisquare test and the age difference was analyzed using one-way analysis of variance (ANOVA). As there was a significant difference across groups with respect to age and sex, these were used as covariates in the further analysis. Differences in RVTI and RATI across the three groups were examined using analysis of co-variance (ANCOVA) with age and sex as covariates. As there were two primary outcome measures, a Bonferroni correction of $a=0.05 / 2=0.025$ was considered significant. Post-hoc analysis was conducted to examine differences between pairs of groups. To calculate the extent of contribution by age and sex on RVTI and RATI, we also conducted linear regression analyses with RATI and RVTI as dependent variables and group, age, and sex as predictor variables. To examine the relation between ST and clinical variables, Pearson's correlation analyses 
were performed with RATI, RVTI and BPRS, YMRS, HDRS, age at onset of illness, duration of illness, and chlorpromazine equivalent of antipsychotic dose $\mathrm{e}^{53}$. As a subgroup of patients had nicotine dependence, a sub-analysis was conducted after excluding these patients to avoid the confounding effect of nicotine use on retinal vascular tortuosity ${ }^{54-56}$. In addition, a sub-analysis was conducted for sub-group of patients for whom BMI and systolic blood pressure were recorded.

\subsection{RESULTS}

\subsubsection{Comparison of demographic variables}

The differences in demographic and clinical variables across the groups are shown in Table 1. There was a significant difference across the three groups in age and gender distribution. Duration of illness and age at onset of illness were not significantly different in patients with SCZ and BD.

Table 1.

Comparison of demographic and clinical details between the groups.

\begin{tabular}{|l|c|c|c|c|c|}
\hline & $\begin{array}{c}\text { HV } \\
(\mathbf{n = 7 8 )}\end{array}$ & $\begin{array}{c}\mathbf{S C Z} \\
(\mathbf{n = 7 9 )}\end{array}$ & $\begin{array}{c}\mathbf{B D} \\
(\mathbf{n}=\mathbf{8 6})\end{array}$ & $\mathbf{F / t / \mathbf { X } ^ { \mathbf { 2 } }}$ & $\mathbf{p}$ \\
\hline Age & $30 \pm 7.6$ & $32.7 \pm 6$ & $33.2 \pm 6.2$ & 5.57 & $0.004^{*}$ \\
\hline Gender ratio (M/F) & $35 / 43$ & $55 / 24$ & $50 / 36$ & 9.86 & $0.007^{*}$ \\
\hline Age at onset (years) & - & $25.1 \pm 5.5$ & $23.7 \pm 6$ & 1.7 & 0.19 \\
\hline $\begin{array}{l}\text { Duration of illness } \\
\text { (years) }\end{array}$ & - & $7.7 \pm 5.1$ & $8.7 \pm 5.3$ & 1.16 & 0.28 \\
\hline BPRS & - & $28.3 \pm 5.1$ & - & - & - \\
\hline HDRS & - & - & $3.5 \pm 4.7$ & - & - \\
\hline YMRS & - & - & $1.7 \pm 3.0$ & - & - \\
\hline
\end{tabular}

SCZ - patients with schizophrenia; BD - patients with bipolar disorder; HV - healthy volunteer; BPRS-Brief Psychiatric rating scale, HDRS- Hamilton depression rating scale, YMRS-Young's mania rating scale; $F$ - Analysis of Variance; $t$ - Independent $t$ test; $X^{2}-$ Chi square test; *Significant difference. 
Table 2.

Retinal vascular tortuosity in the three groups.

\begin{tabular}{|l|c|c|c|c|c|}
\hline & $\begin{array}{c}\text { HV } \\
(\mathbf{n}=\mathbf{7 8})\end{array}$ & $\begin{array}{c}\text { SCZ } \\
(\mathbf{n}=\mathbf{7 9})\end{array}$ & $\begin{array}{c}\text { BD } \\
(\mathbf{n}=\mathbf{8 6})\end{array}$ & $\mathbf{F}$ & $\mathbf{p}$ \\
\hline RVTI & $1.031 \pm 0.02$ & $1.027 \pm 0.01$ & $1.026 \pm 0.01$ & 2.23 & 0.051 \\
\hline RATI & $1.023 \pm 0.01$ & $1.0312 \pm 0.01$ & $1.038 \pm 0.02$ & 18.87 & $<0.001^{*}$ \\
\hline
\end{tabular}

SCZ - patients with schizophrenia; BD - patients with bipolar disorder; HV - healthy volunteer; F - ANCOVA with age and sex as covariates; RVTI- Average retinal venular tortuosity index; RATI- Average retinal arteriolar tortuosity index; *Significant difference.

\subsubsection{Differences in RATI and RVTI between groups}

On ANCOVA, there was a significant difference across the three groups only in RATI ( $p$ $<0.001$ ) but not in RVTI ( $p=0.051$ ) (Table 2). On further post-hoc ANOVA both SCZ ( $p$ $=0.003)$ and BD $(p<0.001)$ had significantly higher RATI compared to HV. BD patients also had significantly higher RATI compared to SCZ ( $p=0.017$ ) (Supplement Table S3). In addition, we calculated the effect size to quantify the magnitude of difference between the groups in RATI. The effect size calculation showed a large effect size between BD and HV $(d=0.91 ; r=0.41)$, a medium effect size between SCZ and HV $(d=0.73 ; r=0.33)$; and a small effect size between BD and SCZ $(d=0.39 ; r=0.19)$. To calculate the extent of the contribution of age and sex and to delineate their possible confounding effects on group-wise comparisons, regression analysis was conducted with and without age and sex as additional regressors. The group differences were significant in both instances and the regression coefficients were comparable (Table 3).

In addition, subgroup analyses were done on age and sex-matched sample to rule out confounding effects. $61 \mathrm{HV}(\mathrm{M}: \mathrm{F}=30: 31$; age = 30.4 \pm 6.0 years), $68 \mathrm{SCZ}$ (M:F = 44:24; age $=32.4 \pm 5.3$ years $)$ and $77 \mathrm{BD}(\mathrm{M}: \mathrm{F}=46: 31$; age $=32.53 \pm 5.2$ years $)$ were selected . These three groups were matched on age $(F=2.89 ; p=0.06)$ and $\operatorname{sex}(X 2=3.3 ; p=0.19)$. On ANOVA, there was still a significant difference across the three groups on RATI (HV: $1.0232 \pm 0.0099 ;$ SCZ: $1.0312 \pm 0.0128 ; B D: 1.0367 \pm 0.0194 ; F=13.91, p<0.001)$. As expected, there was no significant difference on RVTI (HV: $1.0302 \pm 0.0136 ;$ SCZ: 1.0278 $\pm 0.0136 ; \mathrm{BD}: 1.0260 \pm 0.0125 ; \mathrm{F}=1.68, \mathrm{p}=0.19$ ). 
The results continued to remain significant after excluding the 15 participants who had nicotine dependence (11 SCZ and $4 \mathrm{BD}$ ); there was a significant difference between groups on RATI (HV: $1.023 \pm 0.01$; SCZ: $1.031 \pm 0.013$; BD: $1.038 \pm 0.019 ; F=18.49 ; p<$ $0.001)$ but no significant difference on RVTI (HV = 1.03 $\pm 0.15 ; \mathrm{SCZ}=1.027 \pm 0.013 ; \mathrm{BD}=$ $1.026 \pm 0.12 ; F=2.36 ; p=0.097$ ) (Details in Supplementary Table S1). In a subgroup of patients, BMI [HV $(n=41)-23.33 \pm 3.4 ;$ SCZ $(n=66)-25.14 \pm 5.2 ; B D(n=52)-25.93 \pm$ 4.4] and systolic blood pressure [HV $(n=23)-115.87 \pm 8.0$; SCZ $(n=49)$ - $118.12 \pm 11.6$; $B D(n=72)-117.4 \pm 10.6]$ were recorded on the day of the retinal vascular examination. Even after controlling for these variables in the regression analysis, there was no significant difference in the findings and results remained significant for RATI (Table 4). On Pearson's correlation analysis, there was no significant correlation between the RATI and clinical variables BPRS, YMRS, HDRS, age at onset of illness and duration of illness ( $p>0.05$ ) (Supplementary Table S2).

Table 3.

Mean difference of retinal tortuosity between groups adjusted for age and sex.

\begin{tabular}{|c|c|c|c|c|c|c|}
\hline \multirow[t]{2}{*}{ Variable } & \multicolumn{2}{|c|}{ Group } & \multicolumn{2}{|c|}{$\begin{array}{l}\text { Not adjusted for age and } \\
\text { sex }\end{array}$} & \multicolumn{2}{|c|}{ Adjusted for age and sex } \\
\hline & & & $\beta(95 \% \mathrm{CI})$ & $\mathbf{p}$ & $\beta(95 \% \mathrm{Cl})$ & $\mathbf{p}$ \\
\hline \multirow{3}{*}{ RVTI } & HV & SCZ & $\begin{array}{c}-0.003 \\
(-0.008 \text { to } 0.001)\end{array}$ & 0.124 & $\begin{array}{c}0.004 \\
(-0.009 \text { to } 0.000)\end{array}$ & 0.054 \\
\hline & HV & $\mathrm{BD}$ & $\begin{array}{c}-0.004 \\
(-0.008 \text { to } 0.000)\end{array}$ & $0.044^{*}$ & $\begin{array}{c}-0.005 \\
(-0.009 \text { to }-0.001)\end{array}$ & $0.021^{*}$ \\
\hline & SCZ & $\mathrm{BD}$ & $\begin{array}{c}-0.001 \\
(-0.005 \text { to } 0.003)\end{array}$ & 0.65 & $\begin{array}{c}-0.001 \\
(-0.005 \text { to } 0.003)\end{array}$ & 0.741 \\
\hline \multirow{3}{*}{ RATI } & HV & SCZ & $\begin{array}{c}0.008 \\
(0.004 \text { to } 0.011)\end{array}$ & $0.001^{*}$ & $\begin{array}{c}0.007 \\
(0.002 \text { to } 0.012)\end{array}$ & $<0.005^{*}$ \\
\hline & HV & BD & $\begin{array}{c}0.014 \\
(0.019 \text { to } 0.009)\end{array}$ & $<0.001^{*}$ & $\begin{array}{c}0.014 \\
(0.009 \text { to } 0.018)\end{array}$ & $<0.001^{*}$ \\
\hline & SCZ & BD & $\begin{array}{c}0.006 \\
(0.002 \text { to } 0.011)\end{array}$ & $0.006^{*}$ & $\begin{array}{c}0.007 \\
(0.002 \text { to } 0.011)\end{array}$ & $0.005^{*}$ \\
\hline
\end{tabular}

SCZ - patients with schizophrenia; BD - patients with bipolar disorder; HV - healthy volunteer; $\beta$ - regression coefficient, $95 \%$ Cl - 95\% confidence interval; *Significant difference 
Table 4.

Details of regression coefficient between groups with BMI and Systolic blood pressure as covariates.

\begin{tabular}{|l|c|c|c|c|c|}
\hline $\begin{array}{l}\text { Retinal arterial } \\
\text { Tortuosity Index } \\
\text { (RATI) }\end{array}$ & \multicolumn{2}{|c|}{$\begin{array}{c}\text { Unstandardized } \\
\text { Coefficients }\end{array}$} & $\begin{array}{c}\text { Standardized } \\
\text { Coefficients }\end{array}$ & t & Sig. \\
\cline { 1 - 4 } & B & $\begin{array}{c}\text { Std. } \\
\text { Error }\end{array}$ & Beta & & \\
\hline (Constant) & 0.988 & 0.029 & & 34.67 & $<.001^{*}$ \\
\hline Group & 0.014 & 0.005 & 0.304 & 2.546 & $0.013^{*}$ \\
\hline Body mass index & 0.000 & 0.001 & 0.042 & 0.343 & 0.733 \\
\hline Systolic Blood pressure & 0.000 & 0.000 & 0.094 & 0.761 & 0.450 \\
\hline
\end{tabular}

*Significant difference

\subsection{DISCUSSION}

To the best of our knowledge, this is the first study to examine retinal vascular tortuosity in patients with SCZ and BD in comparison to HV. Results of the study suggest significantly increased RATI in both BD and SCZ compared to HV. However, there was no significant difference across the groups with respect to RVTI. Studies which examined retinal vascular caliber in SCZ and BD have reported abnormalities in the vascular caliber $^{14,15,17,57}$. Our findings of increased retinal arteriolar tortuosity provide added evidence for retinal vascular abnormalities in SCZ and BD.

A few studies have reported associations between neuropsychiatric conditions and retinal vascular tortuosity; increased RATI has been reported to be associated with ischemic stroke ${ }^{36}$ and Alzheimer's disease ${ }^{37}$. Although retinal vascular tortuosity has not been examined earlier in SCZ or BD, a previous case report has reported increased retinal vascular tortuosity in a patient with SCZ and DiGeorge syndrome ${ }^{29}$. Interestingly, previous studies have also reported increased retinal vascular tortuosity in a considerable proportion of individuals with 22 q11.2 deletion and duplication syndromes ${ }^{58-60}$. These syndromes have a significantly increased prevalence of $\mathrm{SCZ}^{61}$. Our finding of increased tortuosity in retinal arterioles of BD and SCZ provides further support to its association with neuropsychiatric syndromes. 
Several studies have suggested that retinal vascular measures are reliable surrogate markers for increased risk of adverse vascular events ${ }^{20,62}$. It is important to note that patients with SCZ and BD have significantly increased rates of adverse cardio/ cerebrovascular events $s^{63-66}$ and this increased rate exceeds what can be explained by traditional cardiovascular risk factors and life style ${ }^{67}$. Examination of retinal microvascular tortuosity could prove to be an easy and affordable method to identify these patients. Although our study is cross-sectional in design, it provides a rationale for further examination of retinal vascular tortuosity using longitudinal study designs. This could examine whether increased retinal arteriolar tortuosity confers greater risk of adverse vascular events in SCZ and BD. If predictive utility can be demonstrated, retinal examination for arteriolar tortuosity could help in screening individuals with SCZ and BD at risk for developing adverse vascular events.

The pathophysiology behind retinal venular and arteriolar abnormalities is still unclear. Several genetic and environmental theories have been proposed. Vascular tortuosity has been shown to have a high degree of heritability ${ }^{21,22}$. While retinal vascular caliber has strong associations with cardiovascular biochemical markers and hypertension, retinal vascular tortuosity is less influenced by these measures ${ }^{21,22}$. On the other hand, Carotid intima-medial thickness (CMIT) has significant associations with retinal vascular tortuosity ${ }^{22}$. Considering the direct relation of CIMT with stroke and myocardial infarction ${ }^{68}$, the association between retinal vascular tortuosity and CIMT supports the use of retinal vascular tortuosity as a non-invasive surrogate marker for stratifying the risk of future adverse cardio/cerebrovascular events ${ }^{20}$. In addition to these genetic factors, several inflammatory factors associated with metabolic syndrome and diabetes mellitus are also associated with increased retinal vascular tortuosity ${ }^{35}$. Whether similar mechanisms operate in patients with SCZ and BD is yet to be examined. At this stage, we are unclear whether increased retinal arteriolar tortuosity seen in our study may be reflective of the risk of higher prevalence of metabolic syndrome and cardio/ cerebrovascular adverse events in $\mathrm{SCZ}$ and $\mathrm{BD}^{65,66}$. However, other mechanisms also need to be considered as studies in children with 22q11.2 deletion syndrome have reported increased retinal vascular tortuosity even in the absence of vascular adverse events $^{58}$. Familial retinal arteriolar tortuosity, a disorder with autosomal dominant inheritance is caused by mutations in gene COL4A 1 , which codes for a major basement membrane ${ }^{27,69}$. Interestingly, mutations in COL4A1 gene are also known to cause cerebral cortical malformations and neuronal localization defects ${ }^{70}$. Interestingly, the same gene is implicated in altered synaptic elements in superior temporal cortex of 
schizophrenia patients ${ }^{71}$. Hence, at this stage it is not possible to confidently infer whether the increased retinal arteriolar tortuosity in SCZ and BD is the consequence of comorbid cardiovascular risk factors or manifestation of shared genetic vulnerability. Future studies need to incorporate genetic testing in addition to examination of retinal vascular tortuosity for further clarity.

The significant difference in RATI between SCZ and BD was not expected and did not conform to our hypothesis. Considering the shared pathogenic factors ${ }^{41}$ and increased prevalence of vascular adverse events ${ }^{66}$ in both SCZ and BD, we did not expect any difference between SCZ and BD. Only a few studies have reported differences in cognitive functions, brain structure/ function, comorbidities between SCZ and BD ${ }^{72-}$ 76; most other studies have reported significant overlap between SCZ and BD in genetics, brain structure and function ${ }^{41,77}$. We do not have a definitive explanation for this difference at this stage. At this stage our finding of difference between SCZ and $\mathrm{BD}$ must be considered preliminary, requiring further examination in future studies. Similarly, we do not have definitive explanations for the absence of difference between groups in RVTI measurements. A few studies have suggested differential association between retinal arteriolar and venular tortuosity and cardiovascular risk factors and diabetes ${ }^{78,79}$. Though tortuosity can be measured in both retinal arteries and veins, but arteriolar tortuosity is examined more frequently than venular tortuosity. Arteriolar tortuosity changes have been related to arteriosclerosis ${ }^{80}$ and venular tortuosity have been connected to vascular obstruction/occlusion ${ }^{81}$. Anatomically, presence of tunica media makes arteriolar wall thicker and less compliant than venular wall ${ }^{82}$. Whether the difference between arterioles and venules seen in our study is due to mechanical reasons only or not need to be examined in the future.

The following limitations need to be considered while interpreting the results of the study. All patients were on pharmacological treatment and the effects of medication on retinal arteriolar tortuosity are not known. Although there was no correlation between the dosage of antipsychotic and retinal arteriolar tortuosity, the confounding effects of medications cannot be definitively ruled out with the current study design. Examining drug-naïve patients needs to be considered in future studies. We did not record blood pressure and glucose levels on the day of the assessment. As the participants were young, those with hypertension or diabetes were excluded based on history; one cannot rule out the confounding effect of Pre-diabetic or pre-hypertensive status which may be missed in history ${ }^{51,83}$. The relation between retinal vascular tortuosity 
and hypertension is still debated; while no association was reported between blood pressure and retinal vascular tortuosity in one study ${ }^{22}$, significant association has been reported in other studies ${ }^{78,84}$. Future studies need to consider recording blood pressure, fasting blood glucose, renal functions, and life style factors like diet and exercise at the time of retinal vascular assessment. We did not collect the information of family history of cardio/cerebrovascular disorders in study participants which could affect the findings. Future studies need to consider collecting the family history of cardiovascular disorders. Although individual group differences could be detected using the current sample size, larger studies are required for sub-group analysis (ex: BD-I vs BD-II vs SCZ; $B D$ with psychotic symptoms vs BD without psychotic symptoms VS SCZ etc.). Finally, we used the Fagerstrom test for nicotine dependence (FTND) scores as covariate in the analysis. While this could control for the nicotine dependence, this will not control for the confounding effect of the non-dependence pattern of nicotine use which may influence retinal vessel tortuosity as it is shown to be related to venular diameter ${ }^{85}$. Future studies could use smoking status as a covariate instead of or in addition to FTND.

We recruited participants with no current comorbid psychiatric conditions as the effect of comorbid conditions on retinal vascular tortuosity is not known. While this resulted in a homogeneous sample with $\mathrm{SCZ}$ and $\mathrm{BD}$, this could affect generalizability of findings. Similarly, as the retinal image acquisition required participant to sit still in a dark room for $5 \mathrm{~min}$, a major portion of the participants were in euthymic phase. This could have resulted the absence of relation between retinal vascular tortuosity and clinical symptoms. Future studies need to consider inclusion of participants in different stages of illness and comorbidities so that the relation between retinal vascular parameters and acute symptoms, course of the illness in preceding years and sleep disturbances could be examined. Such analyses could potentially reveal the factors underlying the difference between $\mathrm{BD}$ and $\mathrm{SCZ}$ seen in the current study. Considering that the retinal vascular caliber and tortuosity measure different aspects of vascular abnormality and provide complementary information, future studies could consider simultaneous measurement of different retinal vascular parameters to arrive at a composite index in $\mathrm{SCZ}$ and $\mathrm{BD}$. 


\subsection{Conclusion}

Our study indicates significantly increased retinal arteriolar tortuosity in patients with $\mathrm{BD}$ and $\mathrm{SCZ}$ when compared to $\mathrm{HV}$, and possible differences between SCZ and BD. These preliminary findings provide a strong rationale for further systematic examination of retinal arteriolar tortuosity in patients with SCZ and BD. Considering the easy accessibility, non-invasive nature of the examination, and affordability, retinal arteriolar tortuosity examination can be conducted even in outpatient psychiatry settings and could serve as a surrogate marker for abnormalities in the cerebral vasculature. If shown to be of predictive utility in future longitudinal studies, examination of retinal arteriolar tortuosity has the potential to identify BD and SCZ patients at risk of developing adverse vascular events. 


\section{References}

1. Wong $T Y$, Klein R, Klein BE, Tielsch JM, Hubbard L, Nieto FJ. Retinal microvascular abnormalities and their relationship with hypertension, cardiovascular disease, and mortality. Surv Ophthalmol. 2001;46(1):59-80.

2. Patton N, Aslam T, Macgillivray T, Pattie A, Deary IJ, Dhillon B. Retinal vascular image analysis as a potential screening tool for cerebrovascular disease: a rationale based on homology between cerebral and retinal microvasculatures. Journal of anatomy. 2005;206(4):319-348.

3. Wong $T Y$, Klein $R$, Sharrett $A R$, et al. Retinal microvascular abnormalities and cognitive impairment in middle-aged persons: the Atherosclerosis Risk in Communities Study. Stroke; a journal of cerebral circulation. 2002;33(6):1487-1492.

4. Cheung N, Mosley T, Islam A, et al. Retinal microvascular abnormalities and subclinical magnetic resonance imaging brain infarct: a prospective study. Brain : a journal of neurology. 2010;133(Pt 7):1987-1993.

5. Lesage SR, Mosley TH, Wong TY, et al. Retinal microvascular abnormalities and cognitive decline: the ARIC 14-year follow-up study. Neurology. 2009;73(11):862-868.

6. de Jong FJ, Schrijvers EM, Ikram MK, et al. Retinal vascular caliber and risk of dementia: the Rotterdam study. Neurology. 2011;76(9):816-821.

7. Kim DH, Newman AB, Hajjar l, et al. Retinal microvascular signs and functional loss in older persons: The cardiovascular health study. Stroke; a journal of cerebral circulation. 2011;42(6):1589-1595.

8. Curtis CE, lacono WG, Beiser M. Relationship between nailfold plexus visibility and clinical, neuropsychological, and brain structural measures in schizophrenia. Biological psychiatry. 1999;46(1):102-109.

9. Hudson CJ, Lin A, Cogan S, Cashman F, Warsh JJ. The niacin challenge test: Clinical manifestation of altered transmembrane signal transduction in schizophrenia? Biological Psychiatry. 1997;41(5):507-513.

10. Sun C, Wang JJ, Mackey DA, Wong TY. Retinal vascular caliber: systemic, environmental, and genetic associations. Surv Ophthalmol. 2009;54(1):74-95.

11. Goldstein BI. Bipolar Disorder and the Vascular System: Mechanisms and New Prevention Opportunities. Can J Cardiol. 2017;33(12):1565-1576. 
12. Mathew RJ, Wilson $W H$, Tant $S R$, Robinson $L$, Prakash R. Abnormal resting regional cerebral blood flow patterns and their correlates in schizophrenia. Arch Gen Psychiatry. 1988;45(6):542-549.

13. Rubin E, Sackeim HA, Prohovnik I, Moeller JR, SchnurDB, Mukherjee S. Regional cerebral blood flow in mood disorders: IV. Comparison of mania and depression. Psychiatry Res. 1995;61(1):1-10.

14. Meier MH, Shalev W, Moffitt TE, et al. Microvascular Abnormality in Schizophrenia as Shown by Retinal Imaging. Am J Psychiat. 2013;170(12):1451-1459.

15. Meier MH, Gillespie NA, Hansell NK, et al. Retinal microvessels reflect familial vulnerability to psychotic symptoms: A comparison of twins discordant for psychotic symptoms and controls. Schizophr Res. 2015;164(1-3):47-52.

16. Naiberg MR, Hatch JK, Selkirk $B$, et al. Retinal photography: $A$ window into the cardiovascular-brain link in adolescent bipolar disorder. J Affect Disord. 2017;218:227237.

17. Appaji A, Nagendra B, Chako DM, et al. Retinal Vascular Abnormalities in Schizophrenia and Bipolar Disorder: A Window to the Brain. Bipolar Disorder (In Press). 2019.

18. Patton N, Aslam TM, MacGillivray T, et al. Retinal image analysis: concepts, applications and potential. Prog Retin Eye Res. 2006;25(1):99-127.

19. Hao H, Sasongko MB, Wong $T Y$, et al. Does retinal vascular geometry vary with cardiac cycle? Invest Ophthalmol Vis Sci. 2012;53(9):5799-5805.

20. Kalitzeos AA, Lip GY, Heitmar R. Retinal vessel tortuosity measures and their applications. Experimental eye research. 2013;106:40-46.

21. Taarnhøj N, Munch I, Sander B, et al. Straight versus tortuous retinal arteries in relation to blood pressure and genetics. British Journal of Ophthalmology. 2008;92(8):10551060.

22. Kirin M, Nagy R, MacGillivray TJ, et al. Determinants of retinal microvascular features and their relationships in two European populations. Journal of hypertension. 2017;35(8):1646.

23. Fredriksson K, Nordborg C, Kalimo H, Olsson Y, Johansson B. Cerebralmicroangiopathyin stroke-prone spontaneously hypertensive rats. Acta neuropathologica. 1988;75(3):241252. 
24. Williams MA, McGowan AJ, Cardwell CR, et al. Retinal microvascular network attenuation in Alzheimer's disease. Alzheimer's \& dementia (Amsterdam, Netherlands). 2015; 1(2):229-235.

25. Han H-C. Twisted blood vessels: symptoms, etiology and biomechanical mechanisms. Journal of vascular research. 2012;49(3):185-197.

26. Edwards MM, Mammadova-Bach E, Alpy F, et al. Mutations in Lama1 disrupt retinal vascular development and inner limiting membrane formation. J Biol Chem. 2010;285(10):7697-7711.

27. Zenteno JC, Crespi J, Buentello-Volante B, et al. Next generation sequencing uncovers a missense mutation in COLAA1 as the cause of familial retinal arteriolar tortuosity. Graefe's archive for clinical and experimental ophthalmology = Albrecht von Graefes Archiv fur klinische und experimentelle Ophthalmologie. 2014;252(11):1789-1794.

28. Katsel P, Roussos P, Pletnikov M, Haroutunian V. Microvascular anomaly conditions in psychiatric disease. Schizophrenia - angiogenesis connection. Neurosci Biobehav Rev. 2017;77:327-339.

29. De Niro JE, Randhawa S, McDonald HR. Retinal vascular tortuosity in DiGeorge syndrome complicated by solar retinopathy. Retin Cases Brief Rep. 2013;7(4):343-346.

30. Gokturk B, Topcu-Yilmaz P, Bozkurt B, et al. Ocular Findings in Children With 22q11.2 Deletion Syndrome. J Pediatr Ophthalmol Strabismus. 2016;53(4):218-222.

31. Tang SX, Yi JJ, Calkins ME, et al. Psychiatric disorders in 22q11.2 deletion syndrome are prevalent but undertreated. Psychol Med. 2014;44(6):1267-1277.

32. Behere RV, John $M$, Sureshkumar R, et al. Mood disorder in association with moyamoya disease. Psychiatry and clinical neurosciences. 2012;66(2):163-164.

33. Katsman D, Klufas MA, Sarraf D, Sadda S. Retinal Arterial Tortuosity in Moyamoya Disease. JAMA Ophthalmol. 2016;134(1):111-114.

34. Richards M, Grzenda A, Nelson E, Gitlin M. Psychiatric Comorbidity in Moyamoya Disease and Preliminary Guidelines For Treatment. The American journal of psychiatry. 2019;176(4):269-274.

35. Noda K, Nakao S, Zandi S, Sun D, Hayes KC, Hafezi-Moghadam A. Retinopathy in a novel model of metabolic syndrome and type 2 diabetes: new insight on the inflammatory paradigm. FASEB J. 2014;28(5):2038-2046. 
36. Ong YT, De Silva DA, Cheung CY, et al. Microvascular structure and network in the retina of patients with ischemic stroke. Stroke; a journal of cerebral circulation. 2013;44(8):2121-2127.

37. Cheung $C Y$, Ong YT, Ikram MK, et al. Microvascular network alterations in the retina of patients with Alzheimer's disease. Alzheimers Dement. 2014;10(2):135-142.

38. Hennekens $\mathrm{CH}$. Increasing global burden of cardiovascular disease in general populations and patients with schizophrenia. J Clin Psychiatry. 2007;68 Suppl 4:4-7.

39. Kupfer DJ. The increasing medical burden in bipolar disorder. Jama. 2005;293(20):25282530.

40. Swartz HA, Fagiolini A. Cardiovascular disease and bipolar disorder: risk and clinical implications. J Clin Psychiatry. 2012;73(12):1563-1565.

41. Craddock N, Owen MJ. The Kraepelinian dichotomy - going, going... but still not gone. Br J Psychiatry. 2010;196(2):92-95.

42. Meda SA, Ruano G, Windemuth $A$, et al. Multivariate analysis reveals genetic associations of the resting default mode network in psychotic bipolar disorder and schizophrenia. Proc Natl Acad Sci U S A. 2014;111(19):E2066-2075.

43. Narrow WE, Clarke DE, Kuramoto SJ, et al. DSM-5 field trials in the United States and Canada, Part III: development and reliability testing of a cross-cutting symptom assessment for DSM-5. The American journal of psychiatry. 2013;170(1):71-82.

44. Clarke DE, Kuhl EA. DSM-5 cross-cutting symptom measures: a step towards the future of psychiatric care? World psychiatry : official journal of the World Psychiatric Association (WPA). 2014;13(3):314-316.

45. Overall JE, Gorham DR. The brief psychiatric rating scale. Psychological reports. 1962;10(3):799-812.

46. Young RC, Biggs JT, Ziegler VE, Meyer DA. A rating scale for mania: reliability, validity and sensitivity. Br J Psychiatry. 1978;133:429-435.

47. Hamilton M. A rating scale for depression. J Neurol Neurosurg Psychiatry. 1960;23:5662.

48. Jones SH, Thornicroft G, Coffey M, Dunn G. A brief mental health outcome scalereliability and validity of the Global Assessment of Functioning (GAF). Br J Psychiatry. 1995;166(5):654-659. 
49. Busner J, Targum SD. The clinical global impressions scale: applying a research tool in clinical practice. Psychiatry (Edgmont). 2007;4(7):28-37.

50. Nguyen TT, Islam FM, Farouque HM, et al. Retinal vascular caliber and brachial flowmediated dilation: the Multi-Ethnic Study of Atherosclerosis. Stroke; a journal of cerebral circulation. 2010;41(7):1343-1348.

51. Benitez-Aguirre P, Craig ME, Sasongko MB, et al. Retinal vascular geometry predicts incident retinopathy in young people with type 1 diabetes: a prospective cohort study from adolescence. Diabetes Care. 2011;34(7):1622-1627.

52. Benitez-Aguirre $P Z$, Sasongko $M B$, Craig ME, et al. Retinal vascular geometry predicts incident renal dysfunction in young people with type 1 diabetes. Diabetes Care. 2012;35(3):599-604.

53. Adams SA, Nasrallah HA. Multiple retinal anomalies in schizophrenia. Schizophr Res. 2018;195:3-12.

54. Yanagi M, Misumi M, Kawasaki R, et al. Is the association between smoking and the retinal venular diameter reversible following smoking cessation? Invest Ophthalmol Vis Sci. 2014;55(1):405-411.

55. Moschos MM, Nitoda E, Laios K, Ladas DS, Chatziralli IP. The Impact of Chronic Tobacco Smoking on Retinal and Choroidal Thickness in Greek Population. Oxid Med Cell Longev. 2016;2016:2905789.

56. Boretsky A, Gupta P, Tirgan N, et al. Nicotine accelerates diabetes-induced retinal changes. Curr Eye Res. 2015;40(4):368-377.

57. Meier MH, Hill ML, Breitborde NJK. Retinal Imaging: A New Tool for Studying Underlying Liability to Cardiovascular Disease in Schizophrenia. Curr Psychiatry Rev. 2016;12(4):326-334.

58. Casteels I, Casaer P, Gewillig M, Swillen A, Devriendt K. Ocular findings in children with a microdeletion in chromosome 22q11.2. Eur J Pediatr. 2008;167(7):751-755.

59. Cordovez JA, Capasso J, Lingao MD, et al. Ocular manifestations of 22q11. 2 microduplication. Ophthalmology. 2014;121(1):392-398.

60. Hill VE, Pietucha S, Ells AL. Congenital Vascular Tortuosity in DiGeorge Syndrome Mimicking SignificantRetinopathy of Prematurity. Archives of Ophthalmology. 2004;122(1):132-133. 
61. Van L, Boot E, Bassett AS. Update on the 22q11. 2 deletion syndrome and its relevance to schizophrenia. Current opinion in psychiatry. 2017;30(3):191-196.

62. Witt $N$, Wong $T Y$, Hughes $A D$, et al. Abnormalities of retinal microvascular structure and risk of mortality from ischemic heart disease and stroke. Hypertension. 2006;47(5):975981.

63. Prieto $M L$, Cuellar-Barboza $A B$, Bobo WV, et al. Risk of myocardial infarction and stroke in bipolar disorder: a systematic review and exploratory meta-analysis. Acta Psychiatr Scand. 2014;130(5):342-353.

64. Lin HC, Hsiao FH, Pfeiffer S, Hwang YT, Lee HC. An increased risk of stroke among young schizophrenia patients. Schizophr Res. 2008;101(1-3):234-241.

65. Penninx BW, Lange SM. Metabolic syndrome in psychiatric patients: overview, mechanisms, and implications. Dialogues in clinical neuroscience. 2018;20(1):63.

66. Newcomer JW. Medical risk in patients with bipolar disorder and schizophrenia. The Journal of clinical psychiatry. 2006;67:25-30; discussion 36-42.

67. Goldstein Bl, Carnethon MR, Matthews KA, et al. Major Depressive Disorder and Bipolar Disorder Predispose Youth to Accelerated Atherosclerosis and Early Cardiovascular Disease: A Scientific Statement From the American Heart Association. Circulation. 2015;132(10):965-986.

68. Lorenz MW, Markus HS, Bots ML, Rosvall M, Sitzer M. Prediction of clinical cardiovascular events with carotid intima-media thickness: a systematic review and meta-analysis. Circulation. 2007;115(4):459-467.

69. Sutter FK, Helbig H. Familial retinal arteriolar tortuosity: a review. Surv Ophthalmol. 2003;48(3):245-255.

70. Labelle-Dumais C, Dilworth DJ, Harrington EP, et al. COL4A1 mutations cause ocular dysgenesis, neuronal localization defects, and myopathy in mice and Walker-Warburg syndrome in humans. PLoS Genet. 2011;7(5):e1002062.

71. Schmitt A, Leonardi-Essmann F, Durrenberger PF, et al. Structural synaptic elements are differentially regulated in superior temporal cortex of schizophrenia patients. Eur Arch Psychiatry Clin Neurosci. 2012;262(7):565-577.

72. Rao NP, Arasappa R, Reddy NN, Venkatasubramanian G, Gangadhar BN. Antithetical asymmetry in schizophrenia and bipolar affective disorder: a line bisection study. Bipolar Disord. 2010;12(3):221-229. 
73. Bora E. Differences in cognitive impairment between schizophrenia and bipolar disorder: Considering the role of heterogeneity. Psychiatry and clinical neurosciences. 2016;70(10):424-433.

74. Grover S, Nebhinani N, Chakrabarti S, et al. Comparative study of prevalence of metabolic syndrome in bipolar disorder and schizophrenia from North India. Nord J Psychiatry. 2014;68(1):72-77.

75. Redpath HL, Cooper D, Lawrie SM. Imaging symptoms and syndromes: similarities and differences between schizophrenia and bipolar disorder. Biological psychiatry. 2013;73(6):495-496.

76. Whalley HC, Papmeyer M, Sprooten E, Lawrie SM, Sussmann JE, McIntosh AM. Review of functional magnetic resonance imaging studies comparing bipolar disorder and schizophrenia. Bipolar Disord. 2012;14(4):411-431.

77. Pearlson GD. Etiologic, phenomenologic, and endophenotypic overlap of schizophrenia and bipolar disorder. Annual review of clinical psychology. 2015;11:251-281.

78. Cheung $C Y$, Zheng $Y$, Hsu W, et al. Retinal vascular tortuosity, blood pressure, and cardiovascular risk factors. Ophthalmology. 2011;118(5):812-818.

79. Sasongko MB, Wong TY, Nguyen TT, et al. Retinal Vessel Tortuosity and Its Relation to Traditional and Novel Vascular Risk Markers in Persons with Diabetes. Curr Eye Res. 2016;41(4):551-557.

80. Stokoe N, Turner R. Normal retinal vascular pattern. Arteriovenous ratio as a measure of arterial calibre. The British journal of ophthalmology. 1966;50(1):21.

81. Varner P. Significance of Asymmetric Retinal Vasculature Tortuosity - Report of 10 Consecutive Cases. Acta Scientific Ophthalmology. 2019;2:5.

82. Koh V, Cheung CY, Zheng Y, Wong TY, Wong W, Aung T. Relationship of retinal vascular tortuosity with the neuroretinal rim: the singapore malay eye study. Invest Ophthalmol Vis Sci. 2010;51(7):3736-3741.

83. Nguyen TT, Wang JJ, Wong TY. Retinal vascular changes in pre-diabetes and prehypertension: new findings and their research and clinical implications. Diabetes care. 2007;30(10):2708-2715.

84. Cheung CY, Tay WT, Mitchell P, et al. Quantitative and qualitative retinal microvascular characteristics and blood pressure. J Hypertens. 2011;29(7):1380-1391.

85. Hughes $A D$, Wong $T Y$, Witt $N$, et al. Determinants of retinal microvascular architecture in normal subjects. Microcirculation. 2009;16(2):159-166. 


\section{Supplementary Materials}

\section{Supplementary Figure S1:}

Representative image of retinal image acquisition
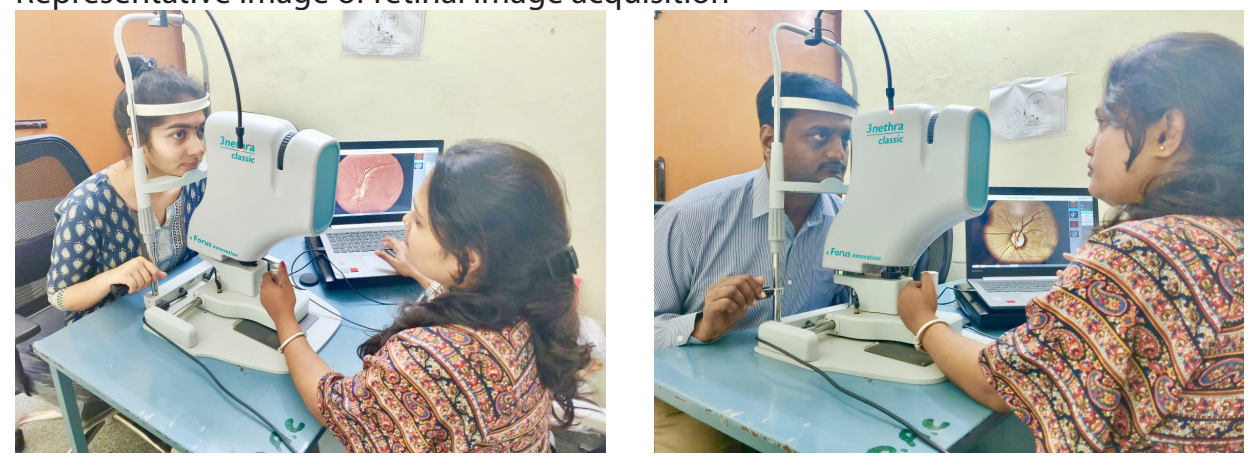

\section{Supplementary Figure S2:}

0.5 to 2 -disc diameter radius zone for calculation of Tortuosity

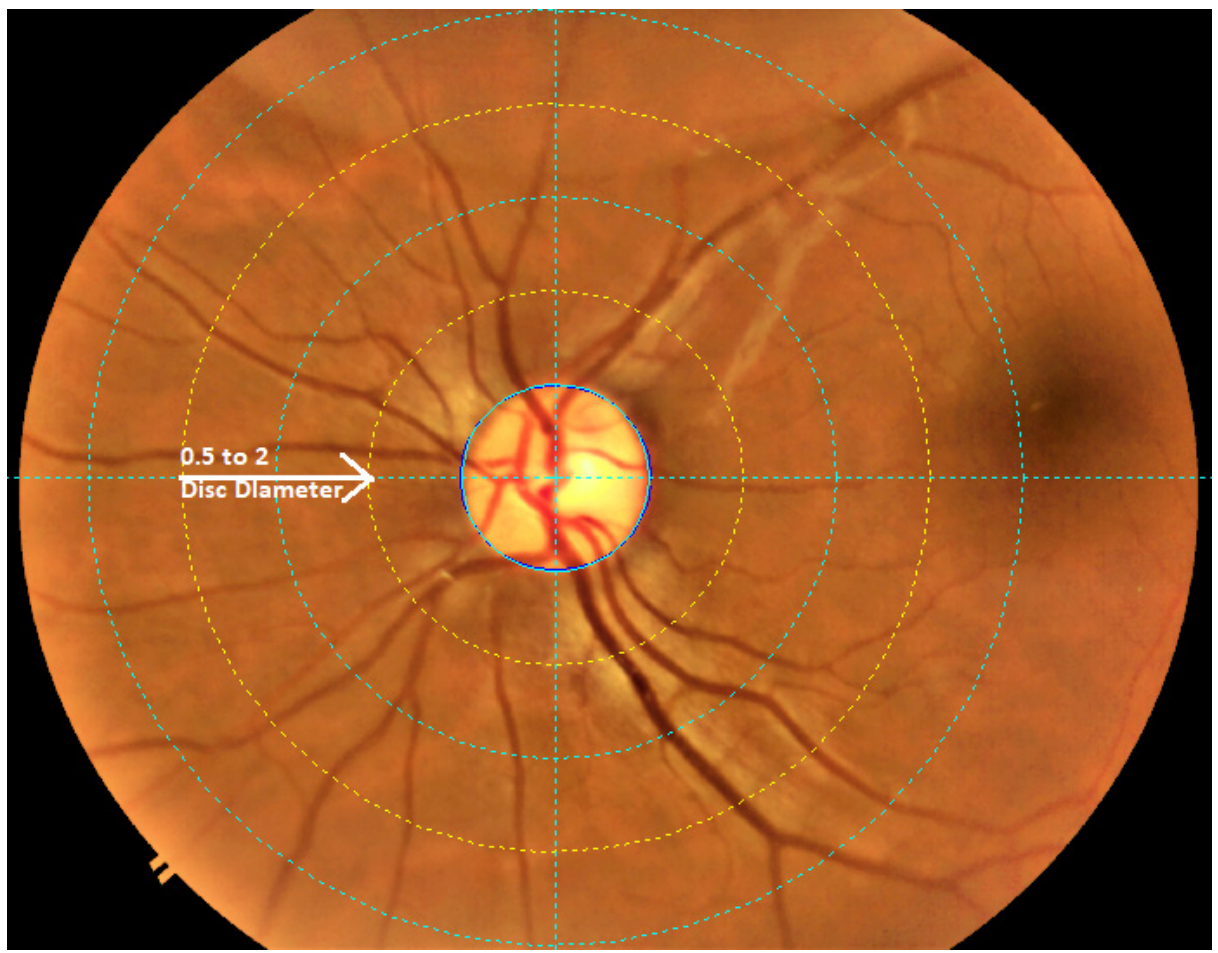


Table S1.

Retinal vascular tortuosity in the three groups after excluding participants who had nicotine dependence

\begin{tabular}{|l|c|c|c|c|c|}
\hline $\begin{array}{l}\text { Retinal } \\
\text { Tortuosity }\end{array}$ & $\begin{array}{c}\text { HV } \\
(\mathbf{n}=\mathbf{7 8})\end{array}$ & $\begin{array}{c}\text { SCZ } \\
(\mathbf{n}=\mathbf{6 8})\end{array}$ & $\begin{array}{c}\text { SCZ } \\
(\mathbf{n = 6 8 )}\end{array}$ & $\begin{array}{c}\text { BD } \\
(\mathbf{n}=\mathbf{8 2})\end{array}$ & $\mathbf{P}$ \\
\hline RVTI & $1.0307 \pm 0.015$ & $1.0271 \pm 0.013$ & $1.0264 \pm 0.012$ & 2.36 & 0.097 \\
\hline RATI & $1.0234 \pm 0.01$ & $1.0312 \pm 0.013$ & $1.0375 \pm 0.019$ & 18.49 & $<0.001^{*}$ \\
\hline
\end{tabular}

SCZ - patients with schizophrenia; BD - patients with bipolar disorder; HV - healthy volunteer; F-ANOVA ; $p$ - Bonferroni post-hoc analysis; RVTI- Average retinal venular tortuosity index; RATI- Average retinal arteriolar tortuosity index; ${ }^{*}$ significant difference

\section{Post Hoc Analysis}

\begin{tabular}{|l|c|c|c|c|c|}
\hline \multirow{2}{*}{$\begin{array}{l}\text { Retinal } \\
\text { Tortuosity }\end{array}$} & \multicolumn{2}{|c|}{ Group } & $\begin{array}{c}\text { Mean } \\
\text { Difference }\end{array}$ & Std. Error & p \\
\hline \multirow{3}{*}{ RVTI } & HV & SCZ & 0.0037 & 0.0022 & 0.298 \\
\cline { 2 - 6 } & SCZ & BD & 0.0043 & 0.0021 & 0.129 \\
\cline { 2 - 6 } & BPAD & BD & 0.0006 & 0.0021 & 1.000 \\
\hline \multirow{3}{*}{ RATI } & HV & SCZ & -0.0078 & 0.0024 & $0.005^{*}$ \\
\cline { 2 - 6 } & SCZ & BD & -0.0141 & 0.0023 & $<0.001^{*}$ \\
\cline { 2 - 6 } & BPAD & BD & -0.0063 & 0.0024 & $0.027^{*}$ \\
\hline
\end{tabular}

SCZ - patients with schizophrenia; BD - patients with bipolar disorder; HV - healthy volunteer; $\mathrm{p}$ - Bonferroni post-hoc analysis; RVTI- Average retinal venular tortuosity index; RATI- Average retinal arteriolar tortuosity index; *Significant difference

Table S2:

Correlation between RATI, RVTI and clinical variables

\begin{tabular}{|c|c|c|c|c|c|}
\hline Clinical variable & N & \multicolumn{2}{|c|}{ RVTI } & \multicolumn{2}{c|}{ RATI } \\
\hline & & $r$ & $p$ & $r$ & $p$ \\
\hline BPRS & 154 & 0.02 & 0.86 & -0.14 & 0.08 \\
\hline YMRS & 152 & 0.15 & 0.07 & 0.01 & 0.94 \\
\hline HDRS & 154 & 0.14 & 0.09 & -0.02 & 0.82 \\
\hline CPZ Equivalent & 107 & 0.11 & 0.26 & -0.17 & 0.86 \\
\hline Age at onset & 127 & 0.06 & 0.50 & 0.03 & 0.71 \\
\hline Duration of illness & 125 & -0.15 & 0.01 & -0.08 & 0.39 \\
\hline
\end{tabular}

RATI- Average retinal arteriolar tortuosity index; RVTI- Average retinal venular tortuosity Index; BPRS- The Brief Psychiatric Rating Scale (BPRS); YMRS- Young Mania Rating Scale (YMRS); HDRS - Hamilton Depression Rating Scale (HDRS); CPZ - Chlorpromazine; $r$ correlation coefficient 
Table S3:

Mean difference between groups and retinal vascular tortuosity on analysis of variance

\begin{tabular}{|l|c|c|c|c|c|}
\hline \multirow{2}{*}{$\begin{array}{l}\text { Retinal } \\
\text { Tortuosity }\end{array}$} & \multicolumn{2}{|c|}{ Group } & $\begin{array}{c}\text { Mean } \\
\text { Difference }\end{array}$ & Std. Error & p \\
\hline \multirow{3}{*}{ RVTI } & HV & SCZ & 0.0033 & 0.0022 & 0.372 \\
\cline { 2 - 6 } & SCZ & BD & 0.0043 & 0.0021 & 0.131 \\
\cline { 2 - 6 } & BPAD & BD & 0.0001 & 0.0021 & 1.000 \\
\hline \multirow{3}{*}{ RATI } & HV & SCZ & -0.0078 & 0.0024 & $0.003^{*}$ \\
\cline { 2 - 6 } & SCZ & BD & -0.0142 & 0.0023 & $<0.001^{*}$ \\
\cline { 2 - 6 } & BPAD & BD & -0.0064 & 0.0023 & $0.017^{*}$ \\
\hline
\end{tabular}

SCZ - patients with schizophrenia; BD - patients with bipolar disorder; HV - healthy volunteer; $\mathrm{p}$ - Bonferroni post-hoc analysis; RVTI- Average retinal venular tortuosity index; RATI- Average retinal arteriolar tortuosity index; $p$ - not controlled for age and sex; *Significant difference 



\section{CHAPTER 4}

\section{RETINAL VASCULAR FRACTAL DIMENSION IN BIPOLAR DISORDER AND SCHIZOPHRENIA}

Abhishek Appaii, Bhargavi Nagendra, Dona Maria Chako, Ananth Padmanabha, Chaitra V Hiremath, Arpitha Jacob, Shivarama Varambally, Muralidharan Kesavan, Ganesan Venkatasubramanian, Shyam Vasudeva Rao, Carroll A.B. Webers, Tos T.J.M. Berendschot, Naren P. Rao JOURNAL OF AFFECTIVE DISORDERS 2019; 259: 98 - 103 



\section{Abstract}

\section{Background:}

Bipolar disorder (BD) and schizophrenia (SCZ), are associated with greater vascular co-morbidities and adverse vascular events. Owing to shared developmental origins and morphology, retinal vasculature is a proxy assessment measure of the cerebral vasculature. Although retinal vascular fractal dimension $\left(D_{f}\right)$, a measure of vascular geometry and complexity of branching, has been shown to be directly associated with cerebrovascular pathology, it has not been examined in SCZ and BD.

\section{Methods:}

We studied 277 participants (92 healthy volunteers, 98 SCZ, and 87 BD) from 18 to 50 years of age. Images were acquired by trained personnel using a non-mydriatic fundus camera and the retinal vascular $D_{f}$ was calculated by the box-counting method using an automated algorithm. The average $D_{f}$ across the left and right eyes were calculated.

\section{Results:}

Both SCZ and BD had significantly increased $D_{f}$ compared to $H V$ despite controlling for possible confounding factors. However, there was no significant difference between $\mathrm{SCZ}$ and $\mathrm{BD}$. These findings suggest abnormal retinal vascular $\mathrm{D}_{f}$ in psychoses.

\section{Limitations:}

The study design was cross sectional, and patients are on medications. Confound of lifestyle factors such as diet and exercise, if any was not controlled. Sub-group analysis between BD-I and BD-II was not performed in view of the small sample.

\section{Conclusions:}

Considering the easy accessibility, affordability, and non-invasive nature of the examination, retinal vascular $D_{f}$ could serve as a surrogate marker for cerebral vascular abnormality and could potentially identify BD and SCZ patients at risk of developing adverse vascular events.

Keywords: Retinal vasculature; Fractal dimension; Fundus; Schizophrenia; Bipolar disorder; Psychoses; Neurodevelopment 


\subsection{INTRODUCTION}

The major psychoses, schizophrenia (SCZ) and bipolar disorder (BD), are associated with increased prevalence of vascular co-morbidities and increased incidence of adverse cerebrovascular events ${ }^{1,2}$. Understandably, examination of cerebral microvascular abnormalities in these disorders has gained considerable interest in the recent past. However, the need for specialized and expensive techniques, and the invasive nature of some of these techniques have posed challenges for the same ${ }^{3}$.

As retinal and cerebral vasculatures share common embryology and have comparable anatomical, physiological, and pathological properties, retinal vasculature is considered an indirect marker of abnormalities in cerebral vasculature ${ }^{4,5}$. Several studies have reported relations of retinal vascular abnormalities with cerebrovascular disorders and neurodegenerative disorders ${ }^{6,7}$. A few studies have examined retinal vascular abnormalities in psychoses. In one of these, authors examined retinal vascular images from participants of the Dunedin birth cohort and reported wider venules in individuals who developed schizophrenia ${ }^{8}$. In another study, those with symptoms of psychosis and their unaffected co-twins had wider venular diameters compared to the healthy, suggesting association of retinal venular diameter with familial vulnerability to psychosis ${ }^{9}$. Compared to SCZ, retinal vascular abnormalities are underexamined in BD; one study reported absence of difference between BD and healthy volunteers (HV) but reported a significant association of the arterio-venular ratio (AVR) with blood pressure and vascular endothelial function in adolescent $\mathrm{BD}^{10}$. Recently, we reported both SCZ and BD patients to have significantly narrower arterioles and wider venules compared to $\mathrm{HV}^{11}$.

All these studies examined retinal vascular calibre. Yet another important structural marker, fractal dimension $\left(D_{f}\right)$, has not been examined in SCZ or BD. Larger blood vessels, including retinal blood vessels, subdivide into smaller branches which in turn also subdivide and so on. This self-similar branching pattern is quantified by a mathematical concept called fractals. Fractals were introduced to ophthalmology ${ }^{12}$ as retinal vasculature is similar on all kinds of scales from the larger vessels coming from the optic disc till the microvasculature near fovea. Hence, this complex branching pattern of retinal vasculature is better quantified by $D_{f}$ than conventional geometrical measures ${ }^{13}$. $D_{f}$ is a single value that indicates the degree of branching complexity of blood vessels ${ }^{14,15}$. $D_{f}$ depends on the number of bifurcations, angles of bifurcations, and 
the length of vessels between two successive bifurcations ${ }^{16}$. A higher $D_{f}$ indicates a greater level of complexity in retinal branching pattern and lower $D_{f}$ indicates absence or decrease in number of branches. Importantly, retinal vascular $D_{f}$ measure is not affected by pulse cycle which may confound the measurement of vascular calibre ${ }^{3}$. Moreover, variations in the ocular and camera magnifications could influence the retinal vessel calibre values but not $D_{f}^{17}$. It is important to note that several studies have reported association of retinal vascular $D_{f}$ with diabetes and diabetic retinopathy, hypertension, cardiovascular disorder, stroke, and dementia ${ }^{18-25}$.

However, despite its significance, retinal vascular $D_{f}$ in $S C Z$ and BD is yet to be examined. Hence, we aimed to investigate retinal vascular $D_{f}$ in $S C Z$ and $B D$. Based on the existing literature, we hypothesized that patients with SCZ and BD would have increased retinal vascular $D_{f}$ when compared to HV. As both $S C Z$ and $B D$ are associated with increased vascular morbidity and have shared pathogenic mechanisms, we also hypothesized that there would be no difference in $D_{f}$ between $S C Z$ and $B D$.

\subsection{METHODOLOGY}

\subsubsection{Study participants}

One hundred patients each with SCZ and BD were recruited from the clinical services of the National Institute of Mental Health and Neurosciences (NIMHANS), Bengaluru, India. One hundred matched healthy volunteers (HV) were also recruited from the same geographical location through flyers and word of mouth. All participants were aged between 18 and 50 years. The patients were examined by a board-certified psychiatrist (BN); and those who met the criteria for SCZ or BD as per the International Classification of disorders $10(\text { ICD-10 })^{26}$ were recruited. Patients with substance abuse or dependence other than nicotine were excluded. Those with concurrent comorbid psychiatric disorders were also excluded. All HV completed self-reported cross cutting symptom measure ${ }^{27}$ and were interviewed by a certified psychiatrist (BN) to rule out Axis I psychiatric diagnoses. Participants with history of hypertension, diabetes, stroke, and trauma or surgery to the eye were excluded from the study. The study was carried out in accordance with the latest version of the Declaration of Helsinki. Written informed consent was obtained from all participants and the study was approved by the institute ethics committee. 


\subsubsection{Clinical assessments}

The severity of clinical symptoms was assessed by a board certified psychiatrist using the Brief Psychiatric Rating Scale (BPRS) in patients with $\mathrm{SCZ}^{28}$, and Young Mania Rating Scale(YMRS) ${ }^{29}$ and Hamilton Depression Rating Scale (HDRS) ${ }^{30}$ in patients with BD. The global severity and functioning was assessed using the Clinical Global Impression (CGI) ${ }^{31}$ and Global Assessment of Functioning (GAF) ${ }^{32}$. To control for the potential confounding effect of systolic blood pressure and body mass index (BMI) on retinal vascular $\mathrm{D}_{\mathrm{f}}$ we measured the same in a subgroup of individuals; systolic blood pressure was measured in $28 \mathrm{SCZ}$ and $57 \mathrm{BD}$ and BMI was measured in $48 \mathrm{HV}, 81 \mathrm{SCZ}$ and $60 \mathrm{BD}$ on the day of acquisition of retinal images.

\subsubsection{Retinal image acquisition}

The procedure of retinal image acquisition was explained to all participants. They were seated in a dark room for approximately $5 \mathrm{~min}$ to enable auto-dilation of the pupil through accommodation. The images were acquired using a non-mydriatic fundus camera, the 3nethra classic by a trained individual. The 3nethra fundus camera illuminates the eye using light flashes to obtain colour images of the fundus. Optic disc centred retinal images of both the eyes were acquired using a valid method described elsewhere ${ }^{33}$.

\subsubsection{Measurement of retinal vascular fractal dimension}

An initial quality check was performed to examine the suitability of images for calculation of the fractal dimension. Twenty-three out of 300 image pairs (left and right eye) were excluded following quality check due to inadequate illumination; the remaining 277 image pairs were considered for analysis. These included 98 SCZ, 87 $B D$, and $92 \mathrm{HV}$. A fully automated software was designed to calculate $D_{f}$ using MATLAB 2018a (The MathWorks Inc, Natick, Massachusetts, USA). The algorithm used to design this customized software was adopted from previous studies and employed the boxcounting method described elsewhere ${ }^{34,35}$. Examination of retinal vascular $D_{f}$ is an advancing field and novel analyses techniques are rapidly emerging ${ }^{36-38}$. We opted for the box-counting method as it is one of the commonly employed methods. 
The following is a brief overview. The image was first enhanced in terms of intensity to aid extraction of the vessels. The acquired retinal images had a spatial resolution of $2048 \times 1536$ pixels and they were suitably scaled for easy calculation of fractal dimension. The measured area was standardized within the region between 0.5 and 2.0-disc diameters from the optic disc. The retinal vessels (both arteries and veins) were automatically traced and segmented to generate a skeletonized image. We calculated the fractal dimension using the box-counting dimension method. In the box counting method, the retinal image was divided into multiple equally sized square boxes. The number of boxes containing the skeletonized line tracing was counted and the process was repeated for different sized squares. The fractal dimension $\left(D_{f}\right)$ was calculated as the gradient of logarithms of the number of boxes and the size of the boxes. Larger values of $D_{f}$ indicate more complex branching patterns. $D_{f}$ was calculated for left and right eyes separately; the average of left and right eye $D_{f}$ was used as the primary outcome measure in the study. The calculation of $\mathrm{D}_{f}$ was completely automated; hence, group bias did not confound the analysis (HV or SCZ or BD).

\subsubsection{Statistical analysis}

The statistical analyses were performed using the Statistical Package for Social Sciences (SPSS) version 25 (SPSS Inc., Chicago, Illinois, USA). The data was found to be normatively distributed on applying the Shapiro Wilk test and hence, parametric tests were applied. The age difference across the three groups was examined using one-way analysis of variance (ANOVA) and the sex distribution using chi-square test. As the age and sex distribution were not similar across the three groups and these were used as covariates for further analyses. Differences in $D_{f}$ across the three groups were examined using analysis of co-variance (ANCOVA) with age and sex as covariates. Bonferroni post-hoc analysis was conducted to examine differences between pairs of groups. To examine the relation between $D_{f}$ and clinical variables, Pearson's correlational analyses were performed for $D_{f}$ with scores on BPRS, YMRS, and HDRS, age at onset of illness, duration of illness, and chlorpromazine equivalent of antipsychotic dose ${ }^{39}$.

To calculate the extent of contribution of age and sex on $D_{f}$ we also conducted linear regression analysis with $D_{f}$ as dependent variable and group, age, and sex as predictor variables. As a subgroup of patients had nicotine dependence, analysis was repeated 
after excluding these patients to avoid the possible confounding effect of nicotine use on retinal vascular $\mathrm{D}_{f}^{40}$. In addition, to rule out the confounding effects of BMI and systolic blood pressure, analysis was also conducted in another sub-group of patients in whom these had been recorded.

\subsection{RESULTS}

\subsubsection{Comparison of demographic variables}

Demographic and clinical variables from the three groups are shown in Table 1. There was a significant difference across the three groups in age and sex distribution. Duration of illness and age at onset of illness were not significantly different in patients with SCZ and $\mathrm{BD}$.

Table 1.

Comparison of demographic and clinical details between the groups.

\begin{tabular}{|l|c|c|c|c|c|}
\hline & $\begin{array}{c}\text { HV } \\
(\mathbf{n = 9 2 )}\end{array}$ & $\begin{array}{c}\text { SCZ } \\
(\mathbf{n = 9 8})\end{array}$ & $\begin{array}{c}\text { BD } \\
(\mathbf{n}=\mathbf{8 7})\end{array}$ & $\mathbf{F / t / \mathbf { X } ^ { \mathbf { 2 } }}$ & $\mathbf{p}$ \\
\hline Age & $30.2 \pm 7.8$ & $32.7 \pm 6$ & $32.9 \pm 6$ & 4.54 & 0.012 \\
\hline Gender ratio (M/F) & $41 / 51$ & $64 / 34$ & $54 / 33$ & 9.48 & 0.009 \\
\hline Age at onset (years) & - & $25.1 \pm 5.3$ & $23.7 \pm 5.9$ & 2.58 & 0.11 \\
\hline $\begin{array}{l}\text { Duration of illness } \\
\text { (in years) }\end{array}$ & - & $7.6 \pm 5.1$ & $9.0 \pm 5.6$ & 2.3 & 0.13 \\
\hline BPRS & - & $28.7 \pm 6.9$ & - & - & - \\
\hline HDRS & - & - & $3.9 \pm 5.3$ & - & - \\
\hline YMRS & - & - & $1.9 \pm 3.1$ & - & - \\
\hline
\end{tabular}

SCZ, patients with schizophrenia; BD, patients with bipolar disorder; HV, healthy volunteer; BPRS, Brief Psychiatric rating scale; HDRS, Hamilton depression rating scale; YMRS-Young's mania rating scale; $F$, analysis of variance; $t$, Independent t test; $X 2$, Chi square test.

\subsubsection{Differences in $D_{f}$ between groups}

On ANCOVA, there was a significant difference across the three groups in left eye $D_{f}$ $(p<0.001)$, right eye $D_{f}(p=0.003)$, and average $D_{f}(p<0.001)$ (Table 2). Further post- 
hoc analysis showed that both $S C Z$ (left eye $D_{f}=0.015$; right eye; $D_{f}=0.006$; average $D_{f}=0.001$ ) and $B D$ (left eye $D_{f}<0.001$; right eye $D_{f}=0.003$; average $D_{f} p<0.001$ ) had significantly higher $\mathrm{D}_{\mathrm{f}}$ compared to $\mathrm{HV}$; however, there was no significant difference between SCZ and BD ( $p>0.05$ ) (Table 3 and Figure S1).

To calculate the extent of contribution of age and sex and to delineate their possible confounding effects on group wise comparisons, regression analyses were conducted with and without age and sex as additional regressors. The group differences were significant in both instances and the regression coefficients were comparable, suggesting that age and sex did not have any significant effects (Table 4). We also conducted a subgroup analysis with a sample of $66 \mathrm{HV}(\mathrm{M}: \mathrm{F}=32: 34$; age $=30.4 \pm$ 6.0 years), $92 \mathrm{SCZ}$ (M:F = 60:32; age $=32.4 \pm 5.3$ years) and $78 \mathrm{BD}(\mathrm{M}: \mathrm{F}=50: 28$; age $=$ $32.53 \pm 5.2$ years $)$ matched on age $(F=2.33 ; p=0.10)$ and $\operatorname{sex}(X 2=5.3 ; p=0.073)$. On ANOVA, there was still a significant difference across the three groups on $D_{f}(F=7.88$, p < 0.001) (details in Supplementary Table S1). As 17 patients (13 SCZ and 4 BD) had nicotine dependence, we compared the groups after excluding these patients to rule out possible confounding effects of nicotine use. There was still a significant difference between groups on left eye $D_{f}$, right eye $D_{f}$ and average $D_{f}$ (details in Supplementary Tables S2A and S2B). In a sub-group of participants, we had measured BMI and recorded blood pressure on the day of retinal image acquisition. ANCOVA and regression analysis with $\mathrm{BMI}$ and blood pressure as a covariate demonstrated that the results were still significant (details in Supplement S3 and Supplementary Tables S4 and S5).

Table 2.

Retinal vascular fractal dimension across the three groups.

\begin{tabular}{|l|c|c|c|c|c|}
\hline $\begin{array}{l}\text { Fractal } \\
\text { dimension }\end{array}$ & $\begin{array}{c}\text { HV } \\
(\mathbf{n = 9 2 )}\end{array}$ & $\begin{array}{c}\text { SCZ } \\
(\mathbf{n = 9 8 )}\end{array}$ & $\begin{array}{c}\text { BD } \\
(\mathbf{n = 8 7})\end{array}$ & F & p \\
\hline Left $\mathrm{D}_{\mathrm{f}}$ & $1.281 \pm 0.096$ & $1.321 \pm 0.093$ & $1.339 \pm 0.01$ & 6.08 & $<0.001$ \\
\hline Right $\mathrm{D}_{\mathrm{f}}$ & $1.266 \pm 0.082$ & $1.31 \pm 0.089$ & $1.316 \pm 0.123$ & 4.05 & 0.003 \\
\hline Average $\mathrm{D}_{\mathrm{f}}$ & $1.273 \pm 0.081$ & $1.316 \pm 0.069$ & $1.327 \pm 0.087$ & 7.52 & $<0.001$ \\
\hline
\end{tabular}

SCZ, patients with schizophrenia; BD, patients with bipolar disorder; HV, healthy volunteer; F, ANCOVA with age and sex as covariates; Left $D_{f}$ left eye fractal dimension; Right $D_{f}$, right eye fractal dimension; $D_{f}$, average fractal dimension. 
Table 3.

Post-hoc analysis showing group differences in retinal vascular fractal dimension.

\begin{tabular}{|l|c|c|c|c|c|}
\hline \multirow{2}{*}{$\begin{array}{l}\text { Fractal } \\
\text { dimension }\end{array}$} & \multicolumn{2}{|c|}{ Group } & $\begin{array}{c}\text { Mean } \\
\text { Difference }\end{array}$ & Std. Error & $p$ \\
\hline \multirow{3}{*}{ Left $_{f}$} & $\mathrm{HV}$ & $\mathrm{SCZ}$ & -0.039 & 0.014 & 0.015 \\
\cline { 2 - 6 } & $\mathrm{HV}$ & $\mathrm{BD}$ & -0.058 & 0.014 & $<0.001$ \\
\cline { 2 - 6 } & $\mathrm{SCZ}$ & $\mathrm{BD}$ & -0.019 & 0.014 & 0.568 \\
\hline \multirow{3}{*}{ Right $\mathrm{D}_{f}$} & $\mathrm{HV}$ & $\mathrm{SCZ}$ & -0.045 & 0.014 & 0.006 \\
\cline { 2 - 6 } & $\mathrm{HV}$ & $\mathrm{BD}$ & -0.05 & 0.015 & 0.003 \\
\cline { 2 - 6 } & $\mathrm{SCZ}$ & $\mathrm{BD}$ & -0.01 & 0.015 & 1.000 \\
\hline \multirow{3}{*}{ Average $\mathrm{D}_{\mathrm{f}}$} & $\mathrm{HV}$ & $\mathrm{SCZ}$ & -0.042 & 0.011 & 0.001 \\
\cline { 2 - 6 } & $\mathrm{HV}$ & $\mathrm{BD}$ & -0.054 & 0.012 & $<0.001$ \\
\cline { 2 - 6 } & $\mathrm{SCZ}$ & $\mathrm{BD}$ & -0.012 & 0.012 & 0.917 \\
\hline
\end{tabular}

SCZ, patients with schizophrenia; BD, patients with bipolar disorder; HV, healthy volunteer; $p$, Bonferroni post-hoc analysis; Left $D_{f}$ left eye fractal dimension; Right $D_{f}$, right eye fractal dimension; $\mathrm{D}_{\mathrm{f}}$, average fractal dimension.

\subsubsection{Relation between clinical variables and retinal vascular $D_{f}$}

Pearson's correlational analysis showed no significant correlation between the $D_{f}$ and clinical variables (BPRS score, YMRS score, HDRS score, age at onset of illness, duration of illness, and CPZ equivalent of antipsychotic dose) ( $p>0.05)$ (Supplementary Table S6).

\subsection{DISCUSSION}

Ours is the first study to examine retinal vascular $\mathrm{D}_{\mathrm{f}}$ in $\mathrm{SCZ}$ and $\mathrm{BD}$ in comparison with $H V$. Results of our study shows increased $D_{f}$ in both BD and SCZ when compared to HV. As hypothesized, there was no significant difference between SCZ and BD in the same. Importantly, the findings remained significant even after controlling for potential confounding factors. There was no significant relation with clinical severity suggesting the possibility that $D_{f}$ may be independent of ongoing psychopathology.

Our findings further add to the existing research demonstrating abnormal retinal 
vascular calibre in $S C Z$ and $B D^{9,11,41}$. We sought to examine retinal vascular $D_{f}$ as several previous studies have reported that the geometric parameters of retinal vasculature, such as the bifurcation angle, number of bifurcations, and length to diameter ratio, are also related to vascular disease processes and could prove to be potential markers of microvascular pathology ${ }^{42,43}$. Although the measurement of retinal vascular $D_{f}$ is more complicated and challenging, it offers several advantages ${ }^{24}$; (a) It is not influenced by the phase of the pulse cycle; pulse to pulse variations may pose problems during vascular calibre measurement (b) It is also independent of other confounding factors like axial length and camera magnification that could influence retinal vessel calibre values (c) $D_{f}$ measurement does not involve assessing individual vessels unlike vessel calibre ${ }^{3,17,44}$. Hence, $D_{f}$ is considered a suitable measure to study individuals longitudinally and across centres in multicentric studies.

Table 4.

Mean difference of retinal fractal dimension between groups adjusted for age and sex

\begin{tabular}{|c|c|c|c|c|c|c|}
\hline \multirow{2}{*}{ Variable } & \multirow{2}{*}{\multicolumn{2}{|c|}{ Group }} & \multicolumn{2}{|c|}{ Not adjusted for age and sex } & \multicolumn{2}{|c|}{ Adjusted for age and sex } \\
\hline & & & $\beta(95 \% \mathrm{Cl})$ & $\mathbf{p}$ & $\beta(95 \% \mathrm{Cl})$ & $\mathbf{p}$ \\
\hline \multirow{3}{*}{ Left $D_{f}$} & $\mathrm{HV}$ & SCZ & $\begin{array}{c}0.192 \\
\text { (0.012 to } 0.067)\end{array}$ & 0.005 & $\begin{array}{c}0.234 \\
(0.02 \text { to } 0.076)\end{array}$ & 0.001 \\
\hline & $\mathrm{HV}$ & $\mathrm{BD}$ & $\begin{array}{c}0.274 \\
(0.03 \text { to } 0.086)\end{array}$ & $<0.001$ & $\begin{array}{c}0.312 \\
\text { (0.037 to } 0.095)\end{array}$ & $<0.001$ \\
\hline & $\mathrm{SCZ}$ & $\mathrm{BD}$ & $\begin{array}{c}0.088 \\
(-0.009 \text { to } 0.046) \\
\end{array}$ & 0.189 & $\begin{array}{c}0.085 \\
(-0.01 \text { to } 0.046)\end{array}$ & 0.199 \\
\hline \multirow{3}{*}{ Right $D_{f}$} & $\mathrm{HV}$ & SCZ & $\begin{array}{c}0.212 \\
(0.017 \text { to } 0.073)\end{array}$ & 0.002 & $\begin{array}{c}0.234 \\
(0.02 \text { to } 0.079)\end{array}$ & 0.001 \\
\hline & $\mathrm{HV}$ & $\mathrm{BD}$ & $\begin{array}{c}0.230 \\
(0.021 \text { to } 0.079)\end{array}$ & 0.001 & $\begin{array}{c}0.249 \\
(0.024 \text { to } 0.084)\end{array}$ & $<0.001$ \\
\hline & SCZ & $\mathrm{BD}$ & $\begin{array}{c}0.024 \\
(-0.024 \text { to } 0.034)\end{array}$ & 0.719 & $\begin{array}{c}0.022 \\
(-0.024 \text { to } 0.034)\end{array}$ & 0.774 \\
\hline \multirow{3}{*}{$\begin{array}{l}\text { Average } \\
D_{f}\end{array}$} & $\mathrm{HV}$ & SCZ & $\begin{array}{c}0.247 \\
\text { (0.02 to } 0.065)\end{array}$ & $<0.001$ & $\begin{array}{c}0.285 \\
\text { (0.026 to } 0.072)\end{array}$ & $<0.001$ \\
\hline & $\mathrm{HV}$ & $\mathrm{BD}$ & $\begin{array}{c}0.307 \\
\text { (0.031 to } 0.077)\end{array}$ & $<0.001$ & $\begin{array}{c}0.342 \\
\text { (0.037 to } 0.084)\end{array}$ & $<0.001$ \\
\hline & SCZ & $\mathrm{BD}$ & $\begin{array}{c}0.068 \\
(-0.011 \text { to } 0.035)\end{array}$ & 0.306 & $\begin{array}{c}0.065 \\
(-0.011 \text { to } 0.034)\end{array}$ & 0.323 \\
\hline
\end{tabular}

$\mathrm{SCZ}$, patients with schizophrenia; $\mathrm{BD}$, patients with bipolar disorder; HV, healthy volunteer; $\beta$, regression coefficient, $95 \% \mathrm{Cl}, 95 \%$ confidence interval; Left $D_{f^{\prime}}$ left eye fractal dimension; Right $D_{f^{\prime}}$ right eye fractal dimension; $D_{f}$ average fractal dimension. 
Several studies have reported association of increased $D_{f}$ with systemic and cerebrovascular pathologies; increased $D_{f}$ is independently associated with lacunar stroke after adjusting for age, sex, other vascular risk factors ${ }^{18}$, diabetes ${ }^{45}$, and early diabetic retinopathy ${ }^{36}$. However, few studies have reported discrepant findings ${ }^{46,47}$. As $D_{f}$ varies significantly based on the method used for analysis, differences in technique could account for these discrepancies ${ }^{24}$. The finding of a positive association between retinal vascular $D_{f}$ and white matter hyperintensities provides direct evidence that retinal vascular $D_{f}$ could be a proxy measure of cerebral vasculature abnormalities ${ }^{48}$. In the background of these studies, our findings could have important implications in SCZ and BD. In conjunction with several other studies along similar lines of research 1,2,11,41,49-52, our findings of altered $D_{f}$ suggest increased risk of adverse vascular events in SCZ and BD. While all patients with BD and SCZ are at risk of developing an adverse vascular event, a few may be at greater risk and it is important to identify these individuals to initiate preventive interventions. Interestingly, retinal vascular $D_{f}$ is shown to be associated with increased risk of adverse vascular events in previous studies ${ }^{18,36,45}$. Considering the affordability and easy accessibility of retinal imaging, retinal microvascular $D_{f}$ examination could serve as a potential screening tool to identify individuals at risk for adverse vascular events. Future studies need to prospectively examine whether retinal vascular $D_{f}$ has the potential to identify individuals with $S C Z$ and $B D$ at greater risk of development of adverse vascular events.

The reason for increased retinal vascular $D_{f}$ in $B D$ and $S C Z$ is not completely known at this stage. An important factor influencing the retinal vascular branching pattern is tissue hypoxia. Optimally timed hypoxia is critical during normal development of retinal vasculature and tissue architecture, but ill-timed hypoxia can result in the pathological changes seen in proliferative diabetic retinopathy, retinopathy of prematurity, and wet form of age-related macular degeneration ${ }^{53}$. Thus, an increased $D_{f}$ could result from either early developmental or late life causes. The underlying mechanisms for increased $D_{f}$ in SCZ and BD are not completely known. Considering the increased prevalence of metabolic syndrome and adverse vascular events in $\mathrm{SCZ}$ and $\mathrm{BD}^{1,2}$, it is possible that these adverse metabolic risk factors remodel the retinal vascular pattern. However, perinatal hypoxia which has been implicated in psychoses ${ }^{54,55}$ could also have influenced the retinal vascular branching pattern. Our study being cross-sectional, it is not possible to rule out either of these reasons. A longitudinal study using a birth cohort could provide further insights. 
Several studies in the recent past have suggested shared risk factors and considerable overlap between pathophysiological processes in $\mathrm{SCZ}$ and $\mathrm{BD}^{56}$. Considering the common developmental origin of these disorders and the significant vascular comorbidity in both, we expected similarities in retinal vascular $D_{f}$ also. Previous studies have reported considerable overlap between BD-I and SCZ in neuroimaging, electrophysiological measures, and susceptibility genes ${ }^{56,57}$. Hence, our finding of no significant difference between $S C Z$ and $B D$ in $D_{f}$ is in accordance with the recent literature suggesting overlap between the two disorders. However, future studies are required as our recent study suggested significant difference between SCZ and BD in retinal vascular calibre ${ }^{11}$. We did not find any relation between retinal vascular $D_{f}$ and severity of clinical variables. However, as all patients were on medications and the study design was cross sectional, our findings need to be considered preliminary and longitudinal studies are required to understand whether the abnormalities in retinal vascular $D_{f}$ are progressive or not.

\subsubsection{Limitations}

Our findings need to be interpreted in the background of a few limitations. All patients were on pharmacological treatment and the effects of medications on $D_{f}$ is not known. $80(82 \%)$ out of 98 SCZ patients and 48 (55\%) out of 87 BD patients were taking atypical antipsychotic medications. As atypical antipsychotics are associated with increased metabolic risk in $\mathrm{BD}$ and $\mathrm{SCZ}^{58,59}$ one cannot rule out the confounding effect of these medications on retinal vascular $D_{f}$ To examine the potential confounding effect of these medications, we examined the relation between retinal vascular $D_{f}$ and $C P Z$ equivalents of antipsychotic medications using Pearson's correlation. Similarly, we examined the correlation between retinal vascular $D_{f}$ and duration of antipsychotic therapy. There was neither a significant correlation with antipsychotic dose (left $D_{f}: r=0.02, p=$ 0.85; right $D_{f}: r=-0.14, p=0.12$; Average $D_{f}: r=-0.08, p=0.36$ ) nor with duration of treatment (left $D_{f}: r=0.02, p=0.82$; right $D_{f}: r=-0.05, p=0.53$; Average $D_{f}: r=-0.02, p$ $=0.78$ ) suggesting absence of significant confounding effect. Examining drug-naive patients could overcome this limitation and needs to be considered in future studies. As the participants were young, we excluded participants with hypertension, diabetes, and chronic renal disease based solely on history. Hence, sub clinical (pre-diabetic or pre-hypertensive) or undiagnosed hypertension/diabetes may have been missed ${ }^{60,61}$. However, we had measured BMI and blood pressure on the day of acquisition of images in a sub-sample and the results remained significant on analysing this sub- 
sample alone. Future studies need to consider recording blood pressure, fasting blood glucose, renal functions, and life style factors such as diet and exercise to complement image acquisition. Future studies also need to consider larger samples as the current sample was inadequate to perform sub-group analyses (e.g., BD-I vs BD-II vs SCZ; BD with psychotic symptoms vs $\mathrm{BD}$ without psychotic symptoms vs $\mathrm{SCZ}$ etc.). As branching patterns of retinal arteries and veins are similar, and to avoid possible human error, we summarized the entire complexity of the retinal vascular structure into a single value of retinal vascular $D_{f}$ Future studies may consider examining the $D_{f}$ of arteries and veins separately.

\subsection{Conclusion}

This germinal study of retinal vascular $\mathrm{D}_{f}$ in $\mathrm{SCZ}$ and $\mathrm{BD}$ suggests increased complexity of the retinal microvasculature branching pattern in $\mathrm{SCZ}$ and $\mathrm{BD}$ when compared to $\mathrm{HV}$. There was no significant difference between $\mathrm{SCZ}$ and BD further supporting the shared pathophysiology and comorbidity in these disorders. Further prospective studies are needed to confirm these findings. However, these preliminary findings provide strong rationale to further examine retinal vascular fractal dimension in SCZ and $\mathrm{BD}$. Considering the easy accessibility, non-invasive nature of examination, and affordability, the examination of retinal vascular $D_{f}$ could serve as a surrogate marker for abnormalities in cerebral vasculature. The findings of this preliminary study examining the retinal vascular $D_{f}$ in $S C Z$ and $B D$ need to be replicated in an independent sample for definitive scientific validation. If shown to be of predictive utility in future longitudinal studies, the examination of $D_{f}$ has the potential to identify BD and SCZ patients at risk of developing adverse vascular events. 


\section{References}

1. Goldstein BI. Bipolar Disorder and the Vascular System: Mechanisms and New Prevention Opportunities. Can J Cardiol. 2017;33(12):1565-1576.

2. Correll CU, Solmi $M$, Veronese $N$, et al. Prevalence, incidence and mortality from cardiovascular disease in patients with pooled and specific severe mental illness: a large-scale meta-analysis of 3,211,768 patients and 113,383,368 controls. World psychiatry: official journal of the World Psychiatric Association (WPA). 2017;16(2):163180.

3. Lavina B. Brain Vascular Imaging Techniques. Int J Mol Sci. 2016;18(1).

4. Wong TY, Klein R, Klein BE, Tielsch JM, Hubbard L, Nieto FJ. Retinal microvascular abnormalities and their relationship with hypertension, cardiovascular disease, and mortality. Surv Ophthalmol. 2001;46(1):59-80.

5. Patton N, Aslam T, Macgillivray T, Pattie A, Deary IJ, Dhillon B. Retinal vascular image analysis as a potential screening tool for cerebrovascular disease: a rationale based on homology between cerebral and retinal microvasculatures. Journal of anatomy. 2005;206(4):319-348.

6. Cabrera DeBuc D, Somfai GM, Koller A. Retinal microvascular network alterations: potential biomarkers of cerebrovascular and neural diseases. American journal of physiology Heart and circulatory physiology. 2017;312(2):H201-H212.

7. Moss HE. Retinal Vascular Changes are a Marker for Cerebral Vascular Diseases. Curr Neurol Neurosci Rep. 2015;15(7):40.

8. Meier MH, Shalev I, Moffitt TE, et al. Microvascular abnormality in schizophrenia as shown by retinal imaging. The American journal of psychiatry. 2013;170(12):14511459.

9. Meier MH, Gillespie NA, Hansell NK, et al. Retinal microvessels reflect familial vulnerability to psychotic symptoms: A comparison of twins discordant for psychotic symptoms and controls. Schizophr Res. 2015;164(1-3):47-52. 
10. Naiberg MR, Hatch JK, Selkirk $B$, et al. Retinal photography: $A$ window into the cardiovascular-brain link in adolescent bipolar disorder. Journal of affective disorders. 2017;218:227-237.

11. Appaji A, Nagendra B, Chako DM, et al. Retinal vascular abnormalities in schizophrenia and bipolar disorder: A window to the brain. Bipolar Disord. 2019(Apr 22. [Epub ahead of print]).

12. Family F, Masters BR, Platt DE. Fractal pattern formation in human retinal vessels. Physica D: Nonlinear Phenomena. 1989;38(1-3):98-103.

13. Mainster MA. The fractal properties of retinal vessels: embryological and clinical implications. Eye (London, England). 1990;4 ( Pt 1):235-241.

14. Lim SW, Cheung N, Wang JJ, et al. Retinal vascular fractal dimension and risk of early diabetic retinopathy: A prospective study of children and adolescents with type 1 diabetes. Diabetes Care. 2009;32(11):2081-2083.

15. Masters BR. Fractal analysis of the vascular tree in the human retina. Annu Rev Biomed Eng. 2004;6:427-452.

16. Liew G, Wang JJ, Cheung N, et al. The retinal vasculature as a fractal: methodology, reliability, and relationship to blood pressure. Ophthalmology. 2008;115(11):19511956.

17. Cheung N, Tikellis G, Saw SM, et al. Relationship of axial length and retinal vascular caliber in children. American journal of ophthalmology. 2007;144(5):658-662.

18. Cheung N, Liew G, Lindley Rl, et al. Retinal fractals and acute lacunar stroke. Annals of neurology. 2010;68(1):107-111.

19. Doubal FN, MacGillivray TJ, Patton N, Dhillon B, Dennis MS, Wardlaw JM. Fractal analysis of retinal vessels suggests that a distinct vasculopathy causes lacunar stroke. Neurology. 2010;74(14):1102-1107.

20. McGrory S, Cameron JR, Pellegrini $E$, et al. The application of retinal fundus camera imaging in dementia: A systematic review. Alzheimer's \& dementia (Amsterdam, Netherlands). 2017;6:91-107.

21. Kim DH, Newman $A B$, Hajjar l, et al. Retinal microvascular signs and functional loss in older persons: The cardiovascular health study. Stroke. 2011;42(6):1589-1595. 
22. Lesage SR, Mosley TH, Wong TY, et al. Retinal microvascular abnormalities and cognitive decline: the ARIC 14-year follow-up study. Neurology. 2009;73(11):862-868.

23. Wong $T Y$, Klein $R$, Sharrett $A R$, et al. Retinal microvascular abnormalities and cognitive impairment in middle-aged persons: the Atherosclerosis Risk in Communities Study. Stroke. 2002;33(6):1487-1492.

24. Huang F, Dashtbozorg B, Zhang J, et al. Reliability of Using Retinal Vascular Fractal Dimension as a Biomarker in the Diabetic Retinopathy Detection. Journal of ophthalmology. 2016;2016:6259047.

25. Popovic N, Radunovic M, Badnjar J, Popovic T. Fractal dimension and lacunarity analysis of retinal microvascular morphology in hypertension and diabetes. Microvascular research. 2018;118:36-43.

26. WHO. The ICD-10 Classification of Mental and Behavioural Disorders: Clinical descriptions and diagnostic guidelines. Vol 1: World Health Organization; 1992.

27. Narrow WE, Clarke DE, Kuramoto SJ, et al. DSM-5 field trials in the United States and Canada, Part III: development and reliability testing of a cross-cutting symptom assessment for DSM-5. The American journal of psychiatry. 2013;170(1):71-82.

28. Overall JE, Gorham DR. The brief psychiatric rating scale. Psychological reports. 1962;10(3):799-812.

29. Young RC, Biggs JT, Ziegler VE, Meyer DA. A rating scale for mania: reliability, validity and sensitivity. Br J Psychiatry. 1978;133:429-435.

30. Hamilton M. A rating scale for depression. J Neurol Neurosurg Psychiatry. 1960;23:5662.

31. Busner J, Targum SD. The clinical global impressions scale: applying a research tool in clinical practice. Psychiatry (Edgmont). 2007;4(7):28-37.

32. Jones SH, Thornicroft G, Coffey M, Dunn G. A brief mental health outcome scalereliability and validity of the Global Assessment of Functioning (GAF). Br J Psychiatry. 1995;166(5):654-659.

33. Nguyen TT, Islam FM, Farouque HM, et al. Retinal vascular caliber and brachial flowmediated dilation: the Multi-Ethnic Study of Atherosclerosis. Stroke; a journal of cerebral circulation. 2010;41(7):1343-1348. 
34. Cheung CY, Thomas GN, Tay W, et al. Retinal vascular fractal dimension and its relationship with cardiovascular and ocular risk factors. American journal of ophthalmology. 2012;154(4):663-674 e661.

35. Zhu P, Huang F, Lin F, et al. The relationship of retinal vessel diameters and fractal dimensions with blood pressure and cardiovascular risk factors. PLoS One. 2014;9(9):e106551.

36. Cheung N, Donaghue KC, Liew G, et al. Quantitative assessment of early diabetic retinopathy using fractal analysis. Diabetes Care. 2009;32(1):106-110.

37. Talu S, Calugaru DM, Lupascu CA. Characterisation of human non-proliferative diabetic retinopathy using the fractal analysis. Int J Ophthalmol. 2015;8(4):770-776.

38. Kostic M, Bates NM, Milosevic N, et al. Investigating the fractal dimension of the foveal microvasculature in relation to the morphology of the foveal avascular zone and to the macular circulation in patients with Type 2 diabetes mellitus. Frontiers in physiology. 2018;9:1233.

39. Woods SW. Chlorpromazine equivalent doses for the newer atypical antipsychotics. The Journal of clinical psychiatry. 2003.

40. Yanagi M, Misumi M, Kawasaki R, et al. Is the association between smoking and the retinal venular diameter reversible following smoking cessation? Invest Ophthalmol Vis Sci. 2014;55(1):405-411.

41. Meier MH, Hill ML, Breitborde NJK. Retinal Imaging: A New Tool for Studying Underlying Liability to Cardiovascular Disease in Schizophrenia. Curr Psychiatry Rev. 2016;12(4):326-334.

42. Witt $N$, Wong $T Y$, Hughes $A D$, et al. Abnormalities of retinal microvascular structure and risk of mortality from ischemic heart disease and stroke. Hypertension. 2006;47(5):975981.

43. Patton N, Pattie A, MacGillivray $T$, et al. The association between retinal vascular network geometry and cognitive ability in an elderly population. Invest Ophthalmol Vis Sci. 2007;48(5):1995-2000.

44. Knudtson M, Klein B, Klein R, et al. Variation associated with measurement of retinal vessel diameters at different points in the pulse cycle. British journal of ophthalmology. 2004;88(1):57-61. 
45. Yau JW, Kawasaki R, Islam FM, et al. Retinal fractal dimension is increased in persons with diabetes but not impaired glucose metabolism: the Australian Diabetes, Obesity and Lifestyle (AusDiab) study. Diabetologia. 2010;53(9):2042-2045.

46. Aliahmad B, Kumar DK, Hao H, et al. Zone specific fractal dimension of retinal images as predictor of stroke incidence. TheScientificWorldJournal. 2014;2014:467462.

47. KawasakiR, CheAzemin MZ,KumarDK, etal. Fractaldimension of the retinalvasculature and risk of stroke: a nested case-control study. Neurology. 2011;76(20):1766-1767.

48. van de Kreeke JA, Nguyen HT, Konijnenberg $E$, et al. Retinal and Cerebral Microvasculopathy: Relationships and Their Genetic Contributions. Invest Ophthalmol Vis Sci. 2018;59(12):5025-5031.

49. Hudson CJ, Lin A, Cogan S, Cashman F, Warsh JJ. The niacin challenge test: clinical manifestation of altered transmembrane signal transduction in schizophrenia? Biol Psychiatry. 1997;41(5):507-513.

50. Mathew RJ, Wilson WH, Tant SR, Robinson L, Prakash R. Abnormal resting regional cerebral blood flow patterns and their correlates in schizophrenia. Arch Gen Psychiatry. 1988;45(6):542-549.

51. Rubin E, Sackeim HA, Prohovnik I, Moeller JR, Schnur DB, Mukherjee S. Regional cerebral blood flow in mood disorders: IV. Comparison of mania and depression. Psychiatry Res. 1995;61(1):1-10.

52. Sun C, Wang J, Mackey DA, Wong TY. Retinal vascular caliber: systemic, environmental, and genetic associations. Surv Ophthalmol. 2009;54(1):74-95.

53. Grimm C, Willmann G. Hypoxia in the eye: a two-sided coin. High Alt Med Biol. 2012;13(3):169-175.

54. Brixey SN, Gallagher BJ, 3rd, McFalls JA, Jr., Parmelee LF. Gestational and neonatal factors in the etiology of schizophrenia. J Clin Psychol. 1993;49(3):447-456.

55. Clarke MC, Harley M, Cannon M. The role of obstetric events in schizophrenia. Schizophr Bull. 2006;32(1):3-8.

56. Craddock N, Owen MJ. The Kraepelinian dichotomy - going, going... but still not gone. Br J Psychiatry. 2010;196(2):92-95. 
57. Tamminga CA, Ivleva El, Keshavan MS, et al. Clinical phenotypes of psychosis in the Bipolar-Schizophrenia Network on Intermediate Phenotypes (B-SNIP). The American journal of psychiatry. 2013;170(11):1263-1274.

58. Vancampfort D, Vansteelandt K, Correll CU, et al. Metabolic syndrome and metabolic abnormalities in bipolar disorder: a meta-analysis of prevalence rates and moderators. American Journal of Psychiatry. 2013;170(3):265-274.

59. Zhang Y, Liu Y, Su Y, et al. The metabolic side effects of 12 antipsychotic drugs used for the treatment of schizophrenia on glucose: a network meta-analysis. BMC psychiatry. 2017;17(1):373.

60. Nguyen TT, Wang JJ, Wong TY. Retinal vascular changes in pre-diabetes and prehypertension: new findings and their research and clinical implications. Diabetes Care. 2007;30(10):2708-2715.

61. Benitez-Aguirre P, Craig ME, Sasongko MB, et al. Retinal vascular geometry predicts incident retinopathy in young people with type 1 diabetes: a prospective cohort study from adolescence. Diabetes Care. 2011;34(7):1622-1627. 


\section{Supplementary Materials}

Figure S1.

Box plot of three groups depicting average fractal dimensions

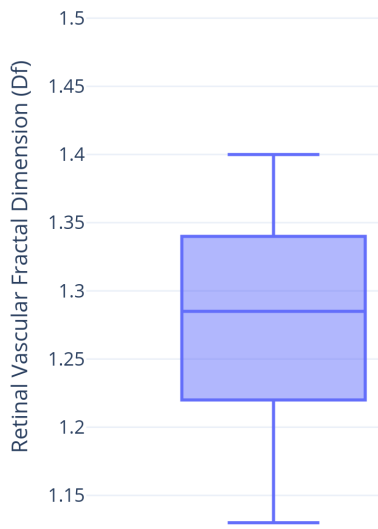

Healthy Volunteers

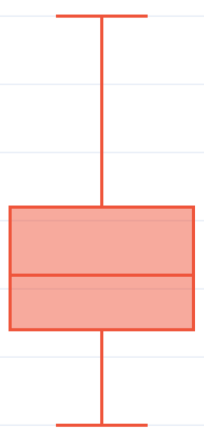

Schizophrenia

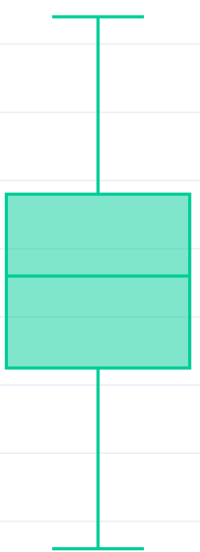

Bipolar Disorder

\section{Supplementary Table S1.}

Retinal vascular fractal dimension across the three groups in a sub-sample matched for age and sex

\begin{tabular}{|l|c|c|c|c|c|}
\hline $\begin{array}{l}\text { Retinal } \\
\text { fractal } \\
\text { dimension }\end{array}$ & $\begin{array}{c}\text { HV } \\
(\mathbf{n}=\mathbf{6 6})\end{array}$ & $\begin{array}{c}\text { SCZ } \\
(\mathbf{n}=\mathbf{9 2})\end{array}$ & $\begin{array}{c}\text { BD } \\
(\mathbf{n = 7 8})\end{array}$ & $\mathbf{F}$ & $\mathbf{p}$ \\
\hline Left $\mathrm{D}_{\mathrm{f}}$ & $1.288 \pm 0.090$ & $1.320 \pm 0.088$ & $1.341 \pm 0.103$ & 5.66 & 0.004 \\
\hline Right $\mathrm{D}_{\mathrm{f}}$ & $1.268 \pm 0.081$ & $1.312 \pm 0.089$ & $1.316 \pm 0.128$ & 4.80 & 0.009 \\
\hline Average $\mathrm{D}_{\mathrm{f}}$ & $1.278 \pm 0.077$ & $1.316 \pm 0.067$ & $1.328 \pm 0.09$ & 7.88 & $<0.001$ \\
\hline
\end{tabular}

$\mathrm{SCZ}$, patients with schizophrenia; $\mathrm{BD}$, patients with bipolar disorder; HV, healthy volunteer; F, ANOVA; $p$, Bonferroni post-hoc analysis; Left Dv, left eye fractal dimension; Right $D_{f}$, right eye fractal dimension; $D_{f}$ - average fractal dimension. 


\section{Supplementary Table S2A.}

Retinal vascular fractal dimension in the three groups after excluding participants who had nicotine dependence

\begin{tabular}{|l|c|c|c|c|c|}
\hline $\begin{array}{l}\text { Retinal } \\
\text { fractal } \\
\text { dimension }\end{array}$ & $\begin{array}{c}\text { HV } \\
(\mathbf{n = 9 2})\end{array}$ & $\begin{array}{c}\text { SCZ } \\
(\mathbf{n}=\mathbf{8 5})\end{array}$ & $\begin{array}{c}\text { BD } \\
(\mathbf{n = 8 3})\end{array}$ & $\mathbf{F}$ & $\mathbf{p}$ \\
\hline Left $\mathrm{D}_{\mathrm{f}}$ & $1.281 \pm 0.096$ & $1.324 \pm 0.093$ & $1.0339 \pm 0.01$ & 8.74 & $<0.001$ \\
\hline Right $\mathrm{D}_{\mathrm{f}}$ & $1.266 \pm 0.082$ & $1.309 \pm 0.086$ & $1.319 \pm 0.13$ & 7.34 & 0.001 \\
\hline Average $\mathrm{D}_{\mathrm{f}}$ & $1.273 \pm 0.081$ & $1.317 \pm 0.067$ & $1.329 \pm 0.087$ & 12.24 & $<0.001$ \\
\hline
\end{tabular}

$\mathrm{SCZ}$, patients with schizophrenia; $\mathrm{BD}$, patients with bipolar disorder; HV, healthy volunteer; $F$, ANOVA; $p$, Bonferroni post-hoc analysis; Left $D_{f^{\prime}}$ left eye fractal dimension; Right $D_{f^{\prime}}$ right eye fractal dimension; Dv - average fractal dimension.

Table S2B:

Post Hoc Analysis of fractal dimension in the three groups after excluding participants who had nicotine dependence

\begin{tabular}{|l|c|c|c|c|c|}
\hline $\begin{array}{l}\text { Retinal } \\
\text { fractal } \\
\text { dimension }\end{array}$ & \multicolumn{2}{|c|}{ Group } & Mean Difference & Std. Error & p \\
\hline \multirow{4}{*}{ Left $D_{f}$} & HV & SCZ & -0.04 & 0.014 & 0.01 \\
\cline { 2 - 6 } & $H V$ & BD & -0.058 & 0.015 & $<0.001$ \\
\cline { 2 - 6 } & SCZ & BD & -0.015 & 0.015 & 0.893 \\
\hline \multirow{4}{*}{ Right $D_{f}$} & HV & SCZ & -0.044 & 0.014 & 0.011 \\
\cline { 2 - 6 } & HV & BD & -0.054 & 0.015 & 0.001 \\
\cline { 2 - 6 } & SCZ & BD & -0.001 & 0.015 & 1.000 \\
\hline \multirow{3}{*}{ Average $D_{f}$} & HV & SCZ & -0.043 & 0.012 & 0.001 \\
\cline { 2 - 6 } & HV & BD & -0.056 & 0.012 & $<0.001$ \\
\cline { 2 - 6 } & SCZ & BD & -0.013 & 0.012 & 0.914 \\
\hline
\end{tabular}

$\mathrm{SCZ}$, patients with schizophrenia; $\mathrm{BD}$, patients with bipolar disorder; HV, healthy volunteer; F, ANOVA; p, Bonferroni post-hoc analysis; Left $D_{f}$ left eye fractal dimension; Right $D_{f}$, right eye fractal dimension; $D_{f}$ - average fractal dimension. 


\section{Supplement S3:}

Analysis between groups with BMI as covariate

ANCOVA was performed on a subgroup HV and patients of which BMI was measured (48 HV, $81 \mathrm{SCZ}$ and $60 \mathrm{BD}$ ). The results were still significant after adding BMI as covariate for right eye $D_{f}(H V: 1.263 \pm 0.088 ; S C Z: 1.306 \pm 0.080 ; B D: 1.326 \pm 0.134 ; F=4.11 ; p=$ $0.007)$ and average eye $D_{f}(H V: 1.275 \pm 0.087 ; S C Z: 1.310 \pm 0.066 ; B D: 1.33 \pm 0.093 ; F=$ 3.87, $p=0.01$ ) but it was not significant for left eye $D_{f}$ among the three groups (HV: $1.287 \pm 0.104 ; S C Z: 1.314 \pm 0.093 ; B D: 1.329 \pm 0.104, F=1.72, p=0.165)$.

\section{Supplementary Table S4.}

Details of regression coefficient between groups with BMI as additional regresso

\begin{tabular}{|c|c|c|c|c|c|}
\hline \multirow[t]{2}{*}{ Average Df } & \multicolumn{2}{|c|}{ Unstandardized Coefficients } & \multirow{2}{*}{$\begin{array}{c}\text { Standardized } \\
\text { Coefficients } \\
\text { Beta }\end{array}$} & \multirow[t]{2}{*}{$\mathbf{t}$} & \multirow[t]{2}{*}{ Sig. } \\
\hline & B & Std. Error & & & \\
\hline (Constant) & 1.293 & 0.033 & & 39.714 & $<.001$ \\
\hline Group & 0.026 & 0.008 & 0.240 & 3.322 & 0.001 \\
\hline $\mathrm{BMI}$ & -0.001 & 0.001 & -0.031 & -0.433 & 0.665 \\
\hline
\end{tabular}

\section{Supplementary Table S5.}

Details of regression coefficient between groups with systolic blood pressure as covariates $(\mathrm{SCZ}=28 ; \mathrm{BD}=57)$

\begin{tabular}{|c|c|c|c|c|c|}
\hline \multirow[t]{2}{*}{ Average Df } & \multicolumn{2}{|c|}{ Unstandardized Coefficients } & \multirow{2}{*}{$\begin{array}{c}\text { Standardized } \\
\text { Coefficients }\end{array}$} & \multirow{2}{*}{$\mathbf{t}$} & \multirow{2}{*}{ Sig. } \\
\hline & B & Std. Error & & & \\
\hline (Constant) & 1.428 & 0.101 & & 14.138 & $<.001$ \\
\hline $\begin{array}{l}\text { Group (SCZ } \\
\text { vs BD) }\end{array}$ & 0.015 & 0.019 & 0.087 & 0.794 & 0.429 \\
\hline Systolic BP & -0.001 & 0.001 & -0.144 & -1.311 & 0.193 \\
\hline
\end{tabular}




\section{Supplementary Table S6.}

Correlation between $D_{f}$ and clinical variables

\begin{tabular}{|l|c|c|c|c|c|c|}
\hline \multirow{2}{*}{$\begin{array}{l}\text { Clinical } \\
\text { variable }\end{array}$} & \multicolumn{2}{|c|}{ Left $_{\mathbf{f}}$} & \multicolumn{2}{c|}{ Right $\mathbf{D}_{\mathbf{f}}$} & \multicolumn{2}{c|}{ Average $\mathbf{D}_{\mathbf{f}}$} \\
\cline { 2 - 7 } & $\mathbf{r}$ & $\mathbf{p}$ & $\mathbf{r}$ & $\mathbf{p}$ & $\mathbf{r}$ & $\mathbf{p}$ \\
\hline BPRS & 0.04 & 0.6 & 0.11 & 0.13 & 0.1 & 0.17 \\
\hline YMRS & 0.04 & 0.62 & -0.02 & 0.81 & 0.11 & 0.88 \\
\hline HDRS & 0.15 & 0.04 & 0.04 & 0.61 & 0.12 & 0.1 \\
\hline $\begin{array}{l}\text { CPZ } \\
\text { Equivalent }\end{array}$ & 0.017 & 0.85 & -0.14 & 0.12 & -0.08 & 0.36 \\
\hline $\begin{array}{l}\text { Age at onset } \\
\text { of illness }\end{array}$ & -0.07 & 0.37 & -0.02 & 0.82 & -0.06 & 0.48 \\
\hline $\begin{array}{l}\text { Duration of } \\
\text { illness }\end{array}$ & 0.01 & 0.93 & 0.02 & 0.78 & 0.02 & 0.8 \\
\hline
\end{tabular}

BPRS, The Brief Psychiatric Rating Scale (BPRS); YMRS, Young Mania Rating Scale; HDRS, Hamilton Depression Rating Scale; CPZ, Chlorpromazine; Left $D_{f}$ left eye fractal dimension; Right $D_{f}$, right eye fractal dimension; $D_{f^{\prime}}$ average fractal dimension; $r$, correlation coefficient. 


\section{CHAPTER 5}

\section{EXAMINATION OF RETINAL VASCULAR TRAJECTORY IN SCHIZOPHRENIA AND BIPOLAR DISORDER}

Abhishek Appaii, Bhargavi Nagendra, Dona Maria Chako, Ananth Padmanabha, Chaitra V Hiremath, Arpitha Jacob,

Shivarama Varambally, Muralidharan Kesavan, Ganesan Venkatasubramanian, Shyam Vasudeva Rao, Carroll A.B. Webers, Tos T.J.M. Berendschot, Naren P. Rao PSYCHIATRY AND CLINICAL NEUROSCIENCES 2019: 73(12); 738-744 



\section{Abstract}

\section{Aim:}

Evidence suggests microvascular dysfunction (wider retinal venules and narrower arterioles) in schizophrenia (SCZ) and bipolar disorder (BD). The vascular development is synchronous with neuronal development in the retina and brain. The retinal vessel trajectory is related to retinal nerve fiber layer thinning and cerebrovascular abnormalities in SCZ and BD and has not yet been examined. Hence, in this study we examined the retinal vascular trajectory in SCZ and BD in comparison with healthy volunteers (HV).

\section{Methods:}

Retinal images were acquired from $100 \mathrm{HV}$, SCZ patients, and BD patients, respectively, with a non-mydriatic fundus camera. Images were quantified to obtain the retinal arterial and venous trajectories using a validated, semiautomated algorithm. Analysis of covariance and regression analyses were conducted to examine group differences. A supervised machine-learning ensemble of bagged-trees method was used for automated classification of trajectory values.

\section{Results:}

There was a significant difference among groups in both the retinal venous trajectory (HV: $0.17 \pm 0.08$; SCZ: $0.25 \pm 0.17 ; \mathrm{BD}: 0.27 \pm 0.20 ; \mathrm{P}<0.001)$ and the arterial trajectory (HV: $0.34 \pm 0.15 ; \mathrm{SCZ}: 0.29 \pm 0.10 ; \mathrm{BD}: 0.29 \pm 0.11 ; \mathrm{P}=0.003)$ even after adjusting for age and sex $(P<0.001)$. On post-hoc analysis, the SCZ and BD groups differed from the HV on retinal venous and arterial trajectories, but there was no difference between SCZ and BD patients. The machine learning showed an accuracy of $86 \%$ and $73 \%$ for classifying HV versus $\mathrm{SCZ}$ and $\mathrm{BD}$, respectively.

\section{Conclusion:}

Smaller trajectories of retinal arteries indicate wider and flatter curves in SCZ and BD. Considering the relation between retinal/cerebral vasculatures and retinal nerve fiber layer thinness, the retinal vascular trajectory is a potential marker for SCZ and BD. As a relatively affordable investigation, retinal fundus photography should be further explored in SCZ and BD as a potential screening measure.

Keywords: bipolar disorder, machine learning, retinal nerve fiber layer, retinal vascular trajectory, schizophrenia. 


\subsection{INTRODUCTION}

The retina, an embryonic extension of the central nervous system, is often considered as a 'window to the brain' due to its easy accessibility'. Retinal imaging is safer, faster and less expensive technique compared to other imaging modalities, like magnetic resonance imaging (MRI), used for psychiatric disorders ${ }^{2}$. The retinal nerve fiber layer (RNFL) which is composed of axons from the retinal ganglion cells, shares embryonic origin with the brain thus permitting surrogate examination of axonal histopathology ${ }^{3}$. Studies have reported thinning of the RNFL as measured by optical coherence tomography (OCT) in several neuropsychiatric conditions ${ }^{1,3}$. RNFL thinning has also been found to be associated with brain atrophy in multiple sclerosis validating its use as a marker for brain abnormality ${ }^{4}$. Several studies in the last decade have reported RNFL thinning in patients with schizophrenia (SCZ) and bipolar disorder (BD) $)^{5-9}$ but not in major depressive disorder ${ }^{10,11}$ suggesting that RNFL abnormalities are limited to SCZ and BD. A recent study has also reported an overlap in genes implicated in macular thickness and systemic diseases, including SCZ ${ }^{12}$. Two genetic loci, rs7432375 and rs7523273, are associated with risk for both age-related macular degeneration and $S C Z^{13-15}$. Though the functional significance of these genes in the pathogenesis of SCZ is not completely known, it is interesting to note that rs7523273 is associated with functional brain activation in the precuneus-posterior cingulate cortex of SCZ patients ${ }^{16}$. Hence, though preliminary, these findings suggest a pleiotropy effect of these genes between RNFL thickness and SCZ.

However, the measurement of RNFL thickness requires $\mathrm{OCT}^{17}$. Though less expensive than brain imaging, the cost of OCT still limits its utility in a wider community under resource constrained settings. Fundus imaging is less expensive than the OCT and ideally suited for its use in community settings. An earlier study has reported significant association of the retinal arterial trajectory measured as retinal artery angle (angle between the supratemporal and infratemporal arteries) with RNFL thickness ${ }^{18}$. This contribution to RNFL thickness by retinal blood vessels could either be direct or indirect and may be bidirectional. An earlier study has suggested that the blood vessels directly contribute to the inter-individual variations in the RNFL thickness in healthy individuals and patients ${ }^{19,20}$. In addition to this direct contribution, because the development of retinal vessels is influenced by axonal distribution, the location of blood vessels influence the variations in RNFL thickness ${ }^{19,20}$. 
The retinal arterial trajectory can be measured using a relatively inexpensive fundus camera $^{21,22}$, and this provides an opportunity to indirectly examine abnormalities in RNFL thickness.

Former studies using fundus cameras have reported abnormalities in retinal vasculature; venular calibers were found to be increased in SCZ patients and unaffected co-twins of SCZ patients ${ }^{23-25}$. Recently, we also reported wider venules and narrower arterioles in $\mathrm{SCZ}$, and BD patients compared to healthy volunteers $(\mathrm{HV})^{26}$. The trajectories of retinal vessels in SCZ and BD patients are yet to be examined, despite their relations with RNFL abnormalities. Hence, in this study we examined retinal vessel trajectory in patients with SCZ and BD in comparison with HV. Based on the literature suggestive of RNFL thinning in SCZ and BD, we hypothesized that these patients would have wider retinal arterial trajectories (in other words flatter curve, with the arms of the curve farther from the fovea) when compared to HV. Several lines of research in the past decade have suggested considerable overlap in the genetic and pathogenic factors across SCZ and $\mathrm{BD}$; though there are a few differences between these two disorders, it is interesting to note that there are considerable similarities as well ${ }^{27}$. Considering these similarities between SCZ and BD, our secondary hypothesis was that there would be no significant difference in retinal arterial trajectories between these two groups. In addition, a proof-of-concept machine-learning method using an ensemble of bagged trees was employed for automated classification of patients and HV based on their vascular trajectory values.

\subsection{METHODS}

\subsubsection{Subjects}

One hundred patients with SCZ and BD, respectively, were recruited from the clinical services of the National Institute of Mental Health and Neurosciences, Bangalore, India. Patients were examined by a board-certified psychiatrist and diagnosed as per the ICD-1028. Patients who had an ongoing psychiatric comorbidity or had substance abuse or dependence (except nicotine) in the previous 12 months were excluded from the study. One hundred HV were recruited using flyers and word of mouth from the same geographical area. None of the HV had a lifetime history of psychiatric disorder, neurological illness, or family history of psychoses in first-degree relatives. All HV 
were interviewed by a qualified psychiatrist and also completed the Cross-Cutting Symptom Scale ${ }^{29,30}$ to rule out any Axis I disorders. Participants diagnosed or treated for hypertension, diabetes, stroke, or history of eye surgery/trauma were excluded from the study. The patients and $\mathrm{HV}$ were also excluded for other ophthalmologic disorders, such as macular degeneration, and glaucoma, based on their medical history. Ophthalmic examinations including refraction, axial length and intraocular pressure were not carried out. All participants were adults, aged 18 to 50 years. The study was approved by the institute ethics board and all participants provided written informed consent.

\subsubsection{Clinical assessments}

The severity of positive symptoms, negative symptoms, and general psychopathology in $\mathrm{SCZ}$ was measured using the Brief Psychiatric Rating Scale (BPRS) ${ }^{31}$. In BD, the severity of clinical symptoms was measured using Young's mania rating scale (YMRS) ${ }^{32}$ and Hamilton Depression rating scale (HDRS) ${ }^{33}$. Functioning was assessed using Global Assessment of Functioning (GAF) $)^{34}$ and the Clinical Global Impression (CGI) ${ }^{35}$ in both SCZ and BD.

\subsubsection{Retinal image acquisition}

The procedure of retinal image acquisition was explained to those who agreed to participate in the study. They were seated in a dark room for $5 \mathrm{~min}$ prior to the procedure to facilitate auto dilation of pupils through accommodation. Optic-diskcentered retinal images of both the eyes were acquired with a valid method by a trained individual using a fundus camera with a 40 degree field of view ${ }^{36}$. The retinal images were acquired using a non-mydriatic 3 Nethra device (Forus Health, Bangalore, India) by an experienced operator. Each participant was asked to sit in front of the fundus camera and to rest his/her chin on its chin rest. The camera was adjusted to acquire the left eye retina by flashing a light and the image was captured and saved in the computer. This image-acquisition method was based on fundus illumination through light flashes forming a color image. The same procedure was repeated for the right eye ${ }^{26}$. 


\subsubsection{Measurement of trajectory of retinal vessels}

All images were visually examined by a board-certified ophthalmologist and pathological conditions of the retina, such as macular degeneration and glaucoma, were ruled out. Experienced raters differentiated the vessels as arteries and veins using an established method ${ }^{37}$. The following criteria were used to differentiate the arteries and veins in accord with previous studies: (i) arteries are brighter in color than veins; (ii) arteries have a smaller caliber than veins; (iii) the central reflex (the light reflex of the inner parts of the vessel) is wider in arteries and narrower in veins; and (iv) arteries and veins usually alternate near the optic disk before branching out. The trajectories of arteries and veins for both the eyes were calculated using a validated mathematical model described in a previous study ${ }^{38}$. A semiautomated software was formulated using MATLAB 2018a (MathWorks, Natick, MA, USA). Initially, the retinal images of the right and left eyes were rotated $90^{\circ}$ clockwise and anticlockwise, respectively. Following this, a minimum of 20 points were marked on the vascular trajectories passing through the infratemporal and supratemporal margin areas of the retinal images such that each arm to the right and left of the optic disk had a minimum of 10 points each (shown in Figure 1). The infratemporal and supratemporal margins/peaks of the optic disk were chosen in view of the thick retinal nerve fiber bundles in this area. The fovea is located between these two peaks/margins, so the retina stretches more horizontally and/or vertically in some eyes due to tension on fovea, resulting in a greater distance between these two peaks where the retinal vessel trajectories are measured. This results in a thinner retina ${ }^{38,39}$. The $\mathrm{x}$ and $\mathrm{y}$ coordinates of the marked points were automatically detected in MATLAB and were converted to new coordinates by shifting the origin to the center of the optic disk. Thereafter, this data of converted coordinates were fitted to a second-degree polynomial $\left(\frac{P_{1} X^{2}}{100}+P_{2} X+P^{3}\right)$ curve-fitting equation based on the best-fit second-degree polynomial by the least squares method as shown in Figure 1. In cases where the retinal artery or vein were branched, and the main artery was larger than the branch artery, the main artery was plotted for the trajectory. However, if the branch artery was as large as the main artery, marking was not done beyond the branching point. In such cases also, a minimum of 20 points were marked. Under these conditions, a larger $P_{1}$ indicated that the curve of retinal vascular trajectory was steeper and narrower, and that the arms of the curve would be closer to the fovea. 
A smaller $\mathrm{P}_{1}$ indicated that the curve of the trajectory was flatter and wider, and the arms of the curve would be farther from the fovea. Hence, the value of $P_{1}$ was used as a single measure of the retinal vascular trajectory to indicate the steepness and width of the trajectory parabola. The average of the retinal vascular trajectories of the right and left eyes was used as the primary outcome measure. The procedure described above was adopted for both retinal arteries and veins separately. A subsample of 30 participant images was analyzed by two independent evaluators to check interrater reliability. A good interrater reliability of 0.83 (intraclass correlation for average artery; kappa $=0.85 ; \mathrm{P}<0.001$; for average vein; $k a p p a=0.81 ; \mathrm{P}<0.001$ ) was obtained for the vascular trajectories.

Figure 1.

Marking of retinal trajectory in a representative fundus image (left) and least square second-degree polynomial Curve fitting (right); (.) cy versus cx; (-) leastsquare fitting.
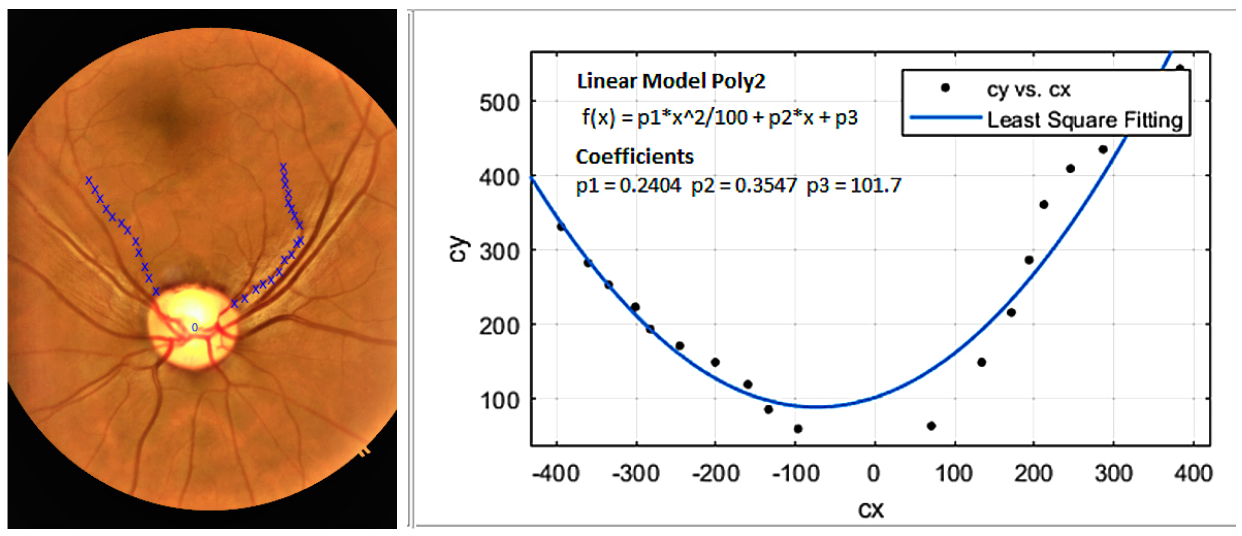

\subsubsection{Statistical analysis}

All statistical analyses were performed using the SPSS version 24 (IBM, Armonk, NY, USA). The Shapiro-Wilk test was used to examine the data for normative distribution. Parametric statistical tests were used as the data were found to be normatively distributed. Differences in age and sex distribution across the groups were analyzed using one-way analysis of variance (ANOVA) and $x 2$-test respectively. Differences in retinal vascular trajectory across the groups were measured using analysis of covariance (ANCOVA). As we compared trajectories of both retinal arteries and veins, we applied the Bonferroni correction for multiple comparisons (three groups and two measures) and considered a corrected P-value of $\leq 0.05 / 6=0.0083$ to be significant. The contribution 
of age and sex as potential confounding variables was assessed using regression coefficients with $95 \%$ confidence interval between the groups, both with and without these as covariates. The relation between retinal trajectories and clinical/demographic variables was assessed using Pearson's correlation analyses using the scores on BPRS, YMRS, HDRS, as well as age at onset of illness, duration of illness, and chlorpromazine equivalent of antipsychotic as predictor variables. A P-value of $<0.01$ was considered significant in view of the multiple variables. To control for the confounding effects of nicotine dependence, a sub analysis was performed after excluding twelve subjects with $\mathrm{SCZ}$ and four subjects with BD who had nicotine dependence.

\subsubsection{Machine-learning analysis}

We conducted a proof-of-concept machine-learning analysis to examine the utility of retinal vascular measures in differentiating the three groups. The machine-learning algorithm was implemented through MATLAB 2018a using a supervised machinelearning approach. The labels used for training were based on the three groups ( $\mathrm{SCZ}, \mathrm{BD}$, and HV). A total of six features from both the left and right eye were used for classification namely, left and right retinal arterial trajectories, left and right retinal venous trajectories, and their respective averages. The supervised machine-learning model was created by feeding a known set of input data (features) and the known group of the data (i.e., labels or classes). This model was then used to classify the new unknown data into one of the three groups through cross-validation. We used five default folds which partitioned the data into five disjoint sets; each fold trains the model using out-of-fold observations and assesses model performance using in-fold data followed by calculation of the average test error of overall folds. The data was partitioned into five equal folds out of which four folds were taken for training and onefold was taken for testing/validation. This process was repeated five times with each fold being used exactly once as the validation fold. This validation model was chosen to avoid overfitting of the data. The method provides good predictive accuracy to the final model trained using all the data. The usage of multiple fits ensures efficient use of all the available data despite small numbers. The learning rate was chosen as 0.1. The bagged decision trees ensemble method was used for classification. We also conducted a support-vector machine (SVM) analysis to independently confirm the findings. We chose SVM and the ensemble of bagged trees as these methods have good speed, high model flexibility, and can be implemented with moderate computational power ${ }^{40,41}$, translating to feasibility in real life clinical scenarios. 


\subsection{RESULTS}

\subsubsection{Comparison of demographic variables}

Out of the 300 participants recruited, 31 were excluded following quality check of retinal images and ambiguity in retinal vascular trajectory marking. Thus, $87 \mathrm{HV}, 94 \mathrm{SCZ}$, and 88 BD were included for the analysis, totaling 269 participants. Demographic details and clinical measures are provided in Table 1. We found a significant difference in age $(p=0.005)$ across the three groups and no difference in sex distribution $(P=0.053)$.

\section{Table 1}

Comparison of demographic and clinical details between the groups

\begin{tabular}{|l|c|c|c|c|c|}
\hline & $\begin{array}{c}\text { HV } \\
(\mathbf{n = 8 7})\end{array}$ & $\begin{array}{c}\text { SCZ } \\
(\mathbf{n = 9 4 )}\end{array}$ & $\begin{array}{c}\text { BD } \\
(\mathbf{n = 8 8})\end{array}$ & $\mathbf{F / t / \mathbf { X } ^ { \mathbf { 2 } }}$ & $\mathbf{p}$ \\
\hline Age (years) & $30.2 \pm 7.6$ & $32.5 \pm 6.0$ & $33.4 \pm 6.0$ & 5.4 & 0.005 \\
\hline Sex ratio (M/F) & $41 / 46$ & $61 / 33$ & $51 / 37$ & 5.87 & 0.053 \\
\hline Age at onset (years) & - & $25.0 \pm 5.2$ & $23.8 \pm 6.0$ & 1.7 & 0.196 \\
\hline $\begin{array}{l}\text { Duration of illness } \\
\text { (years) }\end{array}$ & - & $7.6 \pm 5.2$ & $9.1 \pm 5.6$ & 2.6 & 0.11 \\
\hline BPRS & - & $25.83 \pm 5.4$ & - & - & - \\
\hline HDRS & - & - & $3.97 \pm 5.6$ & - & - \\
\hline YMRS & - & - & $1.75 \pm 2.9$ & - & - \\
\hline
\end{tabular}

BD, bipolar disorder patients; BPRS, Brief Psychiatric Rating Scale; F, analysis of variance; HDRS, Hamilton Depression Rating Scale; HV, healthy volunteer; SCZ, schizophrenia patients; t, independent t-test; YMRS, Young's Mania Rating Scale.

\subsubsection{Differences in trajectory of retinal vessels between HV and patients}

ANCOVA showed a significant difference across the three groups in trajectories of retinal artery (constant $P_{1}$ of HV: $0.34 \pm 0.15 ; S C Z: 0.29 \pm 0.10 ; B D: 0.29 \pm 0.11 ; F=4.1$; $P=0.003)$. The results showed that the value $P_{1}$ of the retinal arterial trajectory was significantly smaller in SCZ $(0.29 \pm 0.10)$ and BD $(0.29 \pm 0.11)$ patients as compared to $\mathrm{HV}(0.34 \pm 0.15)$, indicating flatter and wider retinal arterial trajectories in patients. There was a significant difference across the three groups in the trajectories of retinal veins as well (constant $P_{1}$ of $H V: 0.17 \pm 0.08$; SCZ: $0.25 \pm 0.17 ; B D: 0.27 \pm 0.20 ; F=5.2$; 
$P<0.001)$. However, the value $P_{1}$ of the retinal venous trajectory was significantly greater in SCZ $(0.25 \pm 0.17)$ and BD $(0.27 \pm 0.20)$ patients as compared to HV $(0.17 \pm$ 0.08 ) indicating steeper and narrower retinal venous trajectories in patients. Post-hoc analysis revealed that while there was a significant difference between HV and both SCZ and BD patients in the trajectories of retinal arteries $(P<0.01)$ and veins $(P<0.01)$, there was no significant difference between the two patient groups, SCZ and BD (P > 0.05) on these measures (Figure S1 and Table S1).

The contribution of age and sex as potential confounding variables was assessed using regression analysis. There was no considerable difference in the regression coefficients and significance values either with or without age and sex as additional regressors on separate linear regression analyses (Table 2) suggesting absence of any significant effect of these potential confounders. Further details are provided in Table S2. Similarly, nicotine dependence did not show significant effects either (Appendix S1).

Table 2.

Mean difference of retinal trajectories among HV, SCZ patients, and BD patients adjusted for age and sex

\begin{tabular}{|c|c|c|c|c|c|c|}
\hline \multirow{2}{*}{ Parameter } & \multirow{2}{*}{\multicolumn{2}{|c|}{ Group }} & \multicolumn{2}{|c|}{ Not adjusted for age and sex } & \multicolumn{2}{|c|}{ Adjusted for age and sex } \\
\hline & & & \multirow{2}{*}{$\begin{array}{c}\boldsymbol{\beta}^{+}(\mathbf{9 5} \% \mathrm{Cl}) \\
0.08 \\
(0.041 \text { to } 0.119)\end{array}$} & \multirow{2}{*}{$\begin{array}{c}\mathbf{P} \\
<0.001\end{array}$} & \multirow{2}{*}{$\begin{array}{c}\boldsymbol{\beta}^{+}(\mathbf{9 5} \% \mathrm{Cl}) \\
0.075 \\
(0.035 \text { to } 0.115)\end{array}$} & \multirow{2}{*}{$\begin{array}{c}\mathbf{P} \\
<0.001\end{array}$} \\
\hline \multirow{3}{*}{$\begin{array}{l}\text { Retinal } \\
\text { vein } \\
\text { trajectory }\end{array}$} & $\mathrm{HV}$ & SCZ & & & & \\
\hline & $\mathrm{HV}$ & $\mathrm{BD}$ & $\begin{array}{c}0.102 \\
(0.041 \text { to } 0.119)\end{array}$ & $<0.001$ & $\begin{array}{c}0.107 \\
(0.06 \text { to } 0.153)\end{array}$ & $<0.001$ \\
\hline & SCZ & $\mathrm{BD}$ & $\begin{array}{c}0.022 \\
(-0.031 \text { to } 0.076)\end{array}$ & 0.417 & $\begin{array}{c}0.022 \\
(-0.032 \text { to } 0.076)\end{array}$ & 0.415 \\
\hline \multirow{3}{*}{$\begin{array}{l}\text { Retinal } \\
\text { artery } \\
\text { trajectory }\end{array}$} & $\mathrm{HV}$ & SCZ & $\begin{array}{c}-0.058 \\
(-0.096 \text { to }-0.019)\end{array}$ & 0.003 & $\begin{array}{c}-0.049 \\
(-0.088 \text { to }-0.010)\end{array}$ & 0.014 \\
\hline & $\mathrm{HV}$ & $\mathrm{BD}$ & $\begin{array}{c}-0.056 \\
(-0.096 \text { to }-0.016)\end{array}$ & 0.006 & $\begin{array}{c}-0.042 \\
(-0.083 \text { to }-0.002)\end{array}$ & 0.041 \\
\hline & SCZ & $\mathrm{BD}$ & $\begin{array}{c}0.002 \\
(-0.030 \text { to } 0.033)\end{array}$ & 0.915 & $\begin{array}{c}0.00 \\
(-0.031 \text { to } 0.032)\end{array}$ & 0.985 \\
\hline
\end{tabular}

${ }^{\dagger}$ Regression coefficient; BD, bipolar disorder patients; $\mathrm{Cl}$, confidence interval; HV, healthy volunteers; SCZ, schizophrenia patients. 


\subsubsection{Relation between clinical variables and retinal vascular trajectory}

There was no significant correlation between clinical variables (duration of illness, age at onset, total score on YMRS, HDRS, BPRS, and antipsychotic dose) and trajectories of retinal arteries and veins $(P>0.01)$ on Pearson's partial correlation analyses with and without age and sex as covariates (Table S3).

\subsubsection{Machine learning analyses}

Ensemble of bagged trees had an accuracy of $86 \%$ with sensitivity of $88 \%$ and specificity of $85 \%$ for differentiating $\mathrm{HV}$ and SCZ. A lower but considerably good accuracy of $73 \%$ with sensitivity of $78 \%$ and specificity of $76 \%$ was obtained for differentiating $\mathrm{HV}$ and BD. For differentiating SCZ and BD, the accuracy was $77 \%$ with a sensitivity of $81 \%$ and specificity of $86 \%$. The exploratory SVM analysis showed a similar, but relatively lesser accuracy than the ensemble of bagged trees (Appendix S2).

\subsection{DISCUSSION}

This is the first study to assess the trajectories of retinal vessels in SCZ and BD patients in comparison with $\mathrm{HV}$. The results show that $\mathrm{P}_{1}$ of the retinal arterial trajectory was significantly lesser and $\mathrm{P}_{1}$ of the retinal venous trajectory was significantly greater in SCZ and BD patients as compared to HV. This indicates wider and flatter parabola of the arteries and steeper and narrower parabola of the veins in the patients than in the $\mathrm{HV}$. Neither the arterial nor venous trajectories differed between patients with $\mathrm{SCZ}$ and those with BD.

Our findings of wider retinal arterial trajectories are in accord with our hypothesis and previous findings. During embryonic development, common mechanisms underlie the vascularization of both retina and the brain as the retina is embryologically an extension of the diencephalon ${ }^{42}$. In both the retina and the brain, the vascular development is synchronous to neuronal development; the neurovascular coupling assures simultaneous generation of neuroblasts and blood vessels ${ }^{43}$. In addition, endothelial cells play a critical role in migration and differentiation of oligodendrocytes ${ }^{43}$. Interestingly, emerging evidence suggests the role of angiogenesis and blood vessel pathologies in the pathogenesis of psychoses, importantly SCZ. Preliminary evidence from genetic, post-mortem and imaging studies suggests a vascular remodeling and 
hypoxia signaling as risk factors for $\mathrm{SCZ}^{43,44}$. Considering these relations, it is possible that retinal vascular abnormalities are indicative of cerebral vascular abnormalities which in turn are implicated in the pathogenesis of psychoses.

In addition, the retinal arterial trajectory measured as the retinal artery angle has been shown to have significant association with thinner RNFL ${ }^{18}$ and several studies have reported wider retinal artery trajectories to be associated with RNFL defects ${ }^{38,39,45,46}$.

A few studies have examined RNFL thickness using OCT in SCZ and BD and have reported thinning of the RNFL $5,9,47-49$ and the inner nuclear layer ${ }^{50}$ in patients compared to HV.

Hence, our findings of wider retinal artery trajectories in SCZ and BD patients suggest that the retinal arterial trajectory could be a potential surrogate measure of RNFL thickness seen in psychoses. Our findings provide rationale for further examination of the association between retinal vascular trajectory and RNFL thickness using OCT in SCZ and BD.

Based on the common developmental origins between the retina and the brain ${ }^{51}$, a few studies have examined the relation between RNFL thickness and brain structure. In a large population-based study, a thinner RNFL and ganglion cell layer was shown to be associated with lower gray matter density in the visual cortex and a thinner ganglion cell layer was associated with lower gray matter density in the thalamus ${ }^{51}$. In addition, lower fractional anisotropy of the corpus callosum and optic radiation were associated with thinner RNFL ${ }^{51,52}$. While the definitive mechanisms are still unclear, axonal degeneration has been postulated to be responsible for both thinning of the RNFL and decreased gray matter volume in the brain ${ }^{53}$. However, the brain correlates of thin RNFL have not directly been examined in SCZ and BD to date. Considering the relation between retinal arterial trajectory and RNFL thickness, it is possible that the abnormalities in retinal vascular trajectory may also be related to the structural brain abnormalities seen in $\mathrm{SCZ}$ and $\mathrm{BD}^{54-56}$. However, this speculation is based on indirect evidence as the relation between retinal vascular trajectory and brain structure/function in SCZ or BD remains to be explored.

While several studies have examined retinal arterial trajectories, retinal venous trajectories have taken the backseat. Our findings suggest an inverse relation between the trajectories of retinal artery and vein between the groups. This finding is similar to the inverse relation see in retinal vascular calibre; while patients with psychoses 
had narrower arterioles than $\mathrm{HV}$, they had wider venules ${ }^{26}$. In the absence of joint examination of retinal venous trajectory and RNFL, definitive conclusions cannot be drawn regarding the reasons or pathophysiological mechanisms behind the differential findings across the arteries and veins. Studies employing multimodal examination using fundus photography, OCT, and magnetic resonance imaging in SCZ and BD patients are needed for direct evidence and definitive understanding of these relations.

Our secondary aim was to examine the utility of machine learning techniques to differentiate patients from HV using retinal vessel trajectory as the input variable. Several studies have used the machine learning approach to classify SCZ/BD and HV using neuroimaging/ electrophysiologic / cognitive data as input variables ${ }^{57-61}$. A recent study reported prediction accuracy of $76 \%$ to differentiate SCZ from HV using a multisite machine-learning analysis ${ }^{62}$. Another study reported use of machinelearning analysis and structural MRI to differentiate treatment non-responders from treatment responders with a sensitivity of $71 \%$ and specificity of $68 \%{ }^{63}$. Similar to structural imaging, functional imaging is also used to classify SCZ and HV; a recent study using functional connectivity measure reported an accuracy of $75 \%$ with a sensitivity of $74 \%$ and specificity of $84 \%{ }^{64}$. While several studies have examined the use of machine-learning approach in SCZ, it is relatively less examined in BD. A few studies using neuroimaging measures have reported an accuracy of $70 \%-80 \%$ to classify $\mathrm{BD}$ and $\mathrm{HV}^{65}$. A higher accuracy of $95 \%$ was reported to classify BD and HV using a combination of neuropsychological tests and plasma markers ${ }^{66}$. On the other hand, a few studies have explored the utility of machine learning analyses using retinal images in ophthalmology ${ }^{67-71}$. The machine-learning approach has been successfully used to classify healthy versus diabetic retinopathy, age related macular degeneration (AMD), glaucoma, retinopathy of prematurity, and so forth ${ }^{72-74}$. Ours is the first study to utilize machine-learning analysis to differentiate SCZ/BD from HV using retinal vessel trajectory as the input factor. Findings of our study provide proof of concept to use machine learning techniques using retinal vessel trajectory as an input factor to classify SCZ/BD and HV. The ensemble of bagged trees method of classification crossed the critical threshold of more than $80 \%$ for classifying $\mathrm{HV}$ and $\mathrm{SCZ}{ }^{75,76}$. However, our sample size being small, these findings need to be replicated in future studies with larger samples. 
A few limitations should be considered in relation to our study findings. All patients were on treatment with medication and the confounding effect of pharmacotherapy cannot be ruled out. However, as shown in Table S3, there was no significant correlation between retinal vessel trajectories and chlorpromazine dose equivalents suggesting absence of significant effect of antipsychotics. Future studies with a subsample of drug-naïve subjects can control for this confounder. The representation of BD-I and BD-II patients were not uniform. There were 65 patients with BD-I and rest had BD-II. Considering the small number of participants in each subgroup we could not examine whether the subtypes of BD differ on these parameters. Future studies with larger samples including both BD-I and BD-II patients are needed for the same. The groups were not age matched. However, even after controlling for age, the results remained significant. As shown in Table 2, the regression coefficients were comparable both with and without age and sex as covariates. Sixteen patients had nicotine dependence (four $\mathrm{BD}$ and $12 \mathrm{SCZ}$ ) which could have confounded the results considering that previous studies have reported an association between long-term nicotine use and RNFL thickness ${ }^{77,78}$. However, as nicotine dependence being a common comorbidity in schizophrenia ${ }^{79}$, exclusion of patients with nicotine use would have affected the generalizability of findings. It is important to note that the differences between groups remained significant even after excluding these 16 participants (details in Appendix S1). We did not measure blood pressure, body mass index, or glucose levels of all the participants on the day of examination. Though participants were young and those with a history of hypertension or diabetes mellitus were excluded, one cannot rule out the possibility of undiagnosed hypertension or diabetes mellitus. To control for the potential confound, we measured blood pressure and body mass index in a subgroup of patients and conducted a sub analysis including these measures. The results remained the same even after inclusion of these measures (details in Appendix S3). Future studies need to consider measurement of these parameters on the day of retinal image acquisition. Another major limitation of the study is that we did not measure other ophthalmologic parameters including refraction, axial length and intraocular pressure. It is important to note that ophthalmologic comorbidities are seen commonly in schizophrenia ${ }^{80}$ and may have confounded the findings. Hence, it will be important to measure these parameters in the future. We did not measure the axial length of the eye 
or visual acuity/ refraction which could have influenced the retinal vascular trajectory measurements. However, it is important to note that a previous study has reported a significant association between the retinal arterial trajectory and RNFL thickness even after controlling for the axial length ${ }^{18}$. Moreover, another study has reported that SCZ patients and HV do not differ in axial length of the eye or disorders of refraction ${ }^{81}$. Hence, axial length is not likely to have significant confounding effects on the findings. However, it would be ideal if future studies concurrently measured the axial length and refraction to correct for their effects.

Our study findings have important implications. Retinal vascular abnormalities bear relation to abnormalities in RNFL thickness, which in turn is related to brain abnormalities seen in $\mathrm{SCZ}$ and $\mathrm{BD}^{82,83}$. Fundus photography is relatively inexpensive when compared to OCT or neuroimaging. In addition, the portable nature of the equipment also makes it an ideal tool for use in peripheral centers or where resources are limited. These advantages of fundus photography, together with our findings from machine-learning analysis, indicate the potential utility of this method in wider, resource constrained settings and warrant further studies with larger sample sizes. Machine-learning analysis with the use of a single measure (retinal vessel trajectory) demonstrated reasonable accuracy despite the potential confounding factors, suggesting its potential utility as a clinical marker ${ }^{84}$. Considerable increase in accuracy may be obtained with increase in sample size along with dynamic learning and deep learning. These preliminary findings provide sufficient rationale for future studies along similar lines on larger samples.

\subsection{Conclusion}

The findings of our study indicate significant differences between the retinal vessel trajectories in patients (SCZ and BD) and HV. Both SCZ and BD patients, compared to $\mathrm{HV}$, had smaller $\mathrm{P}_{1}$ for arterial trajectories indicating flatter and wider curves of retinal arteries. As retinal fundoscopic imaging is affordable, accessible, and easy to perform, it could prove to be useful as a surrogate investigation for the RNFL thinning seen in SCZ and BD. The findings from machine-learning analysis provide proof of concept and preliminary support towards its potential to differentiate patients with SCZ and BD from HV. Future studies need to consider examining the relation between retinal vascular trajectory and RNFL using OCT. Also, the relation between retinal vascular trajectory and brain structure and function need to be considered in the future. 


\section{References}

1. Schonfeldt-Lecuona C, Kregel T, Schmidt A, et al. From Imaging the Brain to Imaging the Retina: Optical Coherence Tomography (OCT) in Schizophrenia. Schizophr Bull. 2016;42(1):9-14.

2. Patton N, Aslam T, Macgillivray T, Pattie A, Deary IJ, Dhillon B. Retinal vascular image analysis as a potential screening tool for cerebrovascular disease: a rationale based on homology between cerebral and retinal microvasculatures. Journal of anatomy. 2005;206(4):319-348.

3. London A, Benhar I, Schwartz M. The retina as a window to the brain-from eye research to CNS disorders. Nature reviews Neurology. 2013;9(1):44-53.

4. Gordon-Lipkin E, Chodkowski B, Reich DS, et al. Retinal nerve fiber layer is associated with brain atrophy in multiple sclerosis. Neurology. 2007;69(16):1603-1609.

5. Lee WW, Tajunisah I, Sharmilla K, Peyman M, Subrayan V. Retinal nerve fiber layer structure abnormalities in schizophrenia and its relationship to disease state: evidence from optical coherence tomography. Invest Ophthalmol Vis Sci. 2013;54(12):77857792.

6. Yilmaz U, Kucuk $E$, Ulgen $A$, et al. Retinal nerve fiber layer and macular thickness measurement in patients with schizophrenia. Eur J Ophthalmol. 2016;26(4):375-378.

7. Garcia-Portilla MP, Garcia-Alvarez L, de la Fuente-Tomas $L$, et al. Could structural changes in the retinal layers be a new biomarker of mental disorders? A systematic review and thematic synthesis. Rev Psiquiatr Salud Ment. 2019.

8. Samani NN, Proudlock FA, Siram V, et al. Retinal Layer Abnormalities as Biomarkers of Schizophrenia. Schizophr Bull. 2018;44(4):876-885.

9. Silverstein $S M$, Paterno D, Cherneski L, Green S. Optical coherence tomography indices of structural retinal pathology in schizophrenia. Psychol Med. 2018;48(12):2023-2033.

10. Sonmez I, Kosger F, Aykan U. Retinal Nerve Fiber Layer Thickness Measurement by Spectral-Domain Optical Coherence Tomography in Patients with Major Depressive Disorder. Noro Psikiyatr Ars. 2017;54(1):62-66.

11. Yildiz M, Alim S, Batmaz S, et al. Duration of the depressive episode is correlated with ganglion cell inner plexifrom layer and nasal retinal fiber layer thicknesses: Optical coherence tomography findings in major depression. Psychiatry Res Neuroimaging. 2016;251:60-66. 
12. GaoXR, Huang H, Kim H. Genome-wide association analyses identify 139 loci associated with macular thickness in the UK Biobank cohort. Human molecular genetics. 2018.

13. Grassmann F, Kiel C, Zimmermann ME, et al. Genetic pleiotropy between age-related macular degeneration and 16 complex diseases and traits. Genome medicine. 2017;9(1):29.

14. Jaffe AE, Straub RE, Shin JH, et al. Developmental and genetic regulation of the human cortex transcriptome illuminate schizophrenia pathogenesis. Nature neuroscience. 2018;21(8):1117-1125.

15. Ohi K, Shimada T, Yasuyama T, Uehara T, Kawasaki Y. Variability of 128 schizophreniaassociated gene variants across distinct ethnic populations. Translational psychiatry. 2017;7(1):e988.

16. Erk S, Mohnke S, Ripke S, et al. Functional neuroimaging effects of recently discovered genetic risk loci for schizophrenia and polygenic risk profile in five RDoC subdomains. Translational psychiatry. 2017;7(1):e997.

17. Costa RA, Skaf M, Melo Jr LA, et al. Retinal assessment using optical coherence tomography. Progress in retinal and eye research. 2006;25(3):325-353.

18. Yamashita T, Asaoka R, Tanaka M, et al. Relationship between position of peak retinal nerve fiber layer thickness and retinal arteries on sectoral retinal nerve fiber layer thickness. Invest Ophthalmol Vis Sci. 2013;54(8):5481-5488.

19. Hood DC, Salant JA, Arthur SN, Ritch R, Liebmann JM. The location of the inferior and superior temporal blood vessels and inter-individual variability of the retinal nerve fiber layer thickness. Journal of glaucoma. 2010;19(3):158.

20. Hood DC, Fortune B, Arthur SN, et al. Blood vessel contributions to retinal nerve fiber layer thickness profiles measured with optical coherence tomography. Journal of glaucoma. 2008;17(7):519.

21. Gupta S, Zivadinov R, Ramanathan M, Weinstock-Guttman B. Optical coherence tomography and neurodegeneration: are eyes the windows to the brain? Expert review of neurotherapeutics. 2016;16(7):765-775.

22. Thomson KL, Yeo JM, Waddell B, Cameron JR, Pal S. A systematic review and metaanalysis of retinal nerve fiber layer change in dementia, using optical coherence tomography. Alzheimer's \& dementia (Amsterdam, Netherlands). 2015;1(2):136-143. 
23. Meier MH, Shalev I, Moffitt TE, et al. Microvascular abnormality in schizophrenia as shown by retinal imaging. Am J Psychiatry. 2013;170(12):1451-1459.

24. Meier MH, Gillespie NA, Hansell NK, et al. Retinal microvessels reflect familial vulnerability to psychotic symptoms: A comparison of twins discordant for psychotic symptoms and controls. Schizophr Res. 2015;164(1-3):47-52.

25. Naiberg MR, Hatch JK, Selkirk $B$, et al. Retinal photography: $A$ window into the cardiovascular-brain link in adolescent bipolar disorder. J Affect Disord. 2017;218:227237.

26. Appaji A, Nagendra B, Chako DM, et al. Retinal vascular abnormalities in schizophrenia and bipolar disorder: A window to the brain. Bipolar Disord. 2019.

27. Murray RM, Sham P, Van Os J, Zanelli J, Cannon M, McDonald C. A developmental model for similarities and dissimilarities between schizophrenia and bipolar disorder. Schizophrenia research. 2004;71(2-3):405-416.

28. Sheehan DV, Lecrubier $Y$, Sheehan $K H$, et al. The Mini-International Neuropsychiatric Interview (M.I.N.I.): the development and validation of a structured diagnostic psychiatric interview for DSM-IV and ICD-10. J Clin Psychiatry. 1998;59 Suppl 20:2233;quiz 34-57.

29. Clarke DE, Kuhl EA. DSM-5 cross-cutting symptom measures: a step towards the future of psychiatric care? World psychiatry : official journal of the World Psychiatric Association (WPA). 2014;13(3):314-316.

30. Narrow WE, Clarke DE, Kuramoto SJ, et al. DSM-5 field trials in the United States and Canada, Part III: development and reliability testing of a cross-cutting symptom assessment for DSM-5. The American journal of psychiatry. 2013;170(1):71-82.

31. Overall JE, Gorham DR. The brief psychiatric rating scale. Psychological reports. 1962;10(3):799-812.

32. Young $R C$, Biggs JT, Ziegler VE, Meyer DA. A rating scale for mania: reliability, validity and sensitivity. Br J Psychiatry. 1978;133:429-435.

33. Hamilton M. A rating scale for depression. J Neurol Neurosurg Psychiatry. 1960;23:5662.

34. Jones SH, Thornicroft G, Coffey M, Dunn G. A brief mental health outcome scalereliability and validity of the Global Assessment of Functioning (GAF). Br J Psychiatry. 1995;166(5):654-659. 
35. Busner J, Targum SD. The clinical global impressions scale: applying a research tool in clinical practice. Psychiatry (Edgmont). 2007;4(7):28-37.

36. Nguyen TT, Islam FM, Farouque HM, et al. Retinal vascular caliber and brachial flowmediated dilation: the Multi-Ethnic Study of Atherosclerosis. Stroke; a journal of cerebral circulation. 2010;41(7):1343-1348.

37. Kondermann C, Kondermann D, Yan M. Blood vessel classification into arteries and veins in retinal images. Paper presented at: Medical Imaging 2007: Image Processing2007.

38. Yamashita T, Sakamoto T, Terasaki H, Tanaka M, Kii Y, Nakao K. Quantification of retinal nerve fiber and retinal artery trajectories using second-order polynomial equation and its association with axial length. Investigative ophthalmology \& visual science. 2014;55(8):5176-5182.

39. Yamashita T, Nitta K, Sonoda S, Sugiyama K, Sakamoto T. Relationship Between Location of Retinal Nerve Fiber Layer Defect and Curvature of Retinal Artery Trajectory in Eyes With Normal Tension Glaucoma. Investigative ophthalmology \& visual science. 2015;56(10):6190-6195.

40. Lupascu CA, Tegolo D, Trucco E. Accurate estimation of retinal vessel width using bagged decision trees and an extended multiresolution Hermite model. Med Image Anal. 2013;17(8):1164-1180.

41. Mbogning C, Perdry H, Broet P. A Bagged, Partially Linear, Tree-Based Regression Procedure for Prediction and Variable Selection. Hum Hered. 2015;79(3-4):182-193.

42. Hughes S, Yang H, Chan-Ling T. Vascularization of the human fetal retina: roles of vasculogenesis and angiogenesis. Invest Ophthalmol Vis Sci. 2000;41(5):1217-1228.

43. Katsel P, Roussos P, Pletnikov M, Haroutunian V. Microvascular anomaly conditions in psychiatric disease. Schizophrenia - angiogenesis connection. Neurosci Biobehav Rev. 2017;77:327-339.

44. Baruah J, Vasudevan A. The Vessels Shaping Mental Health or Illness. The Open Neurology Journal. 2019;13(1).

45. Yamashita T, Terasaki H, Yoshihara N, Kii Y, Uchino E, Sakamoto T. Relationship between retinal artery trajectory and axial length in Japanese school students. Japanese journal of ophthalmology. 2018;62(3):315-320. 
46. Yoshihara $N$, Sakamoto T, Yamashita $T$, et al. Wider retinal artery trajectories in eyes with macular hole than in fellow eyes of patients with unilateral idiopathic macular hole. PloS one. 2015;10(4):e0122876.

47. Mehraban A, Samimi SM, Entezari M, Seifi MH, Nazari M, Yaseri M. Peripapillary retinal nerve fiber layer thickness in bipolar disorder. Graefe's archive for clinical and experimental ophthalmology = Albrecht von Graefes Archiv fur klinische und experimentelle Ophthalmologie. 2016;254(2):365-371.

48. Khalil MA, Saleh AA, Gohar SM, Khalil DH, Said M. Optical coherence tomography findings in patients with bipolar disorder. J Affect Disord. 2017;218:115-122.

49. Chu EM, Kolappan M, Barnes TR, Joyce EM, Ron MA. A window into the brain: an in vivo study of the retina in schizophrenia using optical coherence tomography. Psychiatry research. 2012;203(1):89-94.

50. Garcia-Martin E, Gavin A, Garcia-Campayo J, et al. VISUAL FUNCTION AND RETINAL CHANGES IN PATIENTS WITH BIPOLAR DISORDER. Retina (Philadelphia, Pa). 2018.

51. Mutlu U, Ikram MK, Roshchupkin GV, et al. Thinner retinal layers are associated with changes in the visual pathway: A population-based study. Human brain mapping. 2018.

52. Scheel M, Finke C, Oberwahrenbrock T, et al. Retinal nerve fibre layer thickness correlates with brain white matter damage in multiple sclerosis: a combined optical coherence tomography and diffusion tensor imaging study. Multiple sclerosis (Houndmills, Basingstoke, England). 2014;20(14):1904-1907.

53. Kalenderoglu A, Celik M, Sevgi-Karadag A, Egilmez OB. Optic coherence tomography shows inflammation and degeneration in major depressive disorder patients correlated with disease severity. J Affect Disord. 2016;204:159-165.

54. Bellani M, Yeh PH, Tansella M, Balestrieri M, Soares JC, Brambilla P. DTI studies of corpus callosum in bipolar disorder. Biochemical Society transactions. 2009;37(Pt 5):10961098.

55. Duarte JA, de Araujo ESJQ, Goldani AA, Massuda R, Gama CS. Neurobiological underpinnings of bipolar disorder focusing on findings of diffusion tensor imaging: a systematic review. Rev Bras Psiquiatr. 2016;38(2):167-175.

56. Hibar DP, Westlye LT, Doan NT, et al. Cortical abnormalities in bipolar disorder: an MRI analysis of 6503 individuals from the ENIGMA Bipolar Disorder Working Group. Mol Psychiatry. 2018;23(4):932-942. 
57. Zhao K, So HC. Drug repositioning for schizophrenia and depression/anxiety disorders: A machine learning approach leveraging expression data. IEEE J Biomed Health Inform. 2018.

58. Tandon N, Tandon R. Will Machine Learning Enable Us to Finally Cut the Gordian Knot of Schizophrenia. Schizophr Bull. 2018.

59. Chung Y, Addington J, Bearden CE, et al. Use of Machine Learning to Determine Deviance in Neuroanatomical Maturity Associated With Future Psychosis in Youths at Clinically High Risk. JAMA Psychiatry. 2018.

60. Mwangi B, Wu MJ, Bauer IE, et al. Predictive classification of pediatric bipolar disorder using atlas-based diffusion weighted imaging and support vector machines. Psychiatry Res. 2015;234(2):265-271.

61. Hajek T, Cooke C, Kopecek M, Novak T, HoschI C, Alda M. Using structural MRI to identify individuals at genetic risk for bipolar disorders: a 2-cohort, machine learning study. J Psychiatry Neurosci. 2015;40(5):316-324.

62. Rozycki M, Satterthwaite TD, Koutsouleris N, et al. Multisite Machine Learning Analysis Provides a Robust Structural Imaging Signature of Schizophrenia Detectable Across Diverse Patient Populations and Within Individuals. Schizophr Bull. 2018;44(5):10351044.

63. Mourao-Miranda J, Reinders AA, Rocha-Rego V, et al. Individualized prediction of illness course at the first psychotic episode: a support vector machine MRI study. Psychol Med. 2012;42(5):1037-1047.

64. Ramkiran S, Sharma A, Rao NP. Resting-state anticorrelated networks in Schizophrenia. Psychiatry Res Neuroimaging. 2019;284:1-8.

65. Librenza-Garcia D, Kotzian BJ, YangJ, etal. The impact of machinelearningtechniques in the study of bipolar disorder: A systematic review. Neurosci Biobehav Rev. 2017;80:538554.

66. Besga A, Gonzalez I, Echeburua E, et al. Discrimination between Alzheimer's Disease and Late Onset Bipolar Disorder Using Multivariate Analysis. Front Aging Neurosci. 2015;7:231.

67. Saha SK, Fernando B, Cuadros J, Xiao D, Kanagasingam Y. Automated Quality Assessment of Colour Fundus Images for Diabetic Retinopathy Screening in Telemedicine. J Digit Imaging. 2018. 
68. Roychowdhury S, Koozekanani DD, Parhi KK. DREAM: diabetic retinopathy analysis using machine learning. IEEE J Biomed Health Inform. 2014;18(5):1717-1728.

69. Ogunyemi O, Kermah D. Machine Learning Approaches for Detecting Diabetic Retinopathy from Clinical and Public Health Records. AMIA Annu Symp Proc. 2015;2015:983-990.

70. Bolon-Canedo V, Ataer-Cansizoglu E, Erdogmus D, et al. Dealing with inter-expert variability in retinopathy of prematurity: A machine learning approach. Comput Methods Programs Biomed. 2015;122(1):1-15.

71. Omodaka K, An G, Tsuda S, et al. Classification of optic disc shape in glaucoma using machine learning based on quantified ocular parameters. PloS one. 2017;12(12):e0190012.

72. Ting DSW, Pasquale $L R$, Peng $L$, et al. Artificial intelligence and deep learning in ophthalmology. 2019;103(2):167-175.

73. Lee A, Taylor P, Kalpathy-Cramer J, Tufail AJO. Machine learning has arrived! 2017;124(12):1726-1728.

74. Gulshan V, Peng L, Coram M, et al. Development and Validation of a Deep Learning Algorithm for Detection of Diabetic Retinopathy in Retinal Fundus Photographs. Jama. 2016;316(22):2402-2410.

75. Savitz JB, Rauch SL, Drevets WC. Clinical application of brain imaging for the diagnosis of mood disorders: the current state of play. Mol Psychiatry. 2013;18(5):528-539.

76. Nunes A, Schnack HG, Ching CRK, et al. Using structural MRI to identify bipolar disorders - 13 site machine learning study in 3020 individuals from the ENIGMA Bipolar Disorders Working Group. Mol Psychiatry. 2018.

77. Ahuja S, Kumar PS, Kumar VP, Kattimani S, Akkilagunta S. Effect of chronic alcohol and tobacco use on retinal nerve fibre layer thickness: a case-control study. BMJ Open Ophthalmol. 2017;1(1):e000003.

78. Dervisogullari MS, Totan Y, Tenlik A, Yuce A, Guler E. Effect of smoking on retina nerve fiber layer and ganglion cell-inner plexiform layer complex. Cutan Ocul Toxicol. 2015;34(4):282-285.

79. de Leon J, Diaz FJ. A meta-analysis of worldwide studies demonstrates an association between schizophrenia and tobacco smoking behaviors. Schizophr Res. 2005;76(23):135-157. 
80. Silverstein SM, Rosen R. Schizophrenia and the eye. Schizophrenia Research: Cognition. 2015;2(2):46-55.

81. Cumurcu T, Keser S, Cumurcu BE, Gunduz A, Kartalci S. Refraction and eye anterior segment parameters in schizophrenic patients. Arq Bras Oftalmol. 2015;78(3):180-184.

82. Pan J, Zhou Y, Xiang Y, Yu J. Retinal nerve fiber layer thickness changes in Schizophrenia: A meta-analysis of case-control studies. Psychiatry research. 2018;270:786-791.

83. Lizano P, Bannai D, Lutz O, Kim LA, Miller J, Keshavan M. A Meta-analysis of Retinal Cytoarchitectural Abnormalities in Schizophrenia and Bipolar Disorder. Schizophrenia bulletin. 2019.

84. Frank RA, Galasko D, Hampel $H$, et al. Biological markers for therapeutic trials in Alzheimer's disease. Neurobiology of aging. 2003;24(4):521-536. 


\section{Supplementary Materials}

Table S1:

Post-hoc analysis of variance of retinal trajectory in the three groups

\begin{tabular}{|l|c|c|c|c|}
\hline \multirow{2}{*}{ Parameter } & Group & $\begin{array}{c}\text { Mean } \\
\text { difference }\end{array}$ & Std error & p \\
\hline \multirow{3}{*}{ Retinal Vein Trajectory } & HV vs SCZ & -0.080 & 0.023 & 0.002 \\
\cline { 2 - 5 } & HV vs BD & -0.102 & 0.024 & $<0.001$ \\
\cline { 2 - 5 } & SCZ vs BD & -0.022 & 0.023 & 1.000 \\
\hline \multirow{3}{*}{ Retinal Artery Trajectory } & HV vs SCZ & 0.058 & 0.019 & 0.006 \\
\cline { 2 - 5 } & HV vs BD & 0.056 & .01882 & 0.010 \\
\cline { 2 - 5 } & SCZ vs BD & -0.002 & .01846 & 1.000 \\
\hline
\end{tabular}

\section{Table S2:}

Details of regression coefficient between groups with and without age and sex as predictor variables.

S2a - Mean difference between HV:SCZ, HV:BD and SCZ:BD without age and sex as predictors

\begin{tabular}{|l|c|c|c|c|c|}
\hline $\begin{array}{l}\text { Retinal } \\
\text { Vein } \\
\text { Trajectory }\end{array}$ & \multicolumn{2}{|c|}{ Unstandardized Coefficients } & $\begin{array}{c}\text { Standardized } \\
\text { Coefficients }\end{array}$ & t & Sig. \\
\hline & B & Std. Error & Beta & & \\
\hline (Constant) & .171 & .014 & & 11.991 & .000 \\
\hline HV SCZ & .080 & .020 & .289 & 4.034 & .000 \\
\hline
\end{tabular}

\begin{tabular}{|c|c|c|c|c|c|}
\hline \multirow{2}{*}{$\begin{array}{l}\text { Retinal } \\
\text { Vein } \\
\text { Trajectory }\end{array}$} & \multicolumn{2}{|c|}{ Unstandardized Coefficients } & \multirow{2}{*}{$\begin{array}{c}\text { Standardized } \\
\text { Coefficients } \\
\text { Beta }\end{array}$} & \multirow{2}{*}{$\mathbf{t}$} & \multirow{2}{*}{ Sig. } \\
\hline & B & Std. Error & & & \\
\hline (Constant) & .171 & .016 & & 10.576 & .000 \\
\hline HV BD & .102 & .023 & .322 & 4.470 & .000 \\
\hline \multirow[t]{2}{*}{$\begin{array}{l}\text { Retinal } \\
\text { Vein } \\
\text { Trajectory }\end{array}$} & \multicolumn{2}{|c|}{ Unstandardized Coefficients } & $\begin{array}{c}\text { Standardized } \\
\text { Coefficients }\end{array}$ & \multirow[t]{2}{*}{$\mathbf{t}$} & \multirow[t]{2}{*}{ Sig. } \\
\hline & B & Std. Error & Beta & & \\
\hline (Constant) & .251 & .019 & & 13.271 & .000 \\
\hline SCZ BD & .022 & .027 & .061 & .813 & .417 \\
\hline
\end{tabular}




\begin{tabular}{|c|c|c|c|c|c|}
\hline \multirow{2}{*}{$\begin{array}{l}\text { Retinal } \\
\text { Vein } \\
\text { Trajectory }\end{array}$} & \multicolumn{2}{|c|}{ Unstandardized Coefficients } & \multirow{2}{*}{$\begin{array}{c}\text { Standardized } \\
\text { Coefficients } \\
\text { Beta }\end{array}$} & \multirow{2}{*}{$\mathbf{t}$} & \multirow{2}{*}{ Sig. } \\
\hline & B & Std. Error & & & \\
\hline (Constant) & .344 & .014 & & 24.585 & .000 \\
\hline HV SCZ & -.058 & .019 & -.216 & -2.965 & .003 \\
\hline
\end{tabular}

\begin{tabular}{|c|c|c|c|c|c|}
\hline \multirow{2}{*}{$\begin{array}{l}\text { Retinal } \\
\text { Vein } \\
\text { Trajectory }\end{array}$} & \multicolumn{2}{|c|}{ Unstandardized Coefficients } & \multirow{2}{*}{$\begin{array}{c}\text { Standardized } \\
\text { Coefficients } \\
\text { Beta }\end{array}$} & \multirow{2}{*}{$\mathbf{t}$} & \multirow{2}{*}{ Sig. } \\
\hline & B & Std. Error & & & \\
\hline (Constant) & .344 & .014 & & 23.960 & .000 \\
\hline HV BD & -.056 & .020 & -.205 & -2.758 & .006 \\
\hline
\end{tabular}

\begin{tabular}{|c|c|c|c|c|c|}
\hline \multirow{2}{*}{$\begin{array}{l}\text { Retinal } \\
\text { Vein } \\
\text { Trajectory }\end{array}$} & \multicolumn{2}{|c|}{ Unstandardized Coefficients } & \multirow{2}{*}{$\begin{array}{c}\text { Standardized } \\
\text { Coefficients } \\
\text { Beta }\end{array}$} & \multirow{2}{*}{$\mathbf{t}$} & \multirow{2}{*}{ Sig. } \\
\hline & B & Std. Error & & & \\
\hline (Constant) & .286 & .011 & & 25.764 & .000 \\
\hline SCZ BD & .002 & .016 & .008 & .107 & .915 \\
\hline
\end{tabular}

S2b - Mean difference between HV:SCZ, HV:BD and SCZ:BD with age and sex as predictors

\begin{tabular}{|c|c|c|c|c|c|}
\hline \multirow{2}{*}{$\begin{array}{l}\text { Retinal } \\
\text { Vein } \\
\text { Trajectory }\end{array}$} & \multicolumn{2}{|c|}{ Unstandardized Coefficients } & \multirow{2}{*}{$\begin{array}{c}\text { Standardized } \\
\text { Coefficients } \\
\text { Beta }\end{array}$} & \multirow{2}{*}{$\mathbf{t}$} & \multirow{2}{*}{ Sig. } \\
\hline & B & Std. Error & & & \\
\hline (Constant) & .188 & .057 & & 3.268 & .001 \\
\hline HV SCZ & .075 & .020 & .271 & 3.674 & .000 \\
\hline Age & .000 & .001 & .025 & .340 & .734 \\
\hline Gender & -.021 & .020 & -.076 & -1.034 & .302 \\
\hline
\end{tabular}




\begin{tabular}{|l|c|c|c|c|c|}
\hline $\begin{array}{l}\text { Retinal } \\
\text { Vein } \\
\text { Trajectory }\end{array}$ & \multicolumn{2}{|c|}{ Unstandardized Coefficients } & $\begin{array}{l}\text { Standardized } \\
\text { Coefficients }\end{array}$ & t & Sig. \\
\hline & B & Std. Error & Beta & & \\
\hline (Constant) & .211 & .064 & & 3.293 & .001 \\
\hline HV BD & .107 & .024 & .338 & 4.535 & .000 \\
\hline Age & -.002 & .002 & -.067 & -.902 & .368 \\
\hline Gender & .003 & .023 & .011 & .145 & .885 \\
\hline
\end{tabular}

\begin{tabular}{|c|c|c|c|c|c|}
\hline \multirow{2}{*}{$\begin{array}{l}\text { Retinal } \\
\text { Vein } \\
\text { Trajectory }\end{array}$} & \multicolumn{2}{|c|}{ Unstandardized Coefficients } & \multirow{2}{*}{$\begin{array}{c}\text { Standardized } \\
\text { Coefficients } \\
\text { Beta }\end{array}$} & \multirow{2}{*}{$\mathbf{t}$} & \multirow{2}{*}{ Sig. } \\
\hline & B & Std. Error & & & \\
\hline (Constant) & .215 & .079 & & 2.708 & .007 \\
\hline SCZ BD & .022 & .027 & .061 & .817 & .415 \\
\hline Age & .002 & .002 & .081 & 1.055 & .293 \\
\hline Gender & -.034 & .029 & -.090 & -1.168 & .244 \\
\hline
\end{tabular}

\begin{tabular}{|c|c|c|c|c|c|}
\hline \multirow{2}{*}{$\begin{array}{l}\text { Retinal } \\
\text { Vein } \\
\text { Trajectory }\end{array}$} & \multicolumn{2}{|c|}{ Unstandardized Coefficients } & \multirow{2}{*}{$\begin{array}{c}\text { Standardized } \\
\text { Coefficients } \\
\text { Beta }\end{array}$} & \multirow{2}{*}{$\mathbf{t}$} & \multirow{2}{*}{ Sig. } \\
\hline & B & Std. Error & & & \\
\hline (Constant) & .406 & .056 & & 7.250 & .000 \\
\hline HV SCZ & -.049 & .020 & -.184 & -2.470 & .014 \\
\hline Age & -.003 & .001 & -.140 & -1.904 & .059 \\
\hline Gender & .013 & .020 & .049 & .668 & .505 \\
\hline
\end{tabular}

\begin{tabular}{|c|c|c|c|c|c|}
\hline \multirow{2}{*}{$\begin{array}{l}\text { Retinal } \\
\text { Vein } \\
\text { Trajectory }\end{array}$} & \multicolumn{2}{|c|}{ Unstandardized Coefficients } & \multirow{2}{*}{$\begin{array}{c}\text { Standardized } \\
\text { Coefficients } \\
\text { Beta } \\
\end{array}$} & \multirow{2}{*}{$\mathbf{t}$} & \multirow{2}{*}{ Sig. } \\
\hline & B & Std. Error & & & \\
\hline (Constant) & .461 & .056 & & 8.247 & .000 \\
\hline HV BD & -.042 & .021 & -.155 & -2.059 & .041 \\
\hline Gender & .005 & .020 & .019 & .257 & .798 \\
\hline Age & -.004 & .001 & -.213 & -2.831 & .005 \\
\hline
\end{tabular}




\begin{tabular}{|l|c|c|c|c|c|}
\hline $\begin{array}{l}\text { Retinal } \\
\text { Vein } \\
\text { Trajectory }\end{array}$ & \multicolumn{2}{|c|}{ Unstandardized Coefficients } & $\begin{array}{l}\text { Standardized } \\
\text { Coefficients }\end{array}$ & t & Sig. \\
\hline & B & Std. Error & Beta & & \\
\hline (Constant) & .241 & .047 & & 5.142 & .000 \\
\hline SCZ BD & .000 & .016 & .001 & .019 & .985 \\
\hline Gender & .006 & .017 & .029 & .378 & .706 \\
\hline Age & .001 & .001 & .062 & .806 & .421 \\
\hline
\end{tabular}

Table S3:

Relation between clinical variables and trajectory of retinal vessels.

\begin{tabular}{|l|c|c|c|c|}
\hline Variable & $\begin{array}{c}\text { Trajectory of } \\
\text { retinal vein }\end{array}$ & $\begin{array}{c}\text { Trajectory of } \\
\text { retinal artery }\end{array}$ & $\begin{array}{c}\text { Trajectory of } \\
\text { retinal vein } \\
\text { (adjusted for } \\
\text { age \& sex) }\end{array}$ & $\begin{array}{c}\text { Trajectory of } \\
\text { retinal artery } \\
\text { (adjusted for } \\
\text { age \& sex) }\end{array}$ \\
\hline YMRS & $\begin{array}{c}r=-0.035, \\
p=0.649\end{array}$ & $\begin{array}{c}r=0.068, \\
p=0.382\end{array}$ & $\begin{array}{c}r=-0.185, \\
p=0.32\end{array}$ & $\begin{array}{c}r=0.45, \\
p=0.011\end{array}$ \\
\hline HDRS & $r=-0.031$, & $r=0.12$, & $r=-0.063$, & $r=0.189$, \\
\hline BPRS & $p=0.691$ & $p=0.873$ & $p=0.735$ & $p=0.310$ \\
\hline Age at onset of illness & $r=-0.006$, & $r=-0.057$, & $r=-0.274$, & $r=0.078$, \\
& $p=0.959$ & $p=0.621$ & $p=0.136$ & $p=0.677$ \\
\hline Duration of illness & $p=0.18$, & $r=-0.009$, & $r=0.01$, & $r=0.029$, \\
& $p=0.129$, & $r=0.066$, & $r=-0.001$, & $r=-0.29$, \\
\hline Chlorpromazine & $p=0.125$ & $p=0.437$ & $p=0.998$ & $p=0.877$ \\
\hline equivalent of & $r=-0.038$, & $r=-0.117$, & $r=-0.182$, & $r=0.063$, \\
antipsychotic & $p=0.681$ & $p=0.204$ & $p=0.327$ & $p=0.746$ \\
\hline
\end{tabular}




\section{Appendix S1. Effect of nicotine use on retinal trajectory measurements}

While subjects with nicotine dependence were not included in the study, 12 subjects with SCZ and 4 subjects with BD had nicotine use. Analysis of variance was conducted to examine the differences between groups after exclusion of these subjects to rule out the possible confounding effect of nicotine use with $87 \mathrm{HV}, 82 \mathrm{SCZ}$ and $84 \mathrm{BD}$. There were significant differences between groups in retinal vein trajectory $(H V=0.17 \pm 0.08$; $S C Z=0.25 \pm 0.17 ; B D=0.27 \pm 0.20$ and $p<0.001)$ and retinal artery trajectory $(H V=0.34 \pm 0.15$; $\mathrm{SCZ}=0.29 \pm 0.10 ; \mathrm{BD}=0.28 \pm 0.11$ and $\mathrm{p}=0.003)$. Overall regression model was still significant except for $\mathrm{SCZ}$ and $\mathrm{BD}$ (similar to main results) for both retinal vein trajectory $\left(H V: S C Z R^{2}=0.077, F_{(1,167)}=13.972, p<0.001 ; H V: B D R^{2}=0.107, F_{(1,169)}=20.257, p<0.001\right.$; $\left.\mathrm{SCZ}: \mathrm{BD} \mathrm{R}^{2}=0.005, \mathrm{~F}_{(1,164)}=0.891, \mathrm{p}=0.347\right)$ and retinal artery trajectory $\left(\mathrm{HV}: \mathrm{SCZ} \mathrm{R}^{2}=\right.$ $0.045, F_{(1,167)}=7.797, p=0.006 ; H V: B D R^{2}=0.046, F_{(1,169)}=8.236, p=0.005 ; S C Z: B D R^{2}=$ $\left.0.00, F_{(1,164)}=0.025, p=0.874\right)$.

\section{Appendix S2. Support vector machine (SVM) performance for classification.}

Supervised SVM model has accuracy of $82 \%$; sensitivity of $81 \%$ and specificity of $82 \%$ for classifying HV and SCZ whereas supervised SVM model has accuracy of 75\%, sensitivity of $74 \%$ and specificity of $76 \%$ for classifying SCZ and BD. The results for HV and BD classification using SVM has accuracy of $68 \%$, sensitivity of $64 \%$ and specificity of $75 \%$.

\section{Appendix S3. Relation between retinal vascular trajectory, body mass index, and blood pressure.}

For a subgroup of patients height and weight was measured and body mass index (BMI) was calculated on the day of retinal examination. BMI details were available for 44 healthy volunteers, 77 patients with SCZ and 58 patients with BD. Mean BMI for HV was 23.9 \pm 4.4 , for $S C Z$ was $25.2 \pm 4.9$ and for BD was $25.8 \pm 4.4$. On analysis of variance, there was no significant difference between the groups on $\mathrm{BMI}(\mathrm{F}=2.27, \mathrm{p}=0.11)$. As mentioned in the manuscript patients with hypertension were excluded from the study. Among those who participated, blood pressure was recorded in 28 patients with SCZ and 54 patients with $\mathrm{BD}$ on the day of retinal examination. On independent $t$ test, mean systolic blood pressure between the groups was not significantly different $[S C Z=115.2 \pm 7.6$, $B D=119.0 \pm 11.8 ; t=-1.55, p=0.12$ ]. Even after inclusion of the $B M I$ and blood pressure as covariates, the results remained the same. There was no significant difference between $S C Z$ and $B D$ on Retinal Vein Trajectory $(S C Z=0.22 \pm 0.15 ; B D=0.23 \pm 0.16 ; F=0.31 ; p=0.82$ ) and Retinal Artery Trajectory $(S C Z=0.29 \pm 0.11 ; B D=0.27 \pm 0.11 ; F=1.17 ; p=0.327)$. 
Figure S1:

Diagrammatic representation of group means of trajectory of retinal veins and retinal arteries.

Comparison of Retinal Vein Trajectories

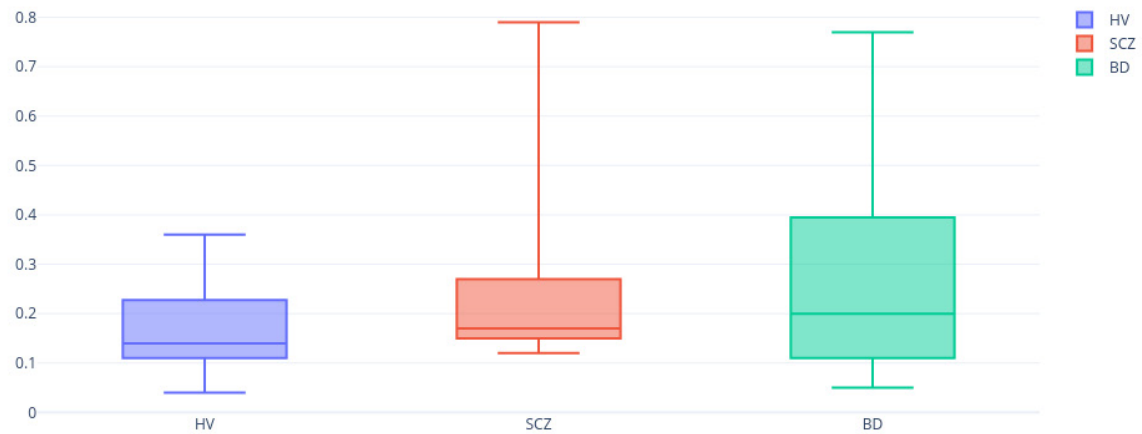

Comparison of Retinal Artery Trajectories

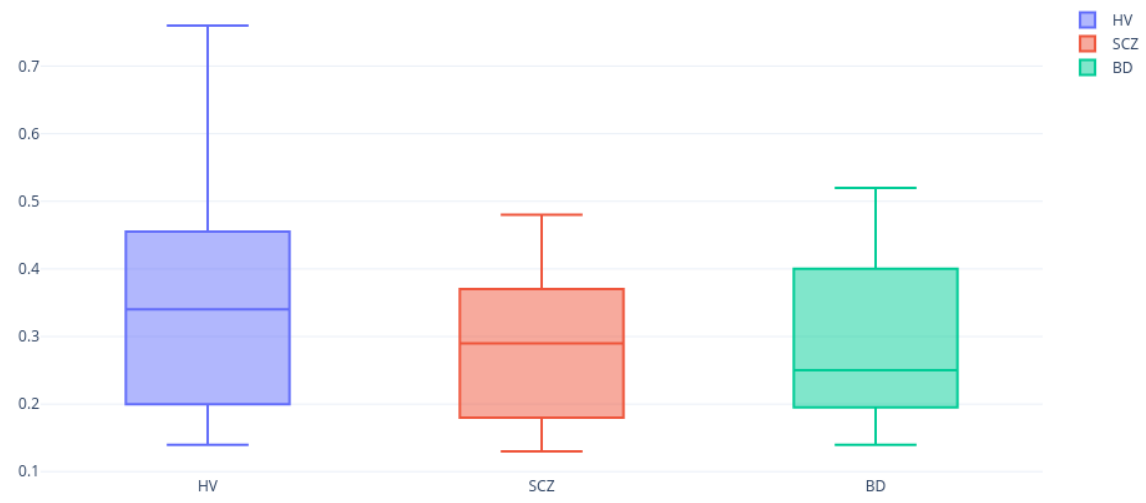




\section{CHAPTER 6}

\section{RELATION BETWEEN RETINAL VASCULAR ABNORMALITIES AND WORKING MEMORY IMPAIRMENTS IN PATIENTS WITH SCHIZOPHRENIA AND BIPOLAR DISORDER}

Abhishek Appaii, Bhargavi Nagendra, Dona Maria Chako, Ananth Padmanabha, Chaitra V Hiremath, Arpitha Jacob, Shivarama Varambally, Muralidharan Kesavan, Ganesan Venkatasubramanian, Shyam Vasudeva Rao, Carroll A.B. Webers, Tos T.J.M. Berendschot, Naren P. Rao 



\section{Abstract}

Emerging evidence indicates abnormal retinal micro-vasculature in schizophrenia (SCZ) and bipolar disorder (BD) and its relation to cognitive functions. However, the association of these abnormalities with the cognitive deficits in these disorders has not been examined till date. Hence, we explored this aspect in patients with $\mathrm{SCZ}, \mathrm{BD}$, and healthy volunteers (HV). We examined 34 with $\mathrm{SCZ}, 39$ with $\mathrm{BD}$, and $45 \mathrm{HV}$. Retinal images were acquired using nonmydriatic fundus camera. The retinal images were analyzed, and average diameters of retinal arterioles and venules were calculated. Working memory was assessed using computerized one-back test from Cogstate ${ }^{\circledR}$ battery. There was significant difference between groups in retinal venules and arterioles caliber $(p<$ $0.001)$. Both SCZ and BD patients had wider venules and narrower arterioles. They had significantly lower working memory accuracy $(p=0.008)$ and higher log mean speed $(p<0.001)$. There was significant positive correlation between one-back test accuracy and retinal arteriolar caliber $(r=0.22 ; p=0.01)$ and between log mean speed score and retinal venular caliber $(r=0.20 ; p=0.02)$. Findings suggest association between working memory and retinal vascular caliber, a potential pointer towards understanding the vascular pathology in cognitive deficits in SCZ and BD. Future studies need to examine whether retinal vascular could be a biomarker for SCZ and BD.

Keywords: Bipolar disorder, Cerebrovascular disorder, Cognitive impairment, Fundus, Retinal vasculature, Schizophrenia. 


\section{Highlights}

- Retinal image is a proxy assessment of the cerebral vasculature.

- The Cognitive impairments adversely affect the functional outcomes in schizophrenia (SCZ) and bipolar disorder (BD).

- SCZ and BD have significantly wider veins and narrower arteries than healthy volunteers.

- These are associated with poorer working memory.

- Retinal examination could help in identifying risk of vascular adverse event. 


\subsection{INTRODUCTION}

Schizophrenia (SCZ) and Bipolar disorder (BD) are common psychiatric conditions with considerable morbidity and financial burden. Cognitive impairment is considered one of the core features of SCZ and BD with deficits in processing speed, attention, working memory, reasoning, and problem solving abilities ${ }^{1}$. Cognitive impairments adversely affect the functional outcomes in both SCZ and BD; cognitive improvement is hence considered an important target in the treatment of both these disorders ${ }^{2}$. Despite being an important determinant of functional recovery, adequate management of cognitive deficits is still an unmet need in SCZ and BD, partly owing to the poor understanding we have regarding its neurobiology ${ }^{3}$.

While the neurobiology of cognitive deficits is not completely known, several studies have indicated associations between cerebrovascular and cardiovascular abnormalities and cognitive deficits ${ }^{4}$. Several studies have suggested vascular abnormalities and higher occurrence of adverse cerebrovascular/cardiovascular incidents in SCZ and $\mathrm{BD}^{5}$. However, assessment of cerebrovascular structure is complex and has been inadequately examined in SCZ and BD. Few studies have used arterial spin labelling and perfusion weighted imaging to examine cerebral blood flow, an indicator of cerebrovascular functioning ${ }^{6}$.

With recent advances in technology, fundus photography has emerged as a simple, non-invasive, proxy measure for assessing cerebral microvasculature. Abnormal retinal vasculature, particularly wider venules and narrower arterioles indicates future risk of stroke ${ }^{7}$. Retinal vascular abnormalities are also linked to white matter hyperintensities. These hyperintensities indicate cerebral microvascularabnormalities ${ }^{8}$ and are commonly seen in BD. A few recent studies have also reported retinal vascular abnormalities in $\mathrm{SCZ}^{8}$ and in twins discordant for $\mathrm{SCZ}$, suggesting that retinal microvasculature may reflect familial vulnerability to psychotic symptoms ${ }^{9}$. Recently, we demonstrated narrower arterioles and wider venules in the retinae of both SCZ and BD compared to $\mathrm{HV}^{10}$. These findings, in conjunction with several other studies that have reported abnormalities in the retinal nerve fiber layer in SCZ suggests the potential use of retinal microvasculature examination as a window to the brain?.

Interestingly, several studies have suggested a relation between retinal vascular abnormality and cognitive functions in healthy individuals as well as in patients with dementia ${ }^{11}$. However, the relation between cognitive deficits and retinal 
microvasculature in SCZ and BD remains to be explored. In view of its clinical significance, and its relation to vascular abnormalities, we examined relation of the caliber of retinal arterioles and venules with cognitive function in patients with SCZ and BD. We examined working memory, an important cognitive domain impaired in both $\mathrm{SCZ}$ and $\mathrm{BD}^{12}$ as the indicator of cognitive deficits. We measured the working memory performance using a valid test, $\mathrm{N}$-back test ${ }^{13}$. As emerging evidence suggests association between impaired cognition and wider retinal venules and narrower arterioles $^{14}$, we hypothesized that wider venules and narrower arterioles would be associated with poorer working memory performance.

\subsection{METHODOLOGY}

\subsubsection{Participants}

A total of 118 participants, 34 patients with SCZ, 39 with BD, and $45 \mathrm{HV}$ were included in the study. They were part of a larger study that examined differences in the caliber of retinal arterioles and venules across these three groups. Patients were recruited from the inpatient and outpatient services of the National Institute of Mental Health and Neurosciences (NIMHANS), Bengaluru, India. Clinical interviews were conducted by a board-certified psychiatrist to ensure that diagnostic criteria for SCZ or BD were met according to the International Classification of disorders (ICD)-10 15 . Those meriting a diagnosis of substance abuse or dependence (except nicotine) or other Axis I psychiatric disorders were excluded. Medical and neurological disorders (hypertension, diabetes, stroke), and history of eye trauma were also part of the exclusion criteria. None of the HV had Axis I psychiatric disorder. They were also assessed by a trained psychiatrist and completed self-rated level 1 cross cutting symptom measure - Adult version $^{16}$. Substance abuse, hypertension, diabetes, stroke, major neurological illnesses, and eye trauma were ruled out in HV also. Adults in the age range of 18 to 50 years with a minimum of 7 years of formal education were included in the study. Those above 50 years were not included as the quality of fundus image obtained through non-mydriatic acquisition is poor in elderly individuals. Those with less than 7 years of formal education were excluded owing to potential confounding effects of education on performance in a computerized cognitive test. Detailed description is available in our former publication ${ }^{10}$. We obtained approval from the institutional ethics committee and all participants provided informed consent. 


\subsubsection{Clinical Assessments}

The tools used for severity of clinical symptoms were as follows. i) The Brief Psychiatric Rating Scale (BPRS) ${ }^{17}$ for positive and negative symptoms, and general psychopathology in schizophrenia, ii) The Young mania rating scale (YMRS) ${ }^{18}$ for manic symptoms, iii) The Hamilton Depression rating scale (HDRS) ${ }^{19}$ for depressive symptoms, iv) Global assessment of functioning (GAF) ${ }^{20}$ for social, occupational, and psychological functioning v) Clinical Global Impression (CGI) ${ }^{21}$.

\subsubsection{Assessment of working memory}

Working memory was examined using the computerized One-back test of the Cogstate $^{\circledR}$ battery ${ }^{12}$. The one-back task is a simple version of the N-back task which is a commonly used for working memory task. It has been shown to detect impairments in patients with $\mathrm{SCZ}$ as well as $\mathrm{BD}^{13}$. This task requires the participant to maintain information in working memory and to indicate whether the card displayed is the same as the one displayed in the preceding trial. The number of correct responses expressed as a percentage of the total number of trials was calculated. Data distributions were then normalized by expressing the percentages as decimals and applying an arcsine transformation. Another related measure log mean speed was also calculated. Log mean speed indicates mean of the log transformed reaction times for correct responses. Scoring was done by the Cogstate ${ }^{\circledR}$ program and the values were noted (for details refer to www.cogstate.com). While lower scores indicate better performance on the log mean speed measure, the same in accuracy measures indicates inferior performance.

\subsubsection{Retinal image acquisition and measurement of retinal vasculature}

The detailed description of acquisition and analysis of retinal images are given in an earlier publication ${ }^{10}$. A brief description is given below. Image acquisition was carried out by competent individuals employing a non-mydriatic fundus camera which has a field of view of 40 degrees. Quantification of the retinal images was performed using a semiautomated software called Vessel Assessment and Measurement Platform for Images of the REtina (VAMPIRE). The tool provides automatic detection of retinal landmarks (optic disc) and quantifies key parameters that are frequently used in investigative studies such as vessel diameter and vessel branching coefficients. The extended zone between 
0.5- and 2-disc diameters from the optic disc were used to perform the measurement of the diameters of the arterioles and venules. A calibration factor was used to adjust for possible magnification differences. Such differences may have been caused by fundus camera optics, image resolution, or patient's refractive errors. The pixels to micrometers $(\mu \mathrm{m})$ conversion was also calculated using the calibration factor ${ }^{10}$ and was applied for individual fundus images. Subsequently, the average central retinal artery equivalent (CRAE) and central retinal vein equivalent (CRVE) were calculated by averaging the arteriolar and venular diameters of the right and left eyes. The images from 40 selected participants were analyzed by two independent raters demonstrating good inter-rater reliability (Intraclass correlation $=0.831$ ).

\subsubsection{STATISTICAL ANALYSIS}

The data was assessed for normative distribution using the Shapiro-Wilk test. Parametric statistical tests were employed for continuous variables. Chi-Square test was used to examine the differences in sex distribution. One-way analysis of variance (ANOVA) was used to analyze the age differences. ANOVA was also used to determine group differences in CRVE and CRAE. Difference between the groups on cognitive measures were compared using analysis of covariance (ANCOVA) with years of education as covariate, as this could confound the performance on the working memory task. Further post-hoc analysis was conducted to examine the difference between group pairs. Partial correlation analysis with years of education as co-variate was used to assess the relation between the retinal vascular caliber and cognitive tests. As we calculated the relation of working memory measures with both arteriolar and venular calibers, for correlation analysis, $a=0.025(0.05 / 2)$, a Bonferroni correction was considered as significant. To examine the relation between other clinical measures and working memory performance, further partial correlations were conducted between oneback accuracy score and log mean speed score with BPRS, YMRS, HDRS, and duration of illness with years of education as co-variate. All analyses were performed using the Statistical Package for Social Sciences (SPSS) version 24. 


\subsection{RESULTS}

\subsubsection{Comparison of demographic variables}

In total 118 volunteers were recruited for the analysis. There was no difference in age $(p=0.80)$ or sex $(p=0.12)$ distribution between the groups. There was a significant difference between the three groups in years of education $(p<0.001)$. On Bonferroni post-hoc analysis, there was a significant difference between HV and SCZ $(p<0.001)$ as well as between $\mathrm{HV}$ and $\mathrm{BD}(\mathrm{p}<0.001)$, but there was no significant difference between SCZ and BD ( $p=1.00)$ (See Table, Supplement Appendix 1).

Table 1.

Comparison of demographic and clinical variables between the groups

\begin{tabular}{|l|c|c|c|c|c|}
\hline & $\begin{array}{c}\mathbf{H V} \\
(\mathbf{n}=\mathbf{4 5})\end{array}$ & $\begin{array}{c}\mathbf{S C Z} \\
(\mathbf{n}=\mathbf{3 4})\end{array}$ & $\begin{array}{c}\mathbf{B D} \\
(\mathbf{n}=\mathbf{3 9})\end{array}$ & $\mathbf{F / t / \mathbf { X } ^ { \mathbf { 2 } }}$ & $\mathbf{p}$ \\
\hline Age & $32.8 \pm 8.0$ & $31.8 \pm 5.0$ & $32.9 \pm 6.0$ & 0.22 & 0.80 \\
\hline Gender ratio (M/F) & $23 / 22$ & $24 / 10$ & $27 / 12$ & 4.2 & 0.12 \\
\hline Years of Education & $16.2 \pm 3.2$ & $12.6 \pm 2.7$ & $12.1 \pm 2.7$ & 25.5 & $<0.001^{*}$ \\
\hline Age at onset (years) & - & $25.5 \pm 4.6$ & $24 \pm 5.8$ & 1.3 & 0.25 \\
\hline $\begin{array}{l}\text { Duration of } \\
\text { untreated illness } \\
\text { (years) }\end{array}$ & - & $6.4 \pm 4.5$ & $7.6 \pm 4.9$ & 3.9 & 0.05 \\
\hline
\end{tabular}

SCZ - patients with schizophrenia; BD - patients with bipolar disorder; HV - healthy volunteer; $F$ - Analysis of Variance; $t$ - Independent $t$ test; $x 2$ - Chi square test; *Significant difference

There was no significant difference between the two patient groups in duration of untreated illness ( $t=0.03 ; p=0.87$ ) or age at onset of illness $(t=1.3 ; p=0.25)$. SCZ patients had a mean score of $28.2 \pm 4.1$ on BPRS and BD patients had mean score of 1.3 \pm 2.7 on YMRS and $3.1 \pm 4.9$ on HDRS. Demographic and clinical variables are given in Table 1. 


\subsubsection{Differences in working memory performance between groups}

The one-back test performance showed a significant difference between the three groups both in terms of accuracy $(F=16.18 ; p<0.001)$ and log mean speed $(F=14.72$; $p<0.001$ ) (Table 2). On post hoc analysis, HV had significantly higher accuracy than SCZ ( $p=0.001)$ as well as BD $(p<0.001)$. Understandably, on analysis of log mean speed, HV had significantly lower scores compared to SCZ $(p<0.001)$ as well as BD $(p<0.001)$. There was no significant difference between SCZ and BD in either accuracy scores or log means speed score ( $p>0.05$ ) (See Table, Supplement Appendix 2).

Table 2.

Retinal vascular caliber and working memory performance between the groups

\begin{tabular}{|l|c|c|c|c|c|}
\hline & $\begin{array}{c}\text { HV } \\
(\mathbf{n}=\mathbf{4 5})\end{array}$ & $\begin{array}{c}\text { SCZ } \\
(\mathbf{n}=\mathbf{3 4 )}\end{array}$ & $\begin{array}{c}\text { BD } \\
(\mathbf{n}=\mathbf{3 9 )}\end{array}$ & $\mathbf{F}$ & $\mathbf{p}$ \\
\hline CRVE & $197.7 \pm 20.9$ & $210.7 \pm 25.4$ & $228.6 \pm 24.9$ & 18.0 & $<0.01^{*}$ \\
\hline CRAE & $116.2 \pm 20.5$ & $93.9 \pm 13.0$ & $92.6 \pm 16.9$ & 24.26 & $<0.001^{*}$ \\
\hline $\begin{array}{l}\text { One back task } \\
\text { - accuracy }\end{array}$ & $1.20 \pm 0.26$ & $0.92 \pm 0.23$ & $0.94 \pm 0.26$ & 5.01 & $0.008^{*}$ \\
\hline $\begin{array}{l}\text { One back task } \\
\text { - log mean } \\
\text { speed }\end{array}$ & $2.90 \pm 0.10$ & $3.00 \pm 0.11$ & $3.03 \pm 0.14$ & 8.70 & $<0.001^{*}$ \\
\hline
\end{tabular}

SCZ - patients with schizophrenia; BD - patients with bipolar disorder; HV - healthy volunteer; F- Analysis of Variance; CRVE- Central Retinal Vein Equivalent, CRAE- Central Retinal Artery Equivalent; * Significant difference

\subsubsection{Differences in retinal vascular caliber}

In accordance with our earlier report ${ }^{10}$, this sub-sample also showed significant differences between the groups in both CRVE $(F=18.00 ; p<0.001)$ and CRAE $(F=24.26$; $\mathrm{p}<0.001$ ) (Table 2). On Bonferroni post-hoc analysis, BD had greater venular diameters compared to both HV $(p<0.001)$ and SCZ $(p=0.005)$. The relatively greater venular diameter in SCZ compared to HV was only at trend level $(p=0.049)$. On the other hand, while both SCZ $(p<0.001)$ and BD $(p<0.001)$ had significantly lower arteriolar diameter compared to HV, there was no significant difference between BD and SCZ ( $p=1.00)$ in this aspect (See Table, Supplement Appendix 1). 


\subsubsection{Correlation between working memory performance measures and retinal vascular caliber}

Even after adjusting for years of education, retinal artery diameter showed a significant positive partial correlation with one-back test accuracy $(r=0.22 ; p=0.01)$ and a trend level negative correlation with $\log$ mean speed score $(r=-0.17 ; p=0.06)$. Retinal venular caliber on the contrary, had significant positive partial correlation with log mean speed score $(r=0.20 ; p=0.02)$ and trend level negative correlation with accuracy score $(r$ $=-0.15 ; p=0.08)$. There were no significant correlations between working memory performance scores and clinical variables (See Table, Supplement Appendix 3).

\subsection{DISCUSSION}

This is the first study to examine the relation between cognitive deficits in the form of impaired working memory, and retinal arteriolar and venular caliber in SCZ and BD. Findings of the study suggest that wider retinal venules and narrower retinal arterioles are associated with working memory deficits in SCZ and BD. Findings of the study provide further support to the role of vascular risk factors in cognitive deficits, typically seen in these psychoses. There was no significant difference between SCZ and BD on working memory task performance as reported in several previous studies ${ }^{22}$. A few studies have reported greater deficits in $\mathrm{SCZ}$ compared to $\mathrm{BD}^{23}$. A potential reason for this discrepancy could be differences in participant characteristics, given that $\mathrm{SCZ}$ and $\mathrm{BD}$ are heterogeneous disorders.

Previous studies in elderly individuals have reported association between wider retinal venules and cognitive dysfunction ${ }^{24}$. Another study reported association between suboptimal network geometry of the retinal vasculature and cognitive function ${ }^{24}$. However, the presence of similar associations in young adults with SCZ and BD had not been examined. Our findings suggest that wider retinal venules are associated with cognitive deficits in adults with $\mathrm{SCZ}$ and $\mathrm{BD}$ also, as has previously been found in other conditions. In addition, our findings also suggest association between narrow retinal arterioles and cognitive deficits in line with emerging evidence ${ }^{14}$. Cerebral small vessel disease has been shown to be associated with cognitive deficits ${ }^{25}$; interestingly, retinal arteriolar caliber is also related to cerebral small vessel disease ${ }^{26}$. Hence, our findings provide preliminary evidence and rationale for further examination of the relation between retinal vascular caliber and cognitive function in SCZ and BD. Following future 
replication, retinal vascular examination may potentially be used to identify those at risk of vascular events. This could help to initiate corrective measures addressing vascular risk factors.

At this stage, the biological mechanisms underlying the association between retinal vascular changes and cognitive function deficits in SCZ and BD are not completely known. Cerebral and retinal microcirculations have similar anatomical, physiological, and embryonic origin. The retina thus provides a unique perspective of cerebral circulation in vivo ${ }^{7}$. Several studies have reported an association of co-morbid metabolic syndrome with impaired cognitive function in SCZ and $\mathrm{BD}^{27}$. Few authors have proposed that adverse metabolic factors may operate via vascular pathways resulting in impaired cognitive function ${ }^{28}$. As retinal vasculature is reflective of abnormalities in cerebral vasculature, it provides a non-invasive means of access to understand cerebral microvasculature abnormalities resulting in impaired cognition. Further longitudinal studies are warranted to comprehensively understand the relation between retinal vasculature and cognitive function.

The interpretation of these results needs to take into account our study's limitations. All patients were on pharmacological therapy. Possible confounding effects of these medications on CRVE, CRAE, or cognitive functions cannot be eliminated. Although examination of drug naive patients would have been ideal, it would have decreased the generalizability of study findings. To assess the effects of antipsychotic medications on these measures, we examined the correlation between antipsychotic dosage in chlorpromazine equivalents and CRVE, CRAE, one-back accuracy, and log mean speed. There was no significant correlation with any of these measures (See Table, Supplement Appendix 3). However, we could not rule out the effects of other medications like mood stabilizers, antidepressants, and sedatives. Future studies in drug-naïve or drug free individuals could provide definitive answers to this question. We had excluded individuals with diagnosed hypertension or diabetes mellitus. However, we did not document blood glucose levels and blood pressure of all participants when the retinal images were acquired. Hence, potential confounding effects of pre-diabetic or prehypertensive status ${ }^{29}$ need to be considered. Our participants belonged to the younger age spectrum, and the possibility of such states is remote. However, the risk of missing undiagnosed medical conditions remains. Future studies need to include objective measurements of these risk factors and control for them. We chose to measure working 
memory deficits alone and no other cognitive domains as working memory deficits are commonly implicated in SCZ and BD. With our study design, it is not possible to infer whether the working memory deficits seen in $\mathrm{SCZ}$ and $\mathrm{BD}$ is primary, or secondary to deficits in other cognitive domains. Future studies need to consider the use of a complete neuropsychological battery including other cognitive domains in addition to working memory. The sample size of our study was small. Although sufficient for across group comparisons, the numbers were not adequate for intragroup correlations between cognitive functions and retinal vascular abnormality. As similar brain networks are recruited in $\mathrm{SCZ}, \mathrm{BD}$, and $\mathrm{HV}$ for working memory ${ }^{30}$, we had no rationale to suspect a differential effect of diagnostic status on the directionality of correlation. The direction of correlation being different across HV vs SCZ vs $B D$, we pooled all participants together to examine the relation between cognitive functions and retinal vascular caliber. Future studies with a greater number of patients could consider examining the relations within a diagnostic subtype or a homogeneous subgroup, e.g., $\mathrm{BD}$ with or without psychotic symptoms. Few patients had nicotine dependence; this could have adversely influenced the cognitive functions and retinal vascular caliber. To control for the effect of nicotine dependence, we re-analyzed the data after excluding 12 patients (8 SCZ and $4 \mathrm{BD}$ ) who had nicotine dependence. However, the findings were similar in the re-analyses suggesting absence of any significant effect of nicotine dependence (See Table, Supplement Appendix 4). There was a significant difference in years of education between patients and controls. This is understandable as previous epidemiological studies have also reported that patients with SCZ and BD tend to attain lower educational levels. As education could have affected the performance on the working memory task, we used it as a covariate in ANCOVA analysis; the results however, remained significant. In addition, we conducted regression analyses between groups, with and without years of education as regressors. Group continued to be the major contributor to the model and the regression coefficients were comparable, with and without education as regressor. This suggests that the findings were not influenced by education alone (See Table, Supplement Appendix 5). Nonetheless, future studies with larger samples could analyze a sub-group of education-matched participants to elucidate the influence of education. 


\subsection{Conclusion}

Our study shows association between working memory and retinal vascular caliber in SCZ and BD. Findings indicate wider venules and narrower arterioles to be associated with poorer working memory. These preliminary findings, if replicated, could provide additional information on understanding the biology of cognitive deficits typically seen in SCZ and BD. Retinal vascular examination could potentially help in identifying those at risk of vascular adverse event. In view of the importance of targeting cognitive deficits for functional recovery in SCZ and $\mathrm{BD}$, it is imperative to further examine the relation between retinal vasculature and cognitive functions in longitudinal studies. 


\section{References}

1. Lynham AJ, Hubbard L, Tansey KE, et al. Examining cognition across the bipolar/ schizophrenia diagnostic spectrum. J Psychiatry Neurosci. 2018;43(4):245-253.

2. Green MF. Cognitive impairment and functional outcome in schizophrenia and bipolar disorder. J Clin Psychiatry. 2006;67 Suppl 9:3-8; discussion 36-42.

3. Tamminga CA. The neurobiology of cognition in schizophrenia. J Clin Psychiatry. 2006;67(9):e11.

4. Burkauskas J, Lang P, Bunevicius A, Neverauskas J, Buciute-Jankauskiene M, Mickuviene $N$. Cognitive function in patients with coronary artery disease: A literature review. J Int Med Res. 2018;46(10):4019-4031.

5. Goldstein BI. Bipolar Disorder and the Vascular System: Mechanisms and New Prevention Opportunities. Can J Cardiol. 2017;33(12):1565-1576.

6. Toma S, MacIntosh BJ, Swardfager W, Goldstein BI. Cerebral blood flow in bipolar disorder: A systematic review. Journal of affective disorders. 2018;241:505-513.

7. Patton N, Aslam T, Macgillivray T, Pattie A, Deary IJ, Dhillon B. Retinal vascular image analysis as a potential screening tool for cerebrovascular disease: a rationale based on homology between cerebral and retinal microvasculatures. Journal of anatomy. 2005;206(4):319-348.

8. Meier MH, Shalev I, Moffitt TE, et al. Microvascular abnormality in schizophrenia as shown by retinal imaging. The American journal of psychiatry. 2013;170(12):14511459.

9. Meier MH, Gillespie NA, Hansell NK, et al. Retinal microvessels reflect familial vulnerability to psychotic symptoms: A comparison of twins discordant for psychotic symptoms and controls. Schizophr Res. 2015;164(1-3):47-52.

10. Appaji A, Nagendra B, Chako DM, et al. Retinal vascular abnormalities in schizophrenia and bipolar disorder: A window to the brain. Bipolar Disord. 2019.

11. McGrory S, Cameron JR, Pellegrini E, et al. The application of retinal fundus camera imaging in dementia: A systematic review. Alzheimer's \& dementia (Amsterdam, Netherlands). 2017;6:91-107. 
12. Bo $Q$, Mao Z, Li X, Wang Z, Wang C, Ma X. Use of the MATRICS consensus cognitive battery (MCCB) to evaluate cognitive deficits in bipolar disorder: A systematic review and meta-analysis. PloS one. 2017;12(4):e0176212.

13. Brandt CL, Eichele T, Melle l, et al. Working memory networks and activation patterns in schizophrenia and bipolar disorder: comparison with healthy controls. Br J Psychiatry. 2014;204:290-298.

14. Ryan CM, Klein BEK, Lee KE, Cruickshanks KJ, Klein R. Associations between recent severe hypoglycemia, retinal vessel diameters, and cognition in adults with type 1 diabetes. $J$ Diabetes Complications. 2016;30(8):1513-1518.

15. WHO. The ICD-10 Classification of Mental and Behavioural Disorders: Clinical descriptions and diagnostic guidelines. Vol 1: World Health Organization; 1992.

16. Narrow WE, Clarke DE, Kuramoto SJ, et al. DSM-5 field trials in the United States and Canada, Part III: development and reliability testing of a cross-cutting symptom assessment for DSM-5. The American journal of psychiatry. 2013;170(1):71-82.

17. Overall JE, Gorham DR. The brief psychiatric rating scale. Psychological reports. 1962;10:799-812.

18. Young RC, Biggs JT, Ziegler VE, Meyer DA. A rating scale for mania: reliability, validity and sensitivity. Br J Psychiatry. 1978;133:429-435.

19. Hamilton M. A rating scale for depression. J Neurol Neurosurg Psychiatry. 1960;23:5662.

20. Jones SH, Thornicroft G, Coffey M, Dunn G. A brief mental health outcome scalereliability and validity of the Global Assessment of Functioning (GAF). Br J Psychiatry. 1995;166(5):654-659.

21. Busner J, Targum SD. The clinical global impressions scale: applying a research tool in clinical practice. Psychiatry (Edgmont). 2007;4(7):28-37.

22. Kuswanto C, Chin R, Sum MY, et al. Shared and divergent neurocognitive impairments in adult patients with schizophrenia and bipolar disorder: Whither the evidence? Neurosci Biobehav Rev. 2016;61:66-89.

23. Simonsen $C$, Sundet $K$, Vaskinn A, et al. Neurocognitive dysfunction in bipolar and schizophrenia spectrum disorders depends on history of psychosis rather than diagnostic group. Schizophr Bull. 2011;37(1):73-83. 
24. Patton N, Pattie A, MacGillivray $T$, et al. The association between retinal vascular network geometry and cognitive ability in an elderly population. Invest Ophthalmol Vis Sci. 2007;48(5):1995-2000.

25. Ostergaard L, Engedal TS, Moreton F, et al. Cerebral small vessel disease: Capillary pathways to stroke and cognitive decline. J Cereb Blood Flow Metab. 2016;36(2):302325.

26. Bettermann K, Slocomb JE, Shivkumar V, Lott ME. Retinal vasoreactivity as a marker for chronic ischemic white matter disease? J Neurol Sci. 2012;322(1-2):206-210.

27. Bora E, Mclntyre RS, Ozerdem A. Neurococognitive and neuroimaging correlates of obesity and components of metabolic syndrome in bipolar disorder: a systematic review. Psychological medicine. 2018:1-12.

28. Yates KF, Sweat V, Yau PL, Turchiano MM, Convit A. Impact of metabolic syndrome on cognition and brain: a selected review of the literature. Arteriosclerosis, thrombosis, and vascular biology. 2012;32(9):2060-2067.

29. Nguyen TT, Wang JJ, Wong TY. Retinal vascular changes in pre-diabetes and prehypertension: new findings and their research and clinical implications. Diabetes Care. 2007;30(10):2708-2715.

30. Brandt CL, Eichele T, Melle l, et al. Working memory networks and activation patterns in schizophrenia and bipolar disorder: comparison with healthy controls. The British Journal of Psychiatry. 2014;204(4):290-298. 


\section{Supplementary Materials}

\section{Supplement Appendix 1}

\section{Table S1:}

Mean difference between groups on demographic measures and retinal vascular diameter:

\begin{tabular}{|c|c|c|c|c|c|}
\hline & Group & Group & $\begin{array}{c}\text { Mean } \\
\text { difference }\end{array}$ & Std error & $\mathbf{p}$ \\
\hline \multirow{3}{*}{ Age } & HV & SCZ & 0.94 & 1.50 & 1.00 \\
\hline & HV & $B D$ & .130 & 1.44 & 1.00 \\
\hline & SCZ & $B D$ & -.810 & 1.55 & 1.00 \\
\hline \multirow{3}{*}{ Years of education } & HV & SCZ & 3.73 & .67 & $<0.001$ \\
\hline & HV & $\mathrm{BD}$ & 4.16 & .64 & $<0.001$ \\
\hline & SCZ & $B D$ & .43 & .69 & 1.00 \\
\hline \multirow{3}{*}{ CRVE } & HV & SCZ & -13.06 & 5.36 & .049 \\
\hline & $\mathrm{HV}$ & $B D$ & -30.97 & 5.17 & $<0.001$ \\
\hline & SCZ & $B D$ & -17.90 & 5.54 & .005 \\
\hline \multirow{3}{*}{ CRAE } & $\mathrm{HV}$ & SCZ & 22.33 & 3.96 & $<0.001$ \\
\hline & $\mathrm{HV}$ & $\mathrm{BD}$ & 23.58 & 3.81 & $<0.001$ \\
\hline & SCZ & $B D$ & 1.24 & 4.09 & 1.00 \\
\hline
\end{tabular}

SCZ - patients with schizophrenia; BD - patients with bipolar disorder; HV - healthy volunteer; p- Bonferroni post-hoc analysis; CRVE- Central Retinal Vein Equivalent, CRAE- Central Retinal Artery Equivalent 


\section{Supplement Appendix 2}

Table S2:

Mean difference between groups on working memory task performance:

\begin{tabular}{|l|c|c|c|c|c|}
\hline & Group & Group & $\begin{array}{c}\text { Mean } \\
\text { difference }\end{array}$ & Std error & $p$ \\
\hline \multirow{2}{*}{$\begin{array}{l}\text { One-back task - log } \\
\text { mean speed }\end{array}$} & HV & SCZ & -0.098 & 0.027 & 0.001 \\
\cline { 2 - 6 } & HV & BD & -0.13 & 0.026 & $<0.001$ \\
\cline { 2 - 6 } & SCZ & BD & -0.04 & 0.027 & 0.584 \\
\hline \multirow{2}{*}{$\begin{array}{l}\text { One-back task - } \\
\text { accuracy }\end{array}$} & HV & SCZ & 0.28 & 0.057 & $<0.001$ \\
\cline { 2 - 6 } & HV & BD & 0.25 & 0.054 & $<0.001$ \\
\cline { 2 - 6 } & SCZ & BD & -0.02 & 0.058 & 1.000 \\
\hline
\end{tabular}

SCZ - patients with schizophrenia; BD - patients with bipolar disorder; HV - healthy volunteer; $\mathrm{p}$ - Bonferroni post-hoc analysis;

\section{Supplement Appendix 3}

Table S3:

Correlation between Retinal Vessel caliber, One back test with Clinical variables

\begin{tabular}{|l|c|c|c|c|c|c|c|c|}
\hline \multirow{2}{*}{ Clinical variable } & \multicolumn{2}{|c|}{ CRVE } & \multicolumn{2}{c|}{ CRAE } & \multicolumn{2}{c|}{$\begin{array}{c}\text { ONB - } \\
\text { Accuracy }\end{array}$} & \multicolumn{2}{c|}{$\begin{array}{c}\text { ONB - } \\
\text { Log mean } \\
\text { speed }\end{array}$} \\
\cline { 2 - 10 } & $\mathbf{r}$ & $\mathbf{p}$ & $\mathbf{r}$ & $\mathbf{p}$ & $\mathbf{r}$ & $\mathbf{p}$ & $\mathbf{r}$ & $\mathbf{p}$ \\
\hline Clinical Variables & $\mathrm{r}$ & $\mathrm{p}$ & $\mathrm{r}$ & $\mathrm{p}$ & $\mathrm{r}$ & $\mathrm{p}$ & $\mathrm{r}$ & $\mathrm{p}$ \\
\hline BPRS & -0.31 & 0.01 & -0.07 & 0.54 & -0.18 & 0.13 & 0.04 & 0.74 \\
\hline YMRS & -0.08 & 0.51 & 0.06 & 0.63 & -0.22 & 0.07 & 0.03 & 0.82 \\
\hline HDRS & -0.14 & 0.25 & 0.17 & 0.16 & 0.15 & 0.22 & -0.01 & 0.92 \\
\hline Age at onset & 0.10 & 0.41 & -0.13 & 0.26 & -0.11 & 0.36 & 0.05 & 0.67 \\
\hline $\begin{array}{l}\text { Duration of } \\
\text { untreated illness }\end{array}$ & 0.01 & 0.95 & 0.19 & 0.12 & -0.10 & 0.40 & 0.17 & 0.15 \\
\hline Duration of illness & 0.02 & 0.89 & 0.07 & 0.54 & -0.13 & 0.30 & 0.13 & 0.28 \\
\hline CPZ equivalent & -0.01 & 0.96 & -0.17 & 0.26 & -0.06 & 0.71 & -0.07 & 0.64 \\
\hline
\end{tabular}

CRVE- Central Retinal Vein Equivalent, CRAE- Central Retinal Artery Equivalent, ONBOne back Task; r- Pearson correlation; $p$ - significance value; 


\section{Supplement Appendix 4}

Table S4:

Effect of Nicotine dependence

To control for the effect of nicotine dependence, we excluded 8 SCZ and 4 BD patients who had nicotine dependence and re-analysed the data. The results were still significant even after excluding these study participants as shown in the table below

\begin{tabular}{|l|c|c|c|c|c|}
\hline & $\begin{array}{c}\text { HV } \\
(\mathbf{n = 4 5 )}\end{array}$ & $\begin{array}{c}\text { SCZ } \\
(\mathbf{n = 2 6 )}\end{array}$ & $\begin{array}{c}\text { BD } \\
(\mathbf{n = 3 5 )}\end{array}$ & $\mathbf{F}$ & $\mathbf{p}$ \\
\hline CRVE & $197.7 \pm 20.9$ & $211.2 \pm 26.5$ & $229.7 \pm 24.5$ & 18.20 & $<0.001$ \\
\hline CRAE & $116.2 \pm 20.5$ & $92.3 \pm 13.0$ & $92.3 \pm 17.6$ & 21.26 & $<0.001$ \\
\hline $\begin{array}{l}\text { One back task } \\
\text { - accuracy }\end{array}$ & $1.20 \pm 0.26$ & $0.91 \pm 0.21$ & $0.93 \pm 0.26$ & 16.05 & $<0.001$ \\
\hline $\begin{array}{l}\text { One back task } \\
\text { - log mean } \\
\text { speed }\end{array}$ & $2.90 \pm 0.10$ & $3.00 \pm 0.11$ & $3.05 \pm 0.14$ & 17.03 & $<0.001$ \\
\hline
\end{tabular}

\section{Supplement Appendix 5}

Table S5:

Regression Analysis for One back task between groups adjusted for years of education

\begin{tabular}{|l|c|c|c|c|c|c|}
\hline \multirow{2}{*}{} & \multicolumn{2}{|c|}{ Group } & \multicolumn{2}{c|}{ Not adjusted for age and sex } & \multicolumn{2}{c|}{ Adjusted for age and sex } \\
\cline { 3 - 7 } & & $\boldsymbol{\beta}(\mathbf{9 5} \% \mathrm{Cl})$ & $\mathbf{P}$ & $\boldsymbol{\beta}(\mathbf{9 5} \% \mathrm{Cl})$ & $\mathbf{p}$ \\
\hline \multirow{2}{*}{$\begin{array}{l}\text { One back } \\
\text { task - } \\
\text { accuracy }\end{array}$} & HV & SCZ & $-0.28(-0.39$ to -0.17$)$ & $<0.001$ & $-0.19(-0.31$ to -0.06$)$ & 0.003 \\
\cline { 2 - 7 } & HV & BD & $-0.26(-0.37$ to -0.15$)$ & $<0.001$ & $-0.15(-0.27$ to -0.03$)$ & 0.014 \\
\hline & SCZ & BD & $0.02(-0.09$ to 0.14$))$ & 0.70 & $0.03(-0.08$ to 0.15$)$ & 0.55 \\
\hline $\begin{array}{l}\text { One back } \\
\text { task - log } \\
\text { mean } \\
\text { speed }\end{array}$ & HV & SCZ & $0.10(0.05$ to 0.15$)$ & $<0.001$ & $0.09(0.03$ to 0.15$)$ & 0.004 \\
\cline { 2 - 7 } & HV & BD & $0.13(0.08$ to -0.19$)$ & $<0.001$ & $0.12(0.06$ to 0.18$)$ & $<0.001$ \\
\cline { 2 - 7 } & SCZ & BD & $0.04(-0.19$ to 0.09$)$ & 0.20 & $0.04(-0.02$ to 0.09$)$ & 0.55 \\
\hline
\end{tabular}

SCZ - patients with schizophrenia; BD - patients with bipolar disorder; HV - healthy volunteer; $\beta$ - regression coefficient, $95 \% \mathrm{Cl}$ - 95\% confidence interval 
CHAPTER 7

GENERAL DISCUSSION 



\section{General Discussion}

The goal of the studies in this thesis was to use the knowledge of the retinal microvasculature features in the field of psychiatry for two major psychiatric conditions viz., Schizophrenia (SCZ) and Bipolar Disorder (BD) and explore if retinal microvascular features can be used as biomarker. In this chapter, a review of the main findings of the thesis, methodological issues, and implications for future development with respect to continuation of the work will be presented. This is the first kind of its study which examined the retinal microvasculature features in schizophrenia and bipolar disorder compared to healthy volunteers (HV).

The overview of the thesis is diagrammatically represented in the figure 1 below.

\section{Figure 1.}

Illustration of overview of thesis

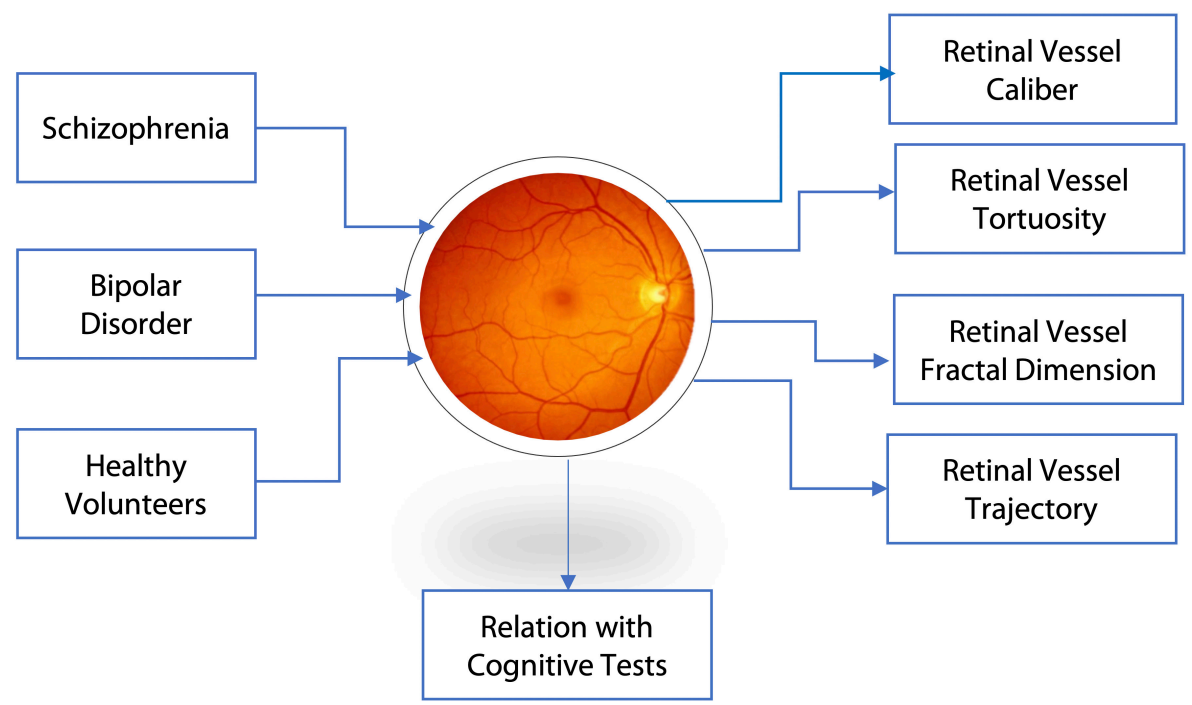

The retinal microvasculatures and cerebral vasculature share common morphological, physiological, and pathological properties. Considering the common embryological origin, the retinal microvasculature examination can be considered for indirect assessment of cerebral vasculature abnormalities. Further, considering the cost effectiveness and easy accessibility of the retina vasculature it is ideally suited for epidemiological research studies for screening these disorders. A significant difference 
in vessel caliber, fractal dimensions, retinal vascular tortuosity and retinal vascular trajectory are observed between patients with $\mathrm{SCZ}$ and $\mathrm{BD}$ when compared to healthy volunteers.

It was observed that the retinal vascular parameters were different in $\mathrm{SCZ}$ and $\mathrm{BD}$ when compared to HV. To summarize: compared to HV, BD and SCZ had wider veins and narrower arteries, higher retinal arteriolar tortuosity index, higher fractal dimension and smaller retinal vascular (both veins and arteries) trajectory.

It is important to note that all the above results are statistically significant even after controlling for age and sex. When available, effect of other confounders like BMI or systemic blood pressure, was also controlled in the statistical analysis. It was interesting to observe that there was significant difference between SCZ and BD as well in retinal vascular caliber (both artery and vein) and tortuosity (artery only). However, there was no difference between SCZ and BD in trajectory or fractal dimension.

The findings are in accord with, and support the only previous study in SCZ which also reported wider venules ${ }^{1}$. However, in contrast to a previous study in adolescent BD $^{2}$ which did not report significant difference, it was found that BD patients had wider venules and narrower arterioles in the retina. As ours is the first study to examine the retinal vascular tortuosity, fractal dimension and trajectory in $\mathrm{SCZ}$ and BD, we were not able to compare with any other previous studies.

In addition to these structural measures, interestingly the retinal vascular abnormalities were related to cognitive deficits typically seen in SCZ and BD. There was a significant association between working memory deficits and narrower arterioles and wider venules; significant positive correlation between one-back test accuracy and retinal arteriolar caliber and significant positive correlation between log mean speed score and retinal venular caliber. These findings of association between working memory deficits and retinal vascular caliber point towards a potential role of vascular pathology in cognitive deficits typically seen in SCZ and BD.

An interesting observation was abnormalities in retinal vessel trajectories. These trajectories are directly related to retinal artery angle which are associated with retinal nerve fiber layer thickness. The findings of machine learning analysis suggest that the retinal vascular trajectory is a potential biomarker for SCZ and BD. Considering the relation between retinal vascular trajectory and retinal nerve fiber layer thickness, there is an opportunity to use retinal fundus camera instead of expensive optical coherence tomography in epidemiological research settings. 
In addition, as an exploratory analysis, machine learning using supervised ensemble of bagged trees was implemented to check if retinal vascular trajectories can be a potential utility as predictive biomarker. It had an accuracy of $86 \%$ with sensitivity of $88 \%$ and specificity of $85 \%$ for differentiating HV and SCZ. However, a lower but considerably good accuracy of $73 \%$ with sensitivity of $78 \%$ and specificity of $76 \%$ was obtained for differentiating HV and BD.

These advantages of fundus photography, together with our findings from machine-learning analysis, indicate the potential utility of this method in wider, resource constrained settings and warrant further studies with larger sample sizes. Machine-learning analysis with the use of a single measure (retinal vessel trajectory) demonstrated reasonable accuracy despite the potential confounding factors.

The retina develops from the same tissue, that is, neuroectoderm as the brain. It is the only part of the central nervous system that can be easily seen non-invasively. The retinal changes may parallel or reflect the integrity of brain structure and function due to the common developmental origins and also because of sharing the anatomical, physiological, and autoregulation properties.

The specific pathophysiological mechanism underlying the retinal vasculature abnormalities as seen in this thesis are not entirely understood. It is currently unclear whether retinal vasculature plays a causal role in the development of psychosis or whether it might represent an associated epiphenomenon. The understanding of the mechanisms underlying abnormalities in retinal vasculature may provide insight about the pathogenesis of psychosis symptoms. It is known from previous research that genetic factors influence retinal vasculatures ${ }^{3}$. Other factors including Inflammation, endothelial dysfunction, and hypoxia have also been found to be associated with retinal vasculature abnormalities, in addition to conventional cardiovascular risks, including dyslipidaemia, obesity, impaired fasting glucose, and smoking ${ }^{4-7}$. All of these factors have been implicated in psychosis as well ${ }^{8-12}$, and few of these factors occur at higher rates than expected in unaffected relatives of patients with psychosis ${ }^{13-16}$ and in individuals with symptoms of psychosis ${ }^{17-19}$.

Although visual processing impairments are common in psychosis, it is not clear to what extent these originate in the eye vs. the brain. One is that there are multiple structural and functional disturbances of the eye in psychosis, all of which could be factors in the visual disturbances and retinal vasculature abnormalities of patients. However, some of these are likely to be illness-related, whereas others may be due 
to medication or comorbid conditions which was used as covariate in the analysis. It is also important to note that retinal findings can serve as biomarkers of neural pathology, and disease progression, in psychosis. The strongest evidence for this to date involves findings of retinal vasculature changes which is also seen in this thesis.

These preliminary findings provide a strong rationale for further systematic examination of usage of retinal vascular features in patients with SCZ and BD. Considering the easy accessibility, non-invasive nature, absence of need for mydriasis and affordability, examination of retinal vascular features using retinal fundus images can be conducted in psychiatric settings, both out-patient clinics and community settings. If shown to be of predictive utility in future longitudinal studies, examination of retinal features has the potential to identify BD and SCZ patients at risk of developing adverse vascular events and it can be one of the easy and an inexpensive tool for prediction of psychoses. Further, it could potentially help clinicians or researchers in screening eligible patients for clinical trials, in monitoring disease progression or in evaluating treatment response.

In the last decade, the search of biomarkers for psychiatric disorder has increased. Considering the contribution of vascular pathology to etiopathogenesis of neuropsychiatric disorders, cerebral vascular features are considered possible biomarkers for neuropsychiatric disorders. However, examination of cerebral vasculature is expensive and requires invasive techniques. Considering the relation with cerebral vasculature, retinal vascular features are potential biomarkers for psychoses, SCZ and BD. In the further paragraphs, the existing gaps and requirement of further studies in psychoses is discussed for future research.

Mediation and interaction: Previous studies as well as the studies presented in this thesis examined retinal vascular changes as novel biomarkers by finding the associations between retinal vascular abnormalities and individual diseases. While this way of doing research is valid, it is important to remember that this cross-sectional association may be influenced by other factors. Hence, it is important to continue the study to find out other confounding factors which may influence/interact with the retinal vascular pathology. Such a study which can control for other confounding factors help in finding apt independent and novel biomarker which could be used in both clinic as well as epidemiological research. A holistic approach involving neuropsychiatry, ophthalmology along with measurement of cardiac, metabolic and renal parameters, could isolate the independent biomarker. 
Comorbidities influence: The values of blood glucose, blood pressure and other comorbidities were taken during the patient admission and not during the acquisition of retinal images. It is important to examine these parameters on the day of the acquisition of the retinal scan. Also, we did not examine the other possible confounders in detail. Examination of confounding comorbidities is very important to conclude whether retinal vascular features are biomarkers for psychoses. Similarly, though HV were excluded if they had received diagnosis of any confounding comorbid medical condition, we did not check their blood sugar or blood pressure or other possible confounders such as lifestyle (exercise, diet, etc), renal function, etc. As previous studies have shown association between retinal vascular features and hypertension and diabetes mellitus ${ }^{20-23}$, future studies need to examine these parameters. Also, whether sub-clinical/pre-diabetes levels of blood sugar or blood pressure have any effect on the retinal vascular features need to be examined in future.

Longitudinal studies: The studies discussed in this thesis are all cross-sectional. However, the results have to be replicated using longitudinal studies to show that the association between psychoses is related to the stage of the illness. The degradation of brain seen in psychoses has been associated with thinning of retinal layers using optical coherence tomography $(\mathrm{OCT})^{24,25}$. It is also seen that the retinal neurodegeneration is associated with brain damage as well. Longitudinal studies will be able to clarify if these associations are due to shared etiology or the retina could serve as a prognostic factor before clinical deterioration is observed. If retinal vasculature or nerve fiber layer (NFL) changes before clinical psychiatric symptoms therapy could be initiated or changed.

Retinal Imaging methods: In this thesis, only retinal fundus imaging is presented. However, there are other modalities including adaptive optics, optical coherence tomography (OCT), Fundus Florescence Angiography (FFA), OCT-Angiography and retinal oximetry that can be explored. These retinal imaging methods and various associated algorithms can be used to explore the association of psychoses and retinal microvasculature. Newer retinal imaging method like hyperspectral imaging may help in identifying retinal amyloid-beta depositions in humans which is present in Alzheimer's disease patient and not in $\mathrm{HV}^{26,27}$. Whether these newer retinal imaging methods can have utility in SCZ and BD needs be explored. In addition to the retinal vascular imaging using fundus camera, structural and functional brain imaging can be used to examine the relation between the retinal vascular changes and brain 
abnormalities. The brain structure can be examined for abnormalities in volume, thickness or area using the voxel-based morphometric or surface based morphometric analysis. The cerebral vasculature can be examined using Arterial Spin Labelling (ASL) and functional activity of the brain can be examined using the functional MRI (fMRI). Future studies need to examine both retinal vasculature and brain using these imaging methods to assess the relation between retinal vascular features and brain structure and function. It will also be interesting to compare the brain imaging-based features and retinal vascular features as biomarkers to SCZ and BD.

Additional Retinal features: In this thesis, retinal microvasculature features including vessel calibre, tortuosity, fractal dimension and trajectory are implemented. There are many other features which can be used for finding the association of retinal microvasculature and psychoses. One of the features which can be explored is Length to Diameter ratio (LDR). LDR can be calculated as the length from the midpoint of the first branch to the midpoint of the second branch, divided by the diameter of the parent vessel at the first branch ${ }^{28,29}$. Another feature is bifurcation angle which is the angle made between the vessels where they bifurcate. These angles may change the due to various systemic disease $\mathrm{e}^{30,31}$. The angle made between the retinal artery trajectory viz., artery angle can also be explored to find if there is association with psychoses and recent study showed that there is variation in cup to disc ratio varies for psychoses ${ }^{32,33}$. Also, all the retinal features discussed in the previous chapters have to be combined and such a multivariate analysis may give a better outcome than individual feature. Another interesting parameter to be explored can be retinal vascular optimal score which is based on the features of calibre and fractal dimension to measure the severity and complexity of the vasculature ${ }^{34}$.

Clinical research: Though there is an increase in research using retinal vasculature as, it is not yet in clinical practice as biomarkers for brain disorders. It is important to examine whether the retinal vascular features can aid the clinician for better diagnostic and predictive accuracy. It is also important to examine the accuracy of retinal vascular feature-based biomarker in comparison with other biomarkers based on other imaging modalities. On the other hand, retinal microvasculature features can be of better utility for population-based epidemiological studies considering their affordability and portable nature of the equipment. With further research, retinal vascular features can be used as preliminary screening tool. 
22q11.2 Deletion Syndrome: 22q11.2 deletion syndrome (22qDS) is a genetic syndrome associated with deletion of a chromosome $22 q 11.2$. The variable phenotypic expression of this genetic syndrome commonly includes Schizophrenia. It is reported that approximately $1 \%$ of patients with SCZ have $22 q D S$. Individuals with a $22 q D S$ form of schizophrenia have distinguishable physical features in the form of lower IQ and differ in auxiliary clinical features ${ }^{35,36}$. This 22qDS has shown retinal vascular abnormality and it would be good biomarker for examining the difference between $22 q D S$ and other forms of psychoses ${ }^{36,37}$.

Tool and retinal vascular index: A tool can be developed to assess the severity using various retinal features namely calibre, fractal dimensions, tortuosity, trajectory which can give the effect and severity of psychoses in the population while doing the screening. Apart from this, a vascular index or retinal vascular score can be derived based on the values of each of these features which will definitely be novel and interesting score for clinical research.

First Degree Relatives: Whether the retinal microvascular abnormalities are seen in first degree relatives of patients with SCZ or BD as well is not examined till date. Examination of these measures in first degree relatives will provide definitive answers to the question whether these abnormalities are linked to primary pathogenic process or secondary to medications or medical comorbidities which will be valuable information in clinical research.

Multivariate Analysis: Different features of retinal vasculature were extracted in SCZ and BD, and the statistically significant difference was observed for all features of retinal vasculature in patients when compared to HV. However, all the features are independently analysed, and conclusions are derived for each of them separately, though they are from same group of patients. Hence, a multivariate analysis for all the features included may help in understanding the contribution of each of the features as well as it will help in discovering new findings on interdependency of the features.

Machine Learning and Biomarker: Machine learning using Supervised Support vector machine (SVM) and ensembled of bagged trees was implemented for retinal vascular trajectory. However, the similar machine learning algorithm can be applied with all four feature parameters namely, calibre, tortuosity, fractal dimension and trajectory can be combined together and fed to machine learning to see if the 
prediction is possible to classify patients and HV. Once sufficient retinal images are acquired, the features can be extracted automatically and the same will used for classification using deep learning algorithms. However, acquiring adequate retinal images is always a challenge in medical image processing, hence, another approach for this could be by pixelating (separating one image into many images in terms of pixels) the images and feeding these pixelated images as to machine learning may bring new perspective of classification.

Correlation of existing Biomarkers in SCZ and BD with retina: SCZ is associated with significant cognitive impairment. BD is also associated with cognitive deficits but less severe than SCZ. There are been controversy on analysing the cognitive deficits to distinguish these two psychoses ${ }^{38}$. Hence, further correlation of neuroimaging and other modalities with retinal imaging is important in using retina as biomarker for SCZ or BD. Structural co-variance analyses identified that there is altered structural relationships in the thalamus, frontal, temporal and parietal cortices in SCZ patients ${ }^{39}$. Hence, modalities like voxel-based morphometry (VBM), tract-based spatial statistics (TBSS), diffusion tensor imaging (DTI), visual evoked potential (VEP) ${ }^{40-}$ ${ }^{42}$, electroencephalography (EEG) ${ }^{43,44}$ and Magnetic resonance Imaging (MRI) ${ }^{45}$ can be explored to find their correlation with retinal vascular features. It would be important to explore the accuracy of the measures using these modalities to differentiate SCZ/ $\mathrm{BD}$ from $\mathrm{HV}$ and compare them with our machine learning findings.

This thesis provides new insight for psychoses for using retinal imaging microvasculature as novel biomarker. Furthermore, in this chapter, an overview of the main findings which may serve as groundwork for future research is discussed. 


\section{References}

1. Meier MH, Shalev I, Moffitt TE, et al. Microvascular abnormality in schizophrenia as shown by retinal imaging. Am J Psychiatry. 2013;170(12):1451-1459.

2. Naiberg MR, Hatch JK, Selkirk B, et al. Retinal photography: $A$ window into the cardiovascular-brain link in adolescent bipolar disorder. J Affect Disord. 2017;218:227237.

3. Ikram MK, de Jong FJ, Bos MJ, et al. Retinal vessel diameters and risk of stroke: the Rotterdam Study. Neurology. 2006;66(9):1339-1343.

4. de Jong FJ, Schrijvers EM, Ikram MK, et al. Retinal vascular caliber and risk of dementia: the Rotterdam study. Neurology. 2011;76(9):816-821.

5. Klein R, Klein BE, Knudtson MD, Wong TY, Tsai MY. Are inflammatory factors related to retinal vessel caliber? The Beaver Dam Eye Study. Archives of ophthalmology (Chicago, III : 1960). 2006;124(1):87-94.

6. Nguyen TT, Islam FM, Farouque HM, et al. Retinal vascular caliber and brachial flowmediated dilation: the Multi-Ethnic Study of Atherosclerosis. Stroke; a journal of cerebral circulation. 2010;41(7):1343-1348.

7. Sun C, Wang JJ, Mackey DA, Wong TY. Retinal vascular caliber: systemic, environmental, and genetic associations. Surv Ophthalmol. 2009;54(1):74-95.

8. Schmidt-KastnerR, Van OsJ, EsquivelG, Steinbusch HWM, Rutten BPF. An environmental analysis of genes associated with schizophrenia: hypoxia and vascular factors as interacting elements in the neurodevelopmental model. Molecular psychiatry. 2012;17:1194-1205.

9. Barnett A, Mackin P, Chaudhry l, et al. Minimising metabolic and cardiovascular risk in schizophrenia: diabetes, obesity and dyslipidaemia. Journal of Psychopharmacology. 2007;21(4):357-373.

10. Israel A-K, Seeck A, Boettger MK, et al. Peripheral endothelial dysfunction in patients suffering from acute schizophrenia: a potential marker for cardiovascular morbidity? Schizophrenia research. 2011;128(1-3):44-50.

11. Kirkpatrick B, Miller BJ. Inflammation and schizophrenia. Schizophrenia bulletin. 2013;39(6):1174-1179. 
12. Mitchell AJ, Vancampfort D, Sweers K, van Winkel R, Yu W, De Hert M. Prevalence of metabolic syndrome and metabolic abnormalities in schizophrenia and related disorders-a systematic review and meta-analysis. Schizophrenia bulletin. 2011;39(2):306-318.

13. Lyons MJ, Bar JL, Kremen WS, et al. Nicotine and familial vulnerability to schizophrenia: A discordant twin study. Journal of abnormal psychology. 2002;111(4):687.

14. Martínez-Gras I, García-Sánchez F, Guaza C, et al. Altered immune function in unaffected first-degree biological relatives of schizophrenia patients. Psychiatry research. 2012;200(2-3):1022-1025.

15. Mukherjee S, Schnur D, Reddy R. Family history of type 2 diabetes in schizophrenic patients. The Lancet. 1989;333(8636):495.

16. Nunes S, Matsuo T, Kaminami MS, Watanabe M, Reiche E, Itano EN. An autoimmune or an inflammatory process in patients with schizophrenia, schizoaffective disorder, and in their biological relatives. Schizophrenia research. 2006;84(1):180-182.

17. Degenhardt L, Hall W, LynskeyM. Alcohol, cannabis and tobacco use among Australians: a comparison of their associations with other drug use and use disorders, affective and anxiety disorders, and psychosis. Addiction. 2001;96(11):1603-1614.

18. Foley DL, Mackinnon A, Watts GF, et al. Cardiometabolic risk indicators that distinguish adults with psychosis from the general population, by age and gender. PloS one. 2013;8(12):e82606.

19. Kelleher I, Cannon M. Psychotic-like experiences in the general population: characterizing a high-risk group for psychosis. Psychological medicine. 2011;41(1):1-6.

20. Popovic N, Radunovic M, Badnjar J, Popovic T. Fractal dimension and lacunarity analysis of retinal microvascular morphology in hypertension and diabetes. Microvascular research. 2018;118:36-43.

21. Nguyen TT, Wang JJ, Wong TY. Retinal vascular changes in pre-diabetes and prehypertension: new findings and their research and clinical implications. Diabetes Care. 2007;30(10):2708-2715.

22. Sasongko M, Wong T, Nguyen T, Cheung C, Shaw J, Wang J. Retinal vascular tortuosity in persons with diabetes and diabetic retinopathy. Diabetologia. 2011;54(9):24092416. 
23. Sasongko MB, Wong TY, Nguyen TT, et al. Retinal Vessel Tortuosity and Its Relation to Traditional and Novel Vascular Risk Markers in Persons with Diabetes. Curr Eye Res. 2016;41(4):551-557.

24. Schonfeldt-Lecuona C, Kregel T, Schmidt A, et al. From Imaging the Brain to Imaging the Retina: Optical Coherence Tomography (OCT) in Schizophrenia. Schizophr Bull. 2016;42(1):9-14.

25. Adams SA, Nasrallah HA. Multiple retinal anomalies in schizophrenia. Schizophr Res. 2018;195:3-12.

26. Koronyo-Hamaoui M, Koronyo Y, Ljubimov AV, et al. Identification of amyloid plaques in retinas from Alzheimer's patients and noninvasive in vivo optical imaging of retinal plaques in a mouse model. Neurolmage. 2011;54:S204-S217.

27. More SS, Beach JM, Vince R. Early detection of amyloidopathy in Alzheimer's mice by hyperspectral endoscopy. Investigative ophthalmology \& visual science. 2016;57(7):3231-3238.

28. Sasongko MB, Wang JJ, Donaghue $K C$, et al. Alterations in retinal microvascular geometry in young type 1 diabetes. Diabetes care. 2010;33(6):1331-1336.

29. Hao H, Sasongko MB, Wong TY, et al. Does retinal vascular geometry vary with cardiac cycle? Invest Ophthalmol Vis Sci. 2012;53(9):5799-5805.

30. Patton $N$, Pattie A, MacGillivray $T$, et al. The association between retinal vascular network geometry and cognitive ability in an elderly population. Invest Ophthalmol Vis Sci. 2007;48(5):1995-2000.

31. Golestani S, Banaee T, Daneshvar R, Nabavi A. Retinal bifurcation angles in severe non-proliferative diabetic retinopathy. Investigative Ophthalmology \& Visual Science. 2013;54(15):2422-2422.

32. Yamashita T, Asaoka R, Tanaka M, et al. Relationship between position of peak retinal nerve fiber layer thickness and retinal arteries on sectoral retinal nerve fiber layer thickness. Invest Ophthalmol Vis Sci. 2013;54(8):5481-5488.

33. Silverstein SM, Paterno D, Cherneski L, Green S. Optical coherence tomography indices of structural retinal pathology in schizophrenia. Psychol Med. 2018;48(12):2023-2033.

34. Cheung CY, Thomas GN, Tay $W$, et al. Retinal vascular fractal dimension and its relationship with cardiovascular and ocular risk factors. American journal of ophthalmology. 2012;154(4):663-674 e661. 
35. Tang SX, Yi JJ, Calkins ME, et al. Psychiatric disorders in 22q11.2 deletion syndrome are prevalent but undertreated. Psychol Med. 2014;44(6):1267-1277.

36. Bassett AS, Chow EW. Schizophrenia and 22q11. 2 deletion syndrome. Current psychiatry reports. 2008;10(2):148.

37. Tang S, Yi J, Calkins $M$, et al. Psychiatric disorders in 22q11. 2 deletion syndrome are prevalent but undertreated. Psychological medicine. 2014;44(6):1267-1277.

38. Bora E. Differences in cognitive impairment between schizophrenia and bipolar disorder: Considering the role of heterogeneity. Psychiatry and clinical neurosciences. 2016;70(10):424-433.

39. Wheeler AL, Voineskos AN. A review of structural neuroimaging in schizophrenia: from connectivity to connectomics. Front Hum Neurosci. 2014;8:653.

40. Gonzalez-Hernandez JA, Pita-Alcorta C, Wolters CH, et al. Specificity and sensitivity of visual evoked potentials in the diagnosis of schizophrenia: rethinking VEPs. Schizophr Res. 2015;166(1-3):231-234.

41. Lalor EC, De Sanctis P, Krakowski MI, Foxe JJ. Visual sensory processing deficits in schizophrenia: is there anything to the magnocellular account? Schizophr Res. 2012;139(1-3):246-252.

42. Yeap S, Kelly SP, Reilly RB, Thakore JH, Foxe JJ. Visual sensory processing deficits in patients with bipolar disorder revealed through high-density electrical mapping. Journal of psychiatry \& neuroscience: JPN. 2009;34(6):459.

43. Light GA, Swerdlow NR, Thomas ML, et al. Validation of mismatch negativity and P3a for use in multi-site studies of schizophrenia: characterization of demographic, clinical, cognitive, and functional correlates in COGS-2. Schizophrenia research. 2015;163(13):63-72.

44. Kim D-J, Bolbecker AR, Howell J, et al. Disturbed resting state EEG synchronization in bipolar disorder: a graph-theoretic analysis. Neurolmage: Clinical. 2013;2:414-423.

45. Shaffer JJ, Johnson CP, Fiedorowicz JG, Christensen GE, Wemmie JA, Magnotta VA. Impaired sensory processing measured by functional MRI in Bipolar disorder manic and depressed mood states. Brain imaging and behavior. 2018;12(3):837-847. 
CHAPTER 8

SUMMARY 



\section{Summary}

Over the last few years, retinal vascular imaging has emerged as a technique to investigate microvasculature abnormalities related to the neuropsychiatric disorders. As the microvasculature in the retina and the brain share similarities in anatomy and physiology, changes in the vessels in the retina may reflect similar changes in the brain. Importantly, the imaging of the small vessels of the brain is expensive and at times invasive with current neuroimaging modalities. Retinal vascular imaging however gives a novel and unique opportunity to study the microvasculature non-invasively.

Several studies have reported an association between retinal and brain microvasculature in disorders like stroke and Alzheimer's dementia. However, retinal vascular abnormalities in neuropsychiatric conditions are underexamined. A few studies have reported abnormalities in the thickness of the retinal layers consisting of neurons viz., retinal nerve fibre layer (RNFL) in schizophrenia and bipolar disorder using Optical Coherence Tomography (OCT). The reason for thinning of these RNFL in these neurodevelopmental psychiatric disorders may be due to the common developmental origin; the retina is embryonically formed from the neural tissue. Hence the thinning of the RNFL may indicate abnormal development of the brain. However, no study has examined the retinal microvascular features in schizophrenia and bipolar disorder in comparison to healthy volunteers.

The main objective of this thesis was to investigate the use of retinal microvasculature abnormalities as biomarker for two important psychiatric disorders viz., Schizophrenia (SCZ) and Bipolar Disorder (BD) and expanding the horizon of knowledge of various parameters in the retinal imaging for finding its association with the SCZ and BD. The retinal fundus images were acquired at the National Institute of Mental Health and Neuroscience (NIMHANS), Bengaluru, India a tertiary care hospital. The summary of the thesis chapters are as below.

CHAPTER ONE gives the general introduction about psychiatric disorders and two major conditions namely SCZ and BD. This chapter includes prevalence, diagnosis and treatment of these conditions along with prevalent practices for their diagnosis. How 
the retina vasculature is used as biomarker for other systemic diseases is also discussed in this chapter. The aim and outline of the thesis is described as well.

CHAPTER TWO describes the usage of retinal vascular calibre abnormalities of both veins and arteries in SCZ and BD when compared to healthy volunteers (HV). It was found that the retinal veins were significantly wider in patients when compared to HV. The retinal arteries were significantly narrower in patients when compared to HV. Interestingly, the width was larger in BD when compared to SCZ for retinal veins but the width was smaller in BD when compared to SCZ. The results were significant event after controlling for the confounding factors. The reason for such abnormalities is not known but may be due to wide range of environmental, genetic, and systemic influences such as aging, inflammation, nitric oxide-dependent endothelial dysfunction, and hypoxia/ischemia.

CHAPTER THREE investigated the usage of retinal vascular tortuosity of veins and arteries in SCZ and BD when compared with HV. The results showed significant differences across the three groups in retinal artery tortuosity but not in retinal vein tortuosity. There was significant increase in retinal arterial tortuosity in patients when compared with HV. Interestingly, there was also significant difference in SCZ and BD with BD having higher retinal arteriolar tortuosity. The results were significant even after controlling for possible confounding factors. These retinal arteriolar tortuosity can act as surrogate marker for cerebrovascular abnormalities and have value in predicting patients at risk of developing adverse cerebrovascular events.

CHAPTER FOUR studied the fractal dimension of retinal microvasculature in patients with SCZ and BD. There was a significant difference between the three groups in retinal vascular fractal dimensions. While both SCZ and BD had significantly increased fractal dimension when compared to HV, there was no significant difference between SCZ and BD. Findings remained significant even after controlling for the confounding factors. This study suggests increased possibility of adverse vascular events in SCZ and BD. 
CHAPTER FIVE examines the retinal vessel trajectory as a tool for finding the abnormalities in retinal nerve fibre layer in patients with SCZ and BD when compared with HV. There was a significant difference between the groups for both retinal artery and retinal vein trajectories even after adjusting for age and sex. However, there was no significant difference between SCZ and BD. Supervised machine learning using ensembled of bagged trees was used to classify the three groups using retinal vascular trajectory measures. It showed considerably good accuracy of $86 \%$ with sensitivity of $88 \%$ and specificity of $85 \%$ for differentiating HV and SCZ. However, a lower but considerably good accuracy of $73 \%$ with sensitivity of $78 \%$ and specificity of $76 \%$ was obtained for differentiating HV and BD.

CHAPTER SIX gives the correlation between cognitive test (one back test) and the retinal vascular calibre as described in chapter 2 . It was found that the performance on one back test, a test of working memory had significant positive correlation with retinal arteriolar calibre and significant negative correlation with retinal venular calibre. As anticipated, the patients (both SCZ and BD) had significantly lower working memory accuracy and higher log mean speed. This suggests the role of vascular pathology in cognitive deficits typically seen in SCZ and BD.

CHAPTER SEVEN is a discussion of important findings, issues and implications for future studies based on the above chapters. 

CHAPTER 9

VALORISATION 



\section{Valorisation}

Dealing with patients with psychosis and their caregivers who are struggling with their day to day activities is disheartening and emotionally draining for anybody. I encountered such a moment when I met one of my relatives, in his early teens, suffering from bipolar disorder. The grief and the burden which his parents had to carry on their shoulders triggered my interest to contribute to scientific research in this area. Considering the best outcome is seen when the treatment is initiated early, I decided to work on developing methods for early diagnosis so the treatment can be initiated at the earliest possible time.

Schizophrenia and Bipolar disorder, major psychotic disorders, are characterized by disturbances in cognition, perception, emotion, and motivation. Currently available treatment options reduce symptoms and suffering, however, there is no permanent cure. Mechanisms leading to psychosis are still unknown, which has hampered the development of curative interventions. The causes of psychosis are mostly a combination and interaction of genetic and environmental factors.

Clinically relevant symptoms of the psychosis spectrum have an estimated lifetime prevalence of $2.3 \%$ to $3.5 \%$ in the general population'. They result in high social disabilities and costs to the society because of significant loss of productivity ${ }^{2}$. Besides, societal stigmatization may result in a vicious cycle of discrimination leading to long-standing unemployment and social isolation, which further hinders the functional recovery. Therefore, early diagnosis and intervention are needed to lower the burden on patients with schizophrenia and bipolar disorder, their family members and furthermore, the society. Figure 1 depicts the share of worldwide population distribution for patients with schizophrenia and bipolar disorder.

Despite advances in the medical field, the diagnosis of psychosis is still dependent on the skill of the psychiatrist and hence involves the risk of subjective bias. Although psychiatric assessments have proven successful as a clinical tool for diagnosing psychosis, access to a trained mental health professional is difficult. This is especially true in developing countries including India (in particular the rural sector) where the doctor to patient ratio is very low and psychiatrists are hardly available. Even if a psychiatrist or a mental health professional is available, due to the subjective nature of the assessment, it may be erroneous at times. 
Figure 1.

\section{Share of population with Schizophrenia and Bipolar disorder in 2017}

\section{Share of population with schizophrenia, 2017}

Share of the population suffering from schizophrenia. This share has been age-standardized assuming a constant age structure to compare prevalence between countries and through time. Figures attempt to provide a true estimate (going beyond reported diagnosis) of schizophrenia prevalence based on medical, epidemiological data, surveys and meta-regression modelling.
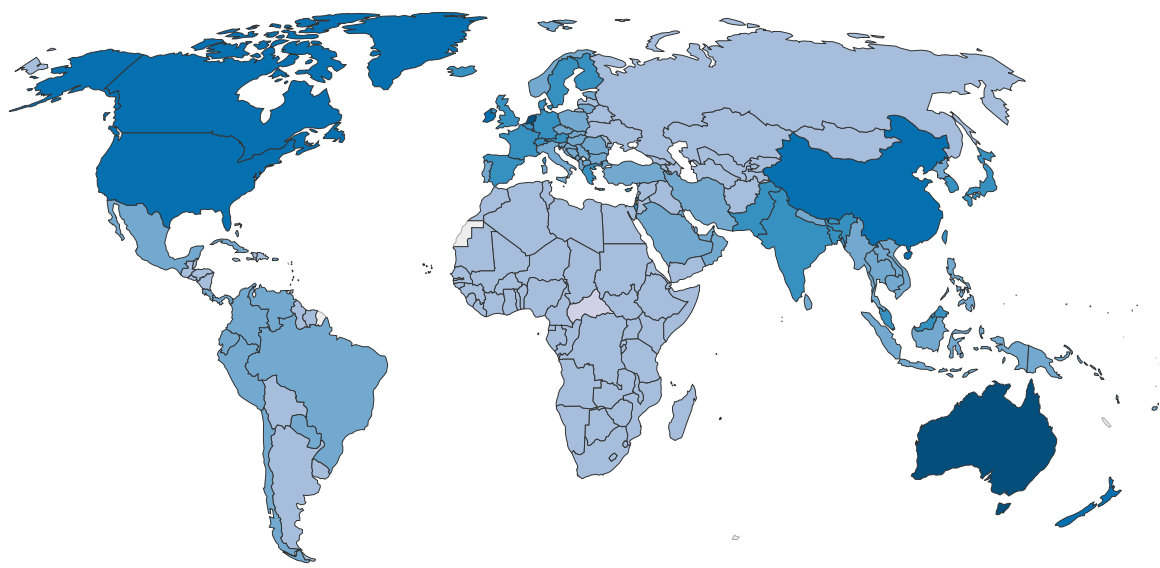

No data $0 \%$

$0.05 \%$

$0.1 \%$

$0.15 \%$

$0.2 \%$

$0.25 \%$

$0.3 \%$

$0.35 \%$

$0.4 \%$

Source: IHME, Global Burden of Disease

\section{Share of population with bipolar disorder, 2017}

Share of the population with bipolar disorder. This share has been age-standardized assuming a constant age structure to compare prevalence between countries and through time. Figures attempt to provide a true estimate (going beyond reported diagnosis) of bipolar disorder prevalence based on medical, epidemiological data, surveys and meta-regression modelling.

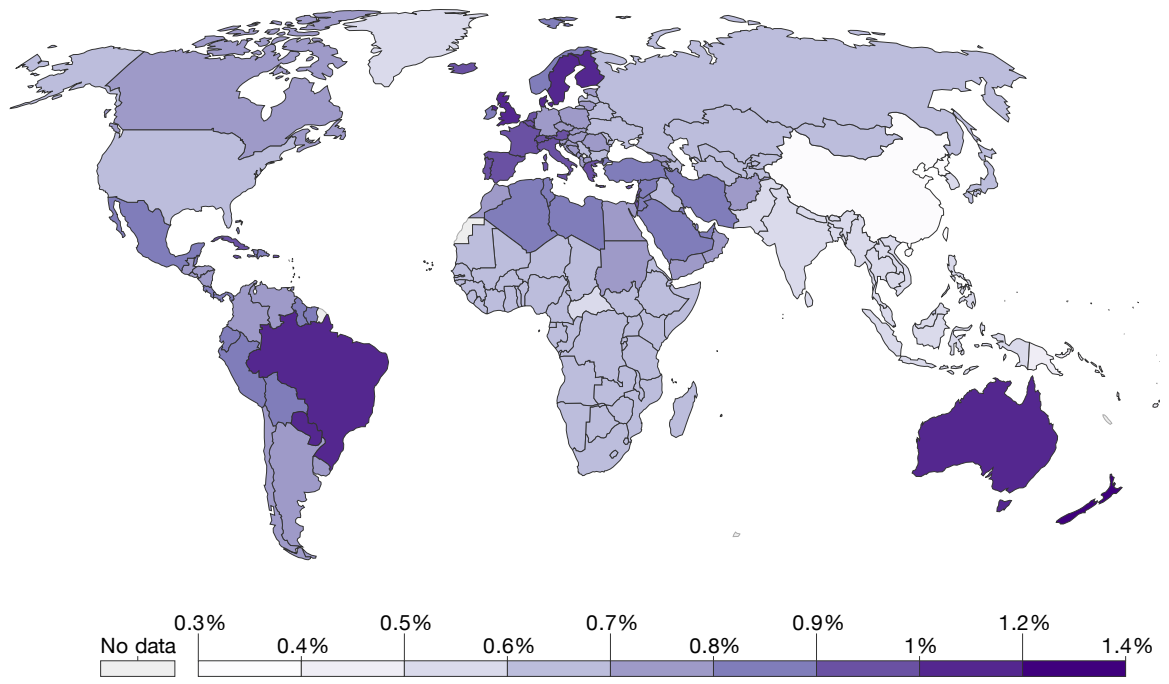

Source: IHME, Global Burden of Disease 
Currently, there is no definitive, quantitative assessment or specific biomarker which can help in the screening or confirmation of the diagnosis of psychiatric disorders. Absence of a biomarker and lack of necessary skill sets among the general practitioners prevents early diagnosis of individuals with psychosis or those who are at risk of development of psychosis. This often leads to undue delay in initiating prompt intervention, not only in resource-constrained societies, but also in urban areas. Hence, there is a requirement of a quantitative biomarker that can help in the early diagnosis of psychiatric disorders and serve as a screening tool for necessary referrals. This biomarker should be easily accessible, non-invasive and affordable to be utilised as a community screening tool.

While several candidate biomarkers are being examined, magnetic resonance imaging (MRI) is well evaluated as it is non-invasive. MRI is a sophisticated modality which allows the physician to visualize the structural, functional and chemical abnormality in the brain. MRI is routinely used as an investigation to examine brain abnormalities in neurological disorders. Several MRI studies have reported structural and functional brain abnormalities in schizophrenia and bipolar disorder, however its utility in routine clinical practice to diagnose psychosis is not well established. Even though MRI is found to be useful as a clinical tool in the diagnostic work up of psychosis, it is neither easily accessible nor affordable. This is notable in developing countries, including India, where only a handful of hospitals and advanced diagnostic centres have the facilities for brain imaging. Rural communities have no access to these facilities and are forced to travel to metropolitan cities for these investigations. Even in places where it is available, it is not as affordable.

Hence, several affordable and portable tools which are proxy markers of brain abnormalities are examined as potential biomarkers. Retinal fundus imaging presented in this thesis is an inexpensive, portable and easily accessible technology which has the potential to help in the early detection of psychosis. The cost-effectiveness, portability and easy accessibility makes retinal fundus imaging an ideal candidate that can be used even in primary and rural healthcare centres. Also, the non-invasive nature of retinal imaging used in this thesis gives an edge for usage in the wider community and paves the way for faster adaptability throughout the society. It is also objective, repeatable and has the potential to be utilized in community mass screening. The screening can be done by non-clinical personnel, as one needs minimal training to use the device. The imaging is non-mydriatic and does not require any kind of dilator. This makes the imaging even easier and does not affect patient's work for the entire day. 
It has been validated and published in this thesis that features from retinal fundus imaging are significantly different in patients with psychiatric disorders versus healthy volunteers. When compared to healthy volunteers (HV), schizophrenia (SCZ) and bipolar disorder (BD) patients had wider veins and narrower arteries (chapter 2). The retinal arteriolar tortuosity index was found to be higher in patients with SCZ and BD when compared to HV (chapter 3), and the results were similar for fractal dimensions (chapter 4). The retinal vascular trajectories were smaller in patients with SCZ and BD when compared to HV in both arterioles and venules (chapter 5).

In addition, as an exploratory analysis, machine learning using a supervised ensemble of bagged trees, was implemented to check if retinal vascular trajectories can be a potential utility as a predictive biomarker. It had an accuracy of $86 \%$ with a sensitivity of $88 \%$ and a specificity of $85 \%$ for differentiating HV and SCZ. However, a lower but considerably good accuracy of $73 \%$ with a sensitivity of $78 \%$ and a specificity of $76 \%$ was obtained for differentiating HV and BD (chapter 5). These findings of machine learning analysis suggested that the automated analysis using retinal vascular trajectory can classify diagnosed patients and healthy volunteers with reasonable accuracy. Hence, retinal vascular trajectory is a potential biomarker for SCZ and BD. In addition to these structural features, the retinal vascular abnormalities were related to cognitive deficits typically seen in SCZ and BD. There was a significant association between working memory deficits, narrower arterioles and wider venules; a significant positive correlation between one-back test accuracy and retinal arteriolar calibre as well as significant positive correlation between log mean speed score and retinal venular calibre (chapter 6).

The machine learning algorithms were implemented using retinal vascular trajectories as features. However, it can be further explored to combine the other features including calibre, tortuosity and fractal dimensions. A combination of measures may provide a higher accuracy when compared to single measure. The machine learning algorithms can be packaged into the software which can be used across operating systems and aid in classifying or identifying the psychosis. The images can be acquired using the existing portable fundus camera or a mobile-based fundus camera in the future. The minimal computational requirement of the machine learning algorithms used in this thesis allows the algorithm to be used in a cloud based analysis and classification so it can be used in resource constrained settings. 
One of the main objectives of this thesis was to cater to the societies in lower- and middle-income countries that do not have easy access to healthcare - especially mental health. It is important to address this issue as the loss of productivity and the burden caused to the caregivers as well as the society due to psychosis is increasing every day due to lack of early diagnosis and prompt intervention. It is also seen that neurobiological changes occur earlier than the development of clinical symptoms. Unfortunately, the psychosis is diagnosed only in advanced stage after the clinical symptoms are more prominent and treatment is started subsequently. The reasons for delay in treatment is due to the absence of tools for early diagnosis and inaccessibility of experts. Hence, this novel method using retinal imaging may help in early diagnosis which will result in early medical intervention. This will also improve the patient's functional recovery and decrease the economic and emotional burden on family and society.

From the present thesis, it can be concluded that retinal vascular abnormalities are present in schizophrenia and bipolar disorder. Fundus imaging may pave the way to novel screening / diagnostic tools and indirectly help in early interventions. Nevertheless, much work is needed before retinal imaging can be used routinely in the clinical setting. Advances in, and direct comparisons of the various analysis methods are to be further tested. While the accuracy of the machine learning analysis was tested in a group level in the present thesis, the efficiency of the tool has to be tested at an individual level for its clinical utility.

The research presented in this thesis would be of interest to the governments of developing countries like India where there is an immediate need to have accessible, inexpensive screening tools for mental health conditions. In the rural community without access to specialists and advanced investigations, retinal fundus imaging may potentially be used to screen for mental disorders. As retinal fundus imaging can be acquired easily, this tool can be employed by general medical practitioners thus increasing its utility in wider community.

Before it can be used in the community or in the clinical setting, it is important to completely validate the research presented in this thesis by correlating the retinal vascular features with the brain vascular abnormalities using well-proven techniques like Arterial Spin Labelling (ASL). This thesis is presented with 100 sample size in each patient group when compared to $100 \mathrm{HV}$. However, the results have to be replicated with wider populations to have scientific validity. Further longitudinal follow-up 
studies will also help in identifying the stage of illness and predicting individuals who are at risk of developing the illness.

Even though the identification of group differences has improved our knowledge, it is necessary to show the difference at an individual level for the tool to be clinically useful. This thesis has paved the way for future individualistic classification. One possible approach is to generate single-subject inferences through machine learning classifiers $^{3,4}$ using retinal vascular features. To arrive at definite conclusions about retinal vascular abnormalities associated with schizophrenia or bipolar disorder, one should replicate this finding from a different geographical location. The present work was conducted at a tertiary health care centre - the National Institute of Mental Health and Neurosciences, Bengaluru, India. Future works in primary and secondary care centres need to be conducted for generalizability of the findings. Subsequently, population-based studies are needed for application as a screening tool in community.

Translating this academic research into an economically sustainable screening and diagnosis program will provide real-life application. Hopefully the results of this thesis will inspire indigenous biomedical device companies in India to investigate further in creating a low-cost screening device that embeds the algorithms of this thesis as an application available with the device. One of the major challenges in using MRI for screening is the cost and the portability of the neuroimaging equipment. If the local products can fill this gap, by integrating the low-cost screening devices with this algorithm, they may increase the outreach of the tool. This Ph.D. research will open doors for replication studies with larger sample size and longitudinal studies. Further clinical validation of such devices would create a global market for the same. Smartphone apps can be developed for analysis and visualization of the patient data which can be available for the technicians, experts and paramedics.

Within the scientific community, knowledge dissemination is done through publications in peer-reviewed journals and presentations at research conferences and other scientific forums. A part of the thesis was presented in the World Bipolar Day Conference on 24 March 2019 at NIMHANS, Bengaluru, India. The conference was attended by clinicians, mental health professionals and researchers across India. Several researchers expressed interest to collaborate further for the research and clinical validation. Research results and methodological developments can be further discussed with other scientists, driving international collaboration and brainstorming on analytic approaches. This thesis was implemented in a developing country (India) 
in collaboration with the Netherlands, but the concepts and the methodology can be further expanded to other countries and may become a model of reverse innovation. This research has already been explored beyond the thesis chapters. Along with one of my co-supervisors, Dr. Naren P. Rao, we had submitted a research proposal to assess the retinal vascular abnormalities in first degree relatives of patients with schizophrenia. This research will provide the necessary next step to establish the potential of this method to identify at risk individuals and whether these abnormalities are endophenotypes. The research project is approved for funding by the Department of Science and Technology (DST), Government of India under Cognitive Science Research Initiative (CSRI). We are in the process of taking necessary permissions from institute ethics committee to start the project. Another proposal is under development to design a hyperspectral device that can give dynamic vessel analysis and oxygen saturation of retinal images which can further help to strengthen the concepts presented in this thesis.

Clinically, retinal fundus imaging is considered as a relatively affordable, accessible and workable tool for screening the patients. Hence, it is our hope that the efforts laid out in this thesis represent a small step in the global effort to improve the lives of patients with schizophrenia and bipolar disorder.

Thus I would like to conclude with a quote "Medicine is a science of uncertainty and an art of probability" - Sir William Osler, a Canadian physician and one of the founding professors of Johns Hopkins Hospital, USA. 


\section{References}

1. Perälä J, Suvisaari J, Saarni SI, et al. Lifetime prevalence of psychotic and bipolar I disorders in a general population. 2007;64(1):19-28.

2. van Os J, Linscott RJ, Myin-Germeys I, Delespaul P, Krabbendam L. A systematic review and meta-analysis of the psychosis continuum: evidence for a psychosis proneness-persistence-impairment model of psychotic disorder. Psychol Med. 2009;39(2):179-195.

3. Mothi SS, Sudarshan M, Tandon N, et al. Machine learning improved classification of psychoses using clinical and biological stratification: Update from the bipolarschizophrenia network for intermediate phenotypes (B-SNIP). Schizophr Res. 2018.

4. Librenza-Garcia D, Kotzian BJ, Yang J, et al. The impact of machine learning techniques in the study of bipolar disorder: A systematic review. Neurosci Biobehav Rev. 2017;80:538-554. 
CHAPTER 10

ACKNOWLEDGEMENTS 



\section{Acknowledgements}

The entire journey of my PhD was very interesting and pleasing because of many individuals who supported and encouraged me throughout this memorable expedition.

Firstly, I would like to thank with great gratitude, my co-supervisor, Dr. Naren P. Rao, Additional Professor at the National Institute of Mental Health and Neurosciences (NIMHANS), Bengaluru, India. I had the opportunity to interact with him for the first time in one of the conferences when I was trying to find a problem definition for my PhD. He inspired me to work in the area of neuro-ophthalmology. Dr. Naren was very patient and helped in various aspects of my $\mathrm{PhD}$ including obtaining necessary permissions, problem identification, design protocol, making connections to medical experts and psychologists and answering my clinical questions. He also consistently kept my research on track when any possibly topic diversions would arise. I am sure I could not ask for a better expert than him as my co-supervisor.

Understanding psychiatry and ophthalmology and its concepts was not at all an easy task for a biomedical engineer. Fortunately, I met Dr. Bhargavi Nagendra, a clinical researcher who works with Dr. Naren. She explained clinical terminologies and protocols, especially during data collection and drafting manuscripts for submission to the journals. I consider myself immensely fortunate to have worked for my research with her.

I am greatly indebted to my other co-supervisor, Dr. Tos T.J.M. Berendschot, Maastricht University Medical Centre (MUMC), Maastricht University (UM), NL, who has taught me many new concepts and tools which have helped me in my research and beyond. He was quick in answering my queries and assisting me in understanding concepts easily. He always used to tell me, once I complete my $\mathrm{PhD}$, I should be in a position to guide another PhD student which insisted that he would accept nothing but perfect. This also gave me a clue that I am not completing my research, but I am geared to start my research independently from now. He has been guiding and inspiring my research from its conception through execution and completion. His perfect balance between scientific advice and guidance made the completion of my $\mathrm{PhD}$ a reality. Not to forget, I also want to thank Dr. Berendschot for assisting me in arranging my stay in Maastricht during my multiple visits, and inviting me for a memorable Christmas party. 
Professor Carroll A.B. Webers, my promotor from MUMC, has always been encouraging with his valuable comments during my $\mathrm{PhD}$ and taking my dissertation and its related processes towards completion. No matter how busy he was, he always had time to answer all my questions and correct my manuscripts on priority.

Before all this, I had one person who had mentored me throughout my career: Dr. Shyam Vasudeva Rao, Technical Director of MUMC, India. During an official meeting at my workplace, he mentioned about the UM PhD program. I was excited and approached him to ask about the process of applying for the $\mathrm{PhD}$ program. I was able to cross the preliminary screening and gain admittance towards this unique program. He has been a great pillar of support for me during my PhD and removed all hurdles with simple and effective solutions.

I am grateful to my institution and alma matter, B.M.S. College of Engineering (BMSCE), Bengaluru, India, who has provided a great facility and required seed money to start my PhD. The management of the college, principal and my colleagues always raised my spirits and gave me confidence by adjusting my teaching load as needed and providing me the necessary permissions to visit UM and NIMHANS for my PhD work. The support I got from BMSCE was unreserved.

I am thankful to NIMHANS for the support and giving the necessary permissions to carry out my research work. More importantly, I was able to gain access to patients from this premier institute with huge patient inflow which is of national importance and repute.

Over the past few years, being a PhD student and working with UM was an extremely inspirational and beneficial experience for me, both in my personal and professional life. I would like to extend my sincere and deep gratitude to UM for providing such a motivating environment for researchers and students. The tools and accessibility of scientific content, as well as the remote facilities provided, is unmatchable. The staff and the ambiance is so welcoming that I wanted to collaborate with UM for my future research as well.

During my initial days, I had the opportunity to work with Narayana Nethralaya, Bengaluru, India on a few retinal image processing projects. This hands-on experience helped me to understand various clinical as well as the modalities related to the retina. I would like to thank the doctors who challenged my skills and equipped me with a plethora of knowledge relating to my $\mathrm{PhD}$ research. 
Maastricht University has a strong base among Indian researchers; being part of the same is my pride and honor. I always had another student or alumni from UM who were always willing to help me in case of any queries. It was easier to learn the process and guidelines while working on my thesis through someone who had completed and reached the destination with flying colors. Dr. Anand Vinekar, Dr. Rajani Battu, Dr. Supriya Dabir, and Dr. Chaitra Jayadev were very easily accessible in spite of their busy schedules as practicing doctors in premier hospitals.

My family has been my first inspiration as they started pushing me to pursue my research since my childhood. My parents, Usha Kiran and A.P. Mahesh had always believed and encouraged me to achieve higher and higher. My sister, Dr. Ashwini Appaji, shared her expertise, experience, and thoughts throughout my PhD journey. A big thanks to my entire family.

I would like to thank my students from BMSCE: especially Ananth Padmanabha and Vittal Koran who helped me organize the research data. I would also like to thank my students Mohammed Jurair and Vishruth Cavale for helping me in designing such an appealing cover page for this thesis.

I would fail my duty without thanking the assessment committee who took great efforts and hard work to review my thesis. Of course the secretary Ellen Vrancken and staff of the Department of Ophthalmology at MUMC, beadles office at UM, etc. for processing my thesis on time.

I would like to thank all my teachers/mentors as well as colleagues for directly and indirectly supporting me during my PhD. A special thanks to all my undergraduate and postgraduate students at BMSCE who adjusted during my absence and nonavailability for a shorter time and reorganizing of the classes.

Apart from the above-mentioned individuals and organizations, many colleagues have helped me in my study directly and indirectly. Thank you to everyone, including almighty God, who has made this possible. It has certainly been one of the hardest and most rewarding periods of my life. I appreciate the unconditional and continuous support I have received from all of them. 

CHAPTER 11

CURRICULUM VITAE AND PUBLICATIONS 



\section{Curriculum Vitae}

Abhishek Mahesh Appaji was born on 23 April 1989 at Hyderabad, India. He graduated from high school and college with top academic honors throughout and was awarded various scholarships.

Because of his interest in science and technology, Abhishek pursued his Bachelor of Engineering in Medical Electronics with University rank from B.M.S. College of Engineering, Bengaluru affiliated to Visvesvaraya Technological University, India and graduated in 2010. After that, he completed his Master of Technology in Information Technology from Karnataka State Open University (KSOU), Mysuru, India in 2012 followed by a Master of Engineering in Bioinformatics from University Visvesvaraya College of Engineering, Bengaluru which is affiliated to Bangalore University, India in 2013.

Due to his passion for Entrepreneurship and management, Abhishek was selected to attend a course on New Ventures leadership with scholarship from the worlds top technical institute, Massachusetts Institute of Technology (MIT), Cambridge, Massachusetts, USA as part of Global Entrepreneurship Bootcamp in 2017 and won this bootcamp among $35+$ teams across the world after which he and his teammates started ventures in Australia and India. He is also mentoring a few start-ups globally.

Abhishek is an active member of professional body, Institute of Electrical and Electronics Engineers (IEEE) and held/holds various office bearer positions including chair of IEEE Young Professionals Bangalore Section (2017-18), Joint Secretary and SIGHT Chair of Bangalore Section, Treasurer of IEEE TEMS Bangalore Section, Vice-Chair, Young Professionals, IEEE TEMS India and Webmaster and membership development chair of IEEE PES Bangalore Chapter.

Abhishek has received various funds for research in Medical Technologies from various agencies in India and abroad including IEEE, Department of Science and Technology (DST), Department of Biotechnology (DBT), Biotechnology Ignition Grant (BIG), Government of India among many others. 
Abhishek has been part of more than 100+ invited talks across the globe in various conferences, workshops, events, and forums. He has various publications in reputed conferences and journals. He has also organized and been part of 50+ organizing committees for various conferences, workshops, Faculty development programs, and seasonal schools, etc.

Abhishek had worked for one year as a research assistant at the Indian Institute of Science (IISC), Bangalore, India during 2011 and currently working as Assistant Professor in Department of Medical Electronics at B.M.S. College of Engineering, Bengaluru, India from 2010.

Abhishek has received many renowned laurels and awards, few of them include IEEE EMBS International Best Paper Award at International Student Conference (ISC), Malaysia, MGH CamTech Jugadathon Awards, Best Nodal Coordinator Award, Gandhian Young Technological Award 2016 at Rastrapahy Bhavan (President of India House), New Delhi, India, Winner of Elderly care hackathon, the Netherlands, Winner of Class 5 Massachusetts Institute of Technology (MIT) Global Entrepreneurship Bootcamp, IEEE MGA Young Professional Award 2018, IEEE Region 10 (Asia-Pacific) Young Professionals Outstanding Volunteer in Academic Award 2019, etc.

\section{Publications}

- Appaji A, Nagendra B, Chako DM, Padmanabha A, Hiremath CV, Jacob A, Varambally S, Kesavan M, Venkarasubramanian G, Rao SV, Webers CAB, Berendschot TTJM, Rao NP, Retinal vascular abnormalities and cognitive impairment in patients with schizophrenia and bipolar disorder., under review.

- $\quad$ Appaji A, Nagendra B, Chako DM, Padmanabha A, Hiremath CV, Jacob A, Varambally S, Kesavan M, Venkarasubramanian G, Rao SV, Webers CAB, Berendschot TTJM, Rao NP. Examination of retinal vascular trajectory in schizophrenia and bipolar disorder. Psychiatry and clinical neurosciences, 2019: 73(12);738-744. 
- Appaji A, Nagendra B, Chako DM, Padmanabha A, Hiremath CV, Jacob A, Varambally S, Kesavan M, Venkarasubramanian G, Rao SV, Webers CAB, Berendschot TTJM, Rao NP, et al. Retinal vascular tortuosity in schizophrenia and bipolar disorder. Schizophrenia research. 2019: 212; 26-32.

- Appaji A, Nagendra B, Chako DM, Padmanabha A, Hiremath CV, Jacob A, Varambally S, Kesavan M, Venkarasubramanian G, Rao SV, Webers CAB, Berendschot TTJM, Rao NP. Retinal vascular fractal dimension in bipolar disorder and schizophrenia. Journal of affective disorders. 2019: 259; 98-103.

- Appaji A, Nagendra B, Chako DM, Padmanabha A, Hiremath CV, Jacob A, Varambally S, Kesavan M, Venkarasubramanian G, Rao SV, Webers CAB, Berendschot TTJM, Rao NP. Retinal vascular abnormalities in schizophrenia and bipolar disorder: A window to the brain. Bipolar disorders. 2019: 21(7); 634-641.

- Alagumalai V, Kadambi P, Appaji A, Interdisciplinarity in New Product Development in an Indian MedTech Perspective: Gap and the Solution. Health and Technology, 2019: 9(5); 817-827.

- $\quad$ Nagendra B, Appaji A, Chacko DM, Hiremath CV, Gowda KM, Krishnappa M, Jacob A, Varambally S, Keshavan M, Venkatsubramaniam G, Rao NP, A window to the brain: Examination of retinal microvasculature in bipolar disorder. Rapid communication in Bipolar disorders, 2018: 20 (S1); 60.

- $\quad$ Lin CT, King JT, Singh AK, Gupta A, Ma Z, Lin JW, Machado AMC, Appaji A, Prasad $M$, Voice Navigation Effects on Real-World Lane Change Driving Analysis Using an Electroencephalogram. IEEE Access, 2018; 6: 26483-26492.

- $\quad$ Lin CT, King JT, Fan JW, Appaji A, Prasad M, The influence of acute stress on brain dynamics during task switching activities. IEEE Access, 2017; 6: 3249-3255.

- Chidambara L, Gadde SGK, Yadav NK, Jayadev C, Banushali D, Appaji A, Akkali $M$, Khurana A, Shetty R, Characteristics and quantification of vascular changes in macular telangiectasia type 2 on optical coherence tomography angiography, British Journal of Ophthalmology, 2016; 100: 1482-88. 


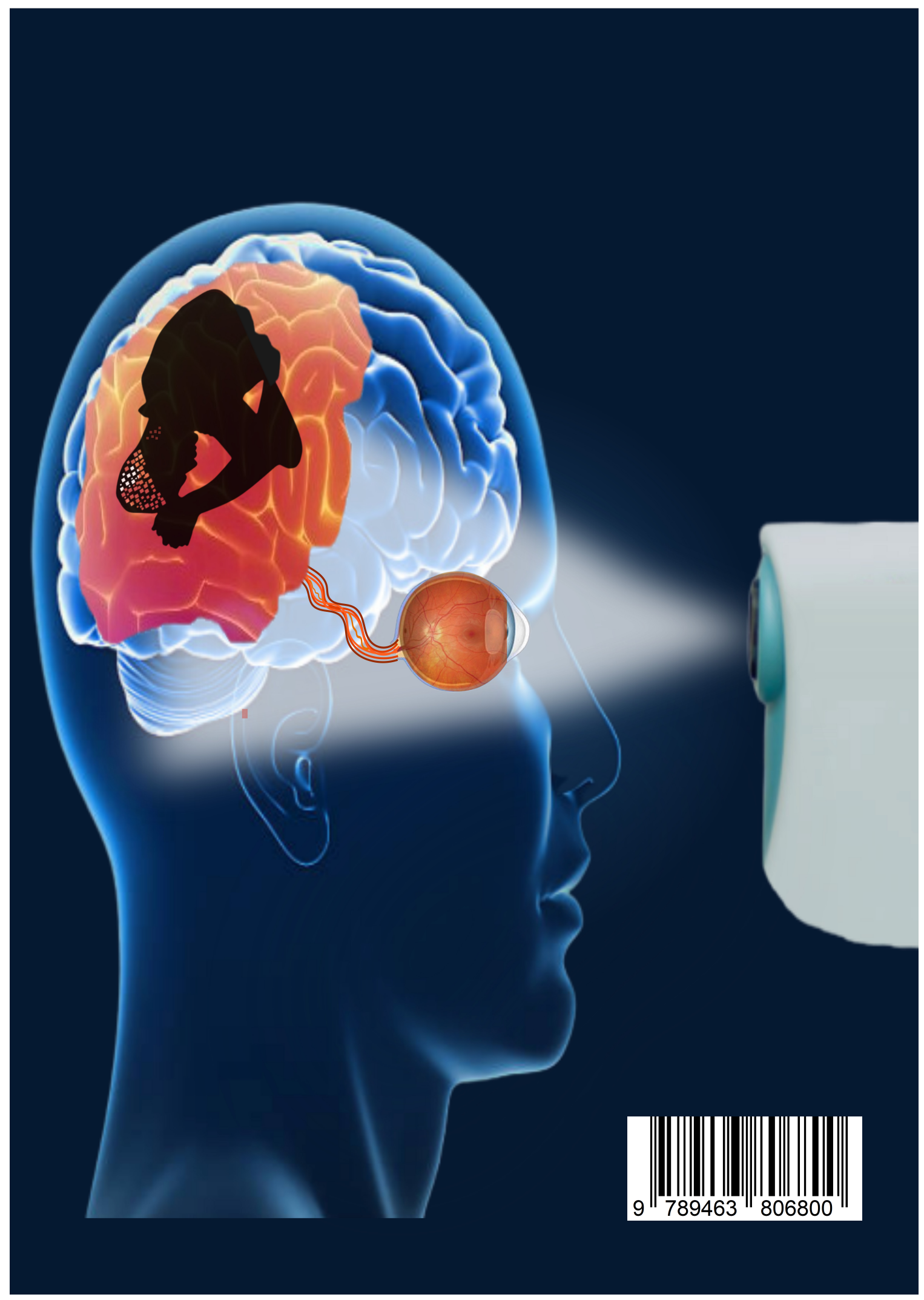

